\title{
TUNING BRIGHTNESS AND OXYGEN SENSITIVITY OF Ru(II) AND Ir(III) LUMINOPHORES
}

PROEFSCHRIFT

ter verkrijging van

de graad van doctor aan de Universiteit Twente,

op gezag van de rector magnificus, prof. dr. H. Brinksma,

volgens besluit van het College voor Promoties

in het openbaar te verdedigen

op vridag 10 juni 2011 om 12:45 uur

door

\author{
Albert Ruggi \\ geboren op 20 Februari 1980 \\ te Napels, Italie
}


Dit proefschrift is goedgekeurd door:

Promotor : $\quad$ Prof. dr. ir. D. N. Reinhoudt

Assistent Promotor: Dr. A. H. Velders 


\section{Table of Contents}

Chapter 1. General introduction

Chapter 2. Tuning luminescence properties and oxygen quenching of ruthenium(II) and iridium(III) complexes

2.1. Introduction

2.2. Luminescence of ruthenium(II) and iridium(III) complexes

2.2.1. Luminescence of transition metal complexes

2.2.2. Luminescence properties of $\mathrm{Ru}(\mathrm{II})$ complexes

2.2.3. Luminescence properties of Ir(III) complexes

2.3. Oxygen quenching of luminescence

2.3.1. Mechanism of oxygen quenching of luminescence

2.3.2. Tuning oxygen quenching of $\mathrm{Ru}(\mathrm{II})$ and $\mathrm{Ir}(\mathrm{III})$ complexes

2.4. Scope of the thesis

Chapter 3. An iridium(III) caged complex with low oxygen quenching

3.1. Introduction

3.2. Design and synthesis

3.3. Characterization

3.4. Photophysical properties

3.5. Conclusions

3.6. Experimental section 
Chapter 4. Understanding luminescence quenching by oxygen of $\operatorname{Ir}(\mathrm{III})$-hemicaged complexes: a systematic approach (1)

4.1. Introduction

4.2. Design and synthesis

4.3. Characterization

4.4. Photophysical properties

4.5. Conclusions

4.6. Experimental section

4.7. References

Chapter 5. Understanding luminescence quenching by oxygen of $\operatorname{Ir}(\mathrm{III})$-hemicaged complexes: a systematic approach (2)

5.1. Introduction

5.2. Design and synthesis

5.3. Characterization

5.4. Photophysical properties

5.5. Conclusions

5.6. Experimental section

5.7. References

Chapter 6. Luminescence quenching by oxygen of an iridium(III) hemicaged complex functionalized with electron-donating groups

6.2. Design and synthesis

6.3. Characterization

6.4. Photophysical properties

Appendix 6.1. Analysis of a computational model of the hemicaged complex 1 and its LUMO localization according to DFT calculations Appendix 6.2. Preliminary results concerning the synthesis of an ether-based caged complex with a benzene-based capping unit 
Chapter 7. Synthesis and oxygen quenching of the luminescence of an Ir(III)-hemicaged complex with a 1,3,5-tris(ethyl)benzene capping unit

7.1. Introduction

7.2. Design and synthesis

7.3. Characterization

7.4. Photophysical properties

7.5. Conclusions

7.6. Experimental section

7.7. References

Appendix 7.1. Synthetic attempts for the synthesis of caged complex 2

Chapter 8. Dendritic Ru(II)-based dyes tunable for diagnostic or therapeutic applications 



\section{Chapter 1}

But I put forth on the high open sea.

Dante, Inf., XXVI

\section{General introduction}

The development of high-performance luminophores (i.e. luminescent compounds with high brightness) is of paramount importance for many applications, such as the realization of luminescent devices, e.g. Organic Light Emitting Diodes (OLEDs), ${ }^{1}$ and for biomedical imaging. ${ }^{2,3}$ Many efforts have been dedicated to the design of suitable luminescent compounds for the realization of high performance luminescent devices and their number has been exponentially increasing in the last years. ${ }^{4,5}$ However, the design of bright luminophores for biological imaging still constitutes a major challenge, especially due to the necessity of combining a high brightness (defined as the product of the quantum yield and the molar absorption coefficient) with a low degree of oxygen quenching. ${ }^{6}$ The latter is not important when fabricating luminescent devices, as they can be assembled under inert atmosphere, but it is a crucial property for luminescent compounds for biological applications, due to the oxygen-rich biological environment where they are applied. Research efforts in this field have been mostly focused on nanoparticles like semiconductor Quantum Dots (QDs), ${ }^{7-9}$ which combine a high brightness with a negligible oxygen sensitivity. However, despite the brilliant performances shown by QDs, there are still some major concerns about their toxicity, especially if the final goal is the human in vivo application. ${ }^{10-12}$ Transition metal complexes are ideal candidates for the realization of bright luminophores, due to their high stability in biological environment and to the possibility of tuning their optical properties by conveniently changing the structure of the ligands. ${ }^{13,14}$ Ruthenium(II) and iridium(III) derivatives are among the most studied luminescent transition metal complexes and this makes them ideal candidates for further improvement. ${ }^{15,16}$

For biological applications, two possible strategies can be followed in order to improve the optical properties of a luminophore: the decrease of oxygen quenching and the amplification 
of brightness. The first strategy is especially useful in order to improve the optical properties of $\operatorname{Ir}(\mathrm{III})$-complexes, which are highly bright in oxygen-free environments but only poorly luminescent in the presence of oxygen. Conversely, the second strategy is particularly attractive for $\mathrm{Ru}(\mathrm{II})$-complexes, which are much less sensitive to oxygen quenching but show also a poor brightness due to their low emission quantum yield. In this thesis both strategies have been followed in order to realise highly bright luminescent $\mathrm{Ru}(\mathrm{II})$ or $\operatorname{Ir}(\mathrm{III})$ complexes. Moreover, since there is only a limited amount of literature concerning the tunability of the oxygen quenching of Ir(III)-complexes, a systematic study to clarify the structure-quenching relationship of these complexes has been conducted.

In Chapter 2 a concise literature study about luminescent $\operatorname{Ru}(\mathrm{II})$ and $\operatorname{Ir}(\mathrm{III})$ complexes is given. After an introduction concerning the processes involved in absorption and emission phenomena, the optical properties of $\mathrm{Ru}(\mathrm{II})$ and $\mathrm{Ir}(\mathrm{III})$ complexes are discussed. Attention is focused on the possible strategies that can be used to tune the emission properties (e.g. the emission wavelength), the nature of the emissive excited state and the oxidation potential of the metal core. Moreover, a theoretical description of the oxygen quenching mechanism and the physical parameters involved are given, followed by a summary of the known strategies for tuning the degree of oxygen quenching in $\mathrm{Ru}(\mathrm{II})$ and $\operatorname{Ir}(\mathrm{III})$ complexes, with several relevant examples from literature. Subsequently the aim of the thesis is discussed in detail.

In Chapter 3 the synthesis of the first Ir(III)-complex with a caged ligand structure is reported. The strategy behind the realization of this complex is discussed, to give a general guideline for the realization of such kind of compounds. Moreover, the geometrical structure of the complex in solution is elucidated using mono- and bidimensional NMR experiments. The absorption and emission properties of the caged complex are reported and compared with the archetypical $\operatorname{Ir}(\text { ppy })_{3}$ and with a partially closed $\operatorname{Ir}(\mathrm{III})$-hemicaged complex. The degree of oxygen quenching of the caged complex is evaluated by Stern-Volmer analysis and it is compared with the oxygen quenching degree of $\operatorname{Ir}(\mathrm{ppy})_{3}$ and the $\operatorname{Ir}(\mathrm{III})$-hemicaged complex.

In Chapter 4 and Chapter 5 the results of a systematic investigation concerning the structure-related effect on oxygen quenching are reported. The syntheses of a series of $\operatorname{Ir}(\mathrm{III})-$ tris(phenylpyridine) derivatives, connected through amide groups with either a capping unit or a noncapping moiety localised on the pyridine rings (Chapter 4) or on the phenyl rings (Chapter 5), are reported. The structural characterisation of the four compounds by means of 
mono- and bidimensional NMR spectroscopy is discussed and compared with the structural properties of the hemicaged and caged complexes described in Chapter 3. Besides the discussion of the absorption and emission properties, a detailed analysis of the oxygen quenching of the two pairs of complexes is reported. The results of the Stern-Volmer analysis and of the evaluation of the thermodynamical parameters are discussed in order to obtain evidence for the structural influence on the oxygen quenching.

In Chapter 6, the synthesis of an $\operatorname{Ir}(\mathrm{III})$-tris(phenylpyridine) hemicaged complex functionalised on the pyridine rings with a 1,3,5-tris(oxymethyl)benzene capping unit is described. The structural characterization of this complex by 1D and 2D-NMR spectroscopy is discussed and compared with an $\operatorname{Ir}(\mathrm{III})$-tris(phenylpyridine) uncapped (open) complex bearing methoxy groups on both the pyridine and the phenyl side of the phenylpyridine ligands. Besides the description of the absorption and emission properties of the two complexes, the degree of oxygen quenching as evaluated by Stern-Volmer analysis is reported. Furthermore, the effect on the oxygen quenching exerted by the aromatic capping unit connected to the phenylpyridine ligands through electron-donating groups is discussed, using also structural data obtained from DFT calculations.

In Chapter 7 the synthesis of an $\operatorname{Ir}(\mathrm{III})$-tris(phenylpyridine) hemicaged complex functionalised with a 1,3,5-tris(ethyl)benzene capping unit on the phenyl rings is reported. The structural characterization with 1D and 2D-NMR spectroscopy is discussed, together with the absorption and emission properties of the hemicaged complex. The optical properties of the hemicaged complex are compared with $\operatorname{Ir}(\mathrm{ppy})_{3}$ in order to evaluate the effect of the presence of the capping unit on the absorption and emission properties. Moreover, the oxygen quenching is studied by Stern-Volmer analysis and compared with that of $\operatorname{Ir}(\mathrm{ppy})_{3}$.

In Chapter 8 the syntheses of two G2-PAMAM dendrimers decorated with 16 positively or negatively charged $\mathrm{Ru}(\mathrm{II})$-derivatives are reported and their structural characterization by $1 \mathrm{D}$, 2D NMR spectroscopy and DOSY is discussed. The absorption and emission properties of the two compounds are studied and compared with those of the single dyes, in order to evaluate the brightness enhancement upon multiple labelling. Finally, the in vitro interaction of the two dendritic molecules with tumour cells is described, with emphasis on bioimaging and phototoxicity. 


\section{References}

(1) Baldo, M. A.; O'Brien, D. F.; You, Y.; Shoustikov, A.; Sibley, S.; Thompson, M. E.; Forrest, S. R. Nature 1998, 395, 151-154.

(2) Lavis, L. D.; Raines, R. T. ACS Chem. Biol. 2008, 3, 142-155.

(3) Leiner, M. J. P. Anal. Chim. Acta 1991, 255, 209-222.

(4) Evans, R. C.; Douglas, P.; Winscom, C. J. Coord. Chem. Rev. 2006, 250, 2093-2126.

(5) Lowry, M. S.; Bernhard, S. Chem. Eur. J. 2006, 12, 7970-7977.

(6) Rao, J. H.; Dragulescu-Andrasi, A.; Yao, H. Q.; Yao, H. Q. Curr. Opin. Biotech. 2007, 18, 17-25.

(7) Debbage, P.; Jaschke, W. Histochem. Cell. Biol. 2008, 130, 845-875.

(8) Sharrna, P.; Brown, S.; Walter, G.; Santra, S.; Moudgil, B. Adv. Coll. Int.Sci. 2006, 123, 471-485.

(9) Tholouli, E.; Sweeney, F.; Barrow, E.; Clay, V.; Hoyland, J. A.; Byers, R. J. J. Pathol. 2008, 216, 275-285.

(10) Cai, W. B.; Hsu, A. R.; Li, Z. B.; Chen, X. Y. Nanoscale Res. Lett. 2007, 2, 265-281.

(11)Derfus, A. M.; Chan, W. C. W.; Bhatia, S. N. Nano Lett. 2004, 4, 11-18.

(12) Hardman, R. Environ. Health Perspect. 2006, 114, 165-172.

(13) Fernandez-Moreira, V.; Thorp-Greenwood, F. L.; Coogan, M. P. Chem. Comm. 2010, 46, 186-202.

(14) Lo, K. K. W. In Photofunctional Transition Metals Complexes 2007; Vol. 123, p 205245.

(15)Campagna, S.; Puntoriero, F.; Nastasi, F.; Bergamini, G.; Balzani, V. In Photochemistry and Photophysics of Coordination Compounds I 2007; Vol. 280, p 117214.

(16) Flamigni, L.; Barbieri, A.; Sabatini, C.; Ventura, B.; Barigelletti, F. In Photochemistry and Photophysics of Coordination Compounds II 2007; Vol. 281, p 143-203. 


\title{
Chapter 2
}

And God said, "Let there be light",

and there was light.

And God saw that the light was good.

Genesis 1:3

\section{Tuning Luminescence Properties and Oxygen Quenching of Ru(II) and Ir(III) Complexes "}

\begin{abstract}
In this chapter a concise literature background about the luminescence properties of transition metal complexes is given, with particular attention to $\operatorname{Ru}(\mathrm{II})$ and $\operatorname{Ir}(\mathrm{III})$ complexes and focussing on the possible strategies to tune their optical properties (e.g. emission wavelength, nature of the emissive state and oxidation potential of the ground state). Moreover, the physical parameters involved in the process of oxygen quenching of luminescence are discussed, together with the possible strategies to tune the sensitivity towards oxygen quenching of transition metal luminophores. Finally, based on the literature results discussed, the aim of the thesis is described.
\end{abstract}

\footnotetext{
" Part of this chapter has been published in Ruggi, A.; Reinhoudt, D. N.; Velders, A. H., Biomedical applications of metal-containing luminophores. In Bioinorganic Medicinal Chemistry, Alessio, E., Ed. Wiley-VCH: 2011, 383-406.
} 


\subsection{Introduction}

Transition metal complexes constitute a fascinating class of luminophores because of their unique optical properties and for the possibility of tuning such properties by (small) changes in the ligands which are involved in the coordination of the metal ion. ${ }^{1}$ Ruthenium(II) and iridium(III) complexes, in particular, have been extensively studied because of their possible applications both in the field of material science (e.g. for the realization of luminescent devices like Organic Light Emitting Diodes -OLEDs-, or "organic" photovoltaic cells) and, more recently, for the wide opportunities offered in the field of bioimaging (e.g. for the realization of luminescent probes). ${ }^{2,3}$

After a general introduction about luminescence (in this Section), the physical phenomena involved in light absorption and emission of transition metal luminophores are described, showing their advantages and drawbacks compared to well-known organic fluorophores (Section 2.2.1.). In particular, the absorption and emission properties of the two archetypical complexes $\left[\mathrm{Ru}(\mathrm{bpy})_{3}\right]^{2+}$ and $f a c-\operatorname{Ir}(\mathrm{ppy})_{3}$ and the strategies used to tune the luminescence properties of $\mathrm{Ru}(\mathrm{II})$ and $\operatorname{Ir}(\mathrm{III})$ luminophores are described (Section 2.2.2 and 2.2.3). Subsequently, the mechanisms of oxygen quenching of luminescence are discussed, with particular attention to the parameters involved in such processes (Section 2.3), and an overview of the possible strategies for tailoring of oxygen quenching of $\operatorname{Ru}($ II) and $\operatorname{Ir}(\mathrm{III})$ luminescence is given (Section 2.3.2). In the last section, starting from the literature overview, the scope of this thesis is illustrated (Section 2.4).

Luminescence processes. Photoluminescence is the emission of light that follows the absorption of photons by a species (luminophore). ${ }^{4}$ Generally speaking, it is possible to distinguish between two forms of photoluminescence, namely fluorescence (spin-allowed emission of light from an electronic excited state) and phosphorescence (spin-forbidden emission of light from an electronic excited state). These two emission mechanisms can be schematically illustrated with the Jablonski diagram (Figure 2.1) in which the excitation and the relaxations pathways are shown. 


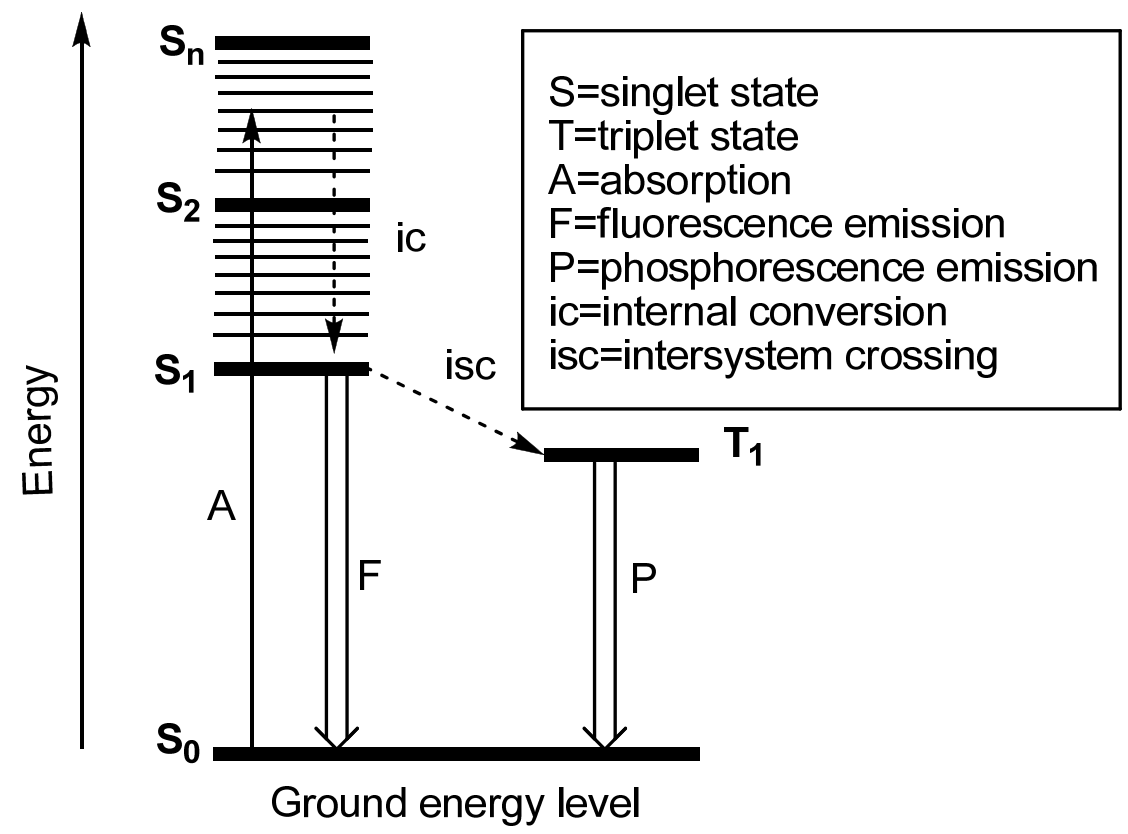

Figure 2.1. Simplified Jablonski diagram for a generic luminophore, showing the possible pathways of excitation and relaxation.

Quantum yield and fluorescence lifetime are the most important characteristics of a luminophore. The quantum yield $(\phi)$ can be defined as in equation 2.1:

$$
\phi=\frac{k_{r}}{k_{r}+\sum k_{n r}}
$$

Where $k_{r}$ is the radiative kinetic constant and $k_{n r}$ are the non-radiative kinetic constants. The quantum yield can be close to unity if the radiationless decay rate is much smaller than the emissive one. The lifetime $(\tau)$ of the excited state is the average time the molecule spends in the excited state prior to return to the ground state, and is defined as in equation 2.2:

$$
\tau=\frac{1}{k_{r}+\sum k_{n r}}
$$

Luminophores can be divided in different families, according to their chemical nature. ${ }^{5}$ Organic and coordination compound-based dyes are among the most popular classes of luminescent compounds. More recently, semiconductor nanoparticles (Quantum Dots) and lanthanide-doped nanoparticles have received great attention due to their remarkable 
luminescent properties. Organic dyes ${ }^{6}$ (Figure 2.2) are the most used fluorophores, due to their generally high quantum yield (often close to unity) and because of the large number of commercially available compounds, which virtually cover the entire visible spectrum, from blue to near-infrared. Among the most used organic labels we can cite fluorescein and rhodamine derivatives, cyanines, BODIPY ${ }^{\circledR}$ and Alexa ${ }^{\circledR}$ dyes. All these compounds are widely used in biological applications, e.g. in protein labelling. ${ }^{7-9}$ Despite the good luminescence and the availability of a large number of fluorescent derivatives, organic dyes show several serious drawbacks, such as the small Stokes shift they exhibit (the difference between the excitation and emission maxima) which often causes self-absorption with as a consequence a decrease of the fluorescence emission upon multiple labelling, the generally poor photochemical stability, the decomposition under repeated excitation (photobleaching), and the very short lifetimes (which makes these compound not suitable for time resolved detection techniques).

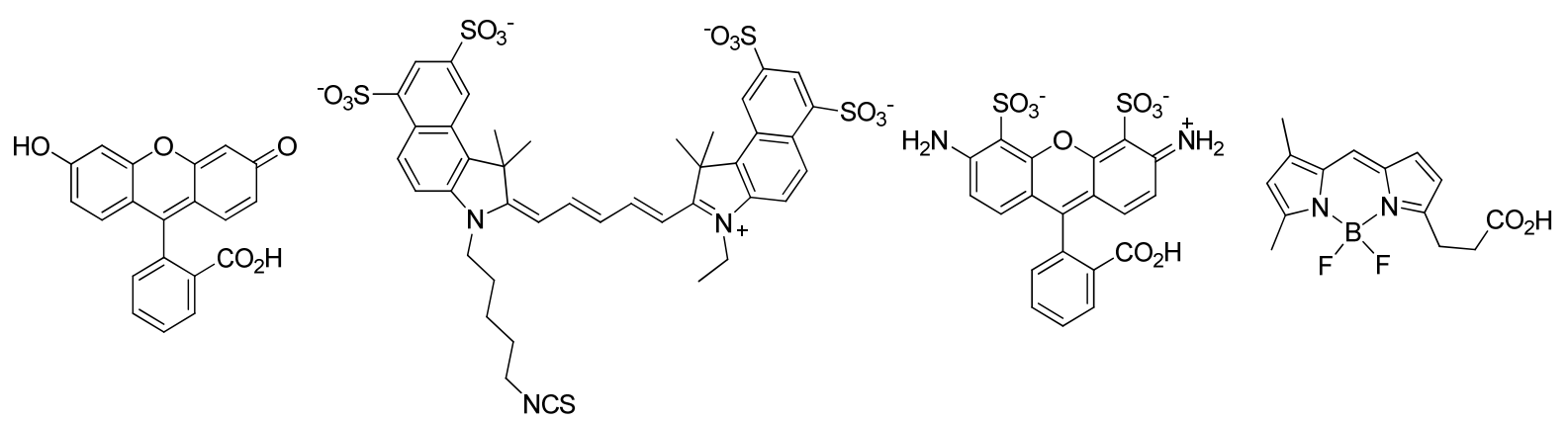

Figure 2.2. Examples of organic dyes (from left to right: fluorescein, Cy5.5 ${ }^{\circledR}$, Alexa ${ }^{\circledR}$, BODIPY®). 


\subsection{Luminescence of ruthenium(II) and iridium(III) complexes}

\subsubsection{Luminescence of transition metal complexes}

Coordination compound-based dyes are currently among the most promising agents for the future development of luminescent imaging dyes, because of their interesting and versatile photophysical properties (which allows coverage of the entire spectrum from blue to NIR). Most of the above mentioned drawbacks of organic dyes can be overcome by using inorganic dyes, ${ }^{10,11}$ which in fact show very useful features like a large Stokes shift (which permits to label a biological molecule with multiple luminophores without reduced fluorescent intensity due to self quenching), a long-lived emission (which permits removal of the background interference of biological molecules -autofluorescence- by using time-resolved detection), ${ }^{12}$ particular anisotropic properties (which can be used for the hydrodynamic study of proteins), ${ }^{13}$ and a sensitive response to the local environment (which can serve as luminescent reporter of the biological surroundings). ${ }^{14}$

Compared to organic molecules, transition metal complexes have unique properties due to their electronic structure. ${ }^{1}$ The electronic structure of transition metal complexes can be described with the Molecular Orbital (MO) theory, in which the molecular orbitals of a complex are constructed as a linear combination of metal and ligand orbitals. A typical MO diagram of a $d^{6}$ low spin metal ion complex with octahedral geometry is shown in Figure 2.3, together with the possible electronic transitions and their nomenclature. A metal complex is emissive only if there is a large energy gap between the lowest excited state and the ground state. The magnitude of the splitting between these two states is denoted as $\Delta$ (ligand-field splitting parameter) and depends on the metal ion (for instance $\Delta$ is proportional to the $d$ orbitals quantum number) and on the strength of the ligands (i.e. their position in the spectrochemical series). The presence of a heavy atom induces a certain degree of spin-orbit coupling. Because of this effect, the spin-forbidden electronic relaxation pathways may become partly allowed and, for this reason, most of the luminescent transition metal complexes show an emission in which spin-allowed (fluorescence) and spin-forbidden (phosphorescence) transitions are combined in varying degrees. The first consequence of this effect is the usually longer lifetimes of the excited state in transition metal complexes compared to organic dyes. 


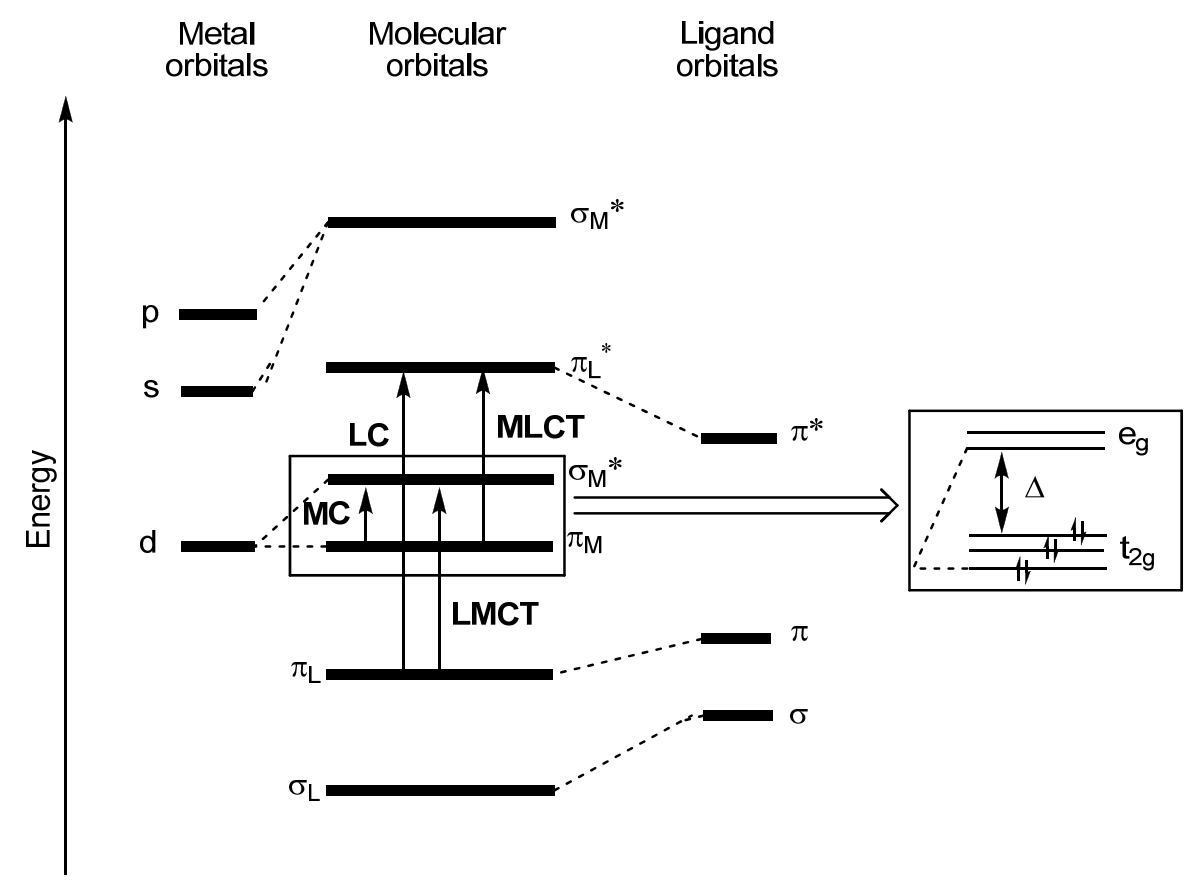

Figure 2.3. MO diagram of a $d^{6}$, low spin, metal ion complex with octahedral geometry, showing possible electronic transitions: Metal Centred (MC), Ligand Centred (LC), Ligand to Metal Charge Transfer (LMCT) and Metal to Ligand Charge Transfer (MLCT) electronic transitions are shown. The splitting of $d$ orbitals $\mathrm{e}_{\mathrm{g}}$ (LUMO) and $\mathrm{t}_{2 \mathrm{~g}}$ (HOMO) and the ligandfield splitting parameter $(\Delta)$ are also shown.

In the next section a general overview of the luminescence properties or ruthenium(II) and iridium(III) complexes is given. $\mathrm{Ru}(\mathrm{II})$-polypyridine complexes are the most widely studied luminescent compounds based on transition metal complexes, both from the theoretical and the application point of view. ${ }^{15,16}$ Conversely, Ir(III)-cyclometallated complexes have received growing attention in the last decade because of their very attractive properties such as the possibility of tuning widely their luminescence properties, which makes them ideal candidates for the preparation of luminescent devices (OLEDs). ${ }^{17,18}$ After a short description of the luminescence properties of these two classes of complexes, in Section 2.2.2 we focus our attention on the description of the photophysical properties of the archetypical $\left[\mathrm{Ru}(\mathrm{bpy})_{3}\right]^{2+}$ (bpy $=2,2^{\prime}$-bipyridine) complex and on the strategies followed in order to tune the emission properties of $\mathrm{Ru}(\mathrm{II})$-based complexes. Moreover, in Section 2.2.3 the absorption and emission properties of the archetypical $f a c-\operatorname{Ir}(\mathrm{ppy})_{3}$ (ppy $=2$-phenylpyridine) are described, together with a summary of the possible strategies for tailoring the emission properties of $\operatorname{Ir}(\mathrm{III})$-based complexes. It is not our aim to give an exhaustive description of 
the thousands of complexes reported in literature, but to report the most illustrative examples of $\mathrm{Ru}(\mathrm{II})$ and $\mathrm{Ir}(\mathrm{III})$ complexes with tailored properties.

\subsubsection{Luminescence properties of $\mathrm{Ru}(\mathrm{II})$ complexes}

Ruthenium(II) complexes have a low spin $d^{6}$ electronic structure and generally form octahedral diamagnetic complexes. Like most octahedral complexes, Ru(II) forms chiral complexes with aromatic bidentate ligands $(\Delta, \Lambda$ isomerism). Since the first observation of $\left[\mathrm{Ru}(\mathrm{bpy})_{3}\right]^{2+}$ (1) luminescence (Figure 2.4), ${ }^{19}$ ruthenium(II) complexes have been the most widely studied among the transition metal-based luminophores. ${ }^{15}$ Among the most important applications, is the extensive use of Ru-based dyes in dye sensitized solar cells (Grätzel cells). ${ }^{20}$ The straightforward synthesis and the remarkable photophysical properties make these complexes very interesting for biological imaging, in spite of their relatively low quantum yield. Generally speaking, the emission quantum yield of ruthenium(II) complexes is usually quite low in degassed solutions (emission quantum yields rarely exceed 0.1 ) and it slightly decreases in presence of dioxygen. ${ }^{17}$ Typical emission lifetimes are in the order of hundreds of ns. These values are due to the low ligand-field splitting parameter $(\Delta)$, which makes the MC levels thermally accessible and, therefore, allows the excited state depopulation via non-radiative processes. ${ }^{16}$ After a description of the luminescence properties of the archetypical $\left[\mathrm{Ru}(\mathrm{bpy})_{3}\right]^{2+}$ complex, in this section we discuss the strategies that can be used to tune the luminescence properties of $\mathrm{Ru}(\mathrm{II})$ complexes with some illustrative examples from literature.

$\left[\mathbf{R u}(\mathbf{b p y})_{3}\right]^{2+}$. The complex $\left[\mathrm{Ru}(\mathrm{bpy})_{3}\right]^{2+}(\mathbf{1})$ is the archetypical compound of the family of $\mathrm{Ru}(\mathrm{II})$-polypyridine complexes. The absorption spectrum of the complex has been extensively studied by several authors and it is reported in Figure 2.4. ${ }^{15}$ The main absorption band between 270 and $300 \mathrm{~nm}$ has been assigned to ligand-centred ${ }^{1}\left(\pi \rightarrow \pi^{*}\right)$ transitions, while the bands between 220 and $270 \mathrm{~nm}$ and between 420 and $470 \mathrm{~nm}$ is usually assigned to ${ }^{1}$ MLCT transitions. Eventually, the shoulders between 320 and $370 \mathrm{~nm}$ have been assigned to MC transitions. The excitation of the complex in any of the absorption bands results in a luminescence emission centred around $620 \mathrm{~nm}$ in solution at room temperature with typical quantum yields in deaerated solutions in the order of 0.04 and lifetime of $650 \mathrm{~ns}$. The lowest emitting state is usually considered to be a ${ }^{3}$ MLCT level. ${ }^{16}$ 


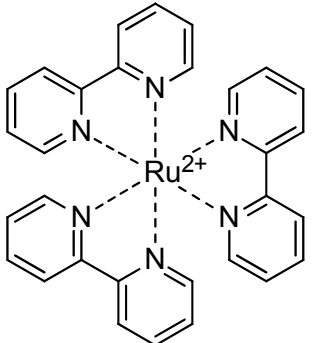

1

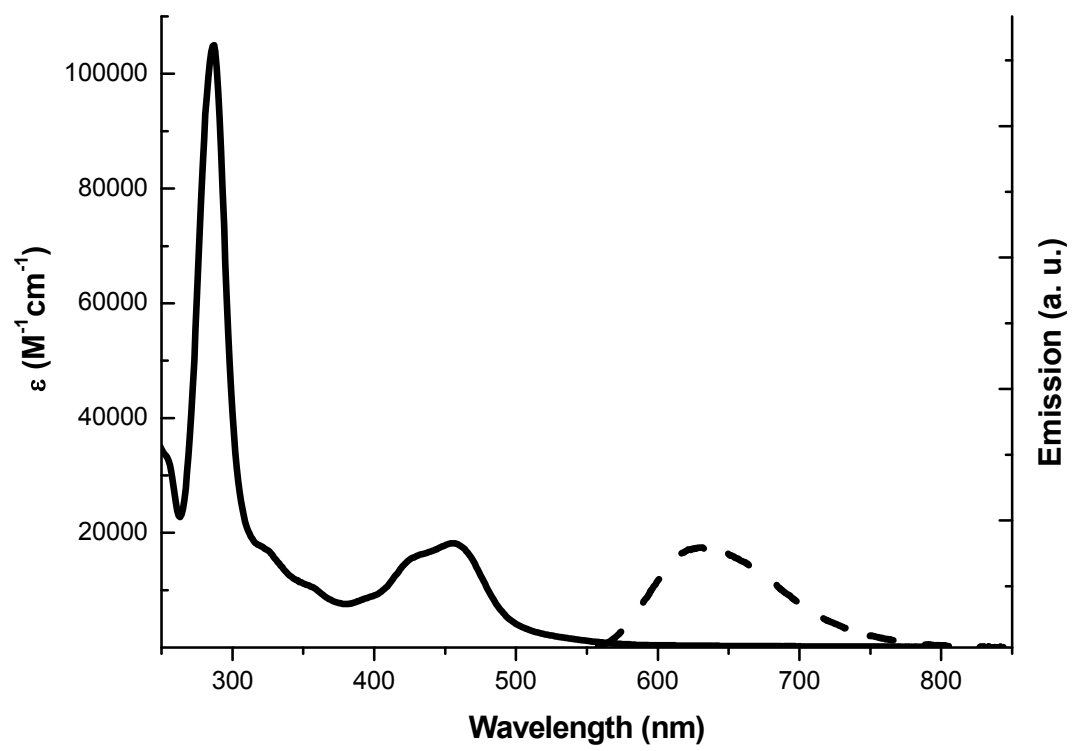

Figure 2.4. Structure of $\left[\mathrm{Ru}(\mathrm{bpy})_{3}\right]^{2+}(\mathbf{1})$ and its absorption (solid line) and emission (dashed line) spectra in aqueous solution.

Tuning luminescence properties or $\mathrm{Ru}(\mathrm{II})$-polypyridine derivatives. Luminescence properties of $\mathrm{Ru}(\mathrm{II})$-polypyridine complexes can be tuned by changing the ligand structures. ${ }^{16}$ First of all, by selecting suitable ligands it is possible to change the nature of the emitting state. It is known that for most of $\mathrm{Ru}(\mathrm{II})$-polypyridine complexes, the emitting state has a ${ }^{3} \mathrm{MLCT}$ nature. A ${ }^{3} \mathrm{MC}$ emission can be induced by introduction of a ligand with a low field strength (e.g. $\mathrm{Cl}^{-}$) and by using a ligand with a negative reduction potential in order to keep the ${ }^{3}$ MLCT level at high energy. An example of a Ru(II) complex showing a clear ${ }^{3} \mathrm{MC}$ emission is $\mathrm{Ru}(\mathrm{i}-\mathrm{biq})_{2} \mathrm{Cl}_{2}$ (2) (Figure 2.5, $\mathrm{i}$-biq = iso-bisquinoline) Conversely, the complex $\left[\mathrm{Ru}(\mathrm{i}-\mathrm{biq})_{3}\right]^{2+}(3)$ shows a ${ }^{3} \mathrm{LC}$ emission. In fact, the ligand has a high ligand-field strength (which increases the energy of ${ }^{3} \mathrm{MC}$ level), a low-lying ${ }^{3} \mathrm{LC}$ level and a suitably negative reduction potential (which keeps ${ }^{3}$ MLCT level at high energy). It is also possible to change the energy of the excited state by changing the ligand structure. For example, the complex $\left[\mathrm{Ru}(\mathrm{bpy})_{2} \mathrm{biq}\right]^{2+}(4)(\mathrm{biq}=$ bisquinoline $)$ shows an emission at $728 \mathrm{~nm}$ at $77 \mathrm{~K} v \mathrm{~s}$ the emission at $580 \mathrm{~nm}$ shown by $\left[\mathrm{Ru}(\mathrm{bpy})_{3}\right]^{2+}$ at $77 \mathrm{~K}$. 


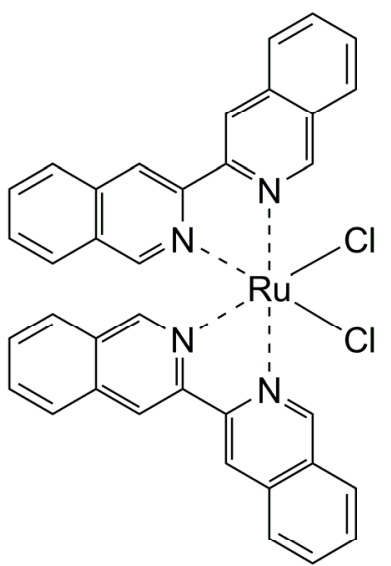

2

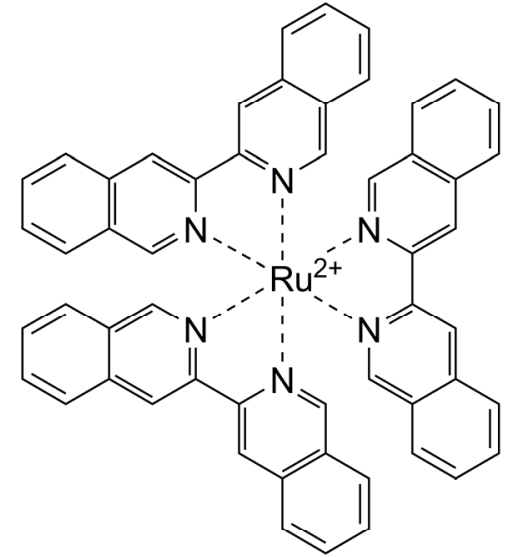

3<smiles></smiles>

4

Figure 2.5. Ruthenium(II) complexes showing ${ }^{3} \mathrm{MC}$ emission (2), ${ }^{3} \mathrm{LC}$ emission (3) and lowenergy ${ }^{3}$ MLCT emission (4).

\subsubsection{Luminescence properties of $\operatorname{Ir}($ III) complexes}

Iridium(III) complexes have a low spin $d^{6}$ electronic structure and form octahedral complexes, with often covalent carbon-iridium bonds, beside nitrogen-iridium coordinative bonds. Although the first example of fluorescence emission from the iridium cyclometallate compound $f a c-\operatorname{Ir}(\text { ppy) })_{3} 5$ (Figure 2.6) was already reported in $1985,{ }^{21}$ the extensive and systematic study of iridium(III)-fluorescent derivatives ${ }^{17}$ has received major interest only in the last 10 years. Compared to other transition metal complexes, iridium(III) complexes possess unique photochemical and photophysical properties like the possibility of tuning the emission along the whole visible spectrum by changing the electronic density of the substituents on the aromatic ring. The absorption and the emission change greatly upon introduction of substituents on the ligand. ${ }^{22}$ Furthermore, the iridium derivatives normally posses high emission quantum yield in deaerated solutions (up to unity) and long emission lifetimes (in the order of milliseconds); the excited state of the complex is usually a combination of singlet and triplet states. On the other hand, in general, Ir(III) complexes are synthetically more demanding compared to other coordination complexes with chelate ligands (like bpy) because of the high activation energies required for the formation of the Ircarbon bond. Cyclometallated Ir(III) complexes show usually a fac, mer isomerism, but because of the poor emissive properties usually shown by the mer isomers, in this section we will describe only complexes with a fac conformation. 
After a description of the luminescence properties of the archetypical $f a c-\operatorname{Ir}(\mathrm{ppy})_{3}$ complex, in this section we discuss the strategies that can be used in order to tune the emission properties of $\operatorname{Ir}(\mathrm{III})$ derivatives with some illustrative examples from literature.

fac-Ir(ppy) $)_{3}$. The complex $f a c-\operatorname{Ir}(\mathrm{ppy})_{3}(\mathbf{5})$ is the simplest member of the family of $\operatorname{Ir}(\mathrm{III})-$ cyclometallated complexes. The absorption spectrum is reported in Figure 2.6. ${ }^{21}$ The main absorption band between 240 and $300 \mathrm{~nm}$ has been assigned to ligand-centred ${ }^{1}\left(\pi \rightarrow \pi^{*}\right)$ transitions whilst the absorption band between 320 and $430 \mathrm{~nm}$ has been assigned to ${ }^{1}$ MLCT transitions and the weak shoulders between 430 and $500 \mathrm{~nm}$ have been assigned to spinforbidden ${ }^{3}$ MLCT transitions, which become partly allowed because of the large spin-orbit coupling induced by the $\operatorname{Ir}(\mathrm{III})$ center. ${ }^{23}$ Upon photoexcitation $\operatorname{Ir}(\mathrm{ppy})_{3}$ shows luminescence emission centred around $520 \mathrm{~nm}$ in solutions at room temperature with typical quantum yields in deaerated solutions in the order of 0.7 and lifetimes of $1.9 \mu \mathrm{s} .{ }^{17}$ The emissive state is usually considered to be an admixture of ${ }^{3} \mathrm{MLCT}$ and ${ }^{3} \mathrm{LC}$ levels. ${ }^{24}$<smiles></smiles>

5

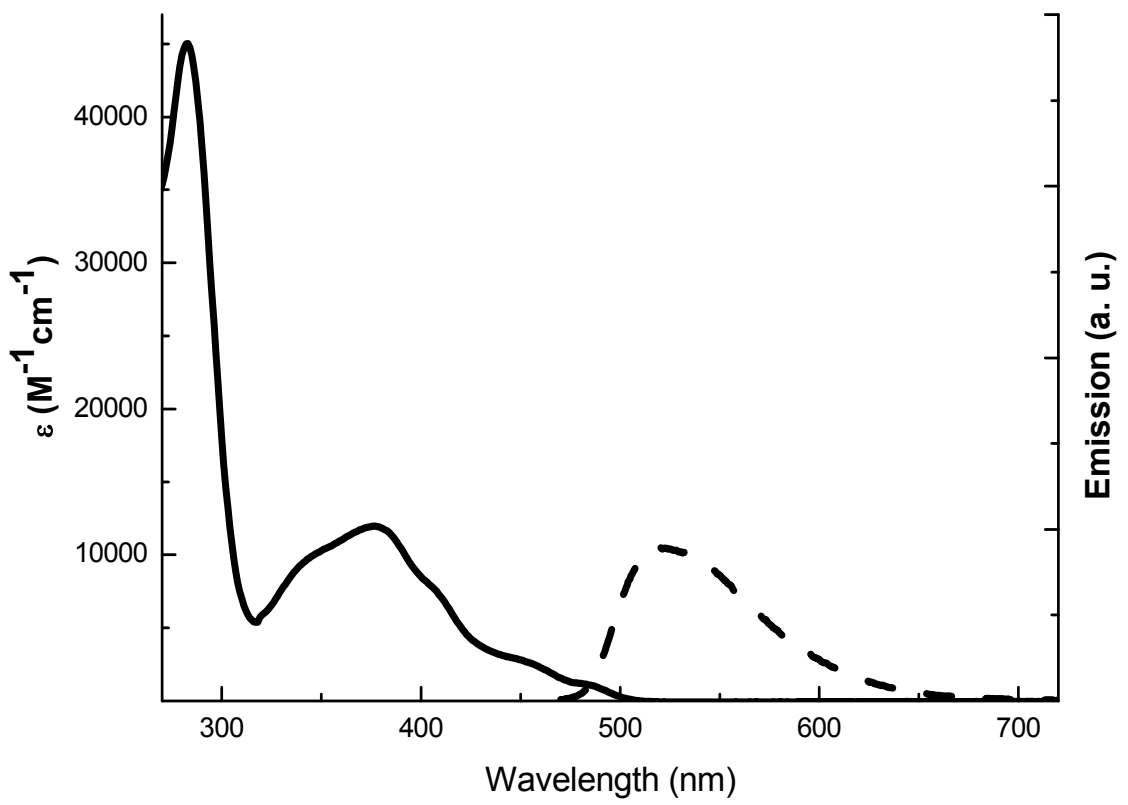

Figure 2.6. Structure of $f a c-\operatorname{Ir}(\mathrm{ppy})_{3}(\mathbf{5})$ and its absorption (solid line) and emission (dashed line) spectra in DMF.

Tuning luminescence properties of Ir(III)-derivatives. The wide tunability of the luminescence properties of $\operatorname{Ir}(\mathrm{III})$-complexes constitutes one of the most attractive properties of these compounds. ${ }^{17}$ In a first approximation, the excitation process of the archetypical fac$\operatorname{Ir}(\text { ppy })_{3}$ can be seen as the promotion of an electron from the HOMO orbital (localized on the 
metal centre and partly on the phenyl ring) to the LUMO orbital (mainly localized on the pyridine ring). Therefore, upon addition of suitable substituents on the phenyl/pyridine ring or replacement of the phenylpyridine ligand with a suitable chelating ligand, it is possible to decrease or increase the energy of the frontier orbitals (i.e. HOMO and LUMO), resulting in a variation of the emission colour. More in detail, by introducing ligands with an extended electronic delocalization, it is possible to tune the emission colour from green $\left(\operatorname{Ir}(\mathrm{ppy})_{3}\right)$, to yellow $\left(\operatorname{Ir}(f l p y)_{3}, 6\right)$ (Figure 2.7, flpy $=2$-(9,9-dimethyl-9H-fluoren-2-yl)pyridine)) to red $\left(\operatorname{Ir}(\text { piq })_{3}, 7\right)$ (piq $=1$-phenylisoquinoline). ${ }^{25} \mathrm{~A}$ similar effect can be also achieved upon introduction of electron-withdrawing groups on the pyridine ring. Different strategies have been followed in order to obtain Ir(III)-complexes with a blue emission. For example, a blue emission can be obtained by stabilising the HOMO orbital upon introduction of electronwithdrawing groups (like fluorine) on the phenyl ring (complex 8, Figure 2.7, shows an emission maximum of $459 \mathrm{~nm}) .{ }^{26}$ A second strategy consists in the replacement of the pyridine ring with moieties having a higher LUMO orbital, like in the case of N-heterocyclic carbene-based ligands. By using this approach it is possible to achieve emissions in the nearUV, like reported for complex 9 (Figure 2.7), which shows an emission maximum of 380 $\mathrm{nm}^{27}$ 


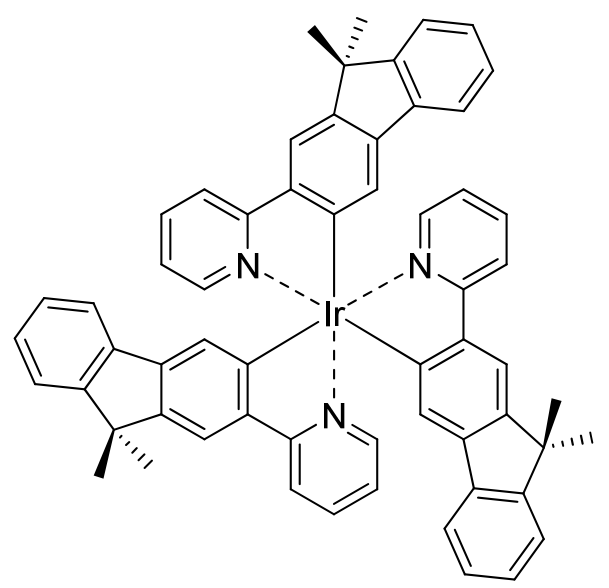

6

$\lambda_{\mathrm{em}}=545 \mathrm{~nm}$<smiles></smiles>

8

$\lambda_{\mathrm{em}}=459 \mathrm{~nm}$<smiles></smiles>

7

$\lambda_{\mathrm{em}}=620 \mathrm{~nm}$

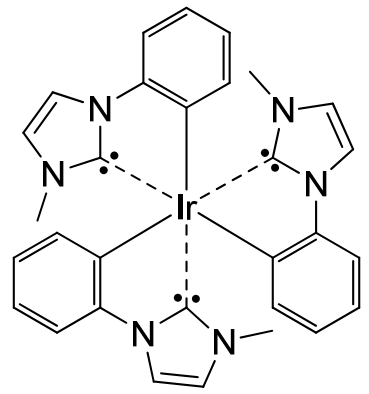

9

$\lambda_{\mathrm{em}}=380 \mathrm{~nm}$

Figure 2.7. Emission tunability of $\operatorname{Ir}(\mathrm{III})$ complexes: structure and emission wavelength of complexes showing yellow (6), red (7), blue (8) and near-UV (9) emission.

Bernhard et al. have reported the possibility of tuning the emission of cationic $\operatorname{Ir}(\mathrm{III})$ complexes along the entire visible spectrum (Figure 2.8) by changing selectively the chemical properties of the ligands. ${ }^{22}$ 

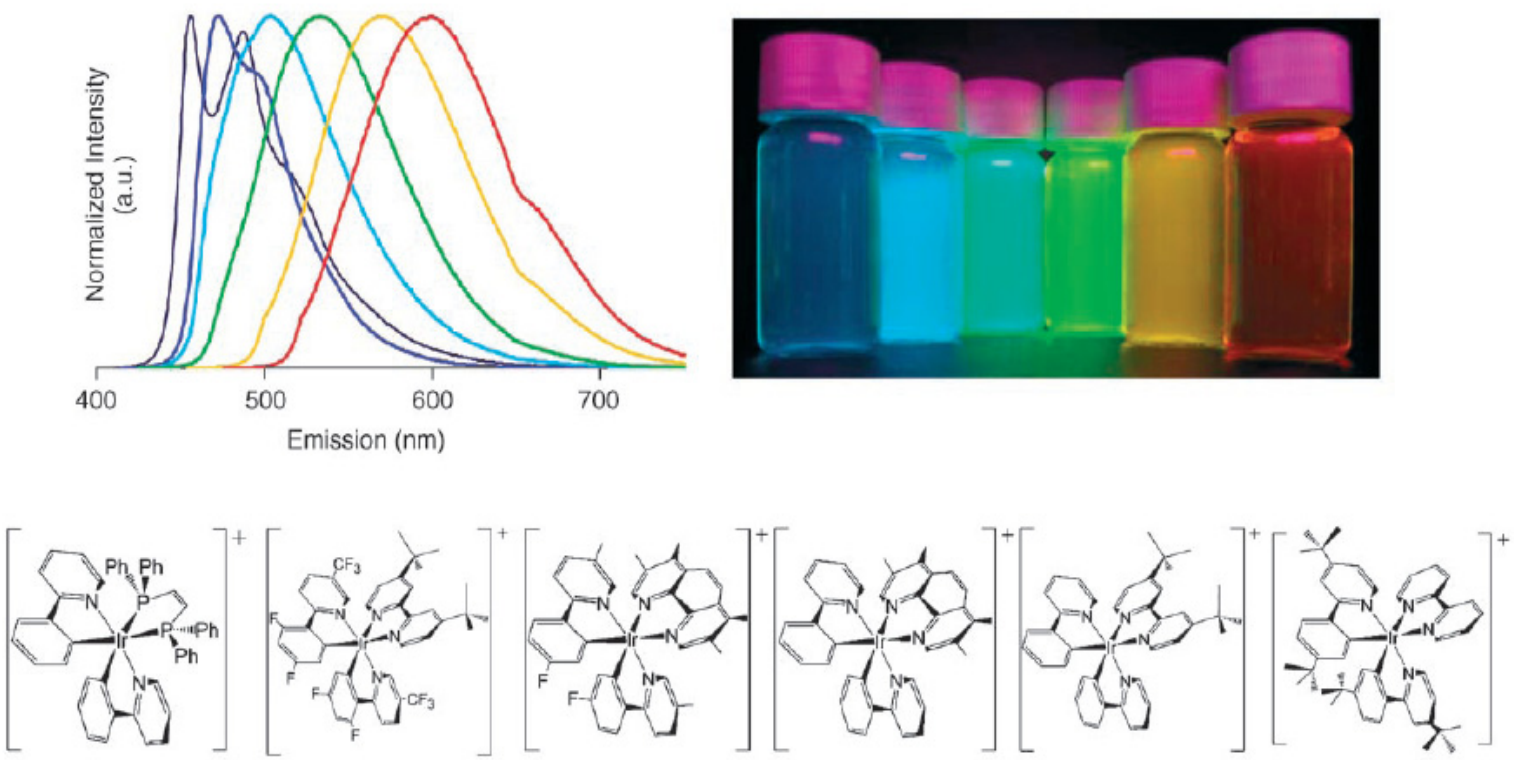

Figure 2.8. Colour tunability of cationic Ir(III) complexes. Reproduced from ref. 22 with permission.

\subsection{Oxygen quenching of luminescence}

Luminescent molecules can interact with a quencher molecule, altering the luminescence of the complex. In this section the oxygen quenching mechanism and the molecular parameters involved in this process are described (Section 2.3.1) and the specific cases for ruthenium(II) and iridium(III) complexes are discussed (Section 2.3.2).

\subsubsection{Mechanism of oxygen quenching of luminescence}

A quencher molecule (viz. dioxygen) colliding with a luminophore in its excited state causes a collision-dependent decrease of luminescence that can be described by the Stern-Volmer equation (eq. 2.3):

$$
\frac{I_{0}}{I}=\frac{\tau_{0}}{\tau}=1+K_{S V}\left[O_{2}\right]=1+k_{q} \tau_{0}\left[O_{2}\right]
$$

Where $I_{0}$ and $I$ are the luminescence intensities without and with quencher (dioxygen), respectively, and $\tau_{0}$ and $\tau$ are the corresponding luminescence lifetimes. $K_{S V}$ is the SternVolmer constant and $k_{\mathrm{q}}$ is the kinetic quenching constant ${ }^{4}$ that reflects the efficiency of the 
quenching process and that can be used to compare luminophores with different lifetimes. The kinetic constant $k_{\mathrm{q}}$ is directly proportional to the diffusion-controlled bimolecular rate constant $k_{\mathrm{d}}$, which is defined according to the Smoluchowski equation (eq. 2.4):

$$
k_{d}=\frac{4 \pi N}{1000}\left(R_{f}+R_{q}\right)\left(D_{f}+D_{q}\right)
$$

Herein is $\mathrm{N}$ the Avogadro number, and are $\mathrm{R}_{\mathrm{f}}$ and $\mathrm{R}_{\mathrm{q}}$ the radii of the luminophore and quencher, respectively, and $D_{f}$ and $D_{q}$ the diffusion constants of the luminophore and quencher, respectively. The oxygen quenching of luminescence for a generic fluorophore is usually a complex process which can involve different kinds of interactions and transitions. In the following section we will present an overview of the relevant processes involved in the luminescence quenching of transition metal complexes. We refer the interested reader to several papers and reviews where it is possible to find theoretical details concerning the mechanisms involved in the oxygen quenching of organic luminophores. ${ }^{28,29}$

Dioxygen quenching of excited triplet states of transition metal complexes can follow two different mechanisms: energy transfer and electron transfer. ${ }^{28,30}$ In the energy transfer mechanism (eq. 2.5) a ground state triplet oxygen molecule $\mathrm{O}_{2}\left(\mathrm{X}^{3} \Sigma_{\mathrm{g}}{ }^{-}\right)$interacts with the triplet excited state of the luminophore *F yielding the ground state of the luminophore $\mathrm{F}$ and singlet oxygen in one of its two possible excited states $\mathrm{O}_{2}\left({ }^{1} \Delta_{\mathrm{g}}\right)$ or $\mathrm{O}_{2}\left({ }^{1} \Sigma_{\mathrm{g}}\right)$ :

$$
* F+O_{2}\left(X^{3} \Sigma_{g}^{-}\right) \longrightarrow F+O_{2}\left({ }^{1} \Delta_{g}\right) \text { or } O_{2}\left({ }^{1} \Sigma_{g}\right)
$$

The singlet oxygen produced during this reaction is an extremely reactive species: it readily reacts with organic molecules giving peroxides, in which the $\mathrm{O}-\mathrm{O}$ bond can be easily cleaved to generate highly reactive oxygen radicals like the hydroperoxide ${ }^{\circ} \mathrm{OH} .{ }^{31}$ The free energy for an energy transfer quenching $\left(\Delta \mathrm{G}_{\mathrm{et}}\right)$ is related to the energy of the $0-0$ transition and the energy of the excited state of oxygen according to equation 2.6:

$$
\Delta G_{e t}=-\left(E_{00}-E_{O_{2} *}\right)
$$

Where $\mathrm{E}_{00}$ is the energy of the $0-0$ transition (i.e. the energy of the triplet excited state) and $\mathrm{E}_{\mathrm{O} 2 *}$ the energy of the (excited state) of singlet oxygen: $\mathrm{E}_{\mathrm{O} 2} *\left({ }^{1} \Sigma_{\mathrm{g}}\right)=1.63 \mathrm{eV}$ and $\mathrm{E}_{\mathrm{O} 2 *\left({ }^{1} \Delta_{\mathrm{g}}\right)=}$ 
$0.98 \mathrm{eV}$ depending on which excited state of dioxygen is initially produced during quenching. ${ }^{32-34}$ The observed quenching constant for energy transfer $\mathrm{k}_{\mathrm{q}}{ }^{\text {en }}$ is given by equation 2.7:

$$
k_{q}^{e t}=\frac{k_{d}}{1+e^{\frac{\Delta G_{e t}}{R T}}}
$$

$\mathrm{R}$ is the gas constant and $\mathrm{T}$ is the temperature. ${ }^{34}$

In the electron transfer mechanism (eq. 2.8) a dioxygen molecule interacts with *F generating an oxidised ground state of the luminophore $\mathrm{F}^{+}$and the superoxide radical $\mathrm{O}_{2}{ }^{\bullet-}$ :

$$
* \mathrm{~F}+\mathrm{O}_{2} \longrightarrow \mathrm{F}^{+}+\mathrm{O}_{2}^{\bullet-}
$$

The superoxide radical $\mathrm{O}_{2}{ }^{-{ }^{-}}$is a toxic species, because it can react with biomolecules, e.g. DNA. $^{35}$ The free energy for electron transfer quenching $\left(\Delta \mathrm{G}_{\mathrm{el}}\right)$ is related to the oxidation potential and to the energy of the $0-0$ transition of the fluorophore (eq. 2.9):

$$
\Delta G_{e l}=F\left(E_{F}^{o x}-E_{o_{2}}^{r e d}\right)-E_{00}+C
$$

Where $\mathrm{F}$ is the Faraday's constant, $\mathrm{E}_{\mathrm{F}}^{\mathrm{ox}}$ is the oxidation potential of the fluorophore (in volt), $\mathrm{E}_{\mathrm{O} 2}^{\mathrm{red}}$ is the reduction potential of oxygen $(-0.78 \mathrm{~V}), \mathrm{E}_{00}$ is the energy of the 0-0 transition (in electronvolt) and $\mathrm{C}$ a Coulomb term (usually neglected in polar solvents). ${ }^{36}$ The observed quenching constant for electron transfer $\mathrm{k}_{\mathrm{q}}{ }^{\mathrm{el}}$ is given by equation 2.10 :

$$
k_{q}^{e l}=Z e^{-\frac{\lambda}{4}\left(1+\frac{\Delta G_{e l}}{\lambda}\right)^{2}}
$$

$\mathrm{Z}$ is an universal frequency factor (for solution reactions usually is assumed $\mathrm{Z}=6 \cdot 10^{11} \mathrm{~s}^{-1}$ ), $\lambda$ is the reorganization energy, $\mathrm{R}$ is the gas constant and $\mathrm{T}$ the temperature. ${ }^{37}$

From eq. 2.6 and eq. 2.9 it is possible to deduce that, in order to modulate the dioxygen quenching of a fluorophore, one can basically tune two crucial parameters: the triplet energy state $\left(\mathrm{E}_{00}\right)$ and the oxidation potential of the luminophore $\left(\mathrm{E}_{\mathrm{F}}^{\mathrm{ox}}\right)$. A further parameter to be considered is the shielding effect provided by the environment (e.g. matrix or suitable 
shielding species in solution) or by the structure itself (e.g. bulky molecules). Such shielding can decrease the degree of quenching by physically preventing the collision between dioxygen and the luminophore in its excited state. In the following section we will provide several examples of applications of these general principles.

\subsubsection{Tuning oxygen quenching of $\mathrm{Ru}(\mathrm{II})$ and $\mathrm{Ir}(\mathrm{III})$ complexes}

Demas et al. first reported about the dioxygen quenching of $\mathrm{Ru}(\mathrm{II})$ and $\mathrm{Ir}(\mathrm{III})$ complexes and proposed an interpretation based on the formation of singlet oxygen, which was proven by photooxygenation of trimethylethylene. ${ }^{38-40}$ Other authors proved the mechanism of electron transfer to be efficient in complexes with low oxidation potential. ${ }^{41}$ The mechanism of singlet oxygen photogeneration has been widely investigated especially in view of the interest of singlet oxygen for therapeutical applications (vide infra). ${ }^{28,31,42,43}$ In this section we summarize the different strategies which have been exploited in order to modify oxygen quenching of $\mathrm{Ru}(\mathrm{II})$ and $\mathrm{Ir}(\mathrm{III})$ complexes, ${ }^{28}$ i.e., modification of triplet energy states, tailoring of the oxidation state, structural modification of ligand to create steric environments, and supramolecular shielding. Most studies about this topic are focused on ruthenium(II) complexes whilst the study of the oxygen quenching tuning of iridium(III) complexes is relatively unexplored. The photophysical properties of the two archetypical compounds $\left[\mathrm{Ru}(\mathrm{bpy})_{3}\right]^{2+}(\mathbf{1})$ and $f a c-\operatorname{Ir}(\mathrm{ppy})_{3}(\mathbf{5})$ are reported in Table 2.1 together with their oxygen quenching constant $\left(\mathrm{k}_{\mathrm{q}}\right)$.

Table 2.1. Photophysical properties and of the archetypical $\left[\mathrm{Ru}(\mathrm{bpy})_{3}\right]^{2+}(\mathbf{1})$ and $f a c-\operatorname{Ir}(\mathrm{ppy})_{3}$ (5).

\begin{tabular}{|l|c|c|c|c|c|c|c|c|}
\hline & $\begin{array}{c}\lambda_{\text {em }} \\
(\mathbf{n m})\end{array}$ & $\phi$ & $\phi_{\text {air }}$ & $\begin{array}{c}\tau \\
(\mathbf{n s})\end{array}$ & $\begin{array}{c}\tau_{\text {air }} \\
(\mathbf{n s})\end{array}$ & $\begin{array}{c}\mathbf{E}_{\mathbf{0 0}} \\
(\mathbf{e V})\end{array}$ & $\begin{array}{c}\mathbf{E}_{\mathbf{o x}} \\
(\mathbf{V})\end{array}$ & $\begin{array}{c}\mathbf{k}_{\mathbf{q}} \\
\left(\mathbf{M}^{-1} \mathbf{s}^{\mathbf{- 1}}\right)\end{array}$ \\
\hline$\left[\mathbf{R u}(\mathbf{b p y})_{3}\right]^{2+\mathrm{a}}$ & 620 & 0.042 & 0.028 & 650 & $390^{\mathrm{b}}$ & $2.13^{\mathrm{c}}$ & $1.28^{\mathrm{c}}$ & $3.1 \cdot 10^{9 \mathrm{c}}$ \\
\hline fac-Ir(ppy) $_{\mathbf{3}}^{\mathrm{d}}$ & 523 & 0.71 & 0.03 & 1873 & 82 & $2.51^{\mathrm{e}}$ & $0.77^{\mathrm{f}}$ & $2.410^{10}$ \\
\hline
\end{tabular}

a) Solution in $\mathrm{H}_{2} \mathrm{O}$. From Ref. ${ }^{44}$ unless otherwise stated. b) Solution in $\mathrm{H}_{2} \mathrm{O}^{45}$ c) Solution in $\mathrm{CH}_{3} \mathrm{CN}$. Potential vs. Saturated Calomel Electrode (SCE). ${ }^{46}$ d) Solution in DMF. From Ref. ${ }^{47}$ unless otherwise stated. e) Solution in $\mathrm{MeOH}^{48}$ f) Potential vs SCE. ${ }^{49}$ 
Triplet-state energy modification. According to theoretical models (vide supra) the easiest strategy to tailor the oxygen quenching of a luminophore, particularly in the case of quenching occurring by energy transfer, is changing the triplet energy of the luminophore's excited states $\mathrm{E}_{00 .}{ }^{29}$ Increasing the triplet energy of the luminophore's excited state it is possible to decrease the dioxygen quenching and, conversely, luminescent complexes with low triplet energy show usually a more pronounced oxygen quenching. By analysing the changes in oxygen quenching of different $\left[\mathrm{Ru}(\mathrm{bpy})_{3}\right]^{2+}$ complexes in which bpy moieties were substituted with benzocrown ether connected through vinyl moiety (10 and 11, Figure 2.8) this effect has been experimentally proven. Complex 10 shows a triplet energy $\mathrm{E}_{00}=$ $1.99 \mathrm{eV}$ and a quenching constant $\mathrm{k}_{\mathrm{q}}=3.0 \cdot 10^{9} \mathrm{M}^{-1} \mathrm{~s}^{-1}$ whilst complex 11 shows a triplet energy $\mathrm{E}_{00}=1.94 \mathrm{eV}$ and a quenching constant $\mathrm{k}_{\mathrm{q}}=3.65 \cdot 10^{9} \mathrm{M}^{-1} \mathrm{~s}^{-1}$. Both the complexes show the same oxidation potential $\left(\mathrm{E}_{\mathrm{ox}}=1.31 \mathrm{~V} v s \mathrm{SCE}\right){ }^{36}$

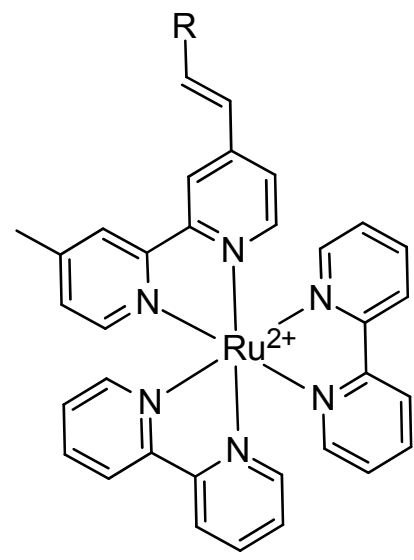

10

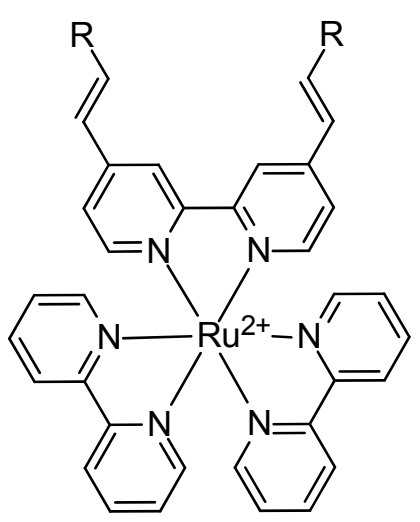

11

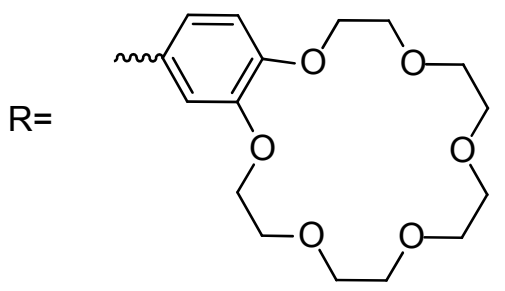

Figure 2.8. Examples of $\mathrm{Ru}(\mathrm{II})$ complexes showing tailored oxygen quenching deriving from different triplet energy. 
Modification of the ground state oxidation potential. An easily oxidizable molecule can give oxygen quenching via charge-transfer (CT) interaction. This effect has initially been observed in ruthenium(II) complexes by Tan-Sie-Hee et al, ${ }^{41}$ who reported that, after substituting a bpy ligand for a 1,4,5,8,9,12-hexaazatriphenylene (hat) ligand (12, Figure 2.9), a large decrease of quenching is obtained in acetonitrile from $\mathrm{k}_{\mathrm{q}}=3.110^{9} \mathrm{M}^{-1} \mathrm{~s}^{-1}$ for $\left[\mathrm{Ru}(\mathrm{bpy})_{3}\right]^{2+}$ to $\mathrm{k}_{\mathrm{q}}=0.5 \cdot 10^{8} \mathrm{M}^{-1} \mathrm{~s}^{-1}$ for $\left[\mathrm{Ru}(\mathrm{hat})_{3}\right]^{2+}$. The analysis of the oxidation potential of the ground state $\left(\mathrm{E}_{\mathrm{ox}}\right)$ shows a significant increase of the potential compared to $\left[\mathrm{Ru}(\mathrm{bpy})_{3}\right]^{2+}$ $\left(+2.07 \mathrm{~V}\right.$ vs $+1.28 \mathrm{~V}$, respectively) whilst the triplet energy $\left(\mathrm{E}_{00}\right)$ basically does not change, proving the importance of electron transfer in dioxygen quenching. The possibility of tuning the oxygen quenching by varying the oxidation potential has also been studied for iridium(III) complexes. ${ }^{50}$ In particular, an Ir(III) complex (13, Figure 2.9) with a remarkably high oxygen quenching constant in acetonitrile $\left(\mathrm{k}_{\mathrm{q}}=2.6 \cdot 10^{10} \mathrm{M}^{-1} \mathrm{~s}^{-1}\right)$ has been reported. The authors ascribe this effect to the relatively low oxidation potential of the complex $\left(\mathrm{E}_{\mathrm{ox}}=\right.$ $+0.54 \mathrm{~V}$ ) which makes the electron transfer highly favourable in terms of free energy. ${ }^{51}$

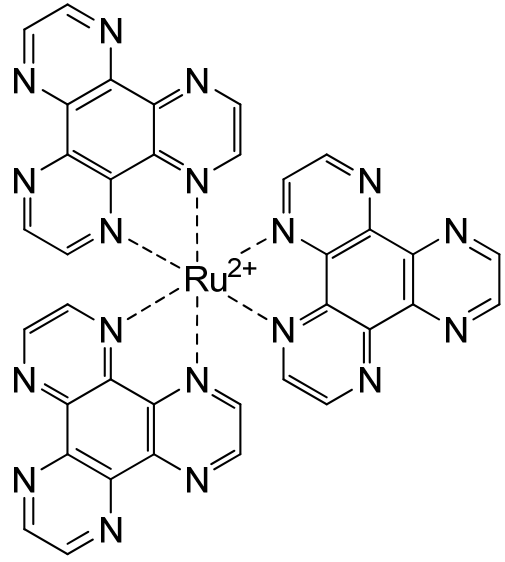

12

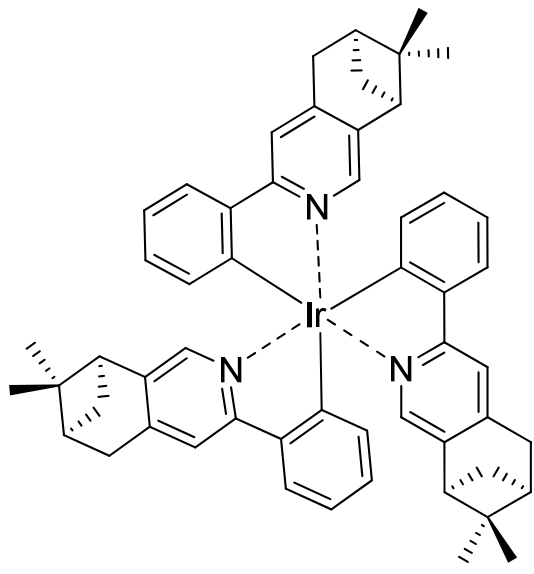

13

Figure 2.9. Examples of $\mathrm{Ru}(\mathrm{II})$ and $\mathrm{Ir}(\mathrm{III})$ complexes showing tailored oxygen quenching deriving from different oxidation potentials.

Structural modification. The effect of ligand size on dioxygen quenching has been investigated since the first observations of the quenching effect on transition metal complexes. Demas et al. ${ }^{40}$ observed only small differences in dioxygen quenching constant between $\left[\mathrm{Ru}(\mathrm{bpy})_{3}\right]^{2+},\left[\mathrm{Ru}(\text { phen })_{3}\right]^{2+}$ and $\left[\mathrm{Ru}(\mathrm{PhPhen})_{3}\right]^{2+}(\mathrm{PhPhen}=4,7$-diphenyl-1,10phenanthroline): these give oxygen quenching constants in methanol $\left(\mathrm{k}_{\mathrm{q}}\right)$ of $1.8 \cdot 10^{9} \mathrm{M}^{-1} \mathrm{~s}^{-1}$, 
3.3 $10^{9} \mathrm{M}^{-1} \mathrm{~s}^{-1}$ and $2.5 \cdot 10^{9} \mathrm{M}^{-1} \mathrm{~s}^{-1}$, respectively. More interestingly, Abdel-Shafi et al. reported that the functionalization of bpy ligands with bulky benzo-crown ethers (14, Figure 2.10) basically does not change the oxygen quenching constant in acetonitrile compared to $\left[\mathrm{Ru}(\mathrm{bpy})_{3}\right]^{2+}\left(\mathrm{k}_{\mathrm{q}}=2.21 \cdot 10^{9} \mathrm{M}^{-1} \mathrm{~s}^{-1}\right.$ and $\mathrm{k}_{\mathrm{q}}=2.75 \cdot 10^{9} \mathrm{M}^{-1} \mathrm{~s}^{-1}$, respectively $){ }^{33}$ Despite the seemingly high steric hindrance given by the benzo-crown ethers, the small dioxygen molecule can still easily interact with the excited state yielding an efficient quenching. However, $\left[\mathrm{Ru}(\mathrm{bpy})_{3}\right]^{2+}$ complexes functionalized with bulky dendritic substituents (15, Figure 2.10) do give a higher steric hindrance and therefore an effective shielding against dioxygen quenching. This results in an almost $90 \%$ decrease of quenching $\left(\mathrm{k}_{\mathrm{q}}=0.22 \cdot 10^{9}\right.$ $\mathrm{M}^{-1} \mathrm{~s}^{-1}$ in acetonitrile). ${ }^{52}$

Alternatively, caged ligands have been successfully explored in order to decrease oxygen quenching. A caged Ru(II) complex by Barigelletti et al. (16, Figure 2.11) shows an 80\% decrease of quenching in acetonitrile $\left(\mathrm{k}_{\mathrm{q}}=0.94 \cdot 10^{9} \mathrm{M}^{-1} \mathrm{~s}^{-1}\right)$ with respect to $\left[\mathrm{Ru}(\mathrm{bpy})_{3}\right]^{2+}{ }^{26}$

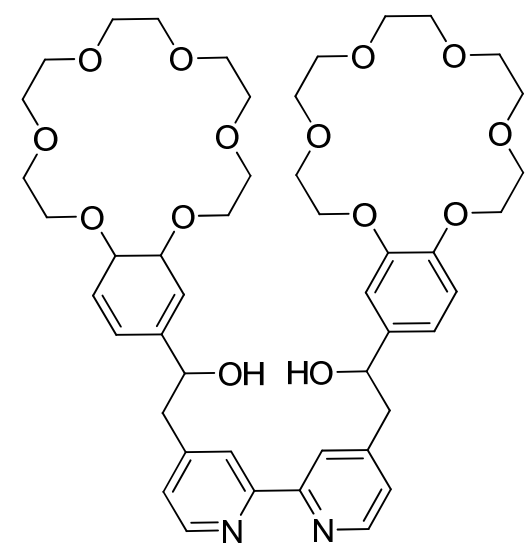

14

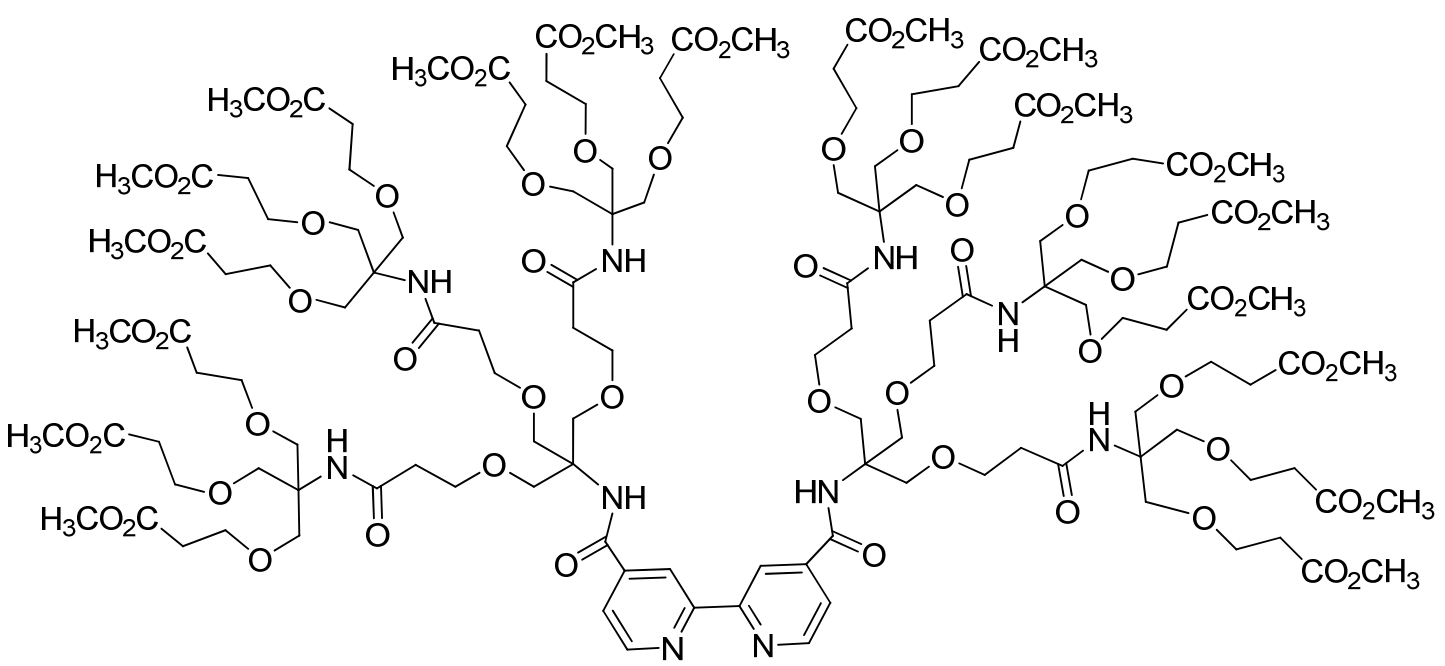

15

Figure 2.10. Bulky ligands used for the synthesis of $\left[\mathrm{RuL}_{3}\right]^{2+}$ complexes $(\mathrm{L}=\mathbf{1 4}, \mathbf{1 5})$ showing different oxygen quenching deriving from structural effects. 
Supramolecular interactions. A fluorophore hosted in a bulky molecule has less interaction with external agents. For instance the luminescence of tryptophan in proteins has varying quenching constants depending on its position in the protein viz. being on the surface or buried in the interior.

This difference is explained in terms of steric shielding: the protein structure physically does not allow the quencher to approach the excited state of the fluorophore, resulting in a decrease of quenching. ${ }^{4}$ A similar "shielding" effect can be synthetically obtained by using supramolecular encapsulation of $\mathrm{Ru}(\mathrm{II})$ and $\mathrm{Ir}(\mathrm{III})$ complexes. For instance, Xu et al. showed that by modifying a $\left[\mathrm{Ru}(\mathrm{phen})_{3}\right]^{2+}$ complex with some extra phenyl units (17, Figure 2.11$)$ it is possible to induce the binding of the $\mathrm{Ru}(\mathrm{II})$ complex to a polymer chain functionalized with several $\beta$-cyclodextrins (CDs). ${ }^{53}$ This interaction leads to a consequent shielding of the excited state and reduces oxygen quenching up to $90 \%$, depending on the length of the polymeric chain. In the absence of poly-CD the degree of oxygen quenching is similar to that found for the reference compound $\left[\mathrm{Ru}(\mathrm{phen})_{3}\right]^{2+}$. The same principle can be applied to other "host" molecules. In fact, recently a zeolite (L) was used to reduce the oxygen quenching of the luminescence of $\mathrm{a}\left[\mathrm{Ru}(\mathrm{bpy})_{3}\right]^{2+}$ in which one of the bpy ligands was functionalized with a tetraphenyl chain (18, Figure 2.11). ${ }^{54}$ The zeolite structure sterically prevents the approach of oxygen and therefore results in a significant decrease of oxygen quenching in $\mathrm{CH}_{2} \mathrm{Cl}_{2}\left(\mathrm{k}_{\mathrm{q}}=\right.$ $0.29 \cdot 10^{9} \mathrm{M}^{-1} \mathrm{~s}^{-1}$ and $\mathrm{k}_{\mathrm{q}}=4.09 \cdot 10^{9} \mathrm{M}^{-1} \mathrm{~s}^{-1}$ in presence or absence of zeolite $\mathrm{L}$, respectively). The quenching decrease was also discussed in terms of orbital shielding: by using computational methods, the authors calculated the electron density distribution of the LUMO orbital, which is mostly located along the "tail". Since only the tetraphenyl tail is small enough to penetrate into the Zeolite L, this makes the shielding very effective (Figure 2.11). Interestingly this effect still occurs, while the Ru(bpy $)_{2}$ "head" resides on the zeolite surface and it is virtually not shielded. This result constitutes a hallmark for the design of systems with low oxygen quenching. Herewith, it is possible to decrease the degree of oxygen quenching of a fluorophore by sterically shielding the region of the molecule where the LUMO is localized. 

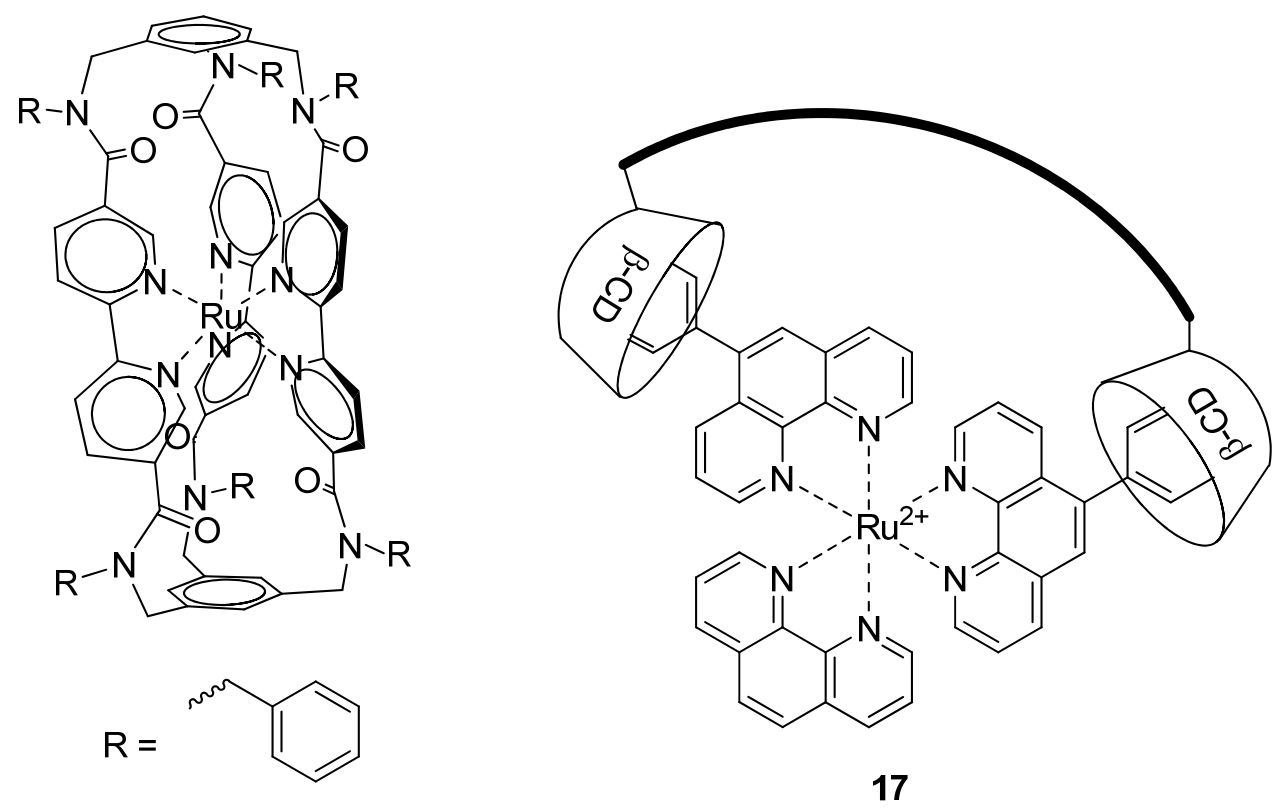

16

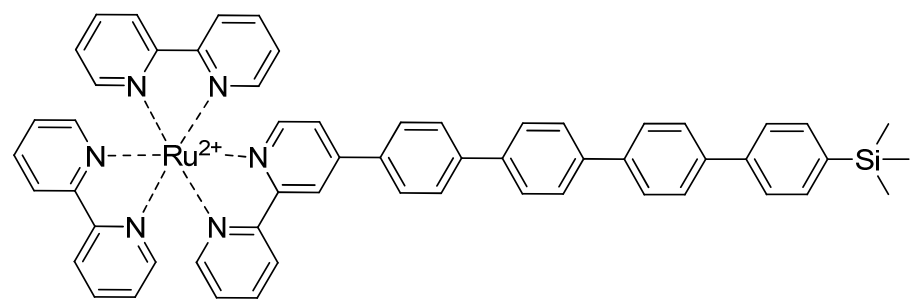

18
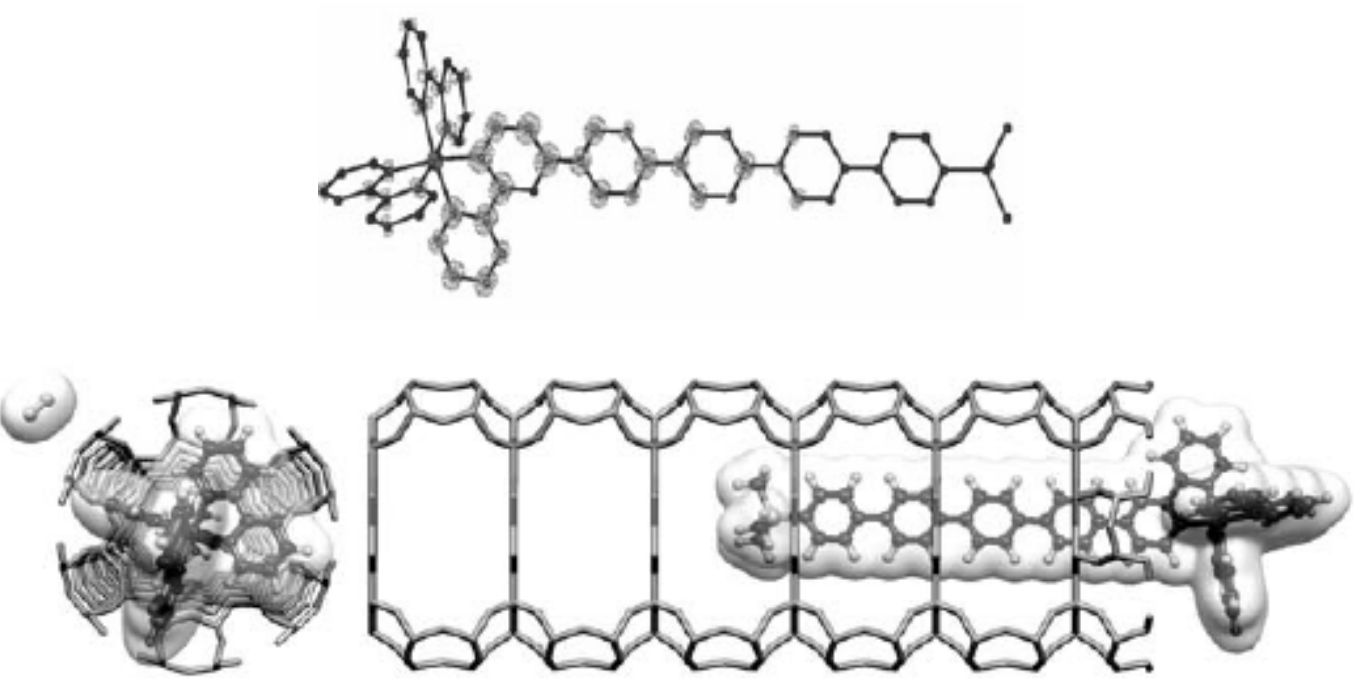

Figure 2.11. $\mathrm{Ru}(\mathrm{II})$ complexes showing reduced oxygen quenching as consequence of intramolecular (16) or supramolecular $(\mathbf{1 7}, \mathbf{1 8})$ shielding against molecular oxygen. Cyclodextrins in complex 17 are connected through $-\left[\mathrm{CH}_{2} \mathrm{CH}(\mathrm{OH}) \mathrm{CH}_{2} \mathrm{O}\right]_{n^{-}}$polymer chains $(n=1-4)$. Reproduced from ref. 55 with permission. 
In conclusion, ruthenium(II) and iridium(III) complexes offer wide possibilities of tuning both emission wavelength and oxygen quenching degree. However, as evident from the examples reported in Section 2.3.2, so far most of the research efforts have focused on the study of the tunability of the oxygen quenching of $\mathrm{Ru}$ (II) complexes and only little is known about the possibility of changing the degree of oxygen quenching of the luminescence of Ir(III) complexes. In particular, the study of the structure-quenching relationship in hemicaged and caged iridium(III) complexes is still an unexplored topic.

\subsection{Scope of the thesis}

Despite the great number of works dedicated to the definition of possible strategies for the realization of bright compounds, we are still far from a "perfect" luminophore for biological applications. In particular, the design of a compound which can conjugate a high brightness (defined as the product of the quantum yield and the molar absorption coefficient) and low oxygen quenching (which is necessary in order to keep a high luminescence in the oxygenrich bio-environment) is still a major challenge. Luminescent nanoparticles like semiconductor Quantum Dots (QDs ) represent so far the best solution to this problem: the high quantum yield (often close to unity) and the insensitivity to oxygen make these luminophores seemingly the best option for biological imaging applications. ${ }^{55-57}$ On the other hand, despite their brilliant performances, there are still serious concerns about the toxicity of

these luminophores, especially when considering the possible biological applications. ${ }^{58-60}$ As shown in this Chapter, transition metal complexes are ideal candidates for the realization of a "perfect" luminophore, due to their stability in biological environments, their usually good optical properties and, more interestingly, the possibility of tuning such properties depending onto the required applications. $\mathrm{Ru}(\mathrm{II})$ and $\mathrm{Ir}(\mathrm{III})$ luminophores are among the best studied transition metal luminophores and the large amount of information available make these compounds ideal starting points for further development of high performance luminophores. On the other hand, as evident from the literature summarized in this chapter, both $\mathrm{Ru}(\mathrm{II})$ and Ir(III) complexes show several drawbacks. Ruthenium(II) luminophores, in particular, show only modest luminescence quantum yields (rarely exceeding 0.1 ), whilst a high brightness is a crucial parameter for biological applications. Conversely, iridium (III) luminophores show remarkably high quantum yields but this value dramatically decreases in the presence of oxygen. Moreover, there is only a limited amount of literature concerning the possibility of 
tuning the oxygen quenching of $\operatorname{Ir}(\mathrm{III})$ complexes, which makes this topic very challenging and stimulating.

In this thesis the design, synthesis and luminescence study of high performance luminophores is described. According to the previously discussed literature, two possible pathways can be followed, namely 1) the realization of an Ir(III)-based luminophore with a reduced oxygen quenching and 2) the improvement of the brightness of Ru(II)-based luminophores. As observed in the case of $\mathrm{Ru}(\mathrm{II})$ complexes, a caged structure is expected to be able to reduce the oxygen quenching of luminescence, therefore an $\operatorname{Ir}(\mathrm{III})$ complex with a caged structure is the most obvious candidate for the realization of an $\operatorname{Ir}(\mathrm{III})$-based luminophore with low oxygen quenching. In Chapter 3, the design and synthesis of such a complex is reported, together with the study of its luminescence properties and of the oxygen quenching of its luminescence. On the other hand, the mechanism of intramolecular shielding against dioxygen in caged complexes (resulting in a decrease of luminescence quenching by oxygen) is not clear yet. Therefore, in Chapters 4 and 5, two $\operatorname{Ir}(\mathrm{III})$ complexes with a hemicaged structure (closed on the pyridine and phenyl side, respectively) are described and the oxygen quenching of their luminescence is compared with the parent open complexes (i.e. complexes without capping units), in order to obtain a clear proof of the intramolecularly induced shielding against oxygen quenching. Moreover, two hemicaged complexes based on a benzene-derivative as capping unit and oxymethyl and ethyl as connecting units are described in Chapters 6 and 7, respectively. These compounds were designed in order to investigate the effect of the capping and connecting units on the oxygen quenching of the luminescence. Furthermore, since transition metal complexes do not suffer from self quenching upon multiple labelling, it should be possible to exploit this property for the realization of a $\mathrm{Ru}(\mathrm{II})$ based luminophore with high brightness upon functionalization of an adequate framework (e.g. a dendrimer) with several $\mathrm{Ru}(\mathrm{II})$-based luminophoric moieties. Such a macromolecular luminophore is described in Chapter 8 , in order to give a proof of principle of a further strategy that can be used for the realization of high performance luminophores.

\subsection{References}

(1) Balzani, V.; Bergamini, G.; Campagna, S.; Puntoriero, F. In Photochemistry and Photophysics of Coordination Compounds I 2007; Vol. 280, p 1-36.

(2) Lamansky, S.; Djurovich, P.; Murphy, D.; Abdel-Razzaq, F.; Lee, H. E.; Adachi, C.; Burrows, P. E.; Forrest, S. R.; Thompson, M. E. J. Am. Chem. Soc. 2001, 123, 4304-4312.

(3) Fernandez-Moreira, V.; Thorp-Greenwood, F. L.; Coogan, M. P. Chem. Comm. 2010, 46, 186-202.

(4) Lakowicz, J. R. Principles of Fluorescence Spectroscopy; Springer: Singapore, 2006. 
(5) Wang, F.; Tan, W. B.; Zhang, Y.; Fan, X. P.; Wang, M. Q. Nanotechnology 2006, 17, R1-R13.

(6) Haugland, R. P. The Handbook. A Guide to Fluorescent Probes and Labeling Technologies; Invitrogen Corp., 2005.

(7) Banks, P. R.; Paquette, D. M. Bioconj. Chem. 1995, 6, 447-458.

(8) Mishra, A.; Behera, R. K.; Behera, P. K.; Mishra, B. K.; Behera, G. B. Chem. Rev. 2000, 100, 1973-2011.

(9) Panchuk-Voloshina, N.; Haugland, R. P.; Bishop-Stewart, J.; Bhalgat, M. K.; Millard, P. J.; Mao, F.; Leung, W. Y.; Haugland, R. P. J. Histochem. Cytochem. 1999, 47, 11791188

(10) Lees, A. J. Chem. Rev. 1987, 87, 711-743.

(11) Selvin, P. R. Ann. Rev. Biophys. Biomol. Struc. 2002, 31, 275-302.

(12) Dickson, E. F. G.; Pollak, A.; Diamandis, E. P. J. Photochem.Photobiol. B 1995, 27, 3-19.

(13) Terpetschnig, E.; Szmacinski, H.; Lakowicz, J. R. In Fluorescence Spectroscopy 1997; Vol. 278, p 295-321.

(14) Lees, A. J. Coord. Chem. Rev. 1998, 177, 3-35.

(15) Campagna, S.; Puntoriero, F.; Nastasi, F.; Bergamini, G.; Balzani, V. In Photochemistry and Photophysics of Coordination Compounds I 2007; Vol. 280, p 117-214. (16) Juris, A.; Balzani, V.; Barigelletti, F.; Campagna, S.; Belser, P.; von Zelewsky, A. Coord. Chem. Rev. 1988, 84, 85-277.

(17) Flamigni, L.; Barbieri, A.; Sabatini, C.; Ventura, B.; Barigelletti, F. In Photochemistry and Photophysics of Coordination Compounds II 2007; Vol. 281, p 143-203.

(18) Lowry, M. S.; Bernhard, S. Chem. Eur. J. 2006, 12, 7970-7977.

(19) Paris, J. P.; Brandt, W. W. J. Am. Chem. Soc. 1959, 81, 5001-5002.

(20) Oregan, B.; Gratzel, M. Nature 1991, 353, 737-740.

(21) King, K. A.; Spellane, P. J.; Watts, R. J. J. Am. Chem. Soc. 1985, 107, 1431-1432.

(22) Lowry, M. S.; Bernhard, S. Chem. Eur. J. 2006, 12, 7970-7977.

(23) Holzer, W.; Penzkofer, A.; Tsuboi, T. Chem. Phys. 2005, 308, 93-102.

(24) Tamayo, A. B.; Alleyne, B. D.; Djurovich, P. I.; Lamansky, S.; Tsyba, I.; Ho, N. N.; Bau, R.; Thompson, M. E. J. Am. Chem. Soc. 2003, 125, 7377-7387.

(25) Tsuboyama, A.; Iwawaki, H.; Furugori, M.; Mukaide, T.; Kamatani, J.; Igawa, S.; Moriyama, T.; Miura, S.; Takiguchi, T.; Okada, S.; Hoshino, M.; Ueno, K. J. Am. Chem. Soc. 2003, 125, 12971-12979.

(26) Ragni, R.; Plummer, E. A.; Brunner, K.; Hofstraat, J. W.; Babudri, F.; Farinola, G. M.; Naso, F.; De Cola, L. J. Mater. Chem. 2006, 16, 1161-1170.

(27) Sajoto, T.; Djurovich, P. I.; Tamayo, A.; Yousufuddin, M.; Bau, R.; Thompson, M. E.; Holmes, R. J.; Forrest, S. R. Inorg. Chem. 2005, 44, 7992-8003.

(28) Schweitzer, C.; Schmidt, R. Chem. Rev. 2003, 103, 1685-1757.

(29) Kawaoka, K.; Khan, A. U.; Kearns, D. R. J. Chem. Phys. 1967, 46, 1842-\&.

(30) Mulazzani, Q. G.; Sun, H.; Hoffman, M. Z.; Ford, W. E.; Rodgers, M. A. J. J. Phys. Chem. 1994, 98, 1145-1150.

(31) Ogilby, P. R. Chem. Soc. Rev. 2010, 39, 3181-3209.

(32) Bodesheim, M.; Schutz, M.; Schmidt, R. Chem. Phys. Lett. 1994, 221, 7-14.

(33) Abdel-Shafi, A. A.; Beer, P. D.; Mortimer, R. J.; Wilkinson, F. J. Phys. Chem. A 2000, 104, 192-202.

(34) Balzani, V.; Bolletta, F.; Scandola, F. J. Am. Chem. Soc. 1980, 102, 2152-2163.

(35) Hernandez-Garcia, D.; Wood, C. D.; Castro-Obregon, S.; Covarrubias, L. Free Radical Biol. Med. 2010, 49, 130-143.

(36) Abdel-Shafi, A. A.; Beer, P. D.; Mortimer, R. J.; F., W. Helv. Chim. Acta 2001, 84, 2784-2795. 
(37) Eberson, L. Electron Transfer Reactions in Organic Chemistry; Springer-Verlag: Berlin Heidelberg, 1987.

(38) Demas, J. N.; Diemente, D.; Harris, E. W. J. Am. Chem. Soc. 1973, 95, 6864-6865.

(39) Demas, J. N.; Harris, E. W.; Flynn, C. M.; Diemente, D. J. Am. Chem. Soc. 1975, 97, 3838-3839.

(40) Demas, J. N.; Harris, E. W.; McBride, R. P. J. Am. Chem. Soc. 1977, 99, 3547-3551.

(41) Tan-Sien-Hee, L.; Jacquet, L.; Kirsch - De Mesmaeker, A. J. Photochem. Photobiol. A 1994, 81, 169-176.

(42) Oter, O.; Ribou, A. C. J. Fluoresc. 2009, 19, 389-397.

(43) DeRosa, M. C.; Crutchley, R. J. Coord. Chem. Rev. 2002, 233, 351-371.

(44) Montalti, M.; Credi, A.; Prodi, L.; Gandolfi, M. T. Handbook of Photochemistry;

CRC Press: Boca Raton, 2006.

(45) Garcia-Fresnadillo, D.; Orellana, G. Helv. Chim. Acta 2001, 84, 2708-2730.

(46) Barigelletti, F.; De Cola, L.; Balzani, V.; Belser, P.; Von Zelewsky, A.; Voegtle, F.; Ebmeyer, F.; Grammenudi, S. J. Am. Chem. Soc. 1989, 111, 4662-4668.

(47) Ruggi, A.; Berenguel Alonso, M.; Reinhoudt, D. N.; Velders, A. H. Chem. Comm. 2010, 46, 6726-6728.

(48) Flamigni, L.; Barbieri, A.; Sabatini, C.; Ventura, B.; Barigelletti, F. Top. Curr. Chem. 2007, 281, 143-203.

(49) D'Andrade, B. W.; Datta, S.; Forrest, S. R.; Djurovich, P.; Polikarpov, E.; Thompson, M. E. Org. Electron. 2005, 6, 11-20.

(50) Gao, R. M.; Ho, D. G.; Hernandez, B.; Selke, M.; Murphy, D.; Djurovich, P. I.; Thompson, M. E. J. Am. Chem. Soc. 2002, 124, 14828-14829.

(51) Schaffner-Hamann, C.; von Zelewsky, A.; Barbieri, A.; Barigelletti, F.; Muller, G.; Riehl, J. P.; Neels, A. J. Am. Chem. Soc. 2004, 126, 9339-9348.

(52) Issberner, J.; Vogtle, F.; DeCola, L.; Balzani, V. Chem. Eur. J. 1997, 3, 706-712.

(53) Xu, W. Y.; Jain, A.; Betts, B. A.; Demas, J. N.; DeGraff, B. A. J. Phys. Chem. A 2002, 106, 251-257.

(54) Albuquerque, R. Q.; Popovic, Z.; De Cola, L.; Calzaferri, G. ChemPhysChem 2006, 7, 1050-1053.

(55) Chan, W. C. W.; Nie, S. M. Science 1998, 281, 2016-2018.

(56) Gao, X. H.; Yang, L. L.; Petros, J. A.; Marshal, F. F.; Simons, J. W.; Nie, S. M. Current Opinion in Biotechnology 2005, 16, 63-72.

(57) Debbage, P.; Jaschke, W. Histochem. Cell Biol. 2008, 130, 845-875.

(58) Cai, W. B.; Hsu, A. R.; Li, Z. B.; Chen, X. Y. Nanoscale Res. Lett. 2007, 2, 265-281.

(59) Derfus, A. M.; Chan, W. C. W.; Bhatia, S. N. Nano Lett. 2004, 4, 11-18.

(60) Hardman, R. Environ. Health Perspect. 2006, 114, 165-172. 
Chapter 2 


\title{
Chapter 3
}

One must have a chaos inside oneself to

give birth to a dancing star.

F. Nietzsche

\section{An iridium(III) caged complex with low oxygen quenching*}

\begin{abstract}
In this chapter the synthesis and structural characterization of the first iridium(III) complex with a caged ligand structure, which shows an $80 \%$ decrease of oxygen quenching compared to the archetypical $\operatorname{Ir}(\text { ppy })_{3}$, is described. After an introduction concerning the general principles followed for the design of such a molecule, the synthetic pathway used for the synthesis of the caged complex (1) and of its parent hemicaged complex (2) is discussed. Moreover, the NMR characterization of these two compounds is extensively discussed, with special regard to the typical through-space NOE couplings observed with bidimensional ROESY experiments. Finally, the absorption and emission properties of the two compounds are discussed, as well as their behaviour towards oxygen quenching with respect to the archetypical $\operatorname{Ir}(\mathrm{ppy})_{3}$.
\end{abstract}

\footnotetext{
* Part of this chapter has been published in Ruggi, A.; Berenguel Alonso, M.; Reinhoudt, D. N., Velders, A. H., Chem. Commun. 2010, 46, 6726-6728.
} 


\subsection{Introduction}

Iridium(III) complexes have received much attention because of their versatile photophysical properties. ${ }^{1,2}$ Cyclometallated iridium(III) complexes, ${ }^{3}$ in particular, have extensively been employed, e.g. as components for electrochemiluminescent devices, ${ }^{4,5}$ as sensitizers for solar cells, ${ }^{6}$ in organic light emitting devices (OLEDs) ${ }^{7,8}$ and, more recently, as luminescent probes for biomedical diagnostic applications. ${ }^{2,9}$ Along with the remarkable photophysical properties, like the tunability of the emission wavelength, ${ }^{10}$ iridium(III) cyclometallated complexes also suffer from a serious drawback: the strong oxygen quenching of the luminescence. ${ }^{11}$ Despite the fact that the synthesis of metalcaged complexes is notoriously challenging, ${ }^{12-15}$ a cage-type ligand can prevent the luminescence quenching by solvent molecules, as shown for lanthanide(III) complexes, ${ }^{15}$ or prevent photo-decomposition as shown for a ruthenium(II) complex (see structure 16, Figure 2.11, Chapter 2). ${ }^{16}$

In this chapter the synthesis, characterization and photophysical characteristics of the first caged $\operatorname{Ir}(\mathrm{III})$ complex are described and compared with the parent Ir(III) hemicaged complex and with the archetypical $\operatorname{Ir}(\mathrm{ppy})_{3}$ (ppy = 2-phenylpyridine) in order to prove the shielding effect against luminescence quenching by oxygen.

\subsection{Design and synthesis}

The Ir(III)-caged complex 1 was designed in order to prove the possibility of reducing the oxygen quenching of the luminescence of Ir(III) complexes by using steric shielding towards molecular oxygen. The main challenge encountered in the design of such a molecule is the necessity of conjugating a structure with a high steric hindrance (in order to avoid the approach of oxygen) with the geometrical flexibility required in order to obtain the octahedral geometry of the complex. In other words, besides the high steric hindrance, the ligand should keep enough flexibility in order to make the complexation possible with the right geometry. Moreover, due to the harsh reaction conditions used during the $\mathrm{Ir}(\mathrm{III})$ complexation (temperature $\sim 200^{\circ} \mathrm{C}$ ), the stability of the ligand should be taken into account, in order to avoid thermal decomposition. Generally speaking, a caged complex is made of three components: 1) a core, consisting in the metal ion and its ligands; 2) a capping unit, which closes the cage structure and 3) a connecting group, which is the linker between the core and the capping unit (Figure 3.1). 

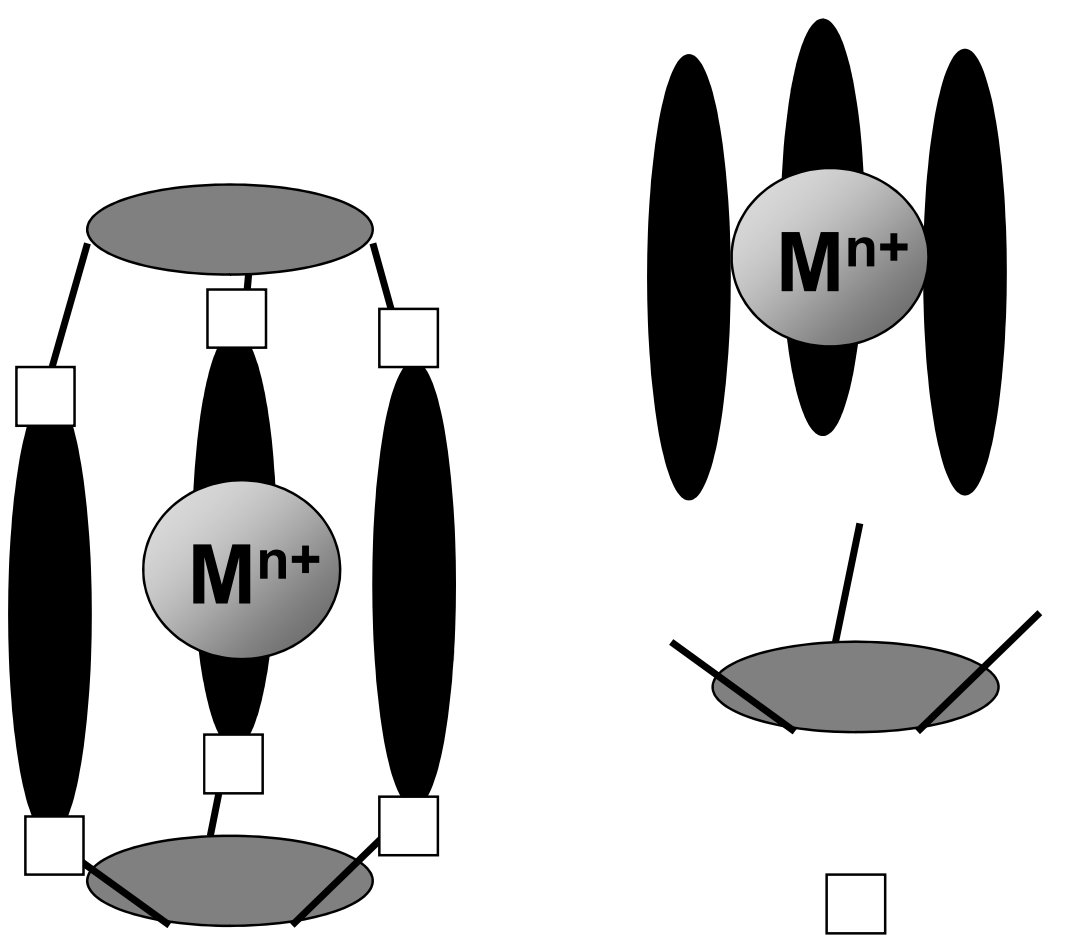

= core

= capping unit

Figure 3.1. General scheme of a metal $\left(\mathrm{M}^{\mathrm{n}+}\right)$ complex with a caged structure. The ligands of the core can be either symmetrical (e.g. 2,2'-bipyridine) or asymmetrical (e.g. 2phenylpyridine). Analogously, the connection group and the capping unit can have the same chemical structure or not.

In our case, the design of the caged complex was developed around the $\operatorname{Ir}(\mathrm{ppy})_{3}$ (ppy =2phenylpyridine) core, since the derivatives of this complex are the most studied. ${ }^{1}$ The amide moiety is an ideal connecting group to bind the ppy ligand to the capping units required for the cage closure. The amide functional group shows indeed a high stability and many different synthetic procedures (mostly based on coupling agents like carbodiimides) have been developed in the past for the synthesis of peptides. The capping unit was chosen due to the commercial availability of compounds with a tripodal structure and with terminal primary amines. From this point of view, despite the relatively low steric hindrance, tris(2-aminoethyl)amine (Tren) was a natural choice. The Ir(III) complex with a caged structure 1 was then designed following these principles (Figure 3.2). Moreover, in order to study a reference compound with a partially open structrure, also the photophysical properties of the hemicaged complex 2 (Figure 3.2), which is a precursor of $\mathbf{1}$, were investigated. 

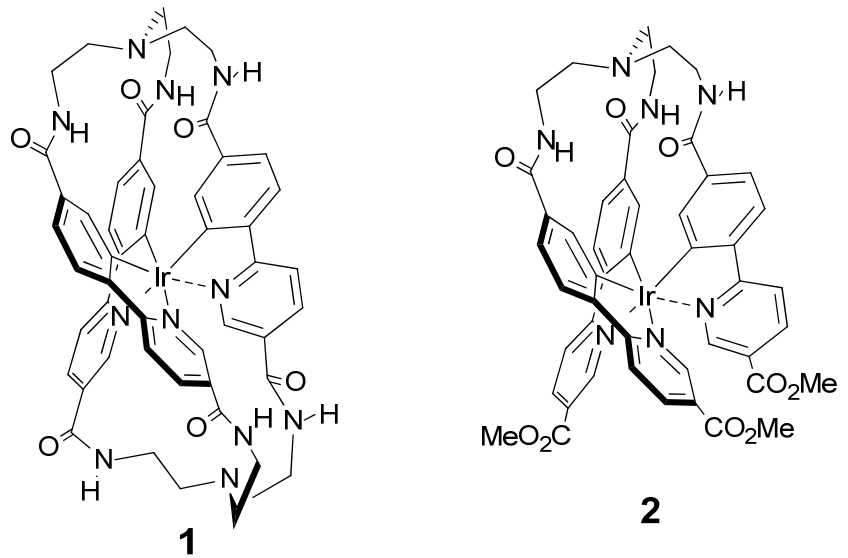

Figure 3.2. Structure of the $\operatorname{Ir}(\mathrm{III})$ caged (1) and hemicaged (2) complexes.

The synthesis of the caged complex 1 was achieved by using a tripodal approach (Scheme 3.1). ${ }^{17}$ The partly protected phenylpyridine derivative $\mathbf{3}$ was chosen as starting material in order to assure an adequate chemoselectivity by avoiding the formation of structural isomers during the subsequent DCC/HOBt coupling (DCC $=N, N^{\prime}$ dicyclohexylcarbodiimide, $\mathrm{HOBt}=1$-Hydroxybenzotriazole).

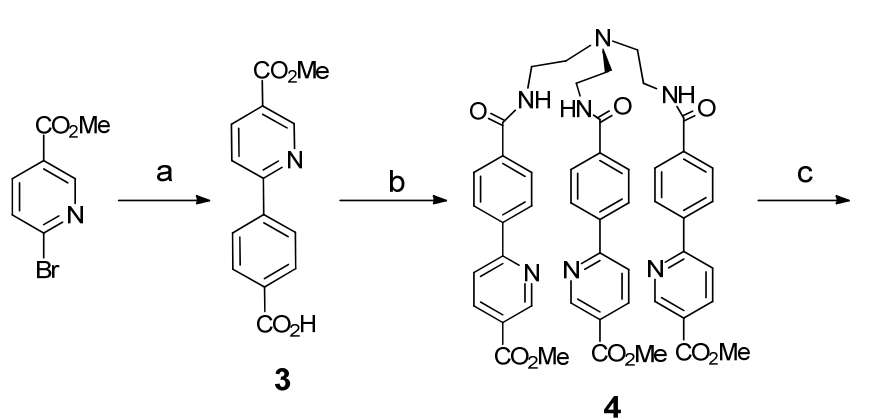

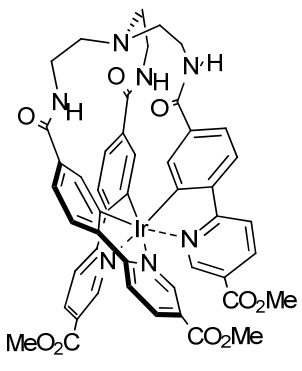

2

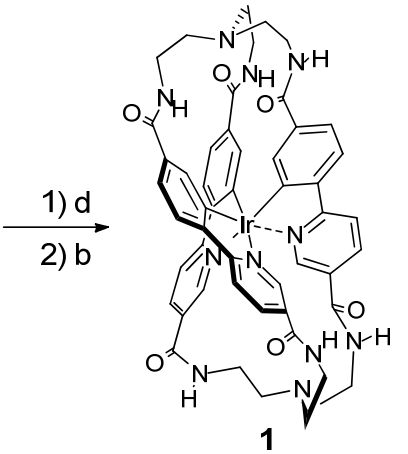

Scheme 3.1. Synthetic pathway for the synthesis of the hemicaged complex 2 and caged complex 1. Reaction conditions: a) 4-carboxyphenylboronic acid, $\mathrm{Pd}\left[\mathrm{PPh}_{3}\right]_{4}, \mathrm{CsF}, \mathrm{MeOH}$, reflux, overnight, Ar; b) DCC, tris(2-aminoethyl)amine, $\mathrm{HOBt}, \mathrm{DMAc}, 50^{\circ} \mathrm{C}$, overnight; c) 1) $\mathrm{IrCl}_{3}, \mathrm{CF}_{3} \mathrm{CO}_{2} \mathrm{Ag}$, ethylene glycol, reflux, overnight, Ar; d) LiOH, THF: $\mathrm{H}_{2} \mathrm{O}$ 1:1, $40^{\circ} \mathrm{C}, 12 \mathrm{~h}$.

The building block 3 was synthesized using a Suzuki coupling under mild conditions (CsF in refluxing methanol) in order to avoid the methyl ester hydrolysis which occurs under basic aqueous conditions. ${ }^{18}$ The phenylpyridine derivative $\mathbf{3}$ was consecutively coupled to tris(2aminoethyl)amine (Tren) via $\mathrm{DCC} / \mathrm{HOBt}$ coupling giving the tripodal ligand 4 , which was reacted with $\mathrm{IrCl}_{3}$ in ethylene glycol at $180^{\circ} \mathrm{C}$. The crude product was found to be a mixture 
of free ligand and hemicaged Ir(III) complexes with different substituents on the hemicage ligand (i.e. methyl and ethylene glycol esters), which are formed by transesterification under such harsh reaction conditions. The crude product from the $\operatorname{Ir}(\mathrm{III})$ complexation of $\mathbf{3}$ was converted into the pure methyl ester 2 by hydrolysis with $\mathrm{LiOH}$ and treatment with dimethylsilyl diazomethane The resulting compound was purified by column chromatography and hydrolyzed again to give the carboxylic acid derivative, which was consecutively used for the synthesis of the caged complex 1 via DCC coupling with Tren.

\subsection{Characterization}

All the intermediates and the target complexes were characterized by NMR spectroscopy and mass spectrometry. The ${ }^{1} \mathrm{H}$ and ${ }^{13} \mathrm{C}$ chemical shifts of the intermediates are reported in the experimental section, while in this section only the NMR spectra of the complexes are discussed. The ${ }^{1} \mathrm{H}-\mathrm{NMR}$ spectrum of hemicaged complex 2 (Figure $3.3 \mathrm{~A}$ ) shows four different signals for the two methylene units, indicating the restrained flexibility in the ethylene moiety of the Tren, causing the geminal protons to be non-equivalent and diastereotopic in the chiral environment of the $\operatorname{Ir}(\mathrm{ppy})_{3}$ unit. The three ethylene units of the tripodal ligand are equivalent as only four signals are observed in the corresponding region of the spectrum. The same observation holds for the caged complex 1 (Figure 3.3 B), i.e. the aliphatic protons give eight different signals. Together with the observation of one single set of phenylpyridine protons, this proves the structure of $\mathbf{1}$ to be highly symmetric, with the 3 -fold symmetry of the $f a c$ - $\operatorname{Ir}(\mathrm{ppy})_{3}$ unit being conserved. 


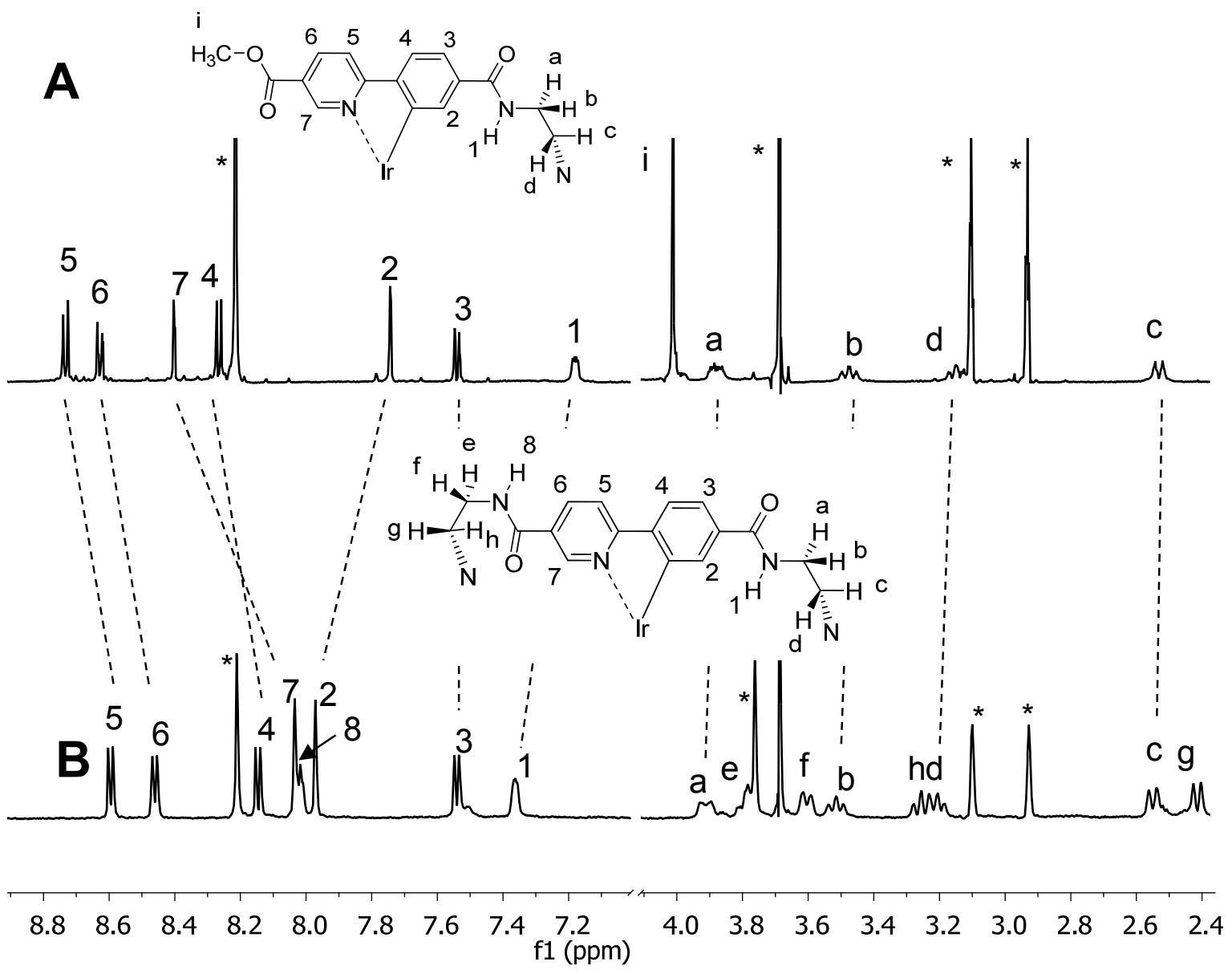

Figure 3.3. ${ }^{1} \mathrm{H}-\mathrm{NMR}$ of $\operatorname{Ir}(\mathrm{III})$-hemicaged complex 2 (A) and $\operatorname{Ir}(\mathrm{III})$-caged complex 1 (B). d7-DMF. $*=$ signals of the residual solvents.

By 2D-NMR experiments (COSY, ROESY, HMQC, HMBC) all signals in the ${ }^{1} \mathrm{H}-\mathrm{NMR}$ spectra were assigned and the structure of the complexes was determined by characteristic NOE signals. The ROESY spectrum of the hemicaged complex 2 shows through-space NOE couplings between the amide proton $(\mathrm{H} 1)$ with four methylene protons (Figure 3.4 B). Due to the geometrical constriction induced by the presence of the $\operatorname{Ir}(\mathrm{III})$ ion, the rotation of the amide group is hampered and therefore it is possible to observe a throughspace NOE coupling (Figure 3.4 A) between the amide proton (H1) and the interal proton on the pyridine ring $(\mathrm{H} 2)$. 


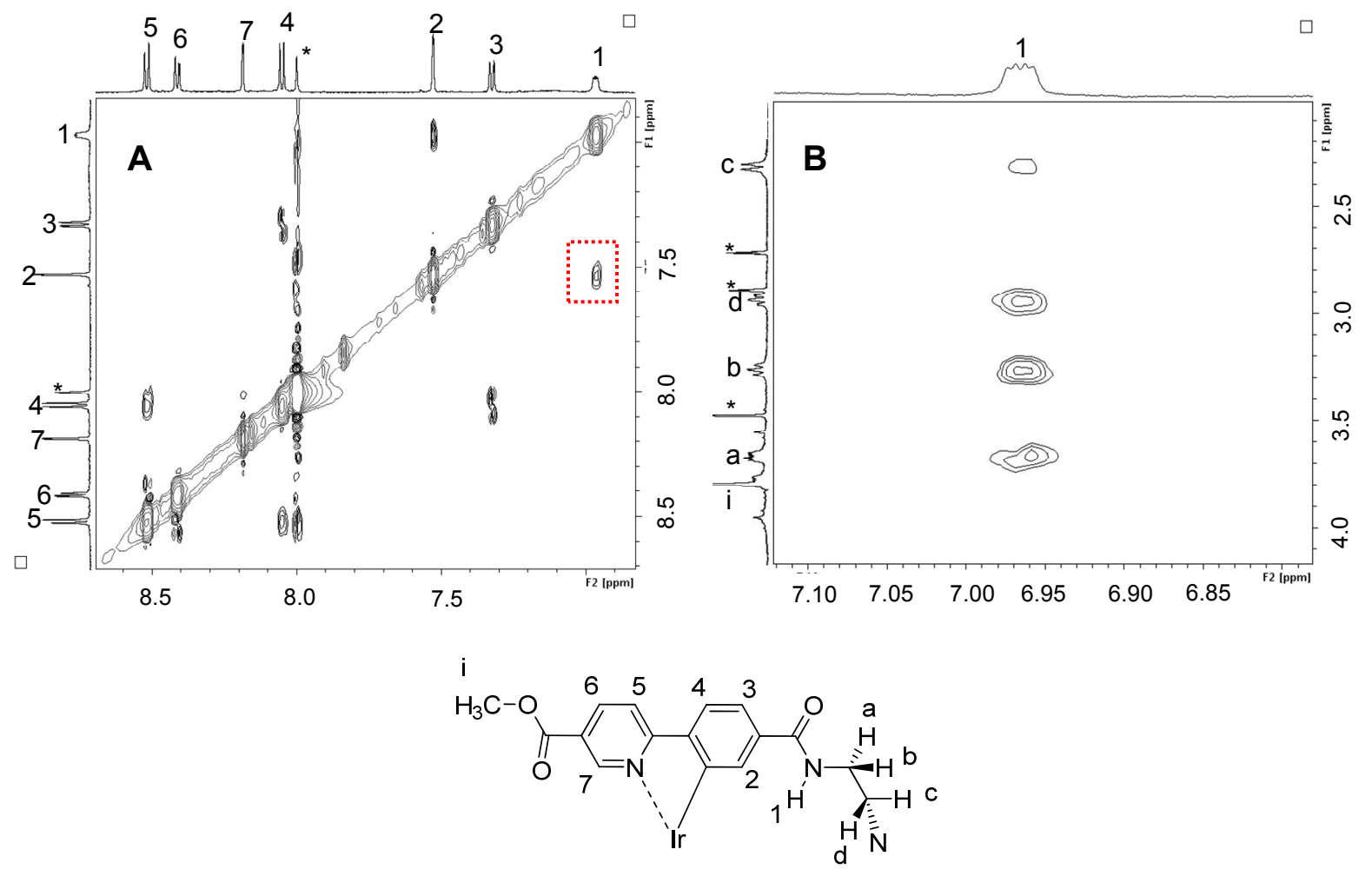

Figure 3.4. 2D-ROESY spectrum of the $\operatorname{Ir}(\mathrm{III})$-hemicaged complex 2 ( $d_{7}$-DMF). Characteristic through-space couplings of amide protons with the aromatic (A) and aliphatic protons (B). The box indicates the through-space coupling between amide proton $\mathrm{H} 1$ and aromatic proton $\mathrm{H} 2 . *$ = residual solvent signals.

Similarly, in the caged complex 1 the through-space NOE couplings between both amide protons with three or four methylene protons (Figure $3.5 \mathrm{~B}$ ) clearly show the tripodal capped structure of both Tren moieties. Interestingly, the aromatic region of the ROESY spectrum of 1 (Figure $3.5 \mathrm{~A}$ ) indicates a different orientation of the two amide groups. The amide protons situated on the phenyl ring (H1) are oriented towards the inner part of the molecule, as proven from the cross peak between this amide proton and the phenyl singlet (H2); the amide protons on the pyridine ring (H8) are oriented towards the outside, as proven from a cross peak with the pyridine doublet (H6). In the pseudo-octahedrical $f a c-\operatorname{Ir}(\text { ppy })_{3}$ complex, the Ir-C bonds are significantly shorter $(2.0246 \AA)$ than the three Ir$\mathrm{N}$ bonds $(2.1325 \AA) .{ }^{19}$ Therefore, the opposite orientations of the amide groups in $\mathbf{1}$ suggest that a capped trigonal pyramid cage is formed, ${ }^{20}$ the top part being smaller and having the bulky oxygens pointing outwards, and a wider bottom with the amide oxygens oriented inwards. 

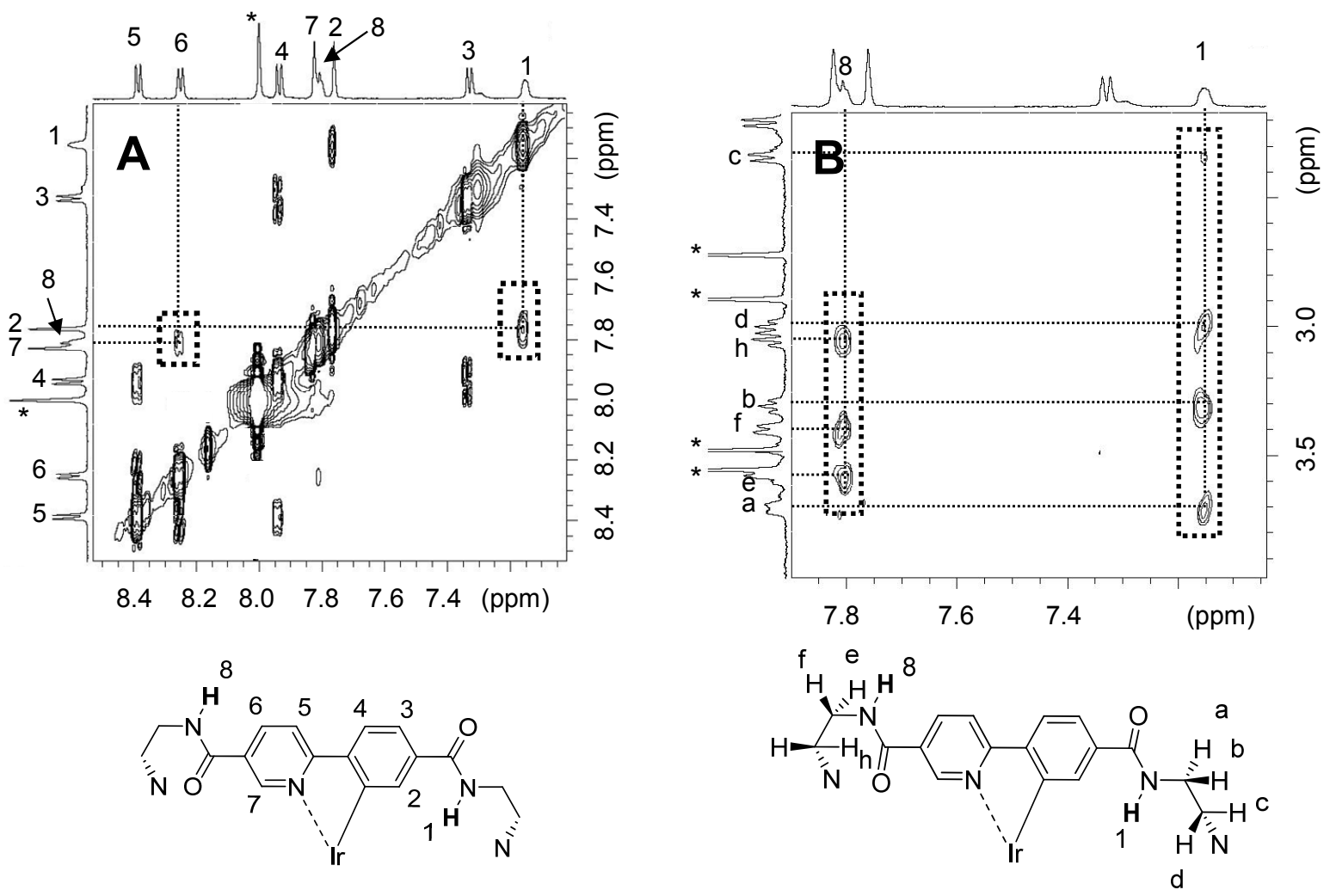

Figure 3.5. $2 \mathrm{D}$-ROESY spectrum of the $\operatorname{Ir}(\mathrm{III})$-caged complex $1\left(d_{7}\right.$-DMF). Characteristic through-space couplings of amide protons with the aromatic (A) and aliphatic protons (B) are indicated by the boxes. $*=$ residual solvents signals.

\subsection{Photophysical properties}

Optical absorption. The UV-Vis absorption spectra and the absorption maxima and shoulder of the two complexes are reported in Figure 3.6. Due to the insufficient amount of compounds, the measurement of the molar absorption coefficients was not possible. Therefore the interpretation of the UV-Vis absorption spectrum has been done by analogy with the other spectra of $\operatorname{Ir}(\mathrm{III})$ complexes described in this thesis (see Chapters 4 and 5). Both the hemicaged (2) and the caged (1) complexes show a strong absorption band between 270 and $350 \mathrm{~nm}$ and a weaker one between 360 and $550 \mathrm{~nm}$. By comparison with the typical absorption shown by $\operatorname{Ir}(\mathrm{ppy})_{3}$ derivatives, the absorption bands between 270 and $350 \mathrm{~nm}$ can be assigned to ligand centred $\pi \rightarrow \pi^{*}$ transitions, while the weaker bands between 360 and 450 $\mathrm{nm}$ can be assigned to spin-allowed singlet-to-singlet metal to ligand charge transfer $\left({ }^{1}\right.$ MLCT). ${ }^{19,21}$ Moreover, the weak shoulder at lower energies (centred around $500 \mathrm{~nm}$ ) can be assigned to spin-forbidden singlet-to-triplet charge transfer ${ }^{3}$ MLCT. The latter transitions are usually observed in complexes containing heavy atoms (like iridium), which show a 
remarkable spin-orbit coupling that makes the singlet-to-triplet transitions partly allowed. The hemicaged complex 2 shows a pronounced red-shift of its absorption bands when compared to the caged complex $\mathbf{1}$, which is due to the presence of the methyl ester moiety (a group with an electron withdrawing effect stronger than the amide) on the pyridine ring which affects the energy level of the LUMO orbital (vide infra). ${ }^{1,16}$

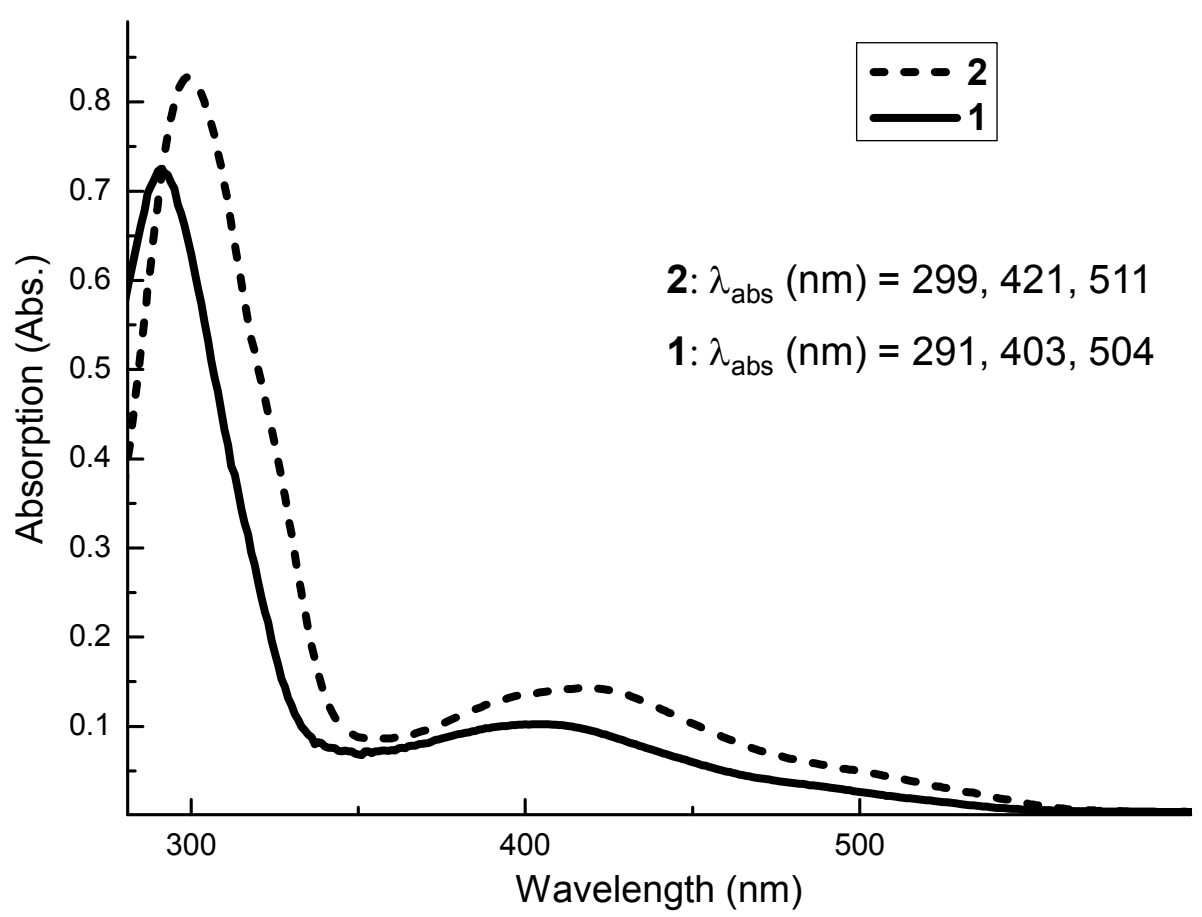

Figure 3.6. UV-Vis absorption spectrum of hemicaged (2) and caged (1) complexes in DMF at room temperature and their absorption wavelength.

Luminescence. The photophysical properties of 1 are reported in Table 1 together with those of the hemicaged 2 and the archetypical $\operatorname{Ir}(\mathrm{ppy})_{3}$ for comparison purposes. The hemicaged and caged compounds both show a red-shift of the emission with respect to $\operatorname{Ir}(\mathrm{ppy})_{3}$, as expected for phenylpyridines with electron withdrawing substituents. ${ }^{1}$ Moreover, the emission maximum of the hemicaged complex $\mathbf{2}$ is more red-shifted than the emission maximum of the caged complex 1, (Figure 3.7) due to the stronger electron-withdrawing effect of the ester moiety compared to the amide (the Hammett constant $\sigma_{\mathrm{m}}$ for the acetamido and methylester groups are 0.14 and 0.35 , respectively). ${ }^{16}$ The methyl ester on the pyridine ring decreases the energy of the LUMO orbital more than the amide, resulting in a red shifted emission. In deaerated solutions a lower quantum yield $\phi_{0}$ is observed both for $\mathbf{2}$ and $\mathbf{1}$, when 
compared to $\operatorname{Ir}(\mathrm{ppy})_{3}$. However, in aerated solutions, the luminescence quantum yield $\phi$ of the caged complex appears higher than that of 2 and twice as high as that of $\operatorname{Ir}(\mathrm{ppy})_{3}$. A similar behaviour is also observed for the excited states lifetimes in deaerated $\left(\tau_{0}\right)$ and aerated $(\tau)$ solutions of the complexes $\mathbf{1}, \mathbf{2}$ and $\operatorname{Ir}(\text { ppy })_{3}$. The long lifetimes in absence of oxygen shown by all the complexes corroborate the hypothesis of a triplet emitting state, as expected for this class of compounds. ${ }^{1}$

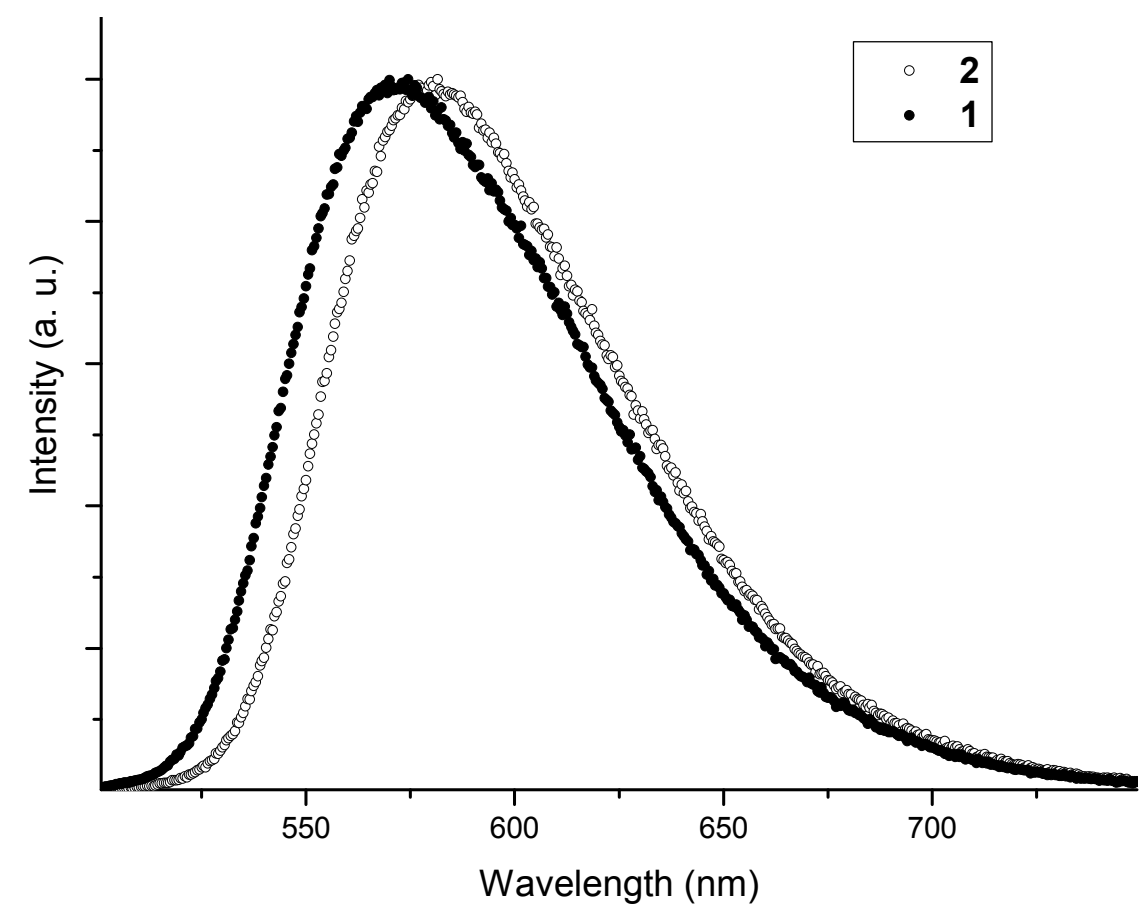

Figure 3.7. Normalized emission profiles of the hemicaged complex (2) and caged complex (1) in DMF at $25^{\circ} \mathrm{C}$.

Table 1. Photophysical properties of hemicaged complex 2, cage complex 1 and $\operatorname{Ir}(\text { ppy })_{3}$, measured in DMF at $25^{\circ} \mathrm{C}$.

\begin{tabular}{|c|c|c|c|c|c|c|}
\hline Compound & $\begin{array}{c}\lambda_{\text {em }} \\
(\mathbf{n m})\end{array}$ & $\phi_{\mathbf{0}}{ }^{\mathbf{a}}$ & $\phi^{\mathbf{a}}$ & $\begin{array}{c}\tau_{\mathbf{0}} \\
(\mathbf{n s})\end{array}$ & $\begin{array}{c}\tau \\
(\mathbf{n s})\end{array}$ & $\begin{array}{c}\mathbf{k}_{\mathbf{q}} \\
\left(\mathbf{M}^{-\mathbf{1}} \mathbf{s}^{-\mathbf{1}}\right)\end{array}$ \\
\hline $\mathbf{1}$ & 570 & 0.46 & 0.06 & 1270 & 168 & $5.2 \cdot 10^{9}$ \\
\hline $\mathbf{2}$ & 580 & 0.48 & 0.05 & 1198 & 120 & $1.4 \cdot 10^{10}$ \\
\hline $\mathbf{I r}(\mathbf{p p y})_{3}$ & 523 & $0.71^{\mathrm{b}}$ & $0.03^{\mathrm{b}}$ & 1873 & 82 & $2.4 \cdot 10^{10}$ \\
\hline
\end{tabular}

$\mathrm{a}=$ measured with reference to $\left[\mathrm{Ru}(\mathrm{bpy})_{3}\right]^{2+}$ in $\mathrm{H}_{2} \mathrm{O}$ unless otherwise stated. $\mathrm{b}=$ measured with reference to fluorescein in $0.1 \mathrm{M} \mathrm{NaOH}$.

Oxygen quenching. In order to evaluate the shielding effect against oxygen quenching, the luminescence emission of samples containing different concentrations of oxygen was 
measured and plotted against the concentration of oxygen according to the Stern-Volmer equation (3.1):

$$
\frac{I_{0}}{I}=1+k_{q} \tau_{0}\left[O_{2}\right]
$$

$\mathrm{I}_{0}$ and $\mathrm{I}$ are the intensity without and with the quencher, respectively, $\mathrm{k}_{\mathrm{q}}$ is the quenching constant, $\tau_{0}$ the excited state lifetime in absence of quencher and $\left[\mathrm{O}_{2}\right]$ the molar concentration of oxygen, the quencher. From the Stern-Volmer plots (see Figure 3.8) the quenching constants $k_{\mathrm{q}}$ were determined to be $5.2 \cdot 10^{9} \mathrm{M}^{-1} \mathrm{~s}^{-1}, 1.4 \cdot 10^{10} \mathrm{M}^{-1} \mathrm{~s}^{-1}$ and $2.4 \cdot 10^{10}$ $\mathrm{M}^{-1} \mathrm{~s}^{-1}$ for $\mathbf{1}, 2$ and $\operatorname{Ir}(\text { ppy) })_{3}$, respectively. This implies a dramatic decrease of the quenching constant for the caged complex of almost $80 \%$ with respect to that of $\operatorname{Ir}(\mathrm{ppy})_{3}$, while the hemicaged complex shows a $40 \%$ decrease of quenching.

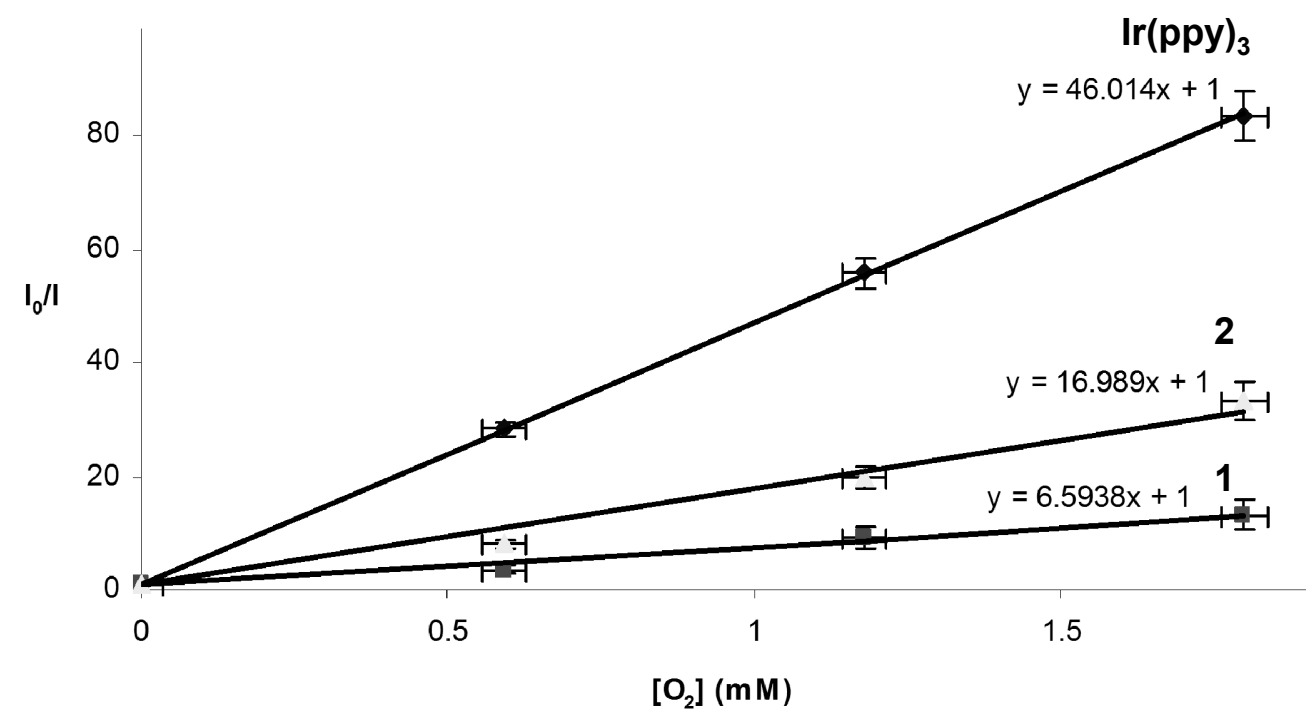

Figure 3.8. Stern Volmer plot of oxygen quenching of $\operatorname{Ir}(\mathrm{ppy})_{3}$, hemicaged complex 2 and caged complex 1 in $\mathrm{DMF}$ at $25^{\circ} \mathrm{C}$.

In the pioneering work on caged ruthenium complexes, a similar decrease has been found by Barigelletti et al. for a $\mathrm{Ru}(\mathrm{II})$-caged system with bipyridine ligands, ${ }^{16}$ attributing the observed decrease in oxygen quenching to an effective shielding of orbitals of the caged complex. The results obtained with the phenylpyridine ligand cage are even more remarkable as the $\mathrm{Ru}(\mathrm{II})$-caged complex (bearing a tripodal aromatic capping unit) is bulky and rigid, whilst the structure of complex 1 looks relatively flexible with the tripodal tri(ethylene)amine capping and does not seem to present high steric constraints. Nevertheless, the NMR data of $\mathbf{1}$ clearly show a sharp sets of signals and no indication of fluxional behaviour of the tripodal capping structures, so the structure might actually be 
rather rigid, corroborating the photophysical properties of the caged iridium(III) structure. Although the reason for the reduced oxygen quenching shown by caged metal complexes is not fully understood, ${ }^{16}$ it is known from literature that the HOMO of $\operatorname{Ir}(\mathrm{III})$ cyclometallated complexes is mostly localized between the Ir and the phenyl ring, whilst the LUMO mainly resides on the pyridine ring. ${ }^{1}$ The presence of electron withdrawing groups on the phenylpyridine ligand could induce a change in the localization of the electron density in the excited state on different position in the pyridine ring, or even on its substituents, resulting in a higher shielding effect towards quenching species, e.g. oxygen, when the latter are further shielded to the environment by substituents like the tripodal Tren. In fact, in order to clarify the origin of such shielding effect against oxygen quenching, we have systematically studied the substitution effect on the phenyl and the pyridine side and the results of these studies are given in Chapter 4 and 5 of this thesis.

\subsection{Conclusions}

In this chapter we have presented the synthesis and characterization of the first iridium(III) complex with a caged ligand structure. The compound $\mathbf{1}$ shows a truncated trigonal pyramid cage structure with 3-fold symmetry, that has been fully analyzed by solution-state NMR spectroscopy. The iridium-caged complex $\mathbf{1}$ is dramatically less subject to luminescence quenching by molecular oxygen than the archetypical $\operatorname{Ir}(\mathrm{ppy})_{3}$ complex. The possibility of shielding iridium complexes from oxygen opens up promising perspectives for the synthesis of bright luminophores for applications in oxygen-rich environments, e.g. biological systems. ${ }^{2,9}$

\subsection{Experimental section}

Oxygen- or water-sensitive reactions were conducted under a positive pressure of argon in oven-dried glassware, using Schlenk techniques. Unless otherwise stated, commercial grade reagents (Aldrich) were used without further purification. The purity of the final compounds was determined by NMR and MS spectrometry. Due to the low amount of final compound, it was not possible to perform elemental analysis. The NMR experiments were performed on a Bruker Avance II NMR spectrometer operating at $600.35 \mathrm{MHz}$ for ${ }^{1} \mathrm{H}$ and $150.09 \mathrm{MHz}$ for

${ }^{13} \mathrm{C}$ or on a Varian Unity 300 spectrometer operating at $300 \mathrm{MHz}$ for ${ }^{1} \mathrm{H}$. Chemicals shifts are given in ppm using the residual solvent signal as reference. Mass spectra were acquired on a Micromass LCT (ESI-MS) or Voyager-DE RP (MALDI-MS) spectrometer. IR spectra were 
measured on a Thermo Scientific Nicolet ${ }^{\mathrm{TM}} 6700$ FT-IR spectrometer equipped with a Smart Orbit diamond ATR accessory. Main bands are reported and assigned to functional groups by using the following abbreviations: br. = broad band; str. = stretching band; def. = deformation band; bend. = bending band. UV-Vis spectra were measured on a Perkin Elmer Lambda 850 UV-Vis spectrophotometer. Steady-state luminescence spectra were measured using an Edinburgh FS900 fluorospectrometer. A $450 \mathrm{~W}$ xenon arc lamp was used as excitation source. Luminescence quantum yields at room temperature ( $\Phi$ and $\Phi_{\text {air }}$ ) were evaluated by comparing wavelength-integrated intensities $\left(I\right.$ and $I_{R}$ ) of isoabsorptive optically diluted solutions $(\mathrm{Abs}<0.1)$ with reference to $\left[\mathrm{Ru}(\mathrm{bpy})_{3}\right] \mathrm{Cl}_{2}\left(\Phi_{\mathrm{R}}=0.028\right.$ in air-equilibrated water $)$, and fluorescein $\left(\Phi_{\mathrm{R}}=0.92\right.$ in $\left.\mathrm{NaOH} 0.1 \mathrm{M}\right)$ standards and by using the equation (3.2)

$$
\Phi=\Phi_{R} \frac{n^{2} I}{n_{R}^{2} I_{R}}
$$

where $n$ and $n_{R}$ are the refractive index of the sample and reference solvent, respectively. ${ }^{22}$ Fluorescence lifetimes were determined using a FluoroMax4, Horiba Jobin Yvon spectrophotometer, equipped with a TCSPC extension and a pulsed $462 \mathrm{~nm}$ NanoLED for excitation (all Horiba Jobin Yvon). The recorded data were analyzed using the DAS6 software package of Horiba Jobin Yvon.

Degassed solutions were prepared by four freeze-pump-thaw cycles. Solutions with different oxygen concentration, suitable for the Stern-Volmer quenching studies, were prepared by using $\mathrm{N}_{2} / \mathrm{O}_{2}$ mixtures prepared with a Brooks 5850S Mass Flow control and by purging the fluorophore solutions for 40 minutes. $\operatorname{Ir}(\mathrm{ppy})_{3}$ (sublimed grade) was purchased from Sigma Aldrich and its purity was checked by NMR prior to use.

Methyl 6-bromonicotinate. $5.73 \mathrm{~g}(28.4 \mathrm{mmol})$ of 6-bromonicotinic acid were dissolved in $100 \mathrm{ml}$ of Methanol/Ether 1:1. $23 \mathrm{ml}(46 \mathrm{mmol})$ of trimethylsilyldiazomethane $(2 \mathrm{M}$ in hexane) were added dropwise during 5 hours till the reaction mixture showed a permanent yellow colour. The reaction was quenched by addition of acetic acid $(5 \mathrm{ml})$ and the solvent was evaporated. The mixture was then dissolved in ether and washed three times with saturated $\mathrm{NaHCO}_{3}$ and eventually with brine. The solution was dried over $\mathrm{Na}_{2} \mathrm{SO}_{4}$ and the solvent removed under vacuum. Yielded $5.5 \mathrm{~g}$ (26 mmol; 90\%) of compound. ${ }^{1} \mathrm{H}-\mathrm{NMR}$ and ESI-MS are compatible with the data reported in literature. ${ }^{23}$

4-(5-(Methoxycarbonyl)pyridin-2-yl)benzoic acid (3). $2.504 \mathrm{~g}$ (11.575 mmol) of methyl 6bromonicotinate, $2.132 \mathrm{~g}$ (12.79 mmol) of 4-carboxybenzylboronic acid, $4.206 \mathrm{~g}$ (27.7 mmol) 
of $\mathrm{CsF}$ and $627 \mathrm{mg}(0.54 \mathrm{mmol})$ of $\mathrm{Pd}\left(\mathrm{PPh}_{3}\right)_{4}$ were dissolved in $100 \mathrm{ml}$ of methanol and oxygen was removed by Ar/vacuum cycles. The mixture was refluxed overnight. The crude mixture was filtered and the solvent evaporated. The crude was dissolved in saturated solution of $\mathrm{Na}_{2} \mathrm{CO}_{3}$ and washed four times with $\mathrm{CHCl}_{3}$. The $\mathrm{pH}$ of the aqueous phase was then adjusted to $\mathrm{pH}=2$ (conc. $\mathrm{HCl}$ ) and the resulting precipitate filtrated and dried under vacuum over $\mathrm{P}_{2} \mathrm{O}_{5}$ overnight. Obtained $912 \mathrm{mg}$ (3.55 mmol; 31\%).

${ }^{1} \mathrm{H}-\mathrm{NMR}\left(300 \mathrm{MHz}, d_{6}\right.$-DMSO): $\delta 3.91(\mathrm{~s}, 3 \mathrm{H}) ; 8.06\left(\mathrm{~d}, 2 \mathrm{H},{ }^{3} J_{\mathrm{HH}}=4.5\right) ; 8.21\left(\mathrm{~d}, 1 \mathrm{H},{ }^{3} J_{\mathrm{HH}}=\right.$ 3), $8.26\left(\mathrm{~d}, 2 \mathrm{H},{ }^{3} J_{\mathrm{HH}}=4.5\right), 8.39\left(\mathrm{~d}, 1 \mathrm{H},{ }^{3} J_{\mathrm{HH}}=3\right), 9.19(\mathrm{~s}, 1 \mathrm{H}) .{ }^{13} \mathrm{C}-\mathrm{NMR}\left(150 \mathrm{MHz}, d_{6^{-}}\right.$ DMSO): $\delta 52.97,121.28,125.14,127.75,130.35,138.65,150.70,158.99,165.52,167.42$. FT-IR(neat): $\mathrm{cm}^{-1} 3000$ br (OH str.), 1725 (C=O str. ester), 1720 (C=O str. acid), 1678 (C=O str. acid), 1427 (OH def, acid) 1286 (C-O str. ester), 1115 ( $\mathrm{OCH}_{2}$ ester), 939 (OH def. acid). ESI-MS calcd. for $\mathrm{C}_{14} \mathrm{H}_{11} \mathrm{NO} 4\left[\mathrm{M}^{+}\right]$257.07, found 257.1.

Tripodal ligand (4). $912 \mathrm{mg}(3,55 \mathrm{mmol})$ of $\mathbf{3}, 143 \mu \mathrm{l}(0.95 \mathrm{mmol})$ of tris(2aminoethyl)amine , $745 \mathrm{mg}(3.6 \mathrm{mmol})$ of $N, N^{\prime}$-dicyclohexylcarbodiimide (DCC) and 482 $\mathrm{mg}(3.57 \mathrm{mmol})$ of 1-Hydroxybenzotriazole $(\mathrm{HOBt})$ were dissolved in $50 \mathrm{ml}$ of anhydrous dimethylacetamide and were stirred at $60^{\circ} \mathrm{C}$ overnight. The reaction mixture was filtrated and the solid dissolved in conc. HCl. After filtration of this solution (in order to remove the side product of the DCC coupling) the product was precipitated by addition of conc. $\mathrm{NaOH}$ and was dried over $\mathrm{P}_{2} \mathrm{O}_{5}$ overnight giving a $699 \mathrm{mg}$ of pure compound $(0.8 \mathrm{mmol} ; 84 \%) .{ }^{1} \mathrm{H}$ NMR (300 MHz, D $2 \mathrm{O}$, TFA): $\delta 2.23$ (s-br, 2H); 2.44 (s-br, 2H); 2.51 (s, 3H); 6.40 (d, 2H, $\left.{ }^{3} J_{\mathrm{HH}}=4 \mathrm{~Hz}\right) ; 6.46\left(\mathrm{~d}, 2 \mathrm{H},{ }^{3} J_{\mathrm{HH}}=4 \mathrm{~Hz}\right) ; 6.79\left(\mathrm{~d}, 1 \mathrm{H},{ }^{3} J_{\mathrm{HH}}=3 \mathrm{~Hz}\right) ; 7.53\left(\mathrm{~d}, 1 \mathrm{H},{ }^{3} J_{\mathrm{HH}}=3\right.$ $\mathrm{Hz}) ; 7.79(\mathrm{~s}, 1 \mathrm{H})$. Due to the extremely low solubility, it was not possible to acquire the ${ }^{13} \mathrm{C}$ NMR spectrum. MALDI-MS calcd. for $\mathrm{C}_{48} \mathrm{H}_{46} \mathrm{~N}_{7} \mathrm{O}_{9} \quad\left[\mathrm{M}+\mathrm{H}^{+}\right]$864.34, found 864.34. FTIR(neat): $\mathrm{cm}^{-1} 3323$ (NH str.), $2928\left(\mathrm{CH}_{2}\right.$ and $\mathrm{OCH}_{3}$ str.), $2849\left(\mathrm{~N}-\mathrm{CH}_{2}\right.$ and $\mathrm{CH}_{2}$ str.) 1725 $\left(\mathrm{C}=\mathrm{O}\right.$ str. ester), 1625 ( $\mathrm{C}=\mathrm{O}$ str. amide), 1536 (N-H bend.), $1475\left(\mathrm{CH}_{2}-\mathrm{N}\right.$ st.), 1292 (C-O str. ester), $1120\left(\mathrm{OCH}_{2}\right.$ ester), 751 (N-C-O str. amide).

Ir(III) hemicaged methylester derivative (2). $619 \mathrm{mg}(0.72 \mathrm{mmol})$ of $\mathbf{1}, 217 \mathrm{mg}(0.73$ mmol) of iridium(III) chloride hydrate and $477 \mathrm{mg}(2.16 \mathrm{mmol})$ of silver trifluoroacetate were dissolved in $25 \mathrm{ml}$ of nitrogen purged ethylene glycol and refluxed overnight. After cooling to room temperature, the mixture was precipitated with brine, filtered and the solid dissolved in $\mathrm{MeOH}$. The solvent was removed and the solid dissolved in THF: $\mathrm{H}_{2} \mathrm{O}$ (1:1) and $601 \mathrm{mg}(25 \mathrm{mmol})$ of $\mathrm{LiOH}$ were added and the solution stirred overnight at $60^{\circ} \mathrm{C}$. The 
aqueous phase was treated with dil. $\mathrm{HCl}(1 \mathrm{M})$ to $\mathrm{pH}=5$ and the orange precipitate collected, suspended in $\mathrm{CH}_{2} \mathrm{Cl}_{2}: \mathrm{MeOH} \quad(9: 1)$ and esterified with an excess of trimethylsilyldiazomethane ( $2 \mathrm{M}$ in hexane). The reaction mixture was filtered, the solvent removed and the crude product purified by column chromatography $\left(\mathrm{SiO}_{2}, \mathrm{CH}_{2} \mathrm{Cl}_{2}: \mathrm{MeOH}\right.$ 94:6 ) and recrystallized from $\mathrm{CH}_{2} \mathrm{Cl}_{2} / \mathrm{Hexane}$. Obtained $151 \mathrm{mg}(0.14 \mathrm{mmol} ; 20 \%)$.

${ }^{1} \mathrm{H}-\mathrm{NMR}\left(600 \mathrm{MHz}, d_{7}\right.$-DMF): $\delta 8.52\left(1 \mathrm{H}, \mathrm{d},{ }^{3} J_{\mathrm{HH}}=6 \mathrm{~Hz}\right) ; 8.41\left(1 \mathrm{H}, \mathrm{d},{ }^{3} J_{\mathrm{HH}}=6 \mathrm{~Hz}\right) ; 8.19$ $(1 \mathrm{H}, \mathrm{s}) ; 8.05\left(1 \mathrm{H}, \mathrm{d},{ }^{3} J_{\mathrm{HH}}=6 \mathrm{~Hz}\right), 7.53(1 \mathrm{H}, \mathrm{s}) ; 7.32\left(1 \mathrm{H}, \mathrm{d},{ }^{3} J_{\mathrm{HH}}=6 \mathrm{~Hz}\right) ; 6.97(1 \mathrm{H}, \mathrm{s}$ broad $)$; $3.80(3 \mathrm{H}, \mathrm{s}) ; 3.66(1 \mathrm{H}, \mathrm{s}$ broad $) ; 3.26\left(1 \mathrm{H}, \mathrm{t},{ }^{2} J_{\mathrm{HH}}=12\right) ; 2.93(1 \mathrm{H}, \mathrm{s}$ broad $) ; 2.32\left(1 \mathrm{H}, \mathrm{d},{ }^{2} J_{\mathrm{HH}}\right.$ $=6 \mathrm{~Hz}$ ) (see Figure 3.3 for peak assignment). ${ }^{13} \mathrm{C}$-NMR: see Figure 3.9. MALDI-MS calcd. for $\mathrm{C}_{48} \mathrm{H}_{42} \mathrm{IrN}_{7} \mathrm{O}_{9}\left[\mathrm{M}+\mathrm{H}^{+}\right]$1054.27, found 1054.28. . FT-IR(neat): $\mathrm{cm}^{-1} 3422$ (N-H str.), 2952 $\left(\mathrm{OCH}_{3}\right.$ str.), 2895 ( $\mathrm{CH}_{2}$ str.), $2841\left(\mathrm{~N}-\mathrm{CH}_{2}\right.$ str. $), 1721$ (C=O str. ester), $1650(\mathrm{C}=\mathrm{O}$ str. amide), 1601 (N-H bend.), 1548 (CNH str.), 1473 (N-CH 2 str.), 1292 (C-O str. ester), 1126 $\left(\mathrm{OCH}_{2}\right.$ ester), 757 (N-C-O str. amide).

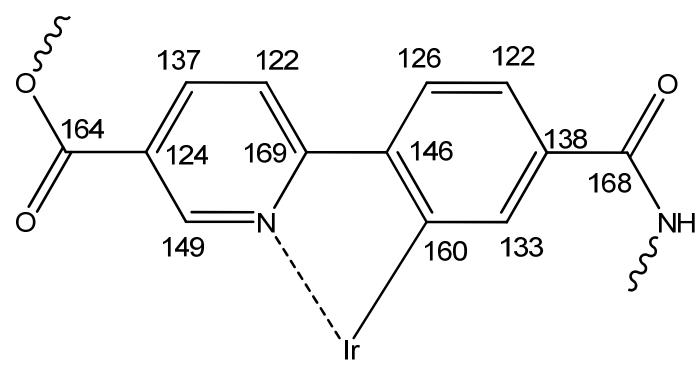

Figure 3.9. ${ }^{13} \mathrm{C}$ assignment of aromatic protons of hemicaged complex 2 .

Ir(III) caged complex (1). $22 \mathrm{mg}$ of $2(0.02 \mathrm{mmol})$ were dissolved in THF: $\mathrm{H}_{2} \mathrm{O}(1: 1)$ and hydrolized with $\mathrm{LiOH} 10 \mathrm{mg}(0.4 \mathrm{mmol})$ overnight. The THF was then removed under vacuum and the acid precipitated with $\mathrm{HCl}(1 \mathrm{M})$. The solid was dried overnight over $\mathrm{P}_{2} \mathrm{O}_{5}$ and dissolved in $10 \mathrm{ml}$ of anhydrous dimethylacetamide. $19 \mathrm{mg}(92.1 \mu \mathrm{mol})$ of $N, N^{\prime}-$ dicyclohexylcarbodiimide (DCC) and $12 \mathrm{mg}(88.8 \mu \mathrm{mol})$ of 1-Hydroxybenzotriazole (HOBt) were added to this mixture and subsequenthly a solution of $2.96 \mu 1$ (mmol) of tris(2aminoethyl)amine in anhydrous dimethylacetamide was added dropwise. The reaction mixture was heated at $50^{\circ} \mathrm{C}$ overnight under inert atmosphere and then cooled down to room temperature. The mixture was filtrated and precipitated with diethylether. The compound was purified by preparative TLC $\left(\mathrm{CH}_{2} \mathrm{Cl}_{2}: \mathrm{MeOH} 9: 1\right)$. Obtained $5 \mathrm{mg}(4.5 \mu \mathrm{mol} ; 22 \%)$.

${ }^{1} \mathrm{H}-\mathrm{NMR}\left(600 \mathrm{MHz}, d_{7}\right.$-DMF): $\delta 8.38\left(1 \mathrm{H}, \mathrm{d},{ }^{3} J_{\mathrm{HH}}=3 \mathrm{~Hz}\right) ; 8.25\left(1 \mathrm{H}, \mathrm{d},{ }^{3} J_{\mathrm{HH}}=3 \mathrm{~Hz}\right) ; 7.93$ $\left(1 \mathrm{H}, \mathrm{d},{ }^{3} J_{\mathrm{HH}}=6 \mathrm{~Hz}\right) ; 7.82(1 \mathrm{H}, \mathrm{s}) ; 7.81(1 \mathrm{H}, \mathrm{t}$ broad $) ; 7.76(1 \mathrm{H}, \mathrm{s}) ; 7.33\left(1 \mathrm{H}, \mathrm{d},{ }^{3} J_{\mathrm{HH}}=6 \mathrm{~Hz}\right)$; 
$7.15(1 \mathrm{H}, \mathrm{s}$ broad); $3.70(1 \mathrm{H}, \mathrm{d}$ broad $) ; 3.56(1 \mathrm{H}, \mathrm{d}$ broad $) ; 3.39(1 \mathrm{H}, \mathrm{d}$ broad $) ; 3.30(1 \mathrm{H}, \mathrm{d}$, $\left.{ }^{2} J_{\mathrm{HH}}=12 \mathrm{~Hz}\right) ; 3.07-2.98\left(2 \mathrm{H}\right.$, multiplet); $2.34\left(1 \mathrm{H}, \mathrm{d},{ }^{2} J_{\mathrm{HH}}=6 \mathrm{~Hz}\right) ; 2.22\left(1 \mathrm{H}, \mathrm{d},{ }^{2} J_{\mathrm{HH}}=6\right.$ $\mathrm{Hz}$ ). (see Figure 3.3 for peak assignment). ${ }^{13} \mathrm{C}-\mathrm{NMR}$ (150 MHz): See Figure 3.10. MALDIMS calcd. for $\mathrm{C}_{51} \mathrm{H}_{48} \mathrm{IrN}_{11} \mathrm{O}_{6}\left[\mathrm{M}+\mathrm{H}^{+}\right]$1104.34, found 1104.34.

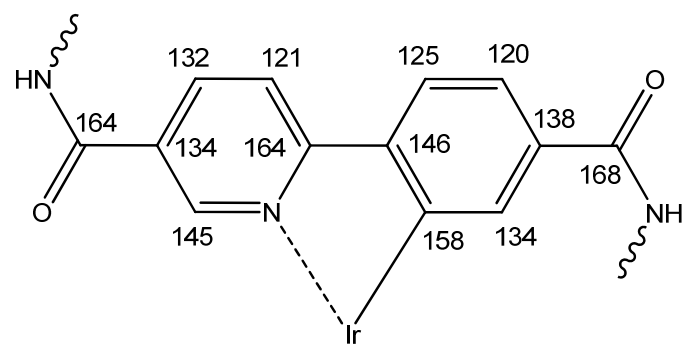

Figure 3.10. ${ }^{13} \mathrm{C}$ assignment of aromatic protons of caged complex $\mathbf{1}$.

\subsection{References}

1. Flamigni, L.; Barbieri, A.; Sabatini, C.; Ventura, B.; Barigelletti, F., Top. Curr. Chem. 2007, 281, 143-203.

2. Zhu-qi, C.; Zu-qiang, B.; Chun-hui, H., Adv. Mater. 2010, 22, 1534-1539.

3. Dedeian, K.; Djurovich, P. I.; Garces, F. O.; Carlson, G.; Watts, R. J., Inorg. Chem. 1991, 30, 1685-1687.

4. Kim, J. I.; Shin, I. S.; Kim, H.; Lee, J. K., J. Am. Chem. Soc. 2005, 127, 1614-1615.

5. Slinker, J.; Bernards, D.; Houston, P. L.; Abruna, H. D.; Bernhard, S.; Malliaras, G. G., Chem. Comm. 2003, 2392-2399.

6. Mayo, E. I.; Kilså, K.; Tirrell, T.; Djurovich, P. I.; Tamayo, A.; Thompson, M. E.; Lewis, N. S.; Gray, H. B., Photochem. Photobiol. Sci. 2006, 5, 871-873.

7. Baldo, M. A.; O'Brien, D. F.; You, Y.; Shoustikov, A.; Sibley, S.; Thompson, M. E.; Forrest, S. R., Nature 1998, 395, 151-154.

8. Sudhakar, M.; Djurovich, P. I.; Hogen-Esch, T. E.; Thompson, M. E., J. Am. Chem. Soc. 2003, 125, 7796-7797.

9. Fernandez-Moreira, V.; Thorp-Greenwood, F. L.; Coogan, M. P., Chem. Commun. 2010, 46, 186-202.

10. Tsuboyama, A.; Iwawaki, H.; Furugori, M.; Mukaide, T.; Kamatani, J.; Igawa, S.; Moriyama, T.; Miura, S.; Takiguchi, T.; Okada, S.; Hoshino, M.; Ueno, K., J. Am. Chem. Soc. 2003, 125, 12971-12979.

11. Schaffner-Hamann, C.; vonZelewsky, A.; Barbieri, A.; Barigelletti, F.; Muller, G.; Riehl, J. P.; Neels, A., J. Am. Chem. Soc. 2004, 126, 9339-9348.

12. Creaser, II; Harrowfield, J. M.; Herlt, A. J.; Sargeson, A. M.; Springborg, J.; Geue, R. J.; Snow, M. R., J. Am. Chem. Soc. 1977, 99, 3181-3182.

13. Belser, P.; De Cola, L.; Von Zelewsky, A., J. Chem. Soc., Chem. Commun. 1988, $1057-$ 1058.

14. Grammenudi, S.; Vogtle, F., Angew. Chem. Int. Ed 1986, 25, 1122-1125.

15. Alpha, B.; Lehn, J. M.; Mathis, G., Angew. Chem. Int. Ed 1987, 26, 266-267.

16. Barigelletti, F.; De Cola, L.; Balzani, V.; Belser, P.; Von Zelewsky, A.; Voegtle, F.; Ebmeyer, F.; Grammenudi, S., J. Am. Chem. Soc. 1989, 111, 4662-4668.

17. Parker, D., Macrocyclic Synthesis: a Practical Approach. Oxford University Press: New York, 1996.

18. Miyaura, N.; Suzuki, A., Chem. Rev. 2002, 95, 2457-2483. 
19. Tamayo, A. B.; Alleyne, B. D.; Djurovich, P. I.; Lamansky, S.; Tsyba, I.; Ho, N. N.; Bau, R.; Thompson, M. E., J. Am. Chem. Soc. 2003, 125, 7377-7387.

20. Knight, J. C.; Alvarez, S.; Amoroso, A. J.; Edwards, P. G.; Singh, N., Dalton Trans. 2010, 39, 3870-3883.

21. Holzer, W.; Penzkofer, A.; Tsuboi, T., Chemical Physics 2005, 308, 93-102.

22. Montalti, M.; Credi, A.; Prodi, L.; Gandolfi, M. T., Handbook of Photochemistry. CRC Press: Boca Raton, 2006.

23. Hashizume, H.; Ito, H.; Kanaya, N.; Nagashima, H.; Usui, H.; Oshima, R.; Kanao, M.; Tomoda, H.; Sunazuka, T.; Nagamitsu, T.; Kumagai, H.; Omura, S., Heterocycles 1994, $38,1551-1571$. 
Chapter 3 


\title{
Chapter 4
}

A scientist in his laboratory is not only a technician: he is also a child placed before natural phenomena which impress him like a fairy tale.

M. Curie

\section{Understanding luminescence quenching by oxygen of Ir(III)- hemicaged complexes: a systematic approach (1)*}

\begin{abstract}
In this chapter the synthesis and full structural characterization in solution by NMR spectroscopy of two fac-tris(phenylpyridine) iridium(III) complexes are reported, which have been functionalized on the pyridine ring with amide functionalities. These functionalities are either tris(2-amidoethyl)amine or ethylamides, resulting in two complexes with a hemicaged or open (without capping unit) structure, respectively. These complexes are part of a systematic investigation of structure-related effects on the oxygen quenching of luminescence. The absorption and emission properties of these compounds have been studied and their behaviour towards oxygen quenching has been investigated through the Stern-Volmer plots of both complexes. The hemicaged complex shows a $40 \%$ decrease of oxygen quenching of luminescence compared to the open complex. From a comparison with the related complexes bearing the same substituents on the side of the phenyl rings (see Chapter 5) it is evident that the introduction of a capping unit on the pyridine ring induces a strong decrease of oxygen quenching, whilst the same capping unit on the phenyl ring does not have any influence on the degree of quenching. Moreover, the thermodynamic parameters involved in the oxygen quenching process of both the hemicaged and the open complex do not show any considerable
\end{abstract}

\footnotetext{
* Part of this chapter has been submitted for publication: A. Ruggi, M. Mauro, F. Polo, D. N. Reinhoudt, L. De Cola and A. H. Velders, submitted.
} 
difference, thus corroborating the structural origin of the oxygen quenching decrease shown by the hemicaged complex.

\subsection{Introduction}

In Chapter 3, the possibility of reducing oxygen quenching of luminescence of $\operatorname{Ir}(\mathrm{III})$ ppycomplexes by using a cage ligand is reported. The reported compound shows a $80 \%$ decrease of its oxygen quenching compared to the archetypical $\operatorname{Ir}(\mathrm{ppy})_{3}$. A similar result has been described in the literature for a $\mathrm{Ru}(\mathrm{II})$-caged complex, with a similar decrease of oxygen quenching. ${ }^{1}$ However, the origin of the ligand induced (intramolecular) shielding effect against oxygen quenching is not clear yet. Although $80 \%$ decrease of oxygen quenching as observed in Chapter 3 is impressive, the comparison between the cage complex and the reference compound $\operatorname{Ir}(\mathrm{ppy})_{3}$ (or the related ester functionalized hemicage) is not completely representative, as several parameters have changed, not only structurally but also electronically. In fact, the degree of oxygen quenching of the luminescence of transition metal complexes strongly depends on the triplet energy and the oxidation potential of the complex in its ground state (see Section 2.3, Chapter 2). ${ }^{2,3}$ The introduction of substituents on the phenylpyridine ligand exerts a significant effect on these two parameters. For instance, the introduction of electron-withdrawing groups (e.g. amide or methylester moieties) usually decreases the triplet energy and increases the oxidation potential, resulting in an overall decrease of the oxygen quenching of the substituted complex (e.g. the hemicaged and caged complexes reported in Chapter 3) compared to the unsubstituted complex (e.g. the $\left.\operatorname{Ir}(\mathrm{ppy})_{3}\right)^{4,5}$ Therefore, a more refined investigation of the parameters involved in oxygen quenching of the luminescence requires compounds that are, in the best possible way, similar to each other. Taking this into consideration, it seems appropriate to compare $\operatorname{Ir}(\mathrm{III})$ complexes that have the same functional groups connected to the phenylpyridine ligands.

In order to investigate the structure-related effect on oxygen quenching of the luminescence of $\operatorname{Ir}(\mathrm{ppy})$ complexes, four structurally and electronically related 'open' (i.e. without any capping unit) and hemicaged (i.e. with one capping unit) complexes have been designed. They are expected to show similar (Chapter 5) or different (this Chapter) excited state properties. In particular, the degree of shielding against quencher species is expected to be highly dependent on the side where the capping unit is located, either on the pyridines' side (where the Lowest Unoccupied Molecular Orbital (LUMO) is mostly localised) or on the phenyls' side (where the Highest Occupied Molecular Orbital (HOMO) is mostly localised). ${ }^{6,7}$ In this Chapter, the synthesis, characterization and photophysical properties of 
two phenylpyridine-based Ir(III) complexes are reported, exhibiting a hemicaged or an open structure, functionalized on the pyridines' side of the complex. The Stern-Volmer analysis of the quenching process has been evaluated together with the thermodynamic parameters involved in the possible quenching pathways (i.e. energy and electron transfer), revealing a clear evidence of the structural-induced shielding against oxygen quenching. ${ }^{8}$

\subsection{Design and synthesis}

In $\operatorname{Ir}(\text { ppy })_{3}$-like complexes, the HOMO orbital is usually localized on the metal ion and on the phenyl ring, while the LUMO orbital (which can be considered as a first approximation of the electronic distribution of the molecule in the electronic excited state) is mostly localized on the pyridine rings. ${ }^{4,9}$ Upon introduction of suitable groups, either on the pyridine or phenyl ring, it is possible to selectively modify the properties of the LUMO or HOMO orbitals, respectively (See Chapter 2). ${ }^{4,10}$ The possibility of decreasing the oxygen quenching of excited states of $\mathrm{Ru}(\mathrm{II})$ complexes by shielding the LUMO orbital with a suitable host molecule (e.g. $\beta$-cyclodextrins and zeolites) has been successfully explored. ${ }^{11,12}$ On the other hand, the remarkable low oxygen quenching observed in luminescent caged $\mathrm{Ru}(\mathrm{II})^{1}$ and Ir(III) complexes suggests a possible structural (intramolecular) shielding of the excited state (i.e. of the atoms where the LUMO orbital is mostly localized). In order to verify this hypothesis and to obtain a clear evidence of the structural-induced shielding against oxygen quenching, a series of complexes with a hemicaged $(\mathbf{1}, \mathbf{3})$ and open $(\mathbf{2}, \mathbf{4})$ structure on the pyridine $(\mathbf{1}, \mathbf{2})$ and phenyl $(\mathbf{3}, \mathbf{4})$ ring were designed (Figure 4.1$)$. The investigation of the shielding properties of these compounds derives from the shielding observed in the caged complex described in Chapter 3. The introduction of a capping unit on the pyridine rings ( $\mathbf{1}$, this Chapter), where the LUMO orbital is mostly localized, is expected to induce a shielding and resulting in a decrease of oxygen quenching compared to the open (unshielded) complex. Conversely, the presence of a capping unit on the phenyl ring (3, see Chapter $\mathbf{5})$, where the HOMO orbital is mostly localized, is not expected to have any effect on the degree of oxygen quenching and, therefore, the behaviour of the hemicaged and open complexes towards oxygen quenching is expected to be the same. In order to establish a close comparison with the results shown in Chapter 3, the same kind of capping unit and connecting group (tris(2amidoethyl)amine and amide moiety, respectively) were used. 


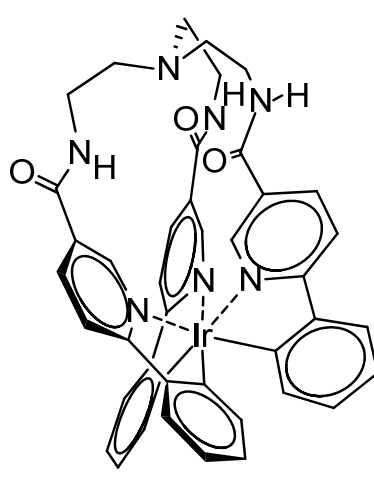

1

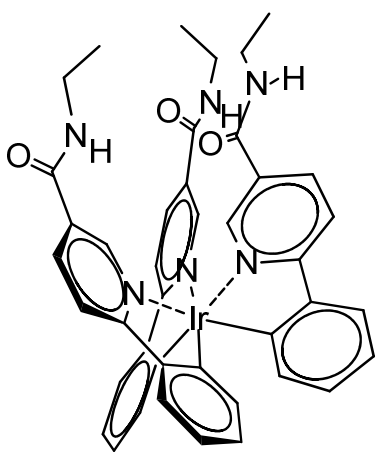

2

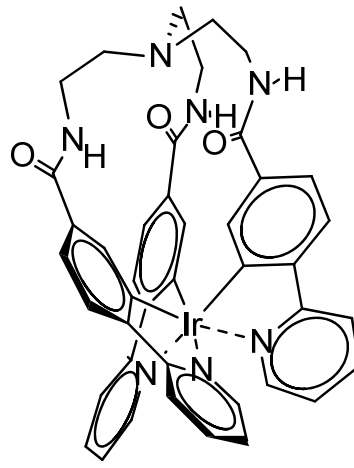

3

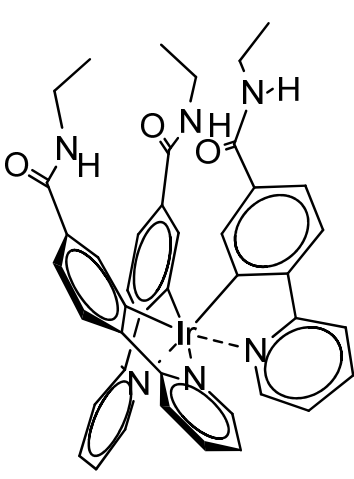

4

Figure 4.1. Structure of hemicaged $(\mathbf{1}, \mathbf{3})$ and open $(\mathbf{2}, \mathbf{4}) \operatorname{Ir}(\mathrm{III})$ complexes functionalized on the pyridine $(\mathbf{1}, \mathbf{2})$ or phenyl $(\mathbf{3}, \mathbf{4})$ ring.

The complexes $\mathbf{1}$ and $\mathbf{2}$ were synthesized according to the synthetic pathway shown in Scheme 4.1. The 6-phenylnicotinic acid (5) was obtained upon Suzuki coupling, ${ }^{13}$ with subsequent amide coupling with Tren or ethylamine to form 6 or 7 , respectively. The tripodal ligand 6 was obtained upon DCC/HOBt coupling with $40 \%$ yield, whilst this method was unsuccessful for the synthesis of the $N$-ethyl-6-phenylnicotinamide 7. Therefore, the latter ligand was prepared by EDC coupling in the presence of pyridine, which gave the desired compound with an $85 \%$ yield. The so obtained ligands were complexed with Ir(III) in order to obtain the desired targets. The hemicaged complex 1 was synthesized by direct reaction of the tripodal ligand 6 with $\mathrm{IrCl}_{3}$ in the presence of $\mathrm{CF}_{3} \mathrm{CO}_{2} \mathrm{Ag}$ in refluxing ethylene glycol with a yield of $20 \%$. This strategy was not successful in the case of the open complex, mainly due to the high polarity of the target compound which makes the isolation of $\mathbf{2}$ from the reaction mixture difficult. Therefore, the open complex 2 was synthesized by a two step approach: ${ }^{14}$ first the dichloro-bridged iridium(III) dimer was obtained by reaction of the desired ligand (7) with $\mathrm{IrCl}_{3}$ in 2-ethoxyethanol and the so obtained intermediate was then reacted with an excess of ligand in the presence of $\mathrm{CF}_{3} \mathrm{SO}_{3} \mathrm{Ag}$ in refluxing toluene giving the open complex 2 with a $10 \%$ yield. 


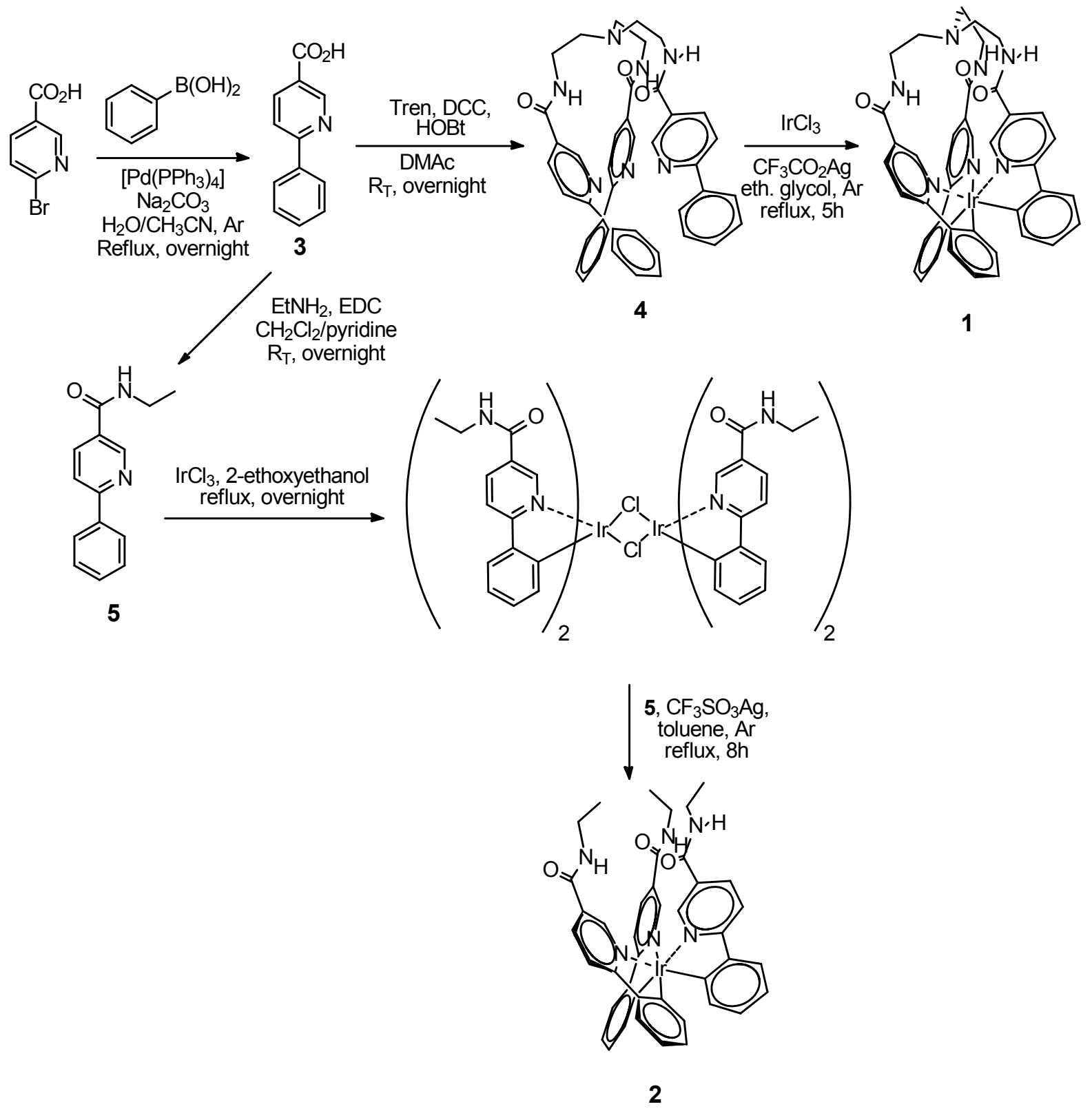

Scheme 4.1. Synthetic pathways for the syntheses of the hemicaged (1) and open (2) Ir(III) complexes.

\subsection{Characterization}

All the intermediates and target complexes $\mathbf{1}$ and $\mathbf{2}$ were characterized by IR and NMR $\left({ }^{1} \mathrm{H}\right.$ and ${ }^{13} \mathrm{C}$ ) spectroscopy and mass spectrometry. The characteristic data are reported in the experimental section. The ${ }^{1} \mathrm{H}-\mathrm{NMR}$ spectrum (see Figure 4.2) of the hemicaged complex 1 shows that, upon iridium(III) complexation, the hemicaged ligand becomes quite rigid: due to the hampered rotation around the $\mathrm{C}-\mathrm{C}$ bond of the ethyl linkers, the four aliphatic protons on each linker become magnetically non-equivalent, resulting in four different peaks in the 
${ }^{1}$ H-NMR spectrum. A similar behaviour was observed also in the case of the related hemicaged and caged Ir(III) complexes described in Chapter 3. The ${ }^{1} \mathrm{H}-\mathrm{NMR}$ spectrum of the open complex 2 does not show any non-equivalency of the two methylene and the three methyl protons, as expected for ethyl moieties with rotational freedom. Also, both the complexes $\mathbf{1}$ and $\mathbf{2}$ show only one set of NMR signals for all three ppy units, which proves that the 3-fold symmetry expected for fac-complexes is maintained. The introduction of the capping unit induces a remarkable difference in the chemical shift of the amide proton $(\mathrm{NH})$ : the NH signal of 2 in $d_{7}$-DMF shows a chemical shift of $8.80 \mathrm{ppm}$, whilst the NH signal of 1 shows a chemical shift of $7.80 \mathrm{ppm}$ (Figure 4.2). A similar change is shown also by the proton Ha, which has a chemical shift of $8.45 \mathrm{ppm}$ in 2 and $8.05 \mathrm{ppm}$ in $\mathbf{1}$. The observed difference in the chemical shift of the amide proton $(\mathrm{NH})$ is probably due to the locally different environment created by the presence of the $\mathrm{N}$ atom belonging to the capping unit or to the different orientation of the NH moiety in the complexes $\mathbf{1}$ and $\mathbf{2}$ (vide infra). On the other hand, the shift observed for the Ha proton is probably due to the magnetic shielding effect exerted by the pyridine rings on the other branches of the molecule. This higher magnetic shielding is probably due to the fact that, upon introduction of the capping unit, the helical structure of the $\operatorname{Ir}(\mathrm{ppy})_{3}$ core of $\mathbf{1}$ becomes more "twisted" with respect to the uncapped complex 2. Nevertheless, further structural investigations are necessary when the aim is to elucidate the structural effect deriving from the introduction of the capping unit. For a more detailed description of the structural differences between hemicaged and open complexes, see Chapter 5. 


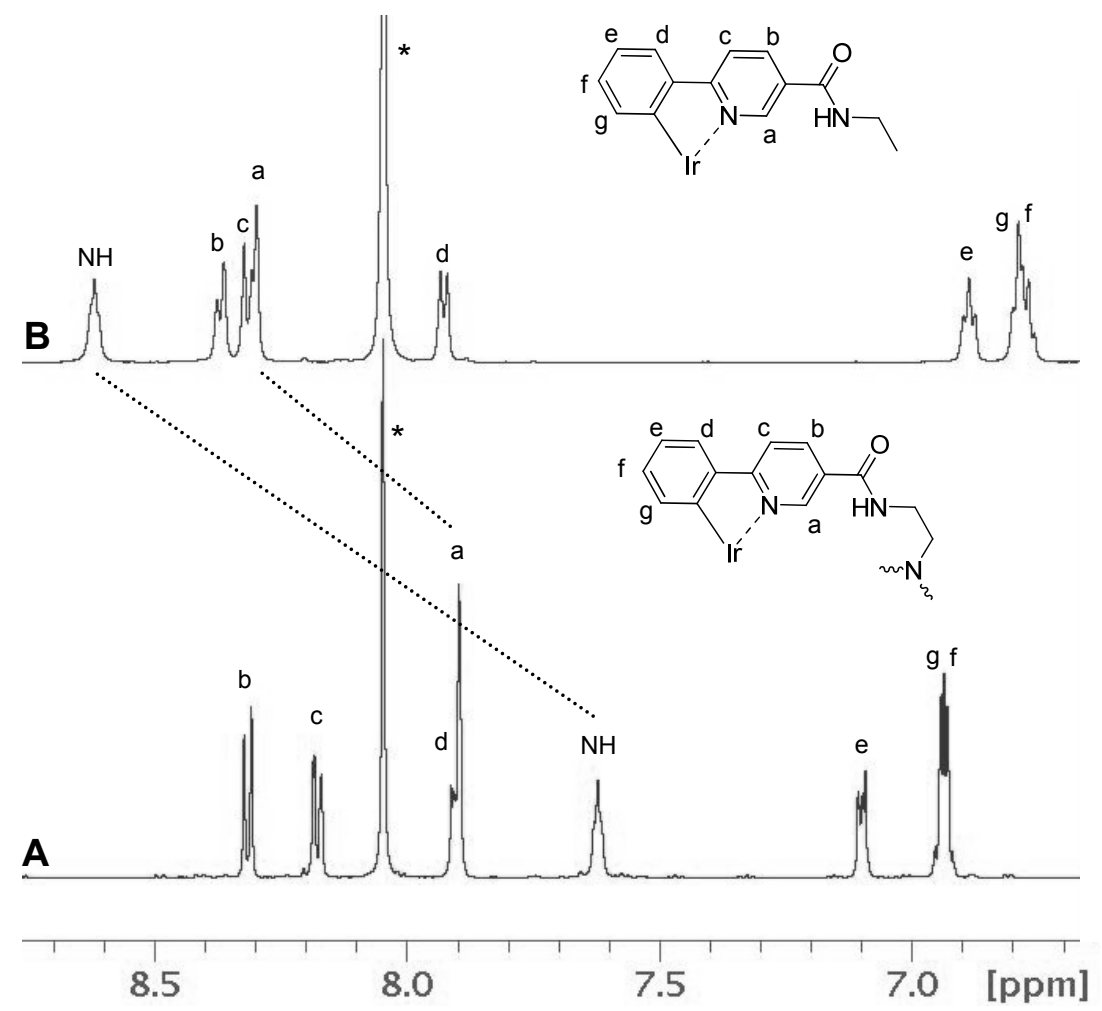

Figure 4.2. ${ }^{1} \mathrm{H}-\mathrm{NMR}$ spectra of hemicaged iridium complex 1 (A) and open iridium complex 2 (B) in $d 7$-DMF. Region of the aromatic protons. * = residual solvents.

To further investigate the geometry of the hemicaged complex 1, a series of 2D-NMR experiments (COSY, NOESY, HMBC and HMQC) was performed. The HH-NOESY spectrum, in particular, revealed the through-space interactions between protons and therefore giving an idea of the three-dimensional structure of the compounds. The amide-aliphatic region of the NOESY spectrum of 1 (Figure 4.3) shows the coupling between the amide proton $(\mathrm{NH})$ and three non-equivalent aliphatic protons of the ethyl linker (Hh, Hh', $\mathbf{H i})$, analogous to what was found for the hemicaged complex shown in Chapter 3. The fourth proton $\left(\mathbf{H i}^{\prime}\right)$ is too far from the amide proton and does not show any through-space coupling. 


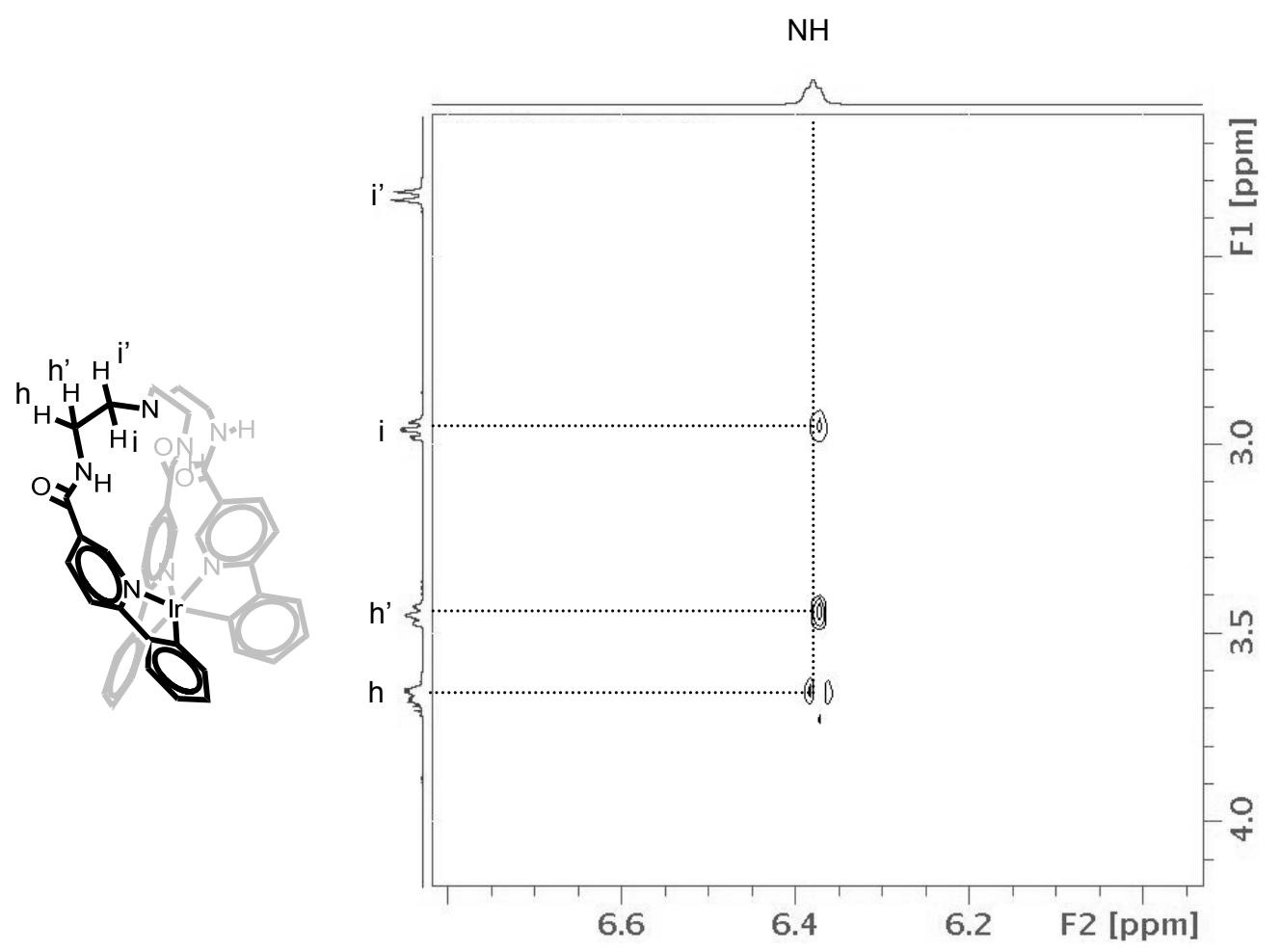

Figure 4.3. HH-NOESY spectrum of the hemicaged complex 1 in $d_{2}-\mathrm{CH}_{2} \mathrm{Cl}_{2}$. Region of the aliphatic-aromatic protons.

In the aromatic region of the NOESY spectrum of the hemicaged complex 1 (Figure 4.4), the characteristic cross-peaks between protons $\mathbf{H c}$ and $\mathbf{H d}$, which are located on the pyridine and phenyl ring, respectively, are evident and this facilitates the assignment of the other ring protons that overlap. Further analysis of the aromatic region of the NOESY spectrum of the hemicaged complex 1 (Figure 4.4) reveals the orientation of the amide moiety: the crosspeaks between the amide proton $(\mathrm{NH})$ and the protons $\mathbf{H a}$ and $\mathbf{H b}$ on the pyridine ring show that the NH group is not coplanar with the pyridine ring and, therefore, gives a coupling with both protons in ortho- position with respect to the amide group. 


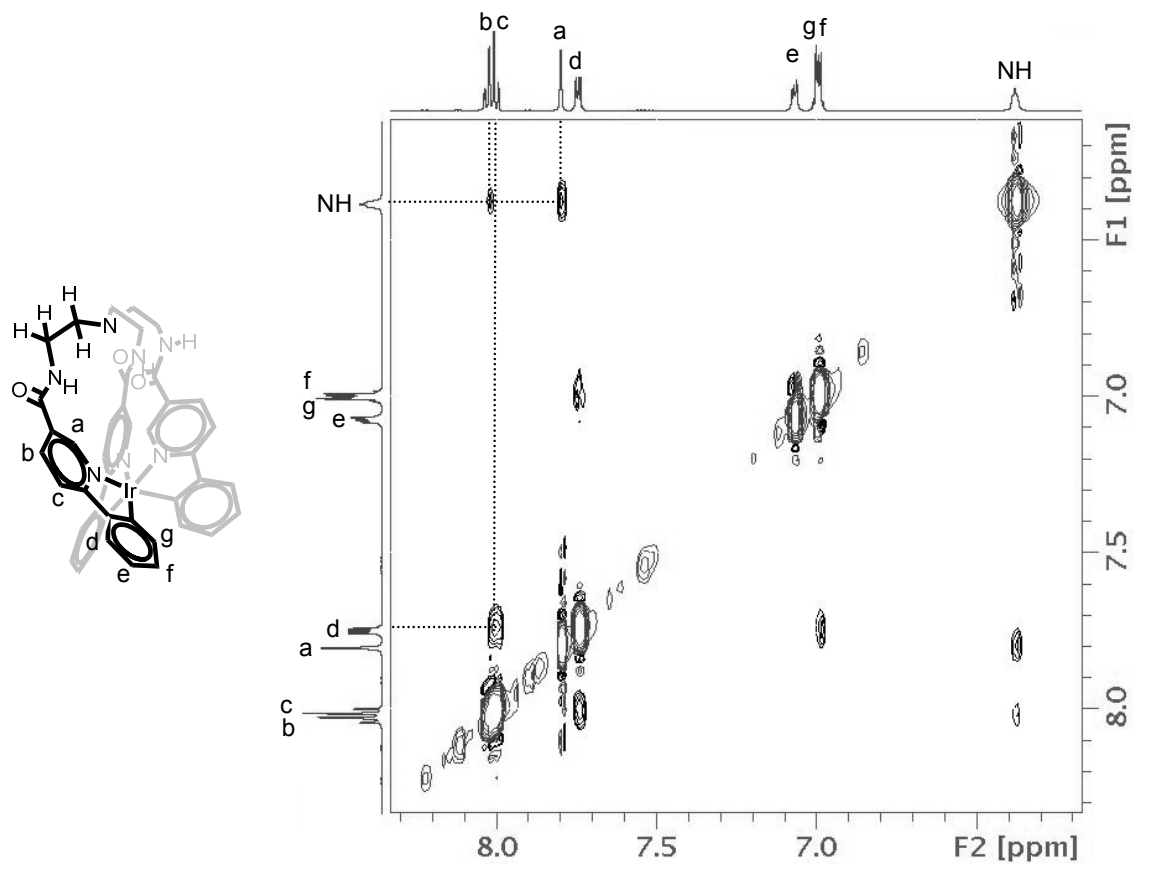

Figure 4.4. HH_NOESY spectrum of the hemicaged complex 1. $d 2-\mathrm{CH}_{2} \mathrm{Cl}_{2}$. Region of the aromatic protons.

The orientation of the amide protons in $\mathbf{1}$ is different from the orientation observed for the amide protons of the hemicaged and caged complexes described in Chapter 3. As discussed in the previous chapter, the NH proton of the amide on the phenyl ring is oriented towards the inside of the molecule and the $\mathrm{NH}$ proton of the amide on the pyridine ring is oriented towards the outside of the molecule. For the sake of comparison, the ppy structures of the hemicaged 1 and those of the hemicaged and caged complexes reported in Chapter 3 are illustrated in Figure 4.5.<smiles>CNC(=O)C1=CN2[I-]c3ccccc3C2=C[I-]1</smiles>

1<smiles>CNC(=O)c1ccc2c(c1)[I-]N1C=C(C(=O)OC)C=CC21</smiles>

A<smiles>CNC(=O)C1=CN2[I-]c3cc(C(=O)NC)ccc3C2=CC1</smiles>

B

Figure 4.5 Comparison of the amide orientation in $\mathbf{1}$ and in the hemicaged (A) and caged (B) complexes reported in Chapter 3. 
The hemicaged complex (A) described in Chapter 3 shows a through-space coupling between the amide proton and the "internal" proton on the phenyl ring (H6); therefore the carbonyl must be oriented towards the outside of the molecule. Interestingly, the caged complex (B) described in Chapter 3 shows opposite orientations for the two different amide moieties. The proton on the amide connected with the pyridine ring gives a NOE coupling with the external proton on the pyridine ring (H2) whilst the proton on the amide connected with the phenyl ring gives a through-space coupling with the internal proton on the phenyl ring (H6). Therefore, the two couplings shown by the amide proton of the hemicaged 1 with both protons $\mathrm{Ha}$ and $\mathbf{H b}$ suggest a completely different orientation of the amide in this complex. In order to give a double NOE coupling with both the external and the internal proton of the pyridine ring, the amide should be rotated with respect to the plane defined by the pyridine ring. On the basis of the NOESY spectrum of $\mathbf{1}$ two different structures can be drawn, namely a structure in which the entire amide group is not coplanar with the pyridine ring and a structure in which the carbonyl is coplanar with the pyridine ring and the $\mathrm{NH}$ is bent out of the pyridine's plane. However, a rotation of the entire amide group with respect to the pyridine ring would result in a lower conjugation of the pyridine ring with the carbonyl moiety and, therefore, the emission of the hemicaged complex 1 would be blue-shifted compared to the open complex 2 (this effect has been observed in a Ru(II) caged complex). ${ }^{1}$ Since 1 shows a clear red-shift with respect to $\mathbf{2}$ (vide infra), it is likely that only the NH group is bent out of the pyridine's plane.

\subsection{Photophysical properties}

Optical absorption. The UV-Vis absorption spectra of the complexes $\mathbf{1}$ and $\mathbf{2}$ are reported in Figure 4.6 and their typical absorption maxima and shoulder are listed in Table 4.1. Both complexes show a strong absorption band $\left(\varepsilon \geq 10^{4} \mathrm{M}^{-1} \mathrm{~cm}^{-1}\right)$ between 280 and $320 \mathrm{~nm}$ and weaker absorption bands $\left(\varepsilon \leq 10^{3} \mathrm{M}^{-1} \mathrm{~cm}^{-1}\right)$ between 350 and $450 \mathrm{~nm}$. By comparing with the typical absorption shown by $\operatorname{Ir}(\text { ppy })_{3}$ derivatives, ${ }^{15,16}$ the absorption bands centred around 300 $\mathrm{nm}$ can be assigned to ligand centred $\pi \rightarrow \pi^{*}$ transitions, while the weaker bands centred around $400 \mathrm{~nm}$ can be assigned to spin-allowed singlet-to-singlet metal to ligand charge transfer $\left({ }^{1}\right.$ MLCT). The weak shoulder at lower energy (centred around $470 \mathrm{~nm}$ ) can be assigned to a spin-forbidden singlet-to-triplet transition ${ }^{3}$ MLCT. The latter transitions are usually observed in complexes containing heavy atoms (like iridium), which show a 
remarkable spin-orbit coupling that makes the singlet-to-triplet transitions partly allowed. The hemicaged complex 1 shows a slight red-shift of its MLCT absorption bands compared to the open complex 2 , which might be caused by the geometry distortion of the $\operatorname{Ir}(p p y)_{3}$ core, observed from NMR data analysis. However, the red shift in the MLCT band corroborates the hypothesis of a strong conjugation of the amide group with the pyridine ring.

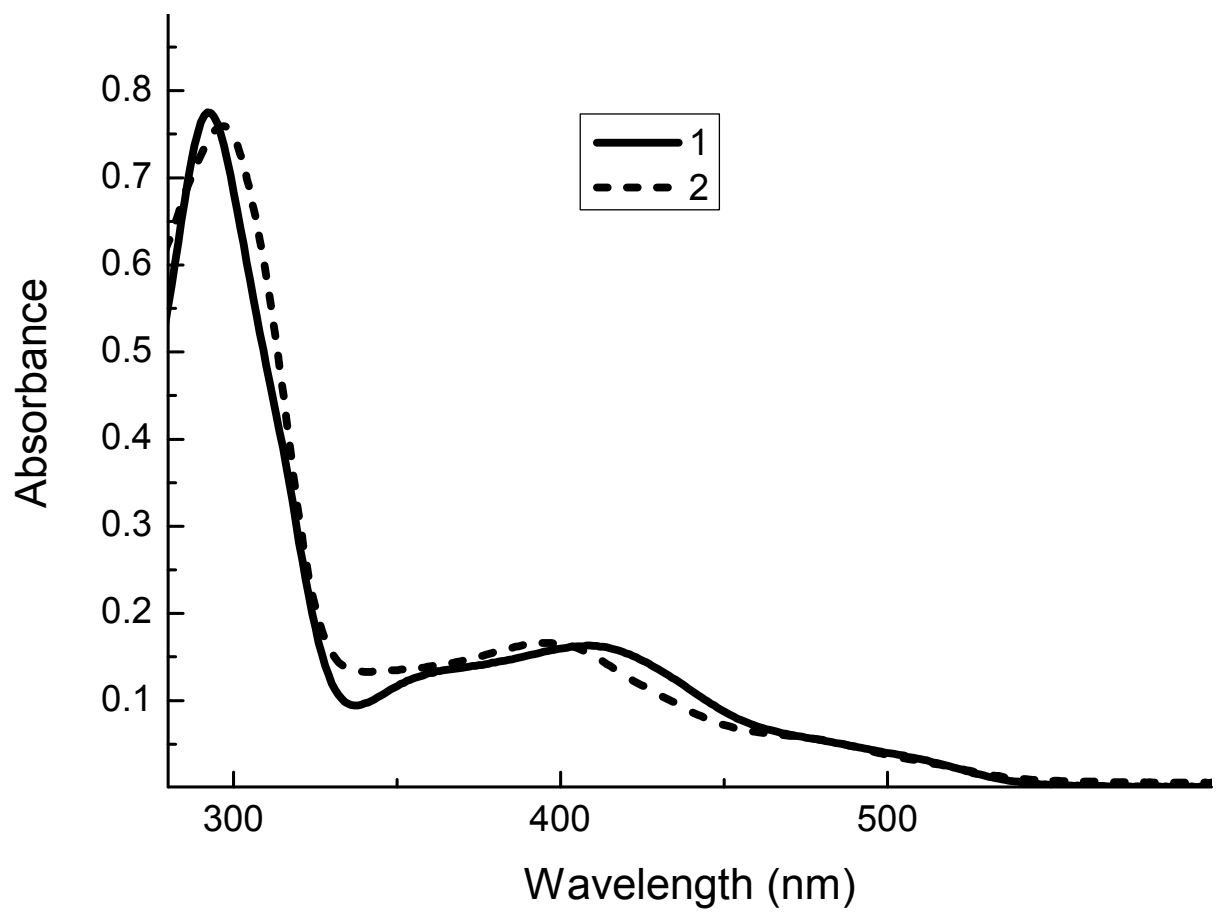

Figure 4.6. UV-Vis absorption of the hemicaged complex 1(solid line) and open complex 2 (dashed line) in DMF at room temperature.

Table 4.1. UV-Vis absorption data of the complexes and their molar absorption coefficient in DMF at room temperature. sh. $=$ shoulder

\begin{tabular}{|c|c|}
\hline Compound & $\begin{array}{c}\text { Absorption } \\
\lambda(\mathbf{n m}),\left(\boldsymbol{\varepsilon}\left(\mathbf{1 0}^{\mathbf{3}} \mathbf{M}^{\mathbf{- 1}} \mathbf{c m}^{\mathbf{- 1}}\right)\right)\end{array}$ \\
\hline $\mathbf{1}$ & $292(45), 302($ sh. 15), 361 (sh. 5.3), 420 (6.5), 487 (sh. 2.1) \\
\hline $\mathbf{2}$ & $297(32), 400(6.9), 487$ (sh. 2.1) \\
\hline
\end{tabular}

Luminescence. Both complexes 1 and $\mathbf{2}$ show intense luminescence at room temperature (Figure 4.7 A). The photophysical properties of the complexes $\mathbf{1}$ and $\mathbf{2}$ are summarized in Table 4.2. As expected, the presence of electron-withdrawing groups on the pyridine ring induces a red shift in the emission compared to the archetypical $\operatorname{Ir}(\mathrm{ppy})_{3}$, mainly due to the decreased energy level of the LUMO orbital. ${ }^{4}$ This red shift is a clear indication of the strong 
conjugation of the amide carbonyl with the pyridine ring both in the case of hemicaged complex 1 as well as in the case of open complex 2, thus corroborating the hypothesis of a substantial coplanarity of the carbonyl with the pyridine ring. ${ }^{1}$ The emission profile of both complexes is structureless, which indicates a ${ }^{3}$ MLCT character of the emissive state. ${ }^{15}$ The hemicaged complex 1 shows an evident red shift of the emission compared to the open complex 2. This red shift can be explained from the geometrical distortion of the complex (already observed in UV-Vis data) or from the locally different polarity induced by the presence of the $\mathrm{N}$ atom of the capping unit (e.g. a kind of local solvatochromism). ${ }^{17}$
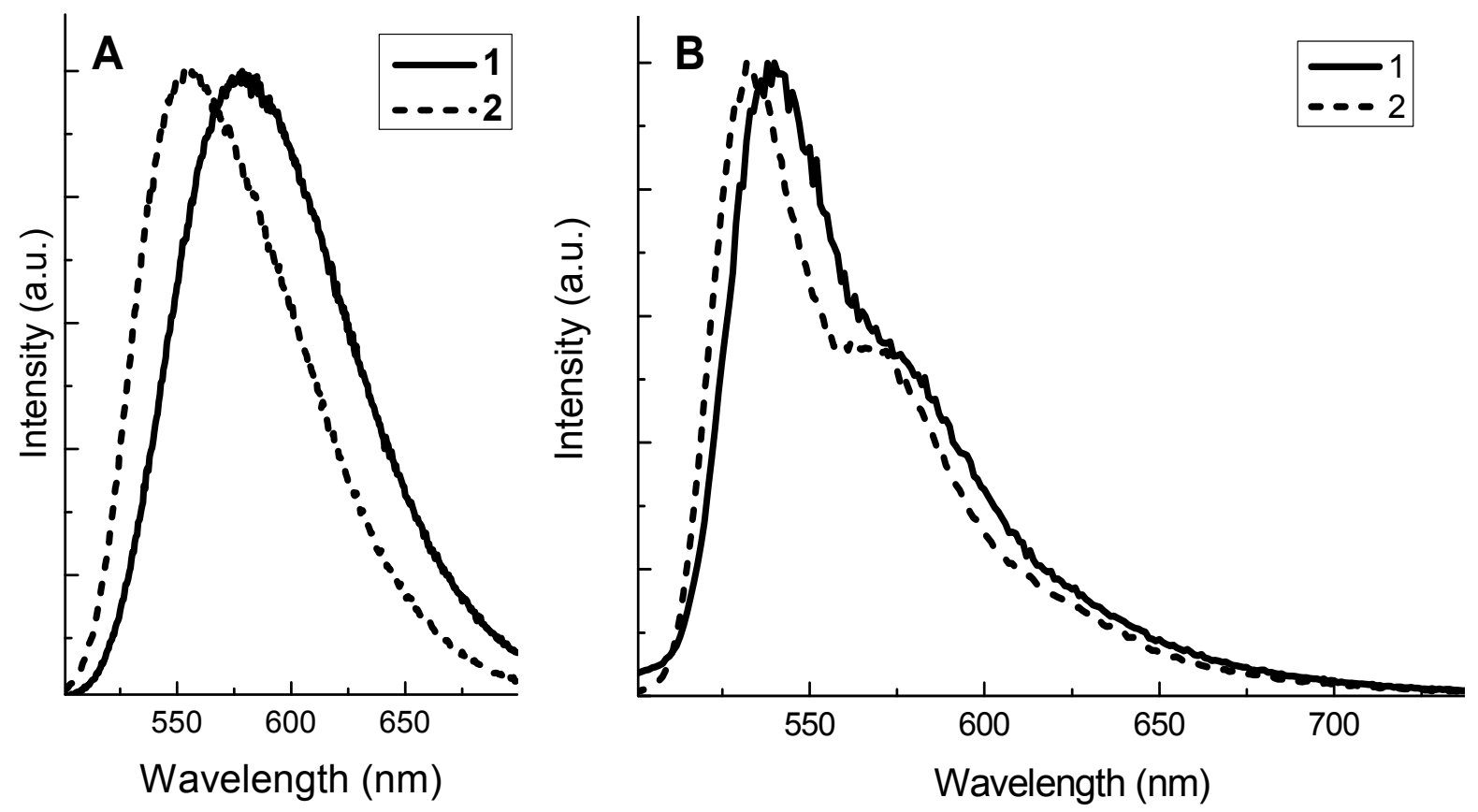

Figure 4.7. Normalized emission profile of 1 and 2 in DMF at room temperature (A) and in $\mathrm{CH}_{2} \mathrm{Cl}_{2}: \mathrm{MeOH}(1: 1)$ glass at $77 \mathrm{~K}$.

Complexes $\mathbf{1}$ and $\mathbf{2}$ are highly luminescent in oxygen-free solvents, with quantum yields in the order of $\phi_{0} \sim 0.60$. Long emission lifetimes $\left(\tau_{0}=1 \mu \mathrm{s}\right)$ are observed for both complexes, corroborating the hypothesis of a triplet originated emission. In aerated solutions a general decrease of quantum yields and lifetimes is observed, as a consequence of the oxygen quenching. In these conditions, the hemicaged complex 1 shows a higher quantum yield $(\phi=$ 0.048) compared to the open form $2(\phi=0.040)$ and the same trend is observed for the emission lifetimes in deaerated solution: the hemicaged complex 1 shows a longer lifetime $(\tau$ $=100 \mathrm{~ns})$ compared to the open complex $2(\tau=78 \mathrm{~ns})$. 
From the analysis of the emission occurring at low temperature $(77 \mathrm{~K})$ it is possible to obtain some indications concerning the energy and the character of the emitting states. The emission profiles recorded at $77 \mathrm{~K}$ (Figure $4.7 \mathrm{~B}$ ) show enhanced vibronic resolution, owing to the known temperature effect. ${ }^{1}$ Both compounds $\mathbf{1}$ and $\mathbf{2}$ show a blue shift of the emission maximum with respect to that of $\mathbf{1}$ and $\mathbf{2}$ at room temperature, which is an indication of the ${ }^{3}$ MLCT nature of the emitting state. ${ }^{18}$ Further evidence stems for the triplet character of the emitting state from the long lifetime recorded at $77 \mathrm{~K}$. The different trend observed for the quantum yields and lifetimes of the hemicaged $\mathbf{1}$ and the open $\mathbf{2}$ complex in absence and presence of oxygen provides a first clue of the different behaviour towards oxygen quenching, which has been further investigated by analyzing Stern-Volmer plots.

Table 4.2. Photophysical properties of the hemicaged (1) and open (2) complexes in DMF at $25^{\circ} \mathrm{C}$ (unless otherwise stated).

\begin{tabular}{|c|c|c|c|c|c|c|c|}
\hline Compound & $\begin{array}{c}\lambda_{\text {em }} \\
(\mathbf{n m})\end{array}$ & $\phi_{\mathbf{0}}$ & $\phi$ & $\begin{array}{c}\tau_{\mathbf{0}} \\
(\mathbf{n s})\end{array}$ & $\begin{array}{c}\tau \\
(\mathbf{n s})\end{array}$ & $\begin{array}{c}\lambda_{\mathrm{em}}(\mathbf{7 7 K}) * \\
(\mathbf{n m})\end{array}$ & $\begin{array}{c}\tau(\mathbf{7 7 K})^{*} \\
(\boldsymbol{\mu s})\end{array}$ \\
\hline $\mathbf{1}$ & 580 & 0.54 & 0.048 & 1013 & 100 & 540 & 5.56 \\
\hline $\mathbf{2}$ & 556 & 0.62 & 0.040 & 1110 & 78 & 532 & 5.06 \\
\hline
\end{tabular}

* Measured in $\mathrm{CH}_{2} \mathrm{Cl}_{2}: \mathrm{MeOH}(1: 1)$ glass.

Oxygen quenching. The luminescence quenching by oxygen of complexes $\mathbf{1}$ and $\mathbf{2}$ was studied by measuring the luminescence intensity of solutions with different concentrations of oxygen and by plotting the obtained results according to the Stern-Volmer equation (eq. 4.1):

$$
\frac{I_{0}}{I}=1+k_{q} \tau_{0}\left[O_{2}\right]
$$

$\mathrm{I}_{0}$ and $\mathrm{I}$ are the emission intensities in presence or absence of quencher, respectively, $\mathrm{k}_{\mathrm{q}}$ is the quenching constant, $\tau_{0}$ is the lifetime in absence of quencher and $\left[\mathrm{O}_{2}\right]$ the concentration of oxygen in solution. ${ }^{19}$ The Stern-Volmer plots of the two complexes $\mathbf{1}$ and $\mathbf{2}$ are shown in Figure 4.8. The quenching constant $\mathrm{k}_{\mathrm{q}}$ can be calculated by dividing the value of the line slope (obtained from the Stern-Volmer plot) by the lifetime of the complex in degassed solution $\left(\tau_{0}\right)$. From the analysis of the quenching constants $\mathrm{k}_{\mathrm{q}}$ (Table 4.3 ) the efficiency of 
oxygen quenching can be evaluated. The hemicaged complex 1 shows decrease of oxygen quenching of $40 \%$ compared to the open complex 2 .

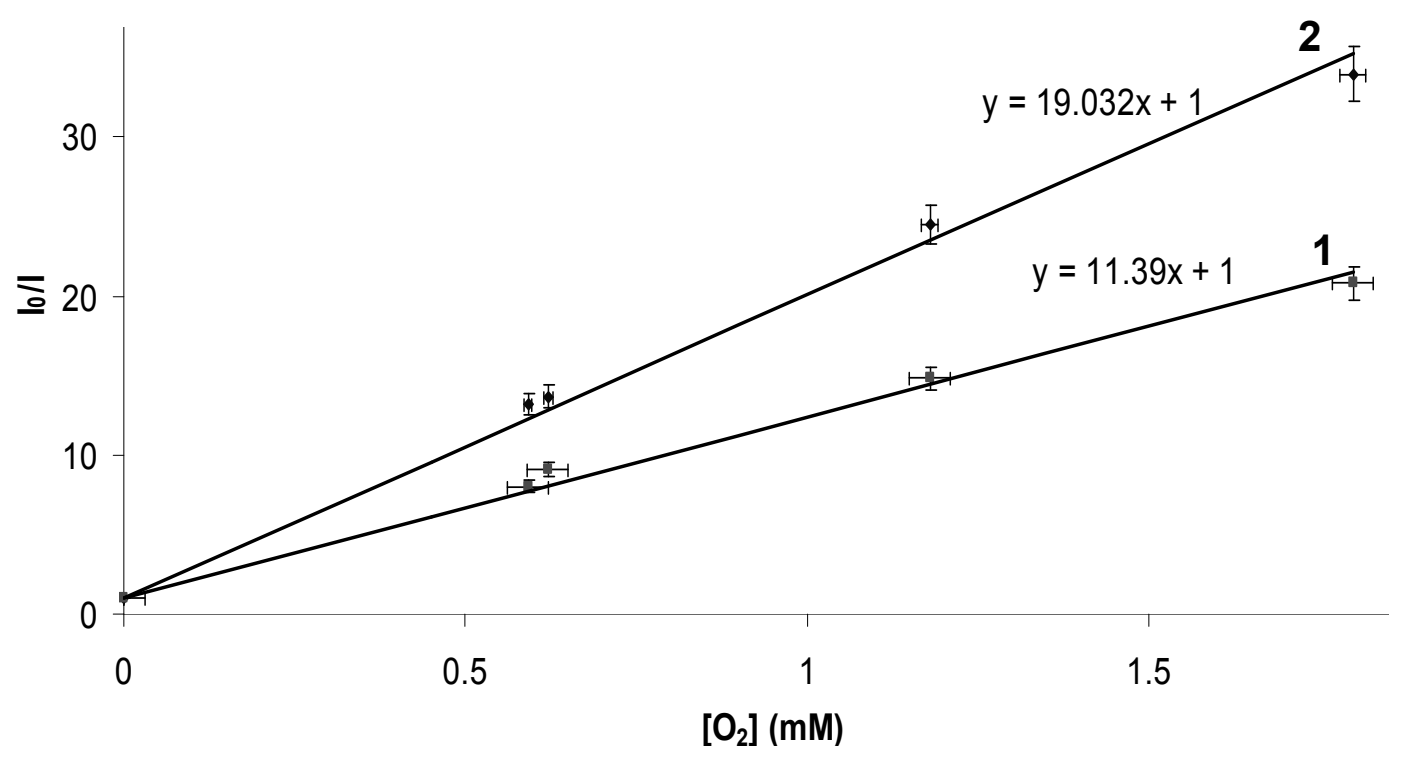

Figure 4.8. Stern-Volmer plot of the hemicaged complex 1 and open complex 2 in DMF at room temperature.

In order to validate the similar terms of energy or electron transfer for $\mathbf{1}$ and $\mathbf{2}$, the free energy of energy transfer $\left(\Delta \mathrm{G}_{\mathrm{et}}\right)$ was calculated, according to eq. 4.2:

$$
\Delta G_{e t}=-\left(E_{00}-E_{O_{2}}\right)
$$

$E_{00}$ is the energy of the 0-0 transition and $E_{02 *}$ the energy of the excited state of singlet

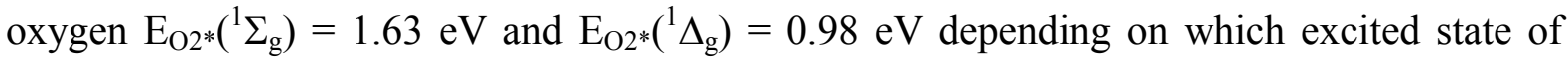
oxygen is initially produced during quenching, and of electron transfer $\left(\Delta \mathrm{G}_{\mathrm{el}}\right)$ according to eq. 4.3:

$$
\Delta G_{e l}=F\left(E_{F}^{o x}-E_{O_{2}}^{r e d}\right)-E_{00}+C
$$

$F$ is the Faraday's constant, $E_{F}^{\mathrm{ox}}$ is the oxidation potential of the fluorophore, $\mathrm{E}_{\mathrm{O} 2}^{\mathrm{red}}$ is the reduction potential of oxygen $(-0.78 \mathrm{~V})$ and $\mathrm{C}$ is a Coulomb term (usually neglected in polar solvents). ${ }^{2,20,21}$ The calculated values of $\Delta \mathrm{G}_{\mathrm{et}}$ and $\Delta \mathrm{G}_{\mathrm{el}}$ for $\mathbf{1}$ and $\mathbf{2}$ are reported in Table 4.3. From the analysis of these data it is possible to conclude that the hemicaged and open 
complex show only modest differences in the thermodynamics of energy or electron transfer. Therefore, the significantly different behaviour towards oxygen quenching is probably due to a structure-related shielding effect.

The lower quenching constant of complex $\mathbf{1}$ is likely due to the shielding effect of the capping unit, which prevents the approach of the quencher species (i.e. molecular oxygen) to the atoms where the LUMO is mostly localized. Since complex 2 does not have any capping unit, molecular oxygen can freely approach the atoms where the LUMO orbital is localized resulting into a higher quenching constant.

Table 4.3. Oxygen quenching constant $\left(\mathrm{k}_{\mathrm{q}}\right)$ and thermodynamic parameters involved in the oxygen quenching mechanisms.

\begin{tabular}{|c|c|c|c|c|c|}
\hline Compound & $\mathbf{E}^{\mathbf{0 0}}(\mathbf{e V})$ & $\begin{array}{c}\mathbf{E}_{\mathbf{0 x}} \\
(\mathbf{V})\end{array}$ & $\begin{array}{c}\Delta \mathbf{G}_{\text {et }} \\
(\mathbf{k J} / \mathbf{m o l}) *\end{array}$ & $\begin{array}{c}\Delta \mathbf{G}_{\text {el }} \\
(\mathbf{k J} / \mathbf{m o l})\end{array}$ & $\mathbf{k}_{\mathbf{q}}\left(\mathbf{M}^{-1} \mathbf{s}^{\mathbf{- 1}}\right)$ \\
\hline $\mathbf{1}$ & 2.42 & 0.921 & -139 & -69 & $1.0 \cdot 10^{10}$ \\
\hline $\mathbf{2}$ & 2.43 & 0.910 & -140 & -71 & $1.7 \cdot 10^{10}$ \\
\hline
\end{tabular}

* calculated by assuming $\mathrm{E}_{\mathrm{O} 2 *}\left({ }^{1} \Delta_{\mathrm{g}}\right)=0.98 \mathrm{eV}$.

A comparison of the quenching constants of the hemicaged complex $\mathbf{1}\left(\mathrm{k}_{\mathrm{q}}=1.0 \cdot 10^{10} \mathrm{M}^{-1} \mathrm{~s}^{-1}\right)$ and the caged complex reported in Chapter $3\left(\mathrm{k}_{\mathrm{q}}=5.2 \cdot 10^{9} \mathrm{M}^{-1} \mathrm{~s}^{-1}\right)$ shows that the caged complex exhibits an almost 50\% lower quenching than the hemicage 1. Obviously, in order to compare the two complexes, it should be considered that the caged complex and the hemicaged 1 show many structural differences and many parameters are different. For instance, the presence of amide moieties on both the phenyl and the pyridine's side in the caged complex is expected to result into a further increase of the oxidation potential $\mathrm{E}_{\mathrm{ox}}$ compared to the hemicage $\mathbf{1}$ (as observed for the hemicage $\mathbf{3}$ described in Chapter 5) with a concomitant increase of the free energy of electron transfer $\Delta \mathrm{G}_{\mathrm{el}}$. From the thermodynamic point of view this explains why the oxygen quenching of the caged complex described in Chapter 3 even less than that of the hemicage $\mathbf{1}$. 


\subsection{Conclusions}

In this Chapter, the synthesis, characterization and photophysical properties of two $\operatorname{Ir}(\mathrm{III})$ tris(phenylpyridine) complexes with a hemicaged (1) and open (2) structure are described. Compound $\mathbf{1}$ and $\mathbf{2}$ are functionalized on the pyridine ring with a tris(2-amidoethyl)amine capping unit (1) or with ethylamide (2). A remarkable decrease of oxygen quenching (40\%) is observed for hemicage $\mathbf{1}$ compared to that of the open complex $\mathbf{2}$. It should be pointed out that the introduction of a capping unit induces a structural change in complex $\mathbf{1}$ with respect to the uncapped complex 2 , as evident from the ${ }^{1} \mathrm{H}-\mathrm{NMR}$. The changes observed in the NMR spectrum are compatible with a higher "twisting" of the helical structure of the $\operatorname{Ir}(\mathrm{ppy})_{3}$ induced by the presence of the capping unit. Some differences have also been observed in the emission spectrum of the two complexes: in particular, a bathochromic shift is observed passing from 2 to 1 . On the other hand, the two compounds show only minor differences in terms of thermodynamic feasibility of oxygen quenching both via energy $\left(\Delta \mathrm{G}_{\mathrm{et}}\right)$ and electron transfer $\left(\Delta \mathrm{G}_{\mathrm{el}}\right)$, thus the thermodynamic effect involved in the different behaviour of the two complexes towards oxygen quenching is quite low. Therefore, the observed decrease of the oxygen quenching between $\mathbf{1}$ and $\mathbf{2}$ can be ascribed to a structural (shielding) effect induced by the presence of the capping unit. A comparison with related compounds functionalized on the phenyl ring and more general conclusions is described in Chapter 5.

\subsection{Experimental section}

The NMR experiments were performed on a Bruker Avance II NMR spectrometer operating at $600.35 \mathrm{MHz}$ for ${ }^{1} \mathrm{H}$ and $150.09 \mathrm{MHz}$ for ${ }^{13} \mathrm{C}$. Chemicals shifts are given in ppm using the residual solvent signal as reference. The multiplicity of the peaks is reported by using the following abbreviations: $\mathrm{s}=$ singlet, $\mathrm{d}=$ doublet, $\mathrm{t}=$ triplet, quint $=$ quintuplet, $\mathrm{m}=$ multiplet. High resolution mass spectra were measured on a Micromass LCT (ESI-TOF) spectrometer. IR spectra were measured on a Thermo Scientific Nicolet ${ }^{\mathrm{TM}} 6700$ FT-IR spectrometer equipped with a Smart Orbit diamond ATR accessory. Main bands are reported and assigned to functional groups by using the following abbreviations: br = broad band; str = stretching band; bend. = bending; def = deformation band. UV-Vis spectra were measured on a Perkin Elmer Lambda $850 \mathrm{UV}$-Vis spectrophotometer by using a quartz cuvette with $1 \mathrm{~cm}$ path length. Steady-state luminescence spectra were measured using an Edinburgh FS900 fluorospectrometer. A $450 \mathrm{~W}$ xenon arc lamp was used as excitation source. Luminescence 
quantum yields at room temperature ( $\Phi$ and $\Phi_{\text {air }}$ ) were evaluated by comparing wavelengthintegrated intensities $\left(I\right.$ or $\left.I_{R}\right)$ of isoabsorptive optically diluted solutions (Abs $\left.<0.1\right)$ with reference to $\left[\mathrm{Ru}(\mathrm{bpy})_{3}\right] \mathrm{Cl}_{2}\left(\Phi_{\mathrm{R}}=0.028\right.$ in air-equilibrated water) by using the equation (4.4)

$$
\Phi=\Phi_{R} \frac{n^{2} I}{n_{R}^{2} I_{R}}
$$

where $n$ and $n_{R}$ are the refractive index of the sample and reference solvent, respectively. ${ }^{22}$ Luminescence lifetimes of the compounds were determined by recording the decay curves of the luminescence intensity at the emission maximum using the TCSPC option on a Horiba Jobin-Yvon Fluoromax 4 instrument and a pulsed solid state LED as excitation source at 462 $\mathrm{nm}$ wavelength. The recorded data were analyzed using the DAS6 software package of Horiba Jobin Yvon. Degassed solutions were prepared by four freeze-pump-thaw cycles. Solutions with different oxygen concentration, suitable for the Stern-Volmer quenching studies, were prepared by using $\mathrm{N}_{2} / \mathrm{O}_{2}$ mixtures prepared with a Brooks 5850S Mass Flow control and by purging the fluorophore solutions for 40 minutes. Electrochemical measurements were done in $N, N$-dimethylformamide (Acros, extra dry over molecular sieves, $99.8 \%$ ) used as arrived without any further purification. Tetra-butylammonium hexafluorophosphate (electrochemical grade, $\geq 99 \%$, Fluka) was used as supporting electrolyte, which was recrystallized from a 1:1 ethanol-water solution and dried at $60{ }^{\circ} \mathrm{C}$ under vacuum. For the electrochemical experiments, a CHI750C Electrochemical Workstation ( $\mathrm{CH}$ Instruments, Inc., Austin, TX, USA) was used. The electrochemical experiments were performed in a glass cell under an Ar atmosphere. To minimize the ohmic drop between the working and the reference electrodes, the feedback correction was employed. The electrochemical experiments were performed by using a $3 \mathrm{~mm}$ diameter glassy carbon disk electrode (homemade from a Tokai glassy carbon rod). Before starting the experiments, the working electrode was polished with a $0.05 \mu \mathrm{m}$ diamond suspension (Metadi Supreme Diamond Suspension, Buehler) and ultrasonically rinsed with ethanol for 5 minutes. The electrode was electrochemically activated in the background solution by means of several voltammetric cycles at $0.5 \mathrm{Vs}^{-1}$ between the anodic and cathodic solvent/electrolyte discharges, until the same quality features were obtained. The reference electrode was a silver quasi-reference electrode (Ag-QRE), which was separated from the catholyte by a glass frit (vycor). The reference electrode was calibrated at the end of each experiment against the ferrocene/ferricenium couple, whose formal potential in $N, N$-dimethylformamide is $0.464 \mathrm{~V}$ against the $\mathrm{KCl}$ saturated calomel electrode (SCE); in the following, all potential values are reported against SCE. A platinum ring or coil served as the counter electrode. 
Oxygen sensitive reactions were carried out by using standard Schlenk techniques. Commercial grade reagents were purchased from Sigma-Aldrich and used without further purification.

6-Phenylnicotinic acid (5). $3 \mathrm{~g}(24.6 \mathrm{mmol})$ of phenylboronic acid, $3.66 \mathrm{~g}(18.2 \mathrm{mmol})$ of 6bromonicotinic acid and $900 \mathrm{mg}(0.78 \mathrm{mmol})$ of tetrakis(triphenylphosphine)palladium(0) were dissolved in $180 \mathrm{ml}$ of a mixture of $\mathrm{Na}_{2} \mathrm{CO}_{3} 0.2 \mathrm{M}$ and acetonitrile (1:1). After several argon/vacuum cycles, the reaction was refluxed for $48 \mathrm{~h}$. The hot reaction mixture was filtered through Celite, the acetonitrile removed and the resulting aqueous solution was extracted several times with $\mathrm{CH}_{2} \mathrm{Cl}_{2}$. The aqueous solution was then acidified with acetic acid and the white precipitate was filtered and dried over $\mathrm{P}_{2} \mathrm{O}_{5}$. Obtained $3.1 \mathrm{~g}(15.6 \mathrm{mmol} ; 85 \%)$ of pure compound.

${ }^{1} \mathrm{H}-\mathrm{NMR}\left(d_{6}\right.$-DMSO): $\delta(\mathrm{ppm}) 9.15(1 \mathrm{H}, \mathrm{s}) ; 8.33(1 \mathrm{H}, \mathrm{d}, J=12 \mathrm{~Hz}) ; 8.15(2 \mathrm{H}, \mathrm{d}, J=6 \mathrm{~Hz})$; $8.10(1 \mathrm{H}, \mathrm{d}, J=12 \mathrm{~Hz}) ; 7.54-7.49(3 \mathrm{H}, \mathrm{m}) .{ }^{13} \mathrm{C}-\mathrm{NMR}\left(d_{6}\right.$-DMSO): See Figure 4.9. IR (neat): 1673 ( $\mathrm{C}=\mathrm{O}$ str. $)$.

ESI-HRMS: calc. for $\mathrm{C}_{12} \mathrm{H}_{9} \mathrm{NO}_{2} 199.063\left(\mathrm{M}^{+}\right)$found 199.065 .

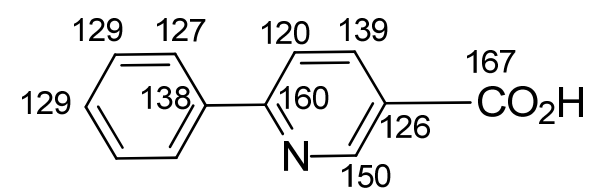

Figure 4.9. ${ }^{13} \mathrm{C}$ chemical shifts of carboxylic acid 5 derived from HMBC/HMQC-NMR data.

Tripodal ligand (6). $600 \mathrm{mg} \quad(3 \mathrm{mmol})$ of $5,620 \mathrm{mg}(3 \mathrm{mmol})$ of $N, N^{\prime}-$ dicyclohexylcarbodiimide and $400 \mathrm{mg}(3 \mathrm{mmol})$ of $\mathrm{N}$-hydroxybenzotriazole were dissolved in $50 \mathrm{ml}$ of dry $N, N^{N}$-dimethylacetamide. $120 \mu \mathrm{l}(0.8 \mathrm{mmol})$ of tris(2-aminoethyl)amine were added dropwise and the resulting mixture was stirred overnight at $60^{\circ} \mathrm{C}$. The reaction mixture was then filtered and added to ca. $400 \mathrm{ml}$ of diethylether under vigorous stirring. The white precipitate was then collected by filtration and washed with hot acetonitrile. Obtained $212 \mathrm{mg}$ $(0.3 \mathrm{mmol} ; 40 \%)$ of pure tripodal ligand.

${ }^{1} \mathrm{H}-\mathrm{NMR}\left(d_{4}-\mathrm{MeOH}\right): 8.90(1 \mathrm{H}, \mathrm{s}) ; 7.93(1 \mathrm{H}, \mathrm{dd}, J=12 \mathrm{~Hz}) ; 7.73(2 \mathrm{H}, \mathrm{d}, J=6 \mathrm{~Hz}) ; 7.43$ $(1 \mathrm{H}, \mathrm{d}, J=6 \mathrm{~Hz}) ; 7.37(1 \mathrm{H}, \mathrm{t}, J=6 \mathrm{~Hz}) ; 7.29(2 \mathrm{H}, \mathrm{t}, J=6 \mathrm{~Hz}) ; 3.60(2 \mathrm{H}, \mathrm{t}, J=6 \mathrm{~Hz}) ; 2.82$ $(2 \mathrm{H}, \mathrm{t}, J=6 \mathrm{~Hz}) .{ }^{13} \mathrm{C}-\mathrm{NMR}\left(d_{4}-\mathrm{MeOH}\right):$ See Figure 4.10. IR (neat): 3396 (NH str.), 2948, 2815 ( $\mathrm{CH}_{2}$ str.), 1630 (C=O str.), 1587 (NH bend.), 1465 ( $\mathrm{CH}_{2}-\mathrm{N}$ str.), 743 (N-C-O str.). ESIHRMS: calc. $690.319\left(\mathrm{M}+\mathrm{H}^{+}\right)$found 690.320. 


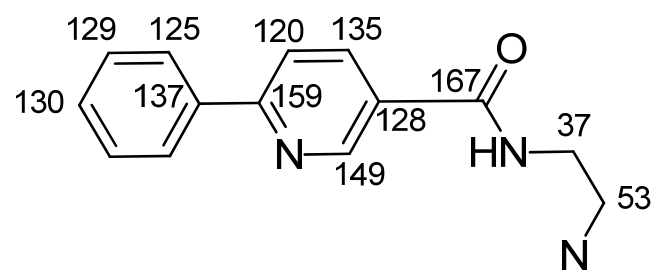

Figure 4.10. ${ }^{13} \mathrm{C}$ chemical shifts of tripodal ligand 6 derived from HMBC/HMQC-NMR.

$N$-Ethyl-6-phenylnicotinamide (7). $1 \mathrm{~g}(5 \mathrm{mmol})$ of 5 and $1.9 \mathrm{~g}(12.5 \mathrm{mmol})$ of 1-ethyl-3(3-dimethylaminopropyl)carbodiimide were dissolved in $60 \mathrm{ml}$ of a mixture of $\mathrm{CH}_{2} \mathrm{Cl}_{2}$ :pyridine (7:3). $3 \mathrm{ml}$ of ethylamine (2.0 $\mathrm{M}$ in THF) were added dropwise and the mixture was stirred at RT. The solvent was removed under vacuum and the crude was then suspended in water and extracted with ethyl acetate. The organic phase was washed with a sat. solution of $\mathrm{CuSO}_{4}$, then with sat. $\mathrm{NH}_{4} \mathrm{Cl}$ and eventually with brine. The organic phase

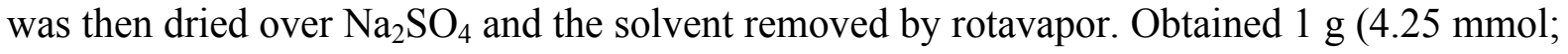
$85 \%$ ) of pure compound.

${ }^{1} \mathrm{H}-\mathrm{NMR}\left(d_{6}\right.$-DMSO): $9.21(1 \mathrm{H}, \mathrm{s}) ; 8.38(1 \mathrm{H}, \mathrm{d}, J=6 \mathrm{~Hz}) ; 8.21(2 \mathrm{H}, \mathrm{d}, J=6 \mathrm{~Hz}) ; 8.13(1 \mathrm{H}$, $\mathrm{d}, J=6 \mathrm{~Hz}) ; 7.57-7.50(3 \mathrm{H}, \mathrm{m}) ; 3.43(2 \mathrm{H}, \mathrm{q}, J=6 \mathrm{~Hz}) ; 1.21(3 \mathrm{H}, \mathrm{t}, J=6 \mathrm{~Hz}) .{ }^{13} \mathrm{C}-\mathrm{NMR}\left(d_{4^{-}}\right.$ MeOH): See Figure 4.11. IR (neat): 3322 (N-H str.), 2975, 2931, 2877 (CH2/ $\mathrm{CH}_{3}$ str.), 1627 (C=O str.), 1522 ( $\mathrm{N}-\mathrm{H}$ bend.), 1469 ( $\mathrm{CH}_{2}-\mathrm{N}$ str.), 746 (N-C-O str.). ESI-HRMS: calc. $226.111\left(\mathrm{M}^{+}\right)$found 226.113.

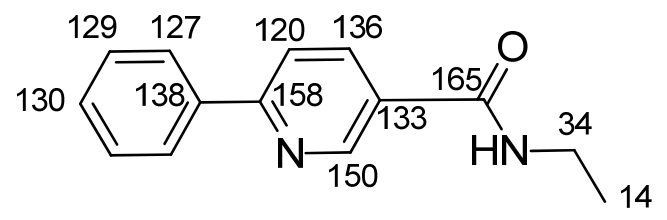

Figure 4.11. ${ }^{13} \mathrm{C}$ chemical shifts of ligand 7 derived from HMBC/HMQC-NMR.

Ir(III) hemicaged complex (1). $100 \mathrm{mg}(0.14 \mathrm{mmol})$ of $6,41 \mathrm{mg}(0.14 \mathrm{mmol})$ of $\mathrm{IrCl}_{3}$ and $89 \mathrm{mg}(0.4 \mathrm{mmol})$ of $\mathrm{CF}_{3} \mathrm{CO}_{2} \mathrm{Ag}$ were stirred in $10 \mathrm{ml}$ of ethylene glycol previously purged with nitrogen. After several cycles of argon/vacuum, the resulting mixture was refluxed overnight. The reaction mixture was cooled down at room temperature, diluted with water and extracted several times with ethyl acetate. The organic phases were collected, washed with brine and dried over $\mathrm{Na}_{2} \mathrm{SO}_{4}$. The product was then purified by column chromatography $\left(\mathrm{SiO}_{2}, \mathrm{CH}_{2} \mathrm{Cl}_{2}: \mathrm{MeOH}\right.$ 95:5). 
${ }^{1} \mathrm{H}-\mathrm{NMR}\left(d_{2}-\mathrm{CH}_{2} \mathrm{Cl}_{2}\right): 7.99(1 \mathrm{H}, \mathrm{d}, J=12 \mathrm{~Hz}), 7.96(1 \mathrm{H}, \mathrm{d}, J=6 \mathrm{~Hz}), 7.76(1 \mathrm{H}, \mathrm{s}), 7.71(1 \mathrm{H}$, m), $7.02(1 \mathrm{H}, \mathrm{d}, J=6 \mathrm{~Hz}), 6.95-6.96(2 \mathrm{H}, \mathrm{m}), 6.34(1 \mathrm{H}, \mathrm{t}, J=6 \mathrm{~Hz}), 3.62(1 \mathrm{H}, \mathrm{d}, J=18 \mathrm{~Hz})$, $3.41(1 \mathrm{H}, \mathrm{t}, J=12 \mathrm{~Hz}), 2.91(1 \mathrm{H}, \mathrm{t}, J=6 \mathrm{~Hz}), 2.30(1 \mathrm{H}, \mathrm{d}, J=12 \mathrm{~Hz}) .{ }^{13} \mathrm{C}-\mathrm{NMR}\left(d_{2^{-}}\right.$ $\mathrm{CH}_{2} \mathrm{Cl}_{2}$ ): See Figure 4.12. IR (neat): 3274 (br, NH str.), 3041 (CH str.), 2925, $2815\left(\mathrm{CH}_{2}\right.$ str.), 1633 (C=O str.), 1539 (NH bend.), 1471 ( $\mathrm{CH}_{2}-\mathrm{N}$ str.), 748 (N-C-O str.). ESI-HRMS: calc. $880.259\left(\mathrm{M}+\mathrm{H}^{+}\right)$found 880.260 .

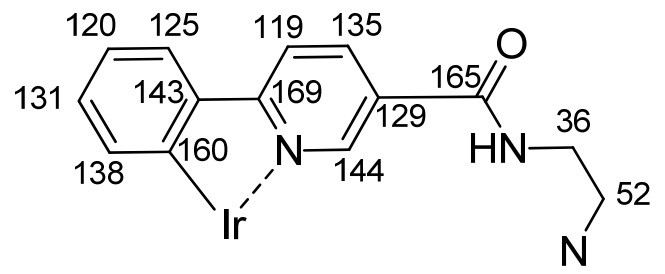

Figure 4.12. ${ }^{13} \mathrm{C}$ chemical shifts of hemicaged complex 1 derived from HMBC/HMQCNMR.

Ir(III) open complex 2. $100 \mathrm{mg}$ of $7(0.42 \mathrm{mmol})$ and $66 \mathrm{mg}(0.22 \mathrm{mmol})$ of $\mathrm{IrCl}_{3}$ were dissolved in a mixture of 2-ethoxyethanol and water (3:1). After several cycles of argon/vacuum, the mixture was refluxed overnight. The reaction mixture was cooled down at room temperature, half of the solvent was evaporated and the resulting solution was poured on ice. The resulting precipitate was filtered, washed with water and diethyl ether and dried under vacuum. The solid (ca. $70 \mathrm{mg}$ ) was then suspended in toluene, $36 \mathrm{mg}$ of ligand $(0.15$ $\mathrm{mmol})$ and $80 \mathrm{mg}(0.30 \mathrm{mmol})$ of $\mathrm{CF}_{3} \mathrm{SO}_{3} \mathrm{Ag}$ were added, several cycles argon/nitrogen were performed in order to remove oxygen and the mixture was refluxed overnight under inert atmosphere. The crude was washed with methanol and then dissolved in $\mathrm{CH}_{2} \mathrm{Cl}_{2}(10 \%$ $\mathrm{MeOH})$, filtered through Celite and eventually purified by preparative TLC $\left(\mathrm{CH}_{2} \mathrm{Cl}_{2}: \mathrm{MeOH}\right.$ 95:5)

${ }^{1} \mathrm{H}-\mathrm{NMR}\left(d_{7}\right.$-DMF): $8.60(1 \mathrm{H}, \mathrm{t}, J=6 \mathrm{~Hz}), 8.35(1 \mathrm{H}, \mathrm{d}, J=6 \mathrm{~Hz}), 8.31-8.28(2 \mathrm{H}, \mathrm{m}), 7.90$ $(1 \mathrm{H}, \mathrm{d}, J=12 \mathrm{~Hz}), 6.87(1 \mathrm{H}, \mathrm{t}, J=6 \mathrm{~Hz}), 6.79-6.74(2 \mathrm{H}, \mathrm{m}), 3.27$ (2H, quint. , $J=6 \mathrm{~Hz})$, $1.08(3 \mathrm{H}, \mathrm{t}, J=6 \mathrm{~Hz}) .{ }^{13} \mathrm{C}-\mathrm{NMR}\left(d_{7}-\mathrm{DMF}\right)$ : See Figure 4.13. IR (neat): 3290 (N-H str.), 3035 (CH str.), 2970, 2930, 2873 ( $\mathrm{CH}_{3} / \mathrm{CH}_{2}$ str.), 1635 (C=O str.), 1540 (N-H bend.), $1473\left(\mathrm{CH}_{2^{-}}\right.$ $\mathrm{N}$ str.), 748 (N-C-O str.). ESI-HRMS: calc. $891.261\left(\mathrm{M}+\mathrm{Na}^{+}\right)$found 891.262. 


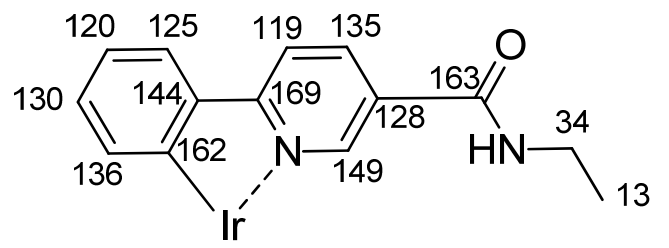

Figure 4.13. ${ }^{13} \mathrm{C}$ chemical shifts of open complex 2 derived from HMBC/HMQC-NMR.

\subsection{References}

(1) Barigelletti, F.; De Cola, L.; Balzani, V.; Belser, P.; Von Zelewsky, A.; Voegtle, F.; Ebmeyer, F.; Grammenudi, S. J. Am. Chem. Soc. 1989, 111, 4662-4668.

(2) Abdel-Shafi, A. A.; Beer, P. D.; Mortimer, R. J.; F., W. Helv. Chim. Acta 2001, 84, 2784-2795.

(3) Balzani, V.; Bolletta, F.; Scandola, F. J. Am. Chem. Soc. 1980, 102, 2152-2163.

(4) Flamigni, L.; Barbieri, A.; Sabatini, C.; Ventura, B.; Barigelletti, F. In Photochemistry and Photophysics of Coordination Compounds II 2007; Vol. 281, p 143-203.

(5) Gao, R. M.; Ho, D. G.; Hernandez, B.; Selke, M.; Murphy, D.; Djurovich, P. I.; Thompson, M. E. J. Am. Chem. Soc. 2002, 124, 14828-14829.

(6) Beeston, R. F.; Larson, S. L.; Fitzgerald, M. C. Inorg. Chem. 1989, 28, 4187-4189.

(7) Demas, J. N.; Diemente, D.; Harris, E. W. J. Am. Chem. Soc. 1973, 95, 6864-6865.

(8) Vlcek, A.; Zalis, S. Coord. Chem. Rev. 2007, 251, 258-287.

(9) Hay, P. J. J. Phys. Chem. A 2002, 106, 1634-1641.

(10)Lowry, M. S.; Bernhard, S. Chem. Eur. J. 2006, 12, 7970-7977.

(11)Xu, W. Y.; Jain, A.; Betts, B. A.; Demas, J. N.; DeGraff, B. A. J. Phys. Chem. A 2002, 106, 251-257.

(12) Albuquerque, R. Q.; Popovic, Z.; De Cola, L.; Calzaferri, G. ChemPhysChem 2006, 7, 1050-1053.

(13)Miyaura, N.; Suzuki, A. Chem. Rev. 2002, 95, 2457-2483.

(14) Tamayo, A. B.; Alleyne, B. D.; Djurovich, P. I.; Lamansky, S.; Tsyba, I.; Ho, N. N.; Bau, R.; Thompson, M. E. J. Am. Chem. Soc. 2003, 125, 7377-7387.

(15)Lamansky, S.; Djurovich, P.; Murphy, D.; Abdel-Razzaq, F.; Lee, H. E.; Adachi, C.; Burrows, P. E.; Forrest, S. R.; Thompson, M. E. J. Am. Chem. Soc. 2001, 123, 4304-4312.

(16) Holzer, W.; Penzkofer, A.; Tsuboi, T. Chem. Phys. 2005, 308, 93-102.

(17) Oyler, K. D.; Coughlin, F. J.; Bernhard, S. J. Am. Chem. Soc. 2007, 129, 210-217.

(18)Juris, A.; Balzani, V.; Barigelletti, F.; Campagna, S.; Belser, P.; Von Zelewsky, A. Coord. Chem. Rev. 1988, 84, 85-277.

(19)Lakowicz, J. R. Principles of Fluorescence Spectroscopy; Springer: Singapore, 2006.

(20) Bodesheim, M.; Schutz, M.; Schmidt, R. Chem. Phys. Lett. 1994, 221, 7-14.

(21) Mulazzani, Q. G.; Sun, H.; Hoffman, M. Z.; Ford, W. E.; Rodgers, M. A. J. J. Phys. Chem. 1994, 98, 1145-1150.

(22) Montalti, M.; Credi, A.; Prodi, L.; Gandolfi, M. T. Handbook of Photochemistry; CRC Press: Boca Raton, 2006. 
Chapter 4 


\title{
Chapter 5
}

There are two possible outcomes: if the result confirms the hypothesis, then you've made a measurement. If the result is contrary to the hypothesis, then you've made a discovery.

E. Fermi

\section{Understanding luminescence quenching by oxygen of $\operatorname{Ir}($ III)- hemicaged complexes: a systematic approach $(2)$ *}

\begin{abstract}
In this Chapter, the synthesis and structural characterization in solution by NMR spectroscopy of two tris(phenylpyridine)-based Ir(III) complexes is reported. The complexes are functionalized on the phenyl rings with amide moieties substituted with either a tris(2amidoethyl)amine or an ethylamide in order to obtain two compounds with a hemicaged and open (without capping unit but with similar functional groups on the ligand) structure. These compounds are part of a systematic investigation of the structure-related effect on oxygen quenching of the fluorescence. Besides the absorption and emission properties, the behaviour of the two compounds towards oxygen quenching is investigated through Stern-Volmer plots and evaluation of the thermodynamic parameters involved in the oxygen quenching process. Both the hemicaged and open compound shows a similar behaviour towards oxygen quenching of luminescence. By comparing the photophysical data with those of the related two complexes 1 and 2 reported in Chapter 4, which have the same substituents but on the pyridines' side of the $\operatorname{Ir}(\mathrm{ppy})_{3}$ moiety, a general picture of the structure-quenching relationship is obtained. Shielding of selected atoms of the pyridine ring (where the LUMO orbital is mostly localized) with a capping unit results in a remarkable (40\%) decrease of oxygen quenching. Conversely, the shielding of atoms of the phenyl ring (where the HOMO orbital is mostly localized) does not induce any change in the oxygen quenching.
\end{abstract}

\footnotetext{
* Part of this chapter has been submitted for publication: A. Ruggi, M. Mauro, F. Polo, D. N. Reinhoudt, L. De Cola and A. H. Velders, submitted.
} 


\subsection{Introduction}

In Chapter 4 the structural shielding of selected atoms in the pyridine ring of two tris(phenylpyridine)-based $\operatorname{Ir}(\mathrm{III})$ complexes functionalized with amide groups and its effect on the degree of oxygen quenching of luminescence have been discussed. More in detail, it has been proven that by introducing a capping unit on the pyridine ring (where the Lowest Occupied Molecular Orbital (LUMO) is mostly localised) it is possible to reduce the oxygen quenching. By using an Ir(III) complex functionalised with amides groups substituted with a tris(ethyl)amine (Tren) capping unit on the pyridine ring, it is possible to achieve a $40 \%$ decrease of oxygen quenching compared to the open structure in which the amides are functionalized with ethylamine. Moreover, on the basis of the thermodynamic feasibility of energy and electron transfer, it has been proven that the difference in oxygen quenching of luminescence between hemicaged and open complexes does derive from a structural (intramolecular) shielding of the LUMO orbital. The effect derived from shielding of the atoms where the Highest Occupied Molecular Orbital (HOMO) is localised is expected to contribute to the definition of a general theory concerning the possibility of tuning the oxygen quenching of luminescence by (intramolecular) shielding of selected atoms. ${ }^{1,2}$ In this Chapter the synthesis, characterization and photophysical properties of the two phenylpyridine-based Ir(III) complexes, functionalized on the phenyl ring with amide groups, is reported. In order to obtain a hemicaged and open complex with a similar structure to that of the compounds 1 and 2 reported in Chapter 4, the amides were functionalized with a tris(ethyl)amine capping unit or with an ethylamine moiety, respectively. The oxygen quenching of the fluorescence was investigated with a Stern-Volmer analysis and evaluated using the thermodynamic parameters involved in the possible quenching pathways (i.e. energy transfer and electron transfer), giving a clear evidence of the structure-dependent shielding against oxygen quenching. ${ }^{3}$

\subsection{Design and synthesis}

The design of $\mathbf{1}, \mathbf{2}, \mathbf{3}$, and $\mathbf{4}$ has been discussed in Chapter 4 (Section 4.2) and, for the sake of clarity, the numbering of these four related molecules has been kept the same in the Chapters 4 and 5 . The shielding effect exerted by the introduction of a capping unit on the phenyl ring is investigated in two molecules, namely the hemicaged (3) and the open (4) structure (Figure 5.1). These molecules are expected to show no difference in terms of oxygen quenching of the fluorescence, since the LUMO orbital is mostly localized on the pyridine ring and, 
therefore, it is expected not to be affected by the presence of the capping unit on the phenyl ring. It is clear from the results described in Chapter 4 that the functional groups directly connected to the phenylpyridine ligands play a crucial role in the determination of the thermodynamic feasibility of oxygen quenching (both via energy and electron transfer). Therefore, complexes $\mathbf{3}$ and $\mathbf{4}$ were designed in order to have the same functional groups (i.e. amides) connected to the phenylpyridine ligands, differing only in the substituents on the amides: the tris(ethyl)amine capping unit (3) or the ethyl moiety (4), respectively.

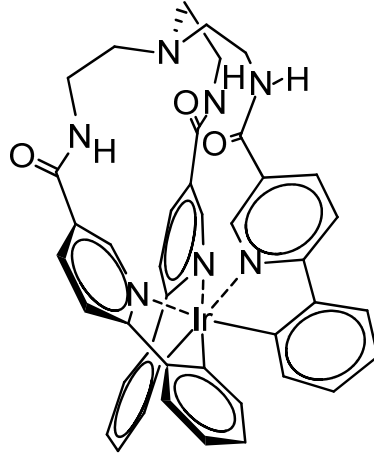

1

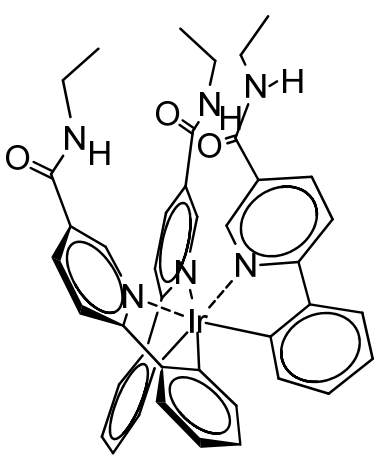

2

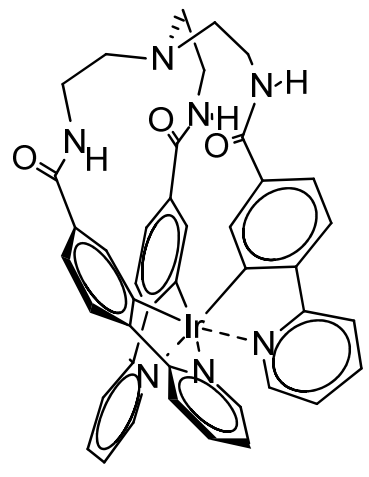

3

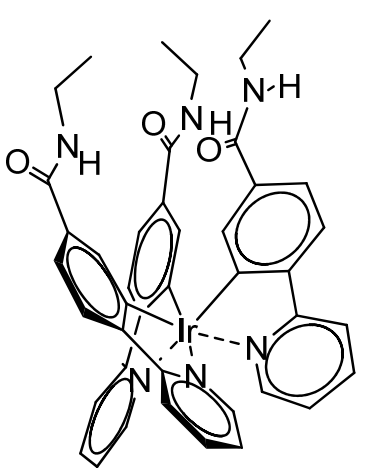

4

Figure 5.1. Structure of hemicaged $(\mathbf{1}, 3)$ and open $(2,4) \operatorname{Ir}(\mathrm{III})$ complexes functionalized on the pyridine $(\mathbf{1}, \mathbf{2})$ and phenyl $(3,4)$ ring.

Complexes $\mathbf{3}$ and $\mathbf{4}$ were synthesized using the same synthetic strategy followed for the compounds reported in Chapter 4. Details concerning the synthetic procedures are reported in the experimental section.

\subsection{Characterization}

All the intermediates and the target complexes $\mathbf{3}$ and $\mathbf{4}$ were characterized by IR and NMR spectroscopy and mass spectrometry. In this section only the NMR spectra of the complexes 3 and $\mathbf{4}$ are discussed. The ${ }^{1} \mathrm{H}$ and ${ }^{13} \mathrm{C}$ chemical shifts of the intermediates are reported in the experimental section together with the most significative IR signals and their interpretation. Analogous to the hemicaged complex 1 described in Chapter 4, the ${ }^{1} \mathrm{H}-\mathrm{NMR}$ spectrum of hemicaged complex 3 shows that, upon iridium(III) complexation, the four protons on each ethyl linker of the hemicaged ligand become magnetically non-equivalent (thus resulting in four different peaks in the ${ }^{1} \mathrm{H}-\mathrm{NMR}$ spectrum) as a consequence of the increased rigidity of the ligand. On the other hand, analogous to what was observed for the open complex 2 
described in Chapter 4, the ${ }^{1}$ H-NMR spectrum of the open complex 4 does not show any nonequivalent methylene or methyl protons, due to the rotational freedom of the ethyl moieties. The presence of only one set of NMR signals in the spectra of both complexes 3 and 4 proves that the 3-fold symmetry expected for fac-complexes is still present.

The presence of the capping unit induces a major change in the chemical shift of the amide proton (NH). In hemicage 3 the NH proton shows a $1.1 \mathrm{ppm}$ upfield shift with respect to the open complex $\mathbf{4}$, whilst a downfield shift $(0.13 \mathrm{ppm})$ passing from $\mathbf{4}$ to $\mathbf{3}$, is observed for proton $\mathrm{Ha}$, which is located between the amide and the carbon atom connected to the Ir. A similar upfield shift of $\mathrm{NH}$ has also been observed between the open (2) and the hemicaged (1) complexes described in Chapter 4. This is probably due to the locally different polarity induced by the presence of the $\mathrm{N}$ atom in the capping unit. However, the downfield shift observed for proton Ha passing from the open (4) to the hemicaged (3) complex (1 ppm) is much higher than the shift observed in complexes $\mathbf{2}$ and $\mathbf{1}$ in Chapter 4, where the Ha proton located between the amide and the atom connected to Ir showed an upfield shift of $0.4 \mathrm{ppm}$. The reason for this (different) behaviour is not clear yet. A possible explanation is that the presence of the capping unit induces a different degree of "twisting" of the helical structure of the $\operatorname{Ir}(\text { ppy })_{3}$ core, thus resulting in a deshielding of proton Ha by the phenyl rings on the other branches of the hemicage. 


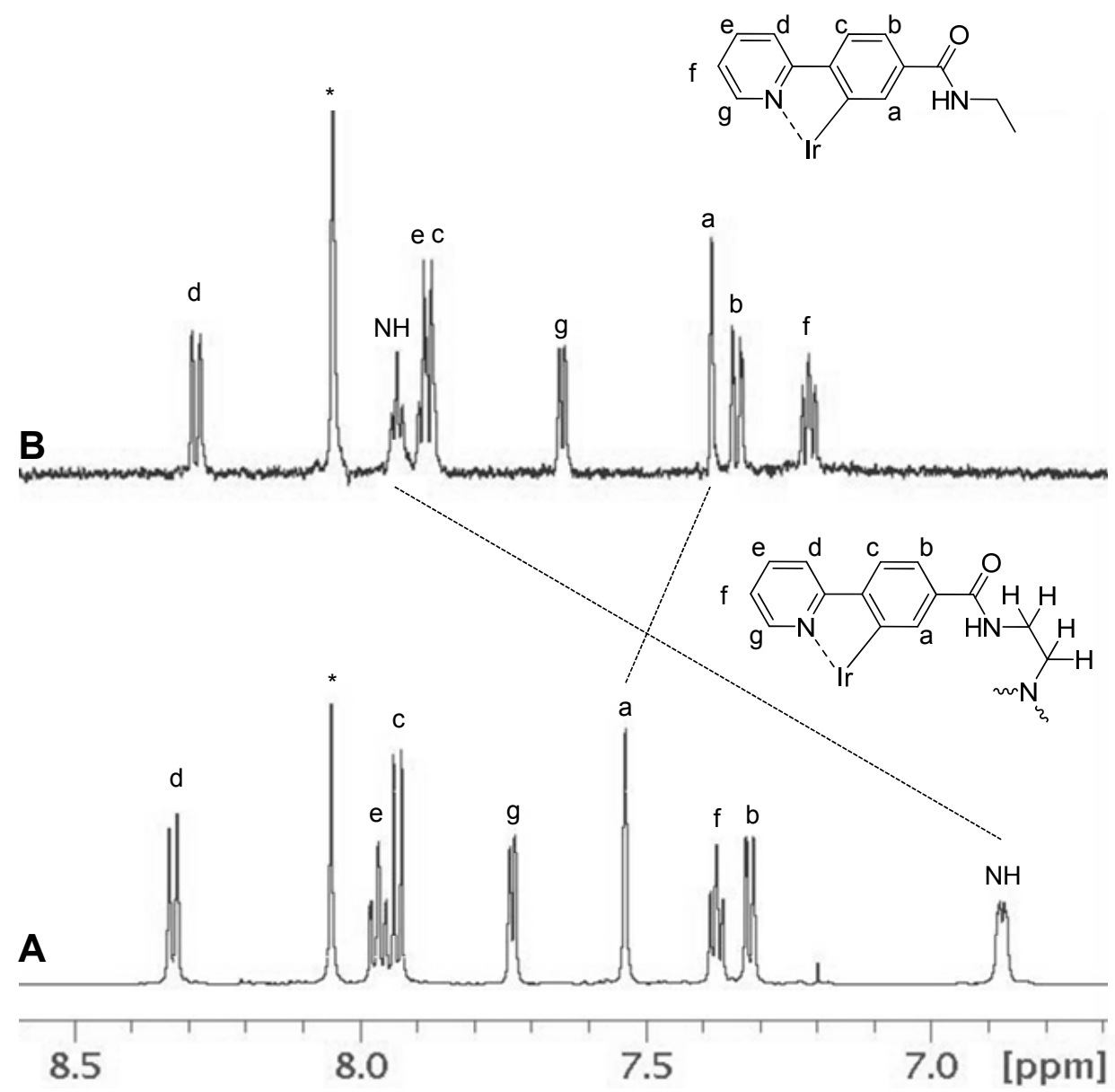

Figure 5.2. A) ${ }^{1} \mathrm{H}-\mathrm{NMR}$ spectra of hemicaged iridium complex $3(\mathrm{~A})$ and open iridium complex $4(\mathrm{~B}) . d_{7}$-DMF. $*=$ residual solvents.

The geometry of the hemicaged complex was further investigated with a series of 2D-NMR experiments (COSY, NOESY, HMBC and HMQC). As it can be observed in Figure 5.3, analogous to what was found for the hemicaged complexes shown in Chapter 3 and 4, the aromatic-aliphatic region of the NOESY spectrum shows the coupling between the amide proton $(\mathrm{NH})$ and three non-equivalent aliphatic protons $\mathbf{H h}, \mathbf{H h}$ ' and $\mathbf{H i}$ on the ethyl linker The fourth proton $\left(\mathbf{H i}^{\prime}\right)$ does not give any through-space coupling, likely because of its longer distance from the amide proton. 

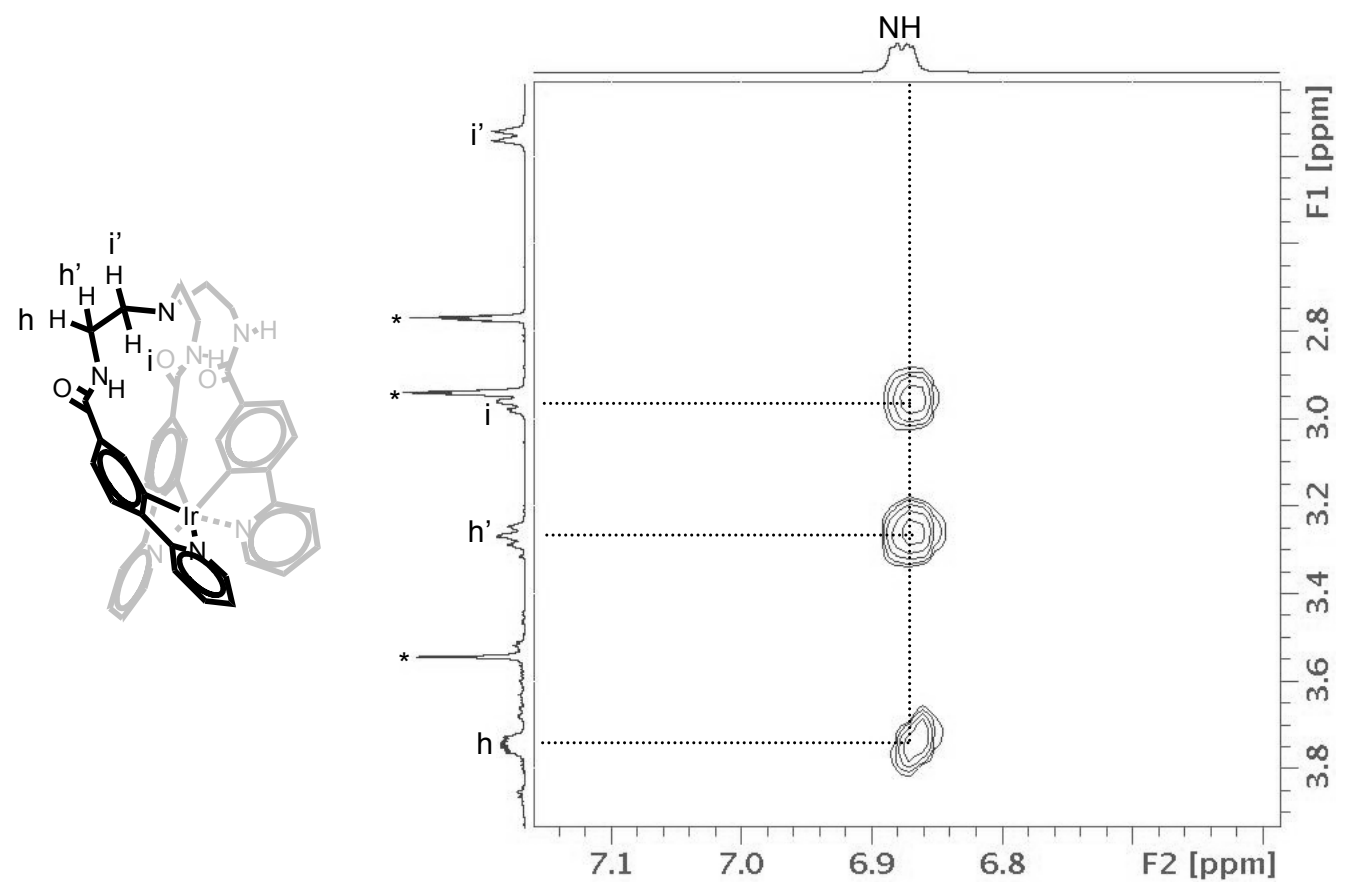

Figure 5.3. HH-NOESY spectrum of the hemicaged complex 3. $d_{7}$-DMF. Region of the aliphatic-aromatic protons. $*=$ residual solvents.

Besides the characteristic inter-ring cross-peaks between protons Hc and Hd (Figure 5.4), located on the pyridine and phenyl ring, the analysis of the aromatic region of the NOESY spectrum of 3 reveals the orientation of the amide moiety. The amide proton $\mathrm{NH}$ gives a cross-peak with the aromatic proton Ha. Therefore, the amide proton NH is oriented towards the inside of the molecule. This orientation is analogous to the orientation of the amide proton observed in the hemicaged complex described in Chapter 3. Moreover, also the amide proton located on the phenyl side of the caged complex reported in Chapter 3 is oriented towards the inner side of the molecule. On the other hand, a comparison of the orientation of the amide proton reveals a major structural difference between the hemicaged complexes 1 (discussed in Chapter 4) and 3. In the latter, the NH proton gives a through-space coupling with both the internal (Ha) and the external $(\mathbf{H b})$ protons in ortho- position with respect to the amide group, whilst in the former the $\mathrm{NH}$ proton gives a coupling only with the internal proton $\mathbf{H a}$. Therefore, the amide group in the hemicaged complex $\mathbf{3}$ is coplanar with the phenyl ring; the $\mathrm{NH}$ moiety is oriented towards the inside of the molecule, whilst the carbonyl is most likely oriented towards the outside of the molecule. The structure of hemicage 1 (discussed in Chapter 4) shows the carbonyl strongly conjugated (thus coplanar) with the pyridine ring, whilst the NH moiety is likely bent out of the plane of the pyridine ring. 

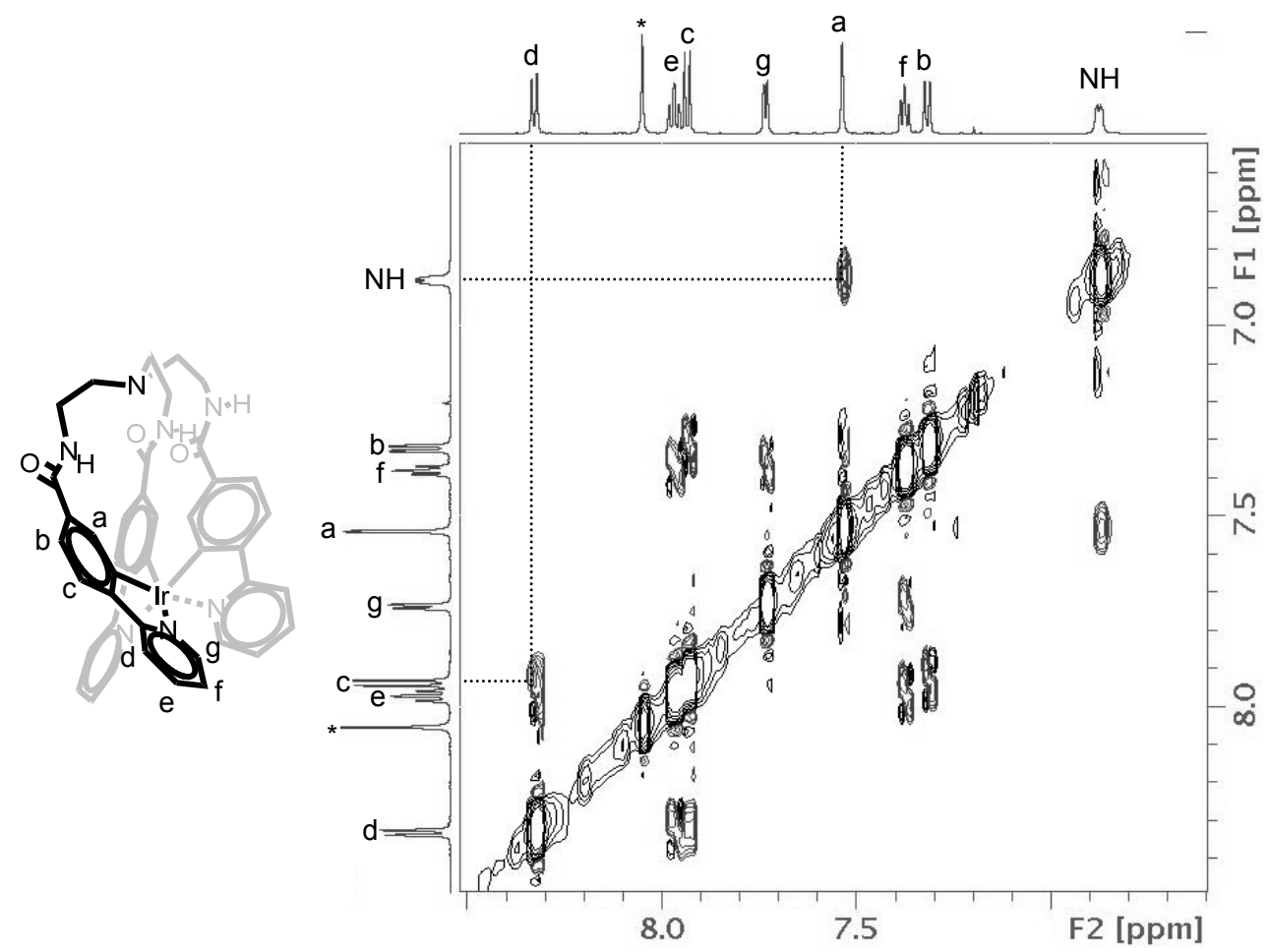

Figure 5.4. HH_NOESY spectrum of hemicaged complex 3. $d 7$-DMF. Region of the aromatic protons. $*$ residual solvents.

The notable difference in the orientation of the amide group with respect to the aromatic plane is probably due to a different degree of "twisting" helical $\operatorname{Ir}(\mathrm{ppy})_{3}$ core. This difference in geometrical distortion between hemicage $\mathbf{1}$ and $\mathbf{3}$ could also explain the different behaviour shown by the proton Ha located between the amide moiety and the atom connected to Ir (vide supra): the high twisting hypothesized for hemicage 1 could cause a magnetic shielding of proton Ha, which would likely face the aromatic ring on another branch of the hemicage. On the other hand, the low twisting of hemicage 3 could induce a magnetic deshielding of the proton Ha, which would likely face only the edge of the aromatic ring located on another branch of the complex. This difference in twisting for the two hemicaged complexes $\mathbf{1}$ and $\mathbf{3}$ is in agreement with the absorption data which shows a bathochromic shift of the MLCT band of $\mathbf{1}$ with respect to the open complex $\mathbf{2}$ and a substantially identical position of the MLCT band of $\mathbf{3}$ with respect to $\mathbf{4}$ (vide infra). 


\subsection{Photophysical properties}

Optical absorption. The UV-Vis absorption spectra of complexes $\mathbf{3}$ and $\mathbf{4}$ are shown in Figure 5.5 and their absorption maxima and shoulder are reported in Table 5.1. A strong absorption band $\left(\varepsilon \geq 10^{4} \mathrm{M}^{-1} \mathrm{~cm}^{-1}\right)$ between 280 and $300 \mathrm{~nm}$ (which can be assigned to ligand centred $\pi \rightarrow \pi^{*}$ transitions) is observed for both complexes, together with weaker absorption bands $\left(\varepsilon \leq 10^{3} \mathrm{M}^{-1} \mathrm{~cm}^{-1}\right.$ ) between 350 and $450 \mathrm{~nm}$ (which are probably due to spin-allowed singlet-to-singlet metal to ligand charge transfer ( $\left.{ }^{1} \mathrm{MLCT}\right)$ transitions). The weak shoulder at lower energies (centred around $470 \mathrm{~nm}$ ) can be assigned to spin-forbidden singlet-to-triplet transitions ${ }^{3}$ MLCT, which are observed in Ir(III) complexes because of the strong spin-orbit coupling of the iridium atom. Compared to the hemicaged (1) and open (2) complexes reported in Chapter 4, complexes 3 and $\mathbf{4}$ show a lower degree of red shift of their absorption bands with respect to the archetypical $\operatorname{Ir}(\text { ppy })_{3}$ : the hemicaged complex 1 shows a ${ }^{1}$ MLCT band with a maximum at $420 \mathrm{~nm}$, the same band shows a maximum at $387 \mathrm{~nm}$ in the hemicaged complex 3, whilst $\operatorname{Ir}(\text { ppy })_{3}$ has a maximum of its ${ }^{1}$ MLCT band at $377 \mathrm{~nm}$. The reason for this difference is the different degree of stabilization (i.e. energy decrease) of the LUMO (in hemicage 1) or the HOMO (in hemicage 3) orbitals due to the atomic contributions given by the carbons where the amide substituent is located. Generally speaking, in $\operatorname{Ir}(\mathrm{ppy})_{3}$ derivatives the LUMO orbital is more affected by substitution effects on the pyridine's atom in para- to the bridge between the rings, since that carbon gives a high contribution to the LUMO orbital. On the other hand, the introduction of a substituent in para- position with respect to the bridge-head atom results in a lower effect on the HOMO orbital, since the HOMO orbital has a node on that atom. ${ }^{5}$ 


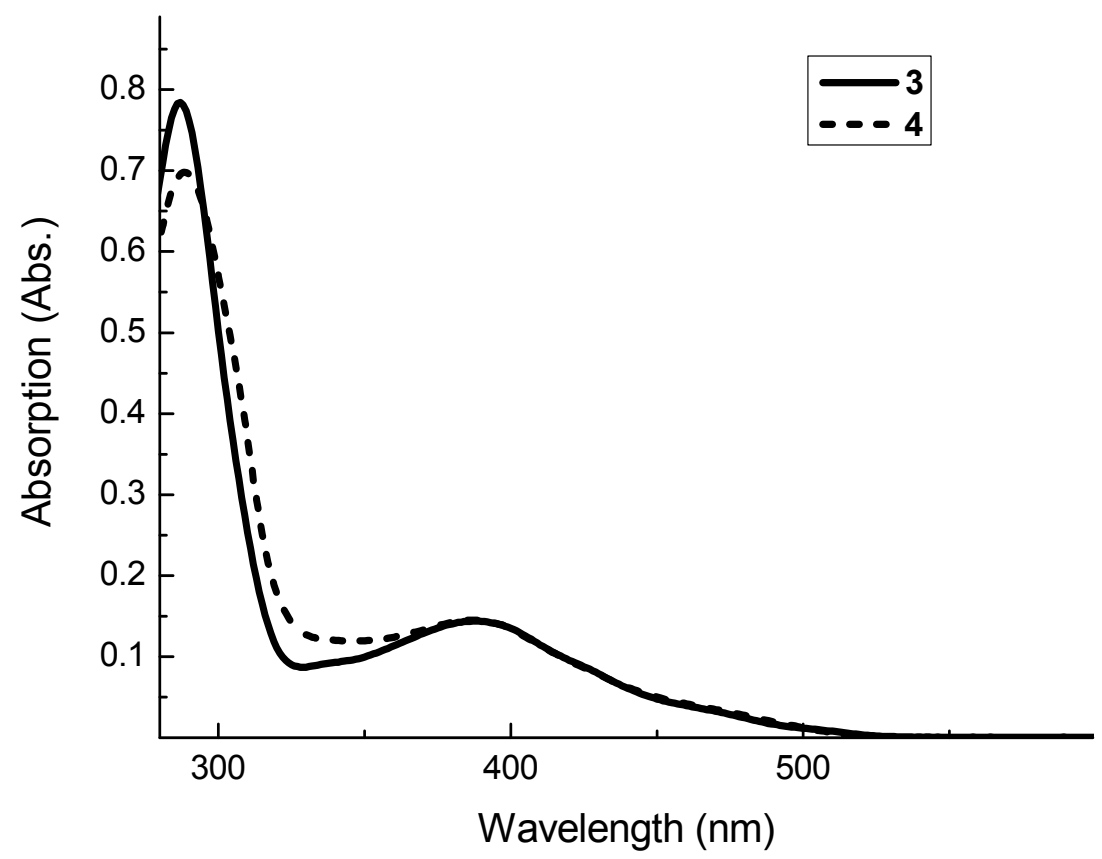

Figure 5.5. UV-Vis absorption of the hemicaged complex 3 (solid line) and open complex 4 (dashed line) in DMF at room temperature.

Complexes 3 and $\mathbf{4}$ show the same MLCT absorption bands, indicating the substantial equivalence of the chromophoric units in these complexes. This observation is in agreement with the low twisting degree of the helical structure of the $\operatorname{Ir}(\mathrm{ppy})_{3}$ core hypothesized for hemicage 3 with respect to open complex 4. Contrarily, in the case of the pyridinefunctionalized complexes 1 and $\mathbf{2}$ reported in Chapter 4, an increased twisting degree for the open complex 2 with respect to the hemicaged complex 1 has been hypothesized. This geometrical distortion is observed also in the absorption spectrum of $\mathbf{1}$, which shows a bathochromic shift of the MLCT maximum with respect to 2 .

Table 5.1. UV-Vis absorption data of the complexes and their molar absorption coefficient in $\mathrm{DMF}$ at room temperature. sh. $=$ shoulder

\begin{tabular}{|c|c|}
\hline Compound & $\begin{array}{c}\text { Absorption } \\
\lambda(\mathbf{n m}),\left(\varepsilon\left(\mathbf{1 0}^{\mathbf{3}} \mathbf{M}^{-\mathbf{1}} \mathbf{c m}^{\mathbf{- 1}}\right)\right)\end{array}$ \\
\hline $\mathbf{1}$ & $292(45), 302($ sh. 15), 361 (sh. 5.3), $420(6.5), 487($ sh. 2.1) \\
\hline $\mathbf{2}$ & $297(32), 400(6.9), 487$ (sh. 2.1) \\
\hline $\mathbf{3}$ & $287(52), 387(9.4), 474$ (sh. 2.1) \\
\hline $\mathbf{4}^{*}$ & $288(45), 387(6.3), 474$ (sh. 2.6) \\
\hline
\end{tabular}

* = due to the low solubility of $\mathbf{4}$ in DMF, molar absorption coefficients of this compound are only estimated. 
Luminescence. An intense luminescence at room temperature is observed for both complexes 3 and 4 (Figure 5.6 A). As expected, the presence of electron-withdrawing groups on the phenyl ring induces only a slight red shift of the emission compared to the archetypical $\operatorname{Ir}(\mathrm{ppy})_{3}\left(\lambda_{\mathrm{em}}=523 \mathrm{~nm}\right.$ in DMF) as a consequence of the decreased energy of the HOMO orbital. ${ }^{6}$ Compared to complexes 1 and $\mathbf{2}$ reported in Chapter 4, the emission of complexes $\mathbf{3}$ and 4 is more blue shifted. For instance the hemicage 3 shows an emission maximum at 532 $\mathrm{nm}$ whilst the emission maximum of hemicage 1 is at $580 \mathrm{~nm}$. This different degree of stabilization of the LUMO (in the case of hemicage 1) or HOMO (in the case of hemicage 3 ) orbital is due to the different effect of the substituent on both orbitals: as already observed from UV-Vis data, the HOMO is relatively less affected than the LUMO by the introduction of an electron-withdrawing group in the para- position. The emission profiles of $\mathbf{3}$ and $\mathbf{4}$ recorded at room temperature (Figure 5.6 A) show a certain degree of vibronic resolution, which is likely due to a higher ${ }^{3} \mathrm{LC}$ contribution. ${ }^{7}$ The structure-less emission band shown by complexes 1 and $\mathbf{2}$ reported in Chapter 4 indicates that the excited state of those complexes has mainly a ${ }^{3}$ MLCT character. The hemicaged complex 3 shows a slight blue shift of the emission compared to the open complex $\mathbf{4}$, which is probably due to the locally different polarity induced by the presence of the $\mathrm{N}$ atom of the capping unit. ${ }^{11}$

Further indications concerning the energy and the character of the emitting states can be obtained from the analysis of the emission occurring at low temperature (77K) (Figure 5.6 B). The photophysical properties of the complexes are summarized in Table 5.2 together with those of the complexes $\mathbf{1}$ and $\mathbf{2}$ for comparison purposes. Both the complexes $\mathbf{3}$ and $\mathbf{4}$ show a blue shift of the emission maximum at $77 \mathrm{~K}$ with respect to that at room temperature, which is an indication of the main ${ }^{3}$ MLCT nature of the emitting state. ${ }^{8}$ The emission profiles of the hemicaged complex 3 and the open complex 4 recorded at 77K (Figure 5.6 B) show enhanced vibronic resolution, owing to the temperature effect. ${ }^{9}$ Also in this case, a comparison of the emission profiles of $\mathbf{1}$ and $\mathbf{2}$ shows that these complexes have only a limited degree of ${ }^{3} \mathrm{LC}$ contribution, whilst complexes 3 and $\mathbf{4}$ have a more pronounced ${ }^{3} \mathrm{LC}$ character. ${ }^{10}$ 

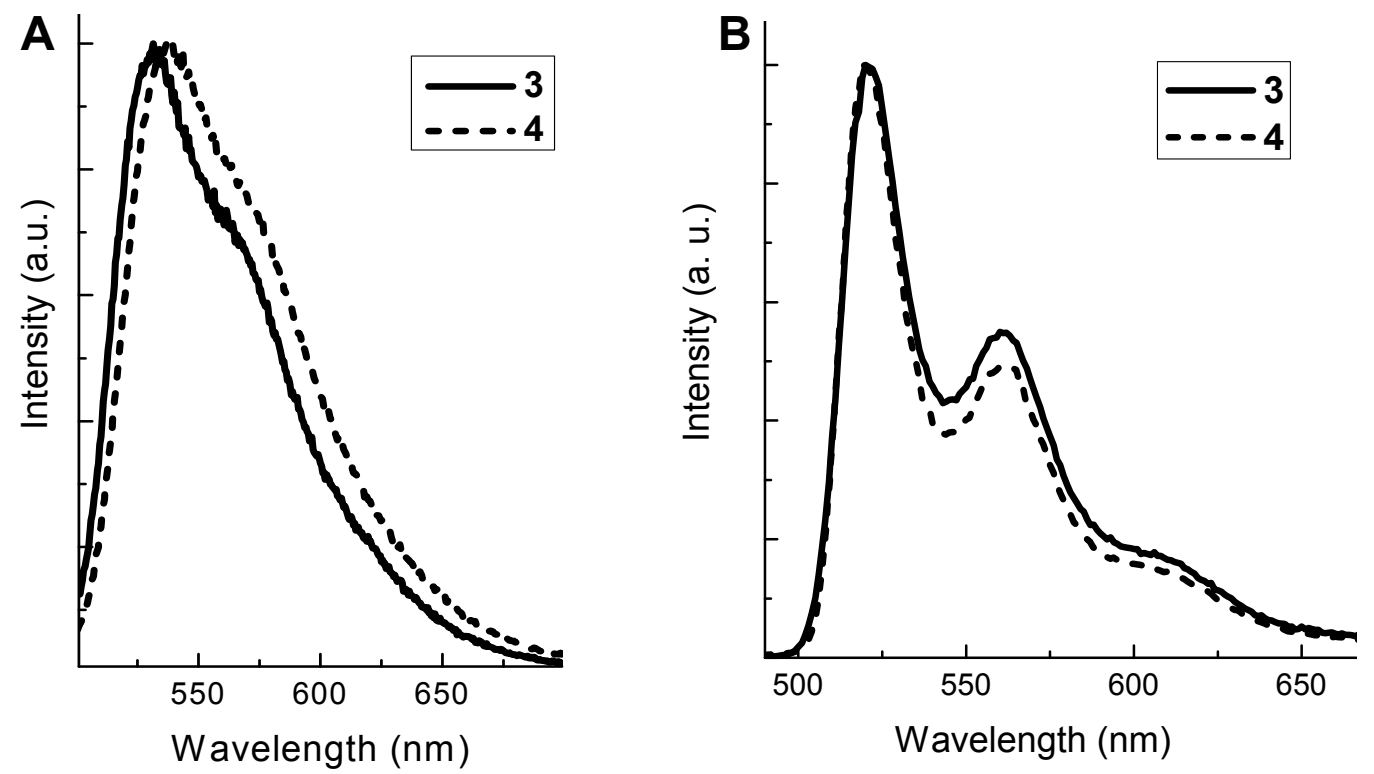

Figure 5.6. Normalized emission profile of 3 and $\mathbf{4}$ in DMF at room temperature (A) and in $\mathrm{CH}_{2} \mathrm{Cl}_{2}: \mathrm{MeOH}(1: 1)$ glass at $77 \mathrm{~K}$.

Analogous to complexes $\mathbf{1}$ and $\mathbf{2}$ described in Chapter 4, complexes $\mathbf{3}$ and $\mathbf{4}$ are highly luminescent in oxygen-free solvents $\left(\phi_{0} \sim 0.60\right)$ and both show long emission lifetimes $\left(\tau_{0} \sim\right.$ 1600-1700 ns), in line with the hypothesis of a triplet originated emission. A general decrease of quantum yields and lifetimes is observed in aerated solutions as a consequence of the oxygen quenching. Under these conditions, both complexes 3 and $\mathbf{4}$ show basically the same quantum yield (within the experimental error) in the order of $\phi \sim 0.040$ and the same phenomenon is observed for the emission lifetimes in deaerated solution: both compounds show an emission lifetime of $\tau \sim 78 \mathrm{~ns}$.

Table 5.2. Photophysical properties of the hemicaged and open complexes in DMF at $25^{\circ} \mathrm{C}$ (unless otherwise stated).

\begin{tabular}{|c|c|c|c|c|c|c|c|}
\hline Compound & $\begin{array}{c}\lambda_{\text {em }} \\
(\mathbf{n m})\end{array}$ & $\phi_{\mathbf{0}}$ & $\phi$ & $\begin{array}{c}\tau_{\mathbf{0}} \\
(\mathbf{n s})\end{array}$ & $\begin{array}{c}\tau \\
(\mathbf{n s})\end{array}$ & $\begin{array}{c}\lambda_{\text {em }}(\mathbf{7 7 K}) * \\
(\mathbf{n m})\end{array}$ & $\begin{array}{c}\tau(\mathbf{7 7 K}) * \\
(\mu \mathbf{s})\end{array}$ \\
\hline $\mathbf{1}$ & 580 & 0.54 & 0.048 & 1013 & 100 & 540 & 5.56 \\
\hline $\mathbf{2}$ & 556 & 0.62 & 0.040 & 1110 & 78 & 532 & 5.06 \\
\hline $\mathbf{3}$ & 532 & 0.67 & 0.035 & 1775 & 78 & 521 & 5.03 \\
\hline $\mathbf{4}$ & 537 & 0.63 & 0.034 & 1620 & 77 & 519 & 4.68 \\
\hline
\end{tabular}

* Measured in $\mathrm{CH}_{2} \mathrm{Cl}_{2}: \mathrm{MeOH}(1: 1)$ glass. 
The two complexes $\mathbf{3}$ and $\mathbf{4}$ show a similar decrease of quantum yields and lifetimes in aerated solutions. This provides a first clue for the absence of any substantial difference in terms of sensitivity towards the oxygen quenching induced by the shielding of the atoms where the HOMO orbital is localized. Conversely, complexes $\mathbf{1}$ and $\mathbf{2}$ (in which some atoms where the LUMO is localised are shielded by the capping unit) show a completely different behaviour: in aerated solutions, the quantum yield and lifetimes of the hemicaged complex 1 decrease much less than observed for the open complex $\mathbf{2}$. For instance, the lifetime of $\mathbf{1}$ is $1013 \mathrm{~ns}$ and $100 \mathrm{~ns}$ in deaerated and aerated solution, respectively, whilst the lifetime of the open complex 2 is $1110 \mathrm{~ns}$ and $78 \mathrm{~ns}$ under the respective conditions. Therefore, by comparing the behaviour of the two pairs of complexes shielded on the pyridine $(\mathbf{1}, \mathbf{2})$ and on the phenyl $(3,4)$ rings, a first evidence of the difference of oxygen sensitivity induced by the shielding of the atoms where the $\operatorname{LUMO}(\mathbf{1}, \mathbf{2})$ or the $\operatorname{HOMO}(\mathbf{3}, \mathbf{4})$ orbitals are localized is obtained. According to these preliminary data, the shielding of the atoms where the LUMO is localised exerts an important effect on the oxygen sensitivity, whilst the shielding of the atoms in the HOMO orbital does not have any relevant effect. A more quantitative evaluation of the difference in oxygen quenching induced by the shielding effect can be obtained by Stern-Volmer analysis of the luminescence quenching (see next section).

Oxygen quenching. The oxygen quenching of the luminescence of $\mathbf{3}$ and $\mathbf{4}$ was studied. by Stern-Volmer analysis according to equation 5.1:

$$
\frac{I_{0}}{I}=1+k_{q} \tau_{0}\left[O_{2}\right]
$$

$\mathrm{I}_{0}$ and $\mathrm{I}$ are the emission intensities in presence or absence of quencher respectively, $\mathrm{k}_{\mathrm{q}}$ is the quenching constant, $\tau_{0}$ is the lifetime in absence of quencher and $\left[\mathrm{O}_{2}\right]$ the concentration of oxygen in solution. ${ }^{12}$ The Stern-Volmer plots for the two sets of complexes are reported in Figure 5.7. 


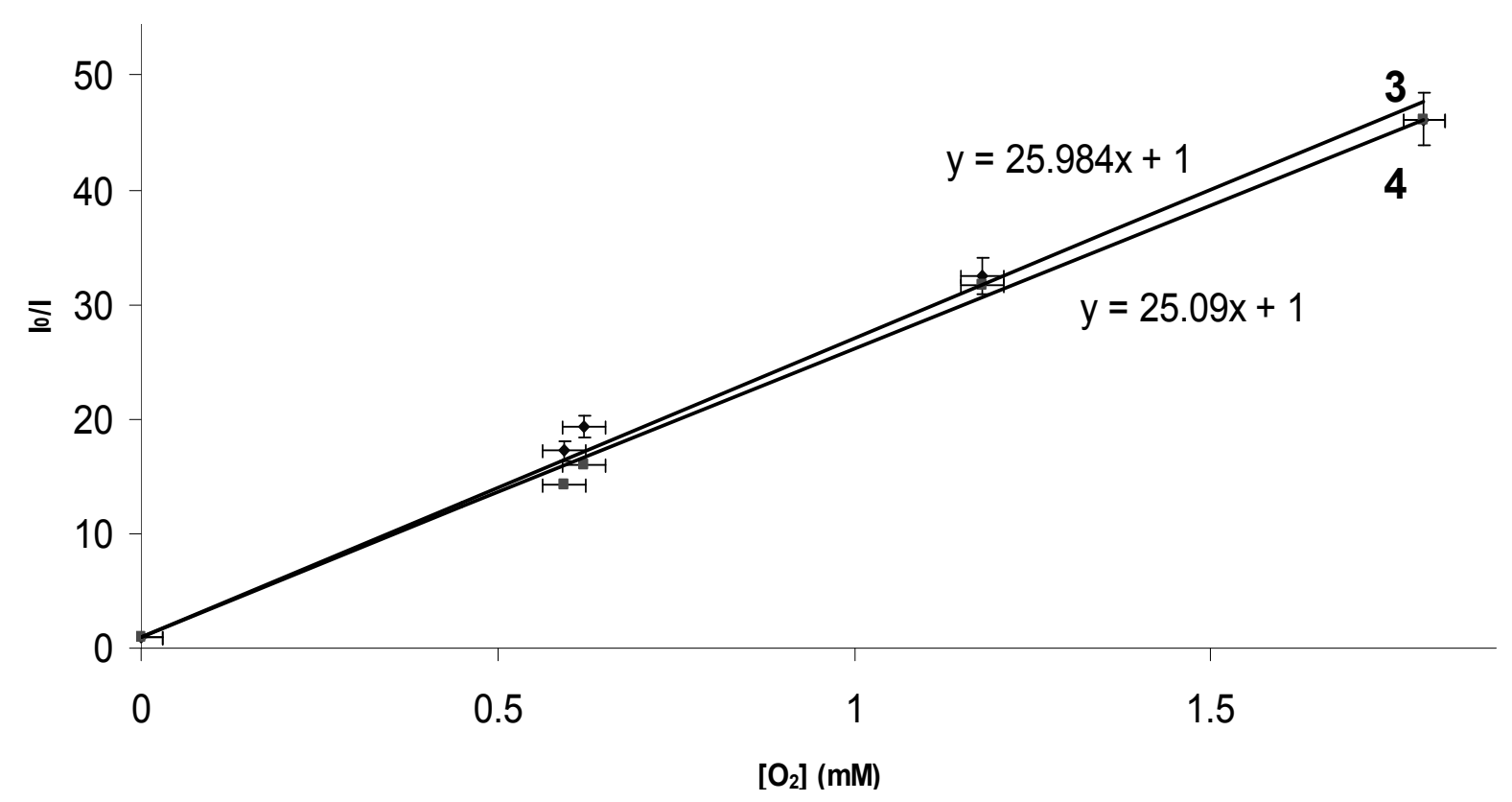

Figure 5.7. Stern-Volmer plot of the hemicaged complex 3 and open complex 4 in DMF at room temperature.

The efficiency of oxygen quenching was determined by analysing the quenching constants $\mathrm{k}_{\mathrm{q}}$ (Table 5.3). Compounds 3 and $\mathbf{4}$ show (almost) the same degree of oxygen quenching and the $6 \%$ difference is within the experimental error. In order to confirm the equivalence of the two systems in terms of energy or electron transfer feasibility, the free energy of energy transfer $\left(\Delta \mathrm{G}_{\mathrm{et}}\right)$ was calculated, according to eq. 5.2 :

$$
\Delta G_{e t}=-\left(E_{00}-E_{O_{2} *}\right)
$$

$\mathrm{E}_{00}$ is the energy of the 0-0 transition and $\mathrm{E}_{\mathrm{O} 2} *$ the energy of the excited state of singlet oxygen: $\mathrm{E}_{\mathrm{O} 2} *\left({ }^{1} \Sigma_{\mathrm{g}}\right)=1.63 \mathrm{eV}$ and $\mathrm{E}_{\mathrm{O} 2} *\left({ }^{1} \Delta_{\mathrm{g}}\right)=0.98 \mathrm{eV}$ depending on which excited state of oxygen is initially produced during quenching, and of electron transfer $\left(\Delta \mathrm{G}_{\mathrm{el}}\right)$ according to eq. 5.3:

$$
\Delta G_{e l}=F\left(E_{F}^{o x}-E_{O_{2}}^{r e d}\right)-E_{00}+C
$$

$\mathrm{F}$ is the Faraday's constant, $\mathrm{E}_{\mathrm{F}}^{\mathrm{ox}}$ is the oxidation potential of the fluorophore, $\mathrm{E}_{\mathrm{O} 2}^{\mathrm{red}}$ is the reduction potential of oxygen $(-0.78 \mathrm{~V})$ and $\mathrm{C}$ is a Coulomb term (usually neglected in polar solvents). ${ }^{13-15}$ The calculated values of $\Delta \mathrm{G}_{\mathrm{et}}$ and $\Delta \mathrm{G}_{\mathrm{el}}$ for $\mathbf{3}$ and $\mathbf{4}$ are reported in Table 5.3 together with the values obtained for $\mathbf{1}$ and $\mathbf{2}$. Unfortunately, due to the low solubility of $\mathbf{4}$ in 
DMF, the evaluation of the $\Delta \mathrm{G}_{\mathrm{el}}$ was not possible. However, since both $\mathrm{k}_{\mathrm{q}}$ and $\Delta \mathrm{G}_{\mathrm{et}}$ appeared to be identical within the experimental error, it is reasonable to assume that also $\Delta \mathrm{G}_{\mathrm{el}}$ has the same value for both compounds.

Table 5.3. Oxygen quenching constant $\left(\mathrm{k}_{\mathrm{q}}\right)$ and thermodynamic parameters involved in the oxygen quenching mechanisms in DMF at room temperature.

\begin{tabular}{|c|c|c|c|c|c|}
\hline Compound & $\mathbf{E}_{\mathbf{0 0}}(\mathbf{e V})$ & $\begin{array}{c}\mathbf{E}_{\mathbf{0 x}} \\
\mathbf{( V )}\end{array}$ & $\begin{array}{c}\Delta \mathbf{G}_{\mathbf{e t}} \\
(\mathbf{k J} / \mathbf{m o l}) *\end{array}$ & $\begin{array}{c}\Delta \mathbf{G}_{\mathbf{e l}} \\
(\mathbf{k J} / \mathbf{m o l})\end{array}$ & $\mathbf{k}_{\mathbf{q}}\left(\mathbf{M}^{\mathbf{- 1}} \mathbf{s}^{\mathbf{- 1}}\right)$ \\
\hline $\mathbf{1}$ & 2.42 & 0.921 & -139 & -69 & $1.0 \cdot 10^{10}$ \\
\hline $\mathbf{2}$ & 2.43 & 0.910 & -140 & -71 & $1.7 \cdot 10^{10}$ \\
\hline $\mathbf{3}$ & 2.47 & 1.063 & -144 & -60 & $1.5 \cdot 10^{10}$ \\
\hline $\mathbf{4}^{\S}$ & 2.47 & - & -144 & - & $1.6 \cdot 10^{10}$ \\
\hline
\end{tabular}

*) calculated by assuming $\left.\mathrm{E}_{02 *}\left({ }^{1} \Delta_{\mathrm{g}}\right)=0.98 \mathrm{eV} ; \S\right)$ due to the low solubility of 4 in DMF it was not possible to acquire the redox data.

Regarding oxygen quenching of hemicages and open complexes shielded on the pyridine (1, 2) or on the phenyl $(\mathbf{3}, \mathbf{4})$ ring, it clear from this study that the hemicaged complex bearing a capping unit on the pyridine rings $(\mathbf{1})$ presents a much lower oxygen quenching $\left(\mathrm{k}_{\mathrm{q}}=1.0 \cdot 10^{10}\right.$ $\left.\mathrm{M}^{-1} \mathrm{~s}^{-1}\right)$ than its parent open complex 2 with ethylamide on the pyridine ring $\left(\mathrm{k}_{\mathrm{q}}=1.7 \cdot 10^{10} \mathrm{M}^{-}\right.$ ${ }^{1} \mathrm{~s}^{-1}$ ). Moreover, the hemicaged complex $\mathbf{3}$, in which the capping unit is connected to the phenyl ring, shows basically the same degree of oxygen quenching as the open complex 4 , which is functionalized with ethylamide on the phenyl ring $\left(\mathrm{k}_{\mathrm{q}}=1.5 \cdot 10^{10} \mathrm{M}^{-1} \mathrm{~s}^{-1}\right.$ and $\mathrm{k}_{\mathrm{q}}=1.6 \cdot 10^{10} \mathrm{M}^{-1} \mathrm{~s}^{-1}$, respectively). From the analysis of the thermodynamic parameters $\Delta \mathrm{G}_{\mathrm{et}}$ and $\Delta \mathrm{G}_{\mathrm{el}}$ it is clear that in terms of thermodynamic feasibility there is only a negligible difference between the members of each pair of compounds (1, 2 and 3, 4). Therefore, the lower quenching shown by $\mathbf{1}$ with respect to $\mathbf{2}$ is likely to be attributed to a structural effect. Since it is known that in $\operatorname{Ir}(\mathrm{III})$-phenylpyridine complexes the LUMO orbital is usually localised on the pyridine ring, whilst the HOMO orbital is localised on the metal centre and on the phenyl ring, ${ }^{6}$ it is possible to conclude that the introduction of a capping unit on the pyridine ring induces a certain degree of shielding of the atoms where the LUMO is localised, thus resulting in a decrease of oxygen quenching. The introduction of a capping unit on the phenyl ring, resulting in the shielding of the atoms where the HOMO is localised, has almost no influence on the degree of oxygen quenching of the complexes. The study of the structure 
and electronic localization of the excited states of the hemicaged and open complexes 1-4 is currently under investigation with computational (DFT and TDDFT) methods.

\subsection{Conclusions}

In this Chapter the synthesis, characterization and photochemical properties of $\operatorname{Ir}(\mathrm{III})$ trisphenylpyridine derivatives functionalized on the phenyl ring with amide groups are discussed. The amides are substituted with a tris(2-aminoethyl)amine capping unit and an ethylamine moiety, in order to obtain two complexes with a hemicaged (3) and an open (4) structure. By comparing the photophysical data of both complexes it is evident that the hemicaged complex 3 , in which the atoms where the HOMO orbital is expected to be localized are shielded, exhibits an almost negligible change in the degree of oxygen quenching when compared to the unshielded complex 4. This result can be explained considering that the introduction of a capping unit on the phenyl rings site of the complex does not affect the LUMO orbital, which is mostly localized on the pyridine ring. Moreover, the presence of a capping unit on the phenyl ring does not have any influence on the degree of shielding of the LUMO orbital towards the quencher. Therefore, a similar behaviour of the hemicaged and open complexes in terms of oxygen quenching is observed. This observation, together with the results previously described in Chapter 4, proves that in order to achieve a decrease of oxygen quenching, it is necessary to shield the atoms where the LUMO orbital is localized.

\subsection{Experimental section}

NMR experiments were performed on a Bruker Avance II NMR spectrometer operating at 600.35 MHz for ${ }^{1} \mathrm{H}$ and $150.09 \mathrm{MHz}$ for ${ }^{13} \mathrm{C}$. Chemicals shifts are given in ppm using the residual solvent signal as reference. The multiplicity of the peaks is reported by using the following abbreviations: $\mathrm{s}=$ singlet, $\mathrm{d}=$ doublet, $\mathrm{t}=$ triplet, quint $=$ quintuplet, $\mathrm{m}=$ multiplet. High resolution mass spectra were measured on a Micromass LCT (ESI-TOF) spectrometer. IR spectra were measured on a Thermo Scientific Nicolet ${ }^{\mathrm{TM}} 6700$ FT-IR spectrometer equipped with a Smart Orbit diamond ATR accessory. Main bands are reported and assigned to functional groups by using the following abbreviations: br = broad band; str = stretching band; def = deformation band, bend. = bending band. UV-Vis spectra were measured on a Perkin Elmer Lambda $850 \mathrm{UV}-$ Vis spectrophotometer by using a quartz cuvette with $1 \mathrm{~cm}$ 
path length. Steady-state luminescence spectra were measured using an Edinburgh FS900 fluorospectrometer. A $450 \mathrm{~W}$ xenon arc lamp was used as excitation source. Luminescence quantum yields at room temperature ( $\Phi$ and $\Phi_{\text {air }}$ ) were evaluated by comparing wavelengthintegrated intensities $\left(I\right.$ or $\left.I_{R}\right)$ of isoabsorptive optically diluted solutions (Abs $\left.<0.1\right)$ with reference to fluorescein $\left(\Phi_{\mathrm{R}}=0.95\right.$ in air-equilibrated $\left.0.1 \mathrm{M} \mathrm{NaOH}\right)$ by using the equation 5.4:

$$
\Phi=\Phi_{R} \frac{n^{2} I}{n_{R}^{2} I_{R}}
$$

where $n$ and $n_{R}$ are the refractive index of the sample and reference solvent, respectively. ${ }^{16}$ Luminescence lifetimes of the compounds were determined by recording the decay curves of the luminescence intensity at the emission maximum using the TCSPC option on a Horiba Jobin-Yvon Fluoromax 4 instrument and a pulsed solid state LED as excitation source at 462 $\mathrm{nm}$ wavelength. The recorded data were analyzed using the DAS6 software package of Horiba Jobin Yvon. Degassed solutions were prepared by four freeze-pump-thaw cycles. Solutions with different oxygen concentration, suitable for the Stern-Volmer quenching studies, were prepared by using $\mathrm{N}_{2} / \mathrm{O}_{2}$ mixtures prepared with a Brooks 5850S Mass Flow control and by purging the fluorophore solutions for 40 minutes. Electrochemical measurements were done in $N, N$-dimethylformamide (Acros, extra dry over molecular sieves, 99.8\%) used as arrived without any further purification. Tetra-butylammonium hexafluorophosphate (electrochemical grade, $\geq 99 \%$, Fluka) was used as supporting electrolyte, which was recrystallized from a 1:1 ethanol-water solution and dried at $60{ }^{\circ} \mathrm{C}$ under vacuum. For the electrochemical experiments, a CHI750C Electrochemical Workstation (CH Instruments, Inc., Austin, TX, USA) was used. The electrochemical experiments were performed in a glass cell under an Ar atmosphere. To minimize the ohmic drop between the working and the reference electrodes, the feedback correction was employed. The electrochemical experiments were performed by using a $3 \mathrm{~mm}$ diameter glassy carbon disk electrode (homemade from a Tokai glassy carbon rod). Before starting the experiments, the working electrode was polished with a $0.05 \mu \mathrm{m}$ diamond suspension (Metadi Supreme Diamond Suspension, Buehler) and ultrasonically rinsed with ethanol for 5 minutes. The electrode was electrochemically activated in the background solution by means of several voltammetric cycles at $0.5 \mathrm{Vs}^{-1}$ between the anodic and cathodic solvent/electrolyte discharges, until the same quality features were obtained. The reference electrode was a silver quasi-reference electrode (Ag-QRE), which was separated from the catholyte by a glass frit 
(vycor). The reference electrode was calibrated at the end of each experiment against the ferrocene/ferricenium couple, whose formal potential in $N, N$-dimethylformamide is $0.464 \mathrm{~V}$ against the $\mathrm{KCl}$ saturated calomel electrode (SCE); in the following, all potential values are reported against SCE. A platinum ring or coil served as the counter electrode.

Oxygen sensitive reactions were carried out by using standard Schlenk techniques. Commercial grade reagents were purchased from Sigma-Aldrich and used without further purification.

4-(pyridin-2-yl)benzoic acid (5) was prepared according to literature procedure. ${ }^{17}$

Tripodal ligand (6). $600 \mathrm{mg}(3 \mathrm{mmol})$ of $5,620 \mathrm{mg}(3 \mathrm{mmol})$ of $N, N^{\prime}-$ dicyclohexylcarbodiimide and $400 \mathrm{mg}(3 \mathrm{mmol})$ of $\mathrm{N}$-hydroxybenzotriazole were dissolved in $50 \mathrm{ml}$ of dry $N, N^{\prime}$-dimethylacetamide. $120 \mu \mathrm{l}(0.8 \mathrm{mmol})$ of tris(2-aminoethyl)amine were added dropwise and the resulting mixture was stirred overnight at $60^{\circ} \mathrm{C}$. The reaction mixture was then filtered and added to ca. $400 \mathrm{ml}$ of diethylether under vigorous stirring. The white precipitate was then collected by filtration and washed with hot acetonitrile. Obtained $212 \mathrm{mg}$ ( $0.3 \mathrm{mmol} ; 40 \%$ yield) of pure tripodal ligand.

${ }^{1} \mathrm{H}-\mathrm{NMR}\left(d_{4}-\mathrm{MeOH}\right): 8.46(1 \mathrm{H}, \mathrm{s}) ; 7.69(2 \mathrm{H}, \mathrm{d}, J=6 \mathrm{~Hz}) ; 7.66(2 \mathrm{H}, \mathrm{d}, J=6 \mathrm{~Hz}) ; 7.59(1 \mathrm{H}, \mathrm{t}$, $J=12 \mathrm{~Hz}) ; 7.49(1 \mathrm{H}, \mathrm{d}, J=6 \mathrm{~Hz}) ; 7.24(1 \mathrm{H}, \mathrm{t}, J=6 \mathrm{~Hz}) ; 3.59(2 \mathrm{H}, \mathrm{t}, J=6 \mathrm{~Hz}) ; 2.82(2 \mathrm{H}, \mathrm{t}$, $J=6 \mathrm{~Hz}) .{ }^{13} \mathrm{C}-\mathrm{NMR}\left(d_{4}-\mathrm{MeOH}\right):$ See Figure 5.8. IR (neat): 3293 (NH str.), 3055 (CH str.), 2790 ( $\mathrm{CH}_{2}$ str.), 1631 (C=O str.), 1537 ( $\mathrm{NH}$ bend.), 1463 ( $\mathrm{CH}_{2}-\mathrm{N}$ str.), 752 (N-C-O str.). HRMS: calc. $690.319\left(\mathrm{M}+\mathrm{H}^{+}\right)$found 690.317.

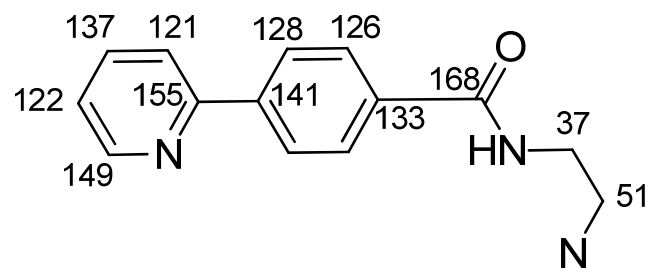

Figure 5.8. ${ }^{13} \mathrm{C}$ chemical shifts of tripodal ligand 6 derived from $\mathrm{HMBC} / \mathrm{HMQC}-\mathrm{NMR}$.

$N$-ethyl-4-(pyridin-2-yl)benzamide (7) $1 \mathrm{~g}(5 \mathrm{mmol})$ of 5 and $1.9 \mathrm{~g}(12.5 \mathrm{mmol})$ of 1 ethyl-3-(3-dimethylaminopropyl)carbodiimide were dissolved in $60 \mathrm{ml}$ of a mixture of $\mathrm{CH}_{2} \mathrm{Cl}_{2}$ :pyridine (7:3). $3 \mathrm{ml}$ of ethylamine (2.0 M in THF) were added dropwise and the mixture was stirred at RT. The solvent was removed under vacuum and the crude was then suspended in water and extracted with ethyl acetate. The organic phase was washed with a sat. solution of $\mathrm{CuSO}_{4}$, then with sat. $\mathrm{NH}_{4} \mathrm{Cl}$ and eventually with brine. The organic phase 
was then dried over $\mathrm{Na}_{2} \mathrm{SO}_{4}$ and the solvent removed under reduced pressure. Obtained $1 \mathrm{~g}$ (4.25 mmol; 85\% yield) of pure compound.

${ }^{1} \mathrm{H}-\mathrm{NMR}\left(d_{6}\right.$-DMSO): $8.71(1 \mathrm{H}, \mathrm{d}, J=6 \mathrm{~Hz}), 8.57(1 \mathrm{H}, \mathrm{t}, J=6 \mathrm{~Hz}), 8.18(2 \mathrm{H}, \mathrm{d}, J=6 \mathrm{~Hz})$, $8.05(1 \mathrm{H}, \mathrm{d}, J=6 \mathrm{~Hz}), 7.96(2 \mathrm{H}, \mathrm{d}, J=6 \mathrm{~Hz}), 7.94(1 \mathrm{H}, \mathrm{t}, J=12 \mathrm{~Hz}), 7.41(1 \mathrm{H}, \mathrm{t}, J=6 \mathrm{~Hz})$, $3.31(\mathrm{~m}), 1.15(3 \mathrm{H}, \mathrm{t}, J=6 \mathrm{~Hz}) .{ }^{13} \mathrm{C}-\mathrm{NMR}\left(d_{4}-\mathrm{MeOH}\right)$ : See Figure 5.9. IR (neat): $3297(\mathrm{~N}-\mathrm{H}$ str.), 2973 (CH str.), 2931, 2870 ( $\mathrm{CH}_{2} / \mathrm{CH}_{3}$ str.), 1627 (C=O str.), 1548 ( $\mathrm{N}-\mathrm{H}$ bend.), 1463 ( $\mathrm{CH}_{2}-\mathrm{N}$ str.), 746 (N-C-O str.). ESI-HRMS: calc. $226.111\left(\mathrm{M}^{+}\right)$found 226.115.

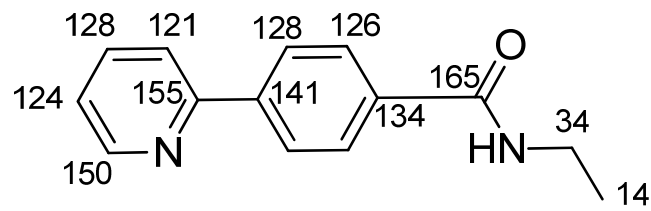

Figure 5.9. ${ }^{13} \mathrm{C}$ chemical shifts of ligand 7 derived from HMBC/HMQC-NMR.

Ir(III) hemicaged complex (3). $100 \mathrm{mg}(0.14 \mathrm{mmol})$ of $6,41 \mathrm{mg}(0.14 \mathrm{mmol})$ of $\mathrm{IrCl}_{3}$ and $89 \mathrm{mg}(0.4 \mathrm{mmol})$ of $\mathrm{CF}_{3} \mathrm{CO}_{2} \mathrm{Ag}$ were stirred in $10 \mathrm{ml}$ of ethylene glycol previously purged with nitrogen. After several cycles of argon/vacuum, the resulting mixture was refluxed overnight. The reaction mixture was cooled down at room temperature, diluted with water and extracted several times with ethyl acetate. The organic phases were collected, washed with brine and dried over $\mathrm{Na}_{2} \mathrm{SO}_{4}$. The products were then purified by column chromatography $\left(\mathrm{SiO}_{2}, \mathrm{CH}_{2} \mathrm{Cl}_{2}: \mathrm{MeOH}\right.$ 95:5).

${ }^{1} \mathrm{H}-\mathrm{NMR}\left(d_{2}-\mathrm{CH}_{2} \mathrm{Cl}_{2}\right): 7.98(1 \mathrm{H}, \mathrm{d}, J=6 \mathrm{~Hz}), 7.75(1 \mathrm{H}, \mathrm{d}, J=12 \mathrm{~Hz}), 7.72(1 \mathrm{H}, \mathrm{d}, J=12$ Hz), $7.59(1 \mathrm{H}, \mathrm{d}, J=6 \mathrm{~Hz}), 7.40(1 \mathrm{H}, \mathrm{d}, J=6 \mathrm{~Hz}), 7.33(1 \mathrm{H}, \mathrm{s}), 7.09(1 \mathrm{H}, \mathrm{t}, J=6 \mathrm{~Hz}), 6.25$ $(1 \mathrm{H}, \mathrm{d}, J=6 \mathrm{~Hz}), 3.90(1 \mathrm{H}, \mathrm{t}, J=6 \mathrm{~Hz}), 3.05(1 \mathrm{H}, \mathrm{t}, J=12 \mathrm{~Hz}), 2.79(1 \mathrm{H}, \mathrm{t}, J=12 \mathrm{~Hz}), 2.37$ $(1 \mathrm{H}, \mathrm{d}, J=12 \mathrm{~Hz}) .{ }^{13} \mathrm{C}-\mathrm{NMR}\left(d_{2}-\mathrm{CH}_{2} \mathrm{Cl}_{2}\right)$ : See Figure 5.10. IR (neat): 3290 (br., NH str.), 3066 ( $\mathrm{CH}$ str.), 2850 ( $\mathrm{CH}_{2}$ str.), 1643 (C=O str.), 1540 ( $\mathrm{NH}$ bend.), $1470\left(\mathrm{CH}_{2}-\mathrm{N}\right.$ str.), 756 (N-C-O str.). ESI-HRMS: calc. $880.259\left(\mathrm{M}+\mathrm{H}^{+}\right)$found 880.262.

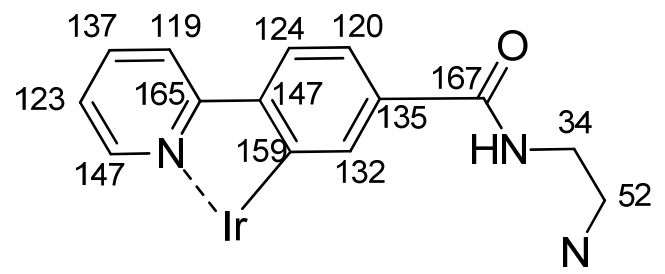

Figure 5.10. ${ }^{13} \mathrm{C}$ chemical shifts of hemicaged complex 3 derived from HMBC/HMQCNMR. 
Ir(III) open complex 4. $100 \mathrm{mg}$ of $7(0.42 \mathrm{mmol})$ and $66 \mathrm{mg}(0.22 \mathrm{mmol})$ of $\mathrm{IrCl}_{3}$ were dissolved in a mixture of 2-ethoxyethanol and water (3:1). After several cycles of argon/vacuum, the mixture was refluxed overnight. The reaction mixture was allowed to cool down at room temperature, half of the solvent was evaporated and the resulting solution was poured on ice. The resulting precipitate was filtered, washed with water and diethyl ether and dried under vacuum. The solid (ca. $70 \mathrm{mg}$ ) was then suspended in toluene, $36 \mathrm{mg}$ of ligand 7 $(0.15 \mathrm{mmol})$ and $80 \mathrm{mg}(0.30 \mathrm{mmol})$ of $\mathrm{CF}_{3} \mathrm{SO}_{3} \mathrm{Ag}$ were added, several cycles argon/nitrogen were performed in order to remove oxygen and the mixture was refluxed overnight under inert atmosphere. After toluene removal, the solid was then washed with methanol and subsequently dissolved in $\mathrm{CH}_{2} \mathrm{Cl}_{2}(10 \% \mathrm{MeOH})$, filtered through Celite and eventually purified by preparative TLC $\left(\mathrm{CH}_{2} \mathrm{Cl}_{2}: \mathrm{MeOH} 95: 5\right)$.

${ }^{1} \mathrm{H}-\mathrm{NMR}\left(d_{7}\right.$-DMF): $8.26(1 \mathrm{H}, \mathrm{d}, J=12 \mathrm{~Hz}), 7.92(1 \mathrm{H}, \mathrm{t}, J=6 \mathrm{~Hz}), 7.86-7.88(2 \mathrm{H}, \mathrm{m}), 7.63$ $(1 \mathrm{H}, \mathrm{d}, J=6 \mathrm{~Hz}), 7.37(1 \mathrm{H}, \mathrm{s}), 7.31(1 \mathrm{H}, \mathrm{d}, J=12 \mathrm{~Hz}), 7.20(1 \mathrm{H}, \mathrm{t}, J=6 \mathrm{~Hz}), 3.22(2 \mathrm{H}$, quint., $J=6 \mathrm{~Hz}), 1.05(3 \mathrm{H}, \mathrm{t}, J=6 \mathrm{~Hz}) .{ }^{13} \mathrm{C}-\mathrm{NMR}\left(d_{7}\right.$-DMF): See Figure 5.11. IR (neat): 3297 (N-H str.), 3060 (CH str.), 2966, 2927, 2852 ( $\mathrm{CH}_{2} / \mathrm{CH}_{3}$ str.), 1633 (C=O str.), 1540 (N$\mathrm{H}$ bend.), $1467\left(\mathrm{CH}_{2}-\mathrm{N}\right.$ str.), 754 (N-C-O str.). ESI-HRMS: calc. $869.279\left(\mathrm{M}+\mathrm{H}^{+}\right)$found 869.278

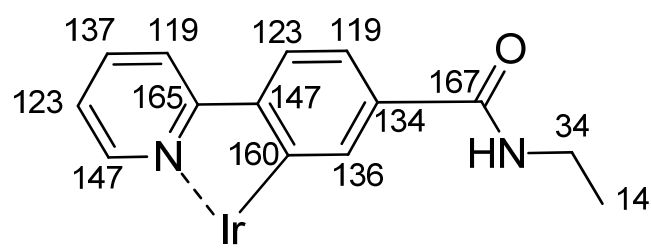

Figure 5.11. ${ }^{13} \mathrm{C}$ chemical shifts of open complex 4 derived from HMBC/HMQC-NMR.

\subsection{References}

1. Beeston, R. F.; Larson, S. L.; Fitzgerald, M. C., Inorg. Chem. 1989, 28, 4187-4189.

2. Demas, J. N.; Diemente, D.; Harris, E. W., J. Am. Chem. Soc. 1973, 95, 6864-6865.

3. Vlcek, A.; Zalis, S., Coord. Chem. Rev. 2007, 251, 258-287.

4. Knight, J. C.; Alvarez, S.; Amoroso, A. J.; Edwards, P. G.; Singh, N., Dalton Trans. 2010, 39, 3870-3883.

5. Avilov, I.; Minoofar, P.; Cornil, J.; De Cola, L., J. Am. Chem. Soc. 2007, 129, 82478258.

6. Flamigni, L.; Barbieri, A.; Sabatini, C.; Ventura, B.; Barigelletti, F., Photochemistry and photophysics of coordination compounds: Iridium. In Photochemistry and Photophysics of Coordination Compounds II, 2007; Vol. 281, pp 143-203.

7. Lamansky, S.; Djurovich, P.; Murphy, D.; Abdel-Razzaq, F.; Lee, H. E.; Adachi, C.; Burrows, P. E.; Forrest, S. R.; Thompson, M. E., J. Am. Chem. Soc. 2001, 123, 43044312. 
8. Juris, A.; Balzani, V.; Barigelletti, F.; Campagna, S.; Belser, P.; Vonzelewsky, A., Coord. Chem. Rev. 1988, 84, 85-277.

9. Barigelletti, F.; De Cola, L.; Balzani, V.; Belser, P.; Von Zelewsky, A.; Voegtle, F.; Ebmeyer, F.; Grammenudi, S., J. Am. Chem. Soc. 1989, 111, 4662-4668.

10. Tsuboyama, A.; Iwawaki, H.; Furugori, M.; Mukaide, T.; Kamatani, J.; Igawa, S.; Moriyama, T.; Miura, S.; Takiguchi, T.; Okada, S.; Hoshino, M.; Ueno, K., J. Am. Chem. Soc. 2003, 125, 12971-12979.

11. Oyler, K. D.; Coughlin, F. J.; Bernhard, S., J. Am. Chem. Soc. 2007, 129, 210-217.

12. Lakowicz, J. R., Principles of Fluorescence Spectroscopy. Springer: Singapore, 2006.

13. Abdel-Shafi, A. A.; Beer, P. D.; Mortimer, R. J.; F., W., Helv. Chim. Acta 2001, 84, 2784-2795.

14. Bodesheim, M.; Schutz, M.; Schmidt, R., Chem. Phys. Lett. 1994, 221, 7-14.

15. Mulazzani, Q. G.; Sun, H.; Hoffman, M. Z.; Ford, W. E.; Rodgers, M. A. J., J. Phys. Chem. 1994, 98, 1145-1150.

16. Montalti, M.; Credi, A.; Prodi, L.; Gandolfi, M. T., Handbook of Photochemistry. CRC Press: Boca Raton, 2006.

17. Gong, Y.; Pauls, H. W., Synlett 2000, 829-831. 


\title{
Chapter 6
}

Truth is a pathless land.

If you already know what you are seeking, you

will never find what you are not looking for.

T. Terzani

\section{Luminescence quenching by oxygen of an iridium(III) hemicaged complex functionalized with electron-donating groups}

\begin{abstract}
In this chapter, the synthesis and structural characterization of the first iridium(III) hemicaged complex with an ether bond as connecting moiety between the $\operatorname{Ir}(\mathrm{ppy})_{3}$-based core and the phenyl-based capping unit are reported. The synthetic pathway followed for the synthesis of the hemicaged complex and its open parent (i.e. with ether groups on the ppy ligands but without phenyl capping unit) complex is described. The complexes have been characterized by $1 \mathrm{D}$ and 2D NMR spectroscopy, with emphasis on the typical through-space couplings observed with NOESY experiments. Furthermore, the absorption and emission properties of the two compounds are discussed, and their behaviour towards oxygen quenching of the fluorescence is reported, together with a possible explanation regarding the low increased shielding effect (10\%) towards oxygen quenching shown by the hemicaged complex when compared to the open complex.
\end{abstract}




\subsection{Introduction}

In the previous Chapters several examples of hemicaged and caged tris(phenylpyridine)Ir(III) complexes and their photophysical properties have been described and special attention has been paid towards oxygen quenching of the luminescence of these complexes. The few hemicaged systems described in literature make use of either the amide unit or a direct carbon-carbon bond in order to assemble tripodal ligands. ${ }^{1-4}$ It has been proven that the functionalization of phenylpyridine ligands with groups which can modify the electronic density of the ligand itself greatly influences the sensitivity of the complex towards oxygen quenching. More specifically, the presence of electron-withdrawing groups (e.g. amides) on the pyridine ring induces the localization of the LUMO orbital on carbon atoms (or on the electron-withdrawing group itself) which are shielded by the capping unit, resulting in a decrease of the oxygen quenching of luminescence (see Chapter 4 and 5). Considering the results so far described in the literature, ${ }^{5}$ together with the new data emerging from the research work described in this thesis, one can conclude that there are no known examples of Ir(III) hemicaged complexes containing electron donating groups on the phenylpyridine ligand. Such complexes would be interesting to investigate because, as predicted on the basis of the resonance structures shown in Figure 6.1, the presence of an electron-donating group is expected to delocalize the LUMO on different positions compared to the amide based ligands. ${ }^{6}$ More in detail, the presence of the electron-withdrawing group in meta- to the pyridine's nitrogen is expected to in duce a higher localization of the LUMO orbital on the atoms belonging to group itself (Figure 6.1). Conversely, an electron-donating group on the same position is expected to induce a higher localization of the LUMO orbital on the atoms which are in ortho- or para- position with respect to the group. This is of course a first approximation of the effect of electron-donating/withdrawing groups on the localization of the LUMO. In particular, the inductive effect (i.e. the push/pull effect due to the electronegativity of the group connected with the ring) also plays a key role. Taking all these facts into consideration, the prediction of the LUMO localization of such systems is not straightforward and the experimental analysis of the quenching behavior of systems with electron-donating groups is expected to add another element to the hypothesis of structureinduced intramolecular shielding against oxygen quenching of luminescence. 


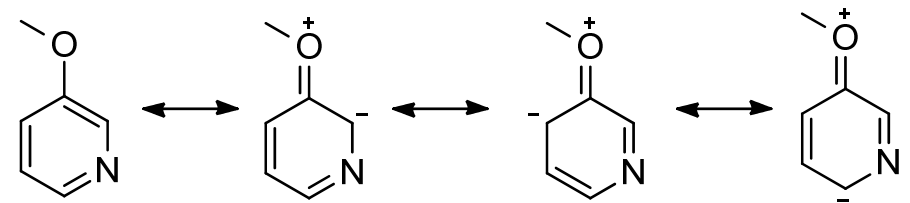<smiles>CNC([O-])=C1C=C[CH-]C=N1</smiles>

Figure 6.1. Resonance structures showing the different electronic density of a pyridine ring substituted with an electron-donating (top) or an electron-withdrawing (bottom) group.

As explained in more detail in the next section, the ether functional group is an ideal candidate for the realization of above-mentioned hemicaged complexes, because of its strong electron donating character, for the relative ease of synthesis and for the strength of the ether bond. The latter makes the so obtained tripodal ligand suitable for iridium complexation. In this chapter the design, synthesis, characterization and photophysical properties of the first ether-based Ir(III) hemicaged complex are described. This complex is functionalized on the pyridine ring with a benzene-based capping unit, in particular because of its higher steric hindrance. Considering the results described in Chapter 5, the synthesis of a hemicaged complex functionalized on the phenyl rings (instead of the pyridine rings) with the same benzene-based capping unit and carbon-based linker is not expected to add any further information in order to define a general theory of the structure-induced shielding effect against oxygen quenching. Furthermore, the synthesis of a caged complex functionalized on both the pyridine and the phenyl ring with a benzene-based capping unit connected to the phenylpyridine ligands through ether functional groups was attempted and a brief description of the synthetic pathway toward the synthesis of such a caged complex is reported in Appendix 6.2. 


\subsection{Design and synthesis}

In our previous studies concerning the luminescence properties of hemicaged and caged iridium(III) complexes (see Chapters 3, 4 and 5) the amide group has always been used to connect the iridium(III) tris(phenylpyridine) core to the capping units. This strategy was followed since the synthesis of the amide moiety is well known and many different procedures (mostly based on coupling agents like carbodiimides) have been developed in the past. Moreover, the amide unit is very stable under the harsh conditions required for the iridium(III) complexation (temperatures up to $200^{\circ} \mathrm{C}$ ). In our search for alternative ways to connect the iridium(III) core to the capping units, we focused on phenyl ethers, which can be easily synthesized and are expected to be as stable as the amides under the iridium(III) complexation conditions. Two new Ir(III) complexes with a hemicaged (1) and open (2) structure were designed (Figure 6.2) in order to obtain two systems with equivalent electronic properties. In this way, any difference regarding the oxygen quenching of the hemicaged complex compared to the open system is attributable to an intramolecular shielding effect.

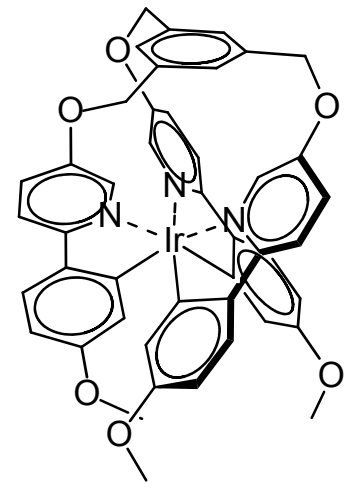

1

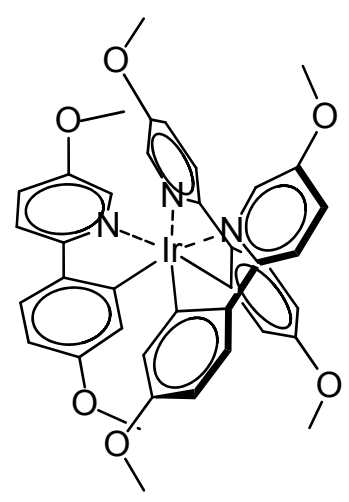

2

Figure 6.2. Structures of the hemicaged (1) and open (2) Ir(III) complexes with ether moieties as connecting groups.

Complex 2 was successfully synthesized according to the strategy shown in Scheme 6.1. Briefly, (6-bromopyridin-3-yl)boronic acid was quantitatively converted into 3 using $\mathrm{H}_{2} \mathrm{O}_{2}$ at room temperature and it was consequently coupled with (4-methoxyphenyl) boronic acid by Suzuki coupling using $\left[\mathrm{Pd}\left(\mathrm{PPh}_{3}\right)_{4}\right]$ and $\mathrm{Na}_{2} \mathrm{CO}_{3}$ as catalyst and base, respectively, and finally converted into ligand 4 by treatment with MeI. ${ }^{7,8}$ The desired open complex 2 was then obtained upon reaction of the ligand 4 with $\operatorname{Ir}(\mathrm{acac})_{3}$ in refluxing glycerin under argon 
atmosphere. ${ }^{9}$ The open complex 2 was purified by column chromatography and obtained in a $27 \%$ yield.<smiles>COc1ccc(Br)nc1</smiles>

3<smiles>COc1ccc(-c2ccc(OC)cn2)cc1</smiles>

4

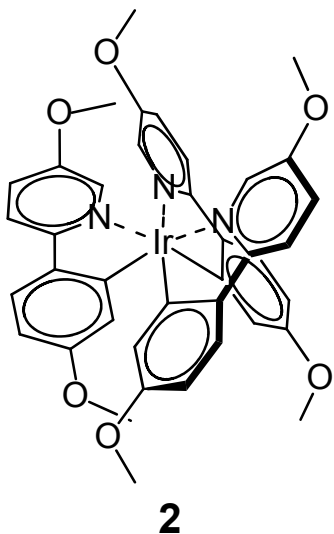

Scheme 6.1. Synthetic pathways of the open complex 2. Reaction conditions: a) $\mathrm{H}_{2} \mathrm{O}_{2}$, $\mathrm{CH}_{2} \mathrm{Cl}_{2}$, room temperature, overnight; b) (4-methoxyphenyl) boronic acid, $\left[\mathrm{Pd}\left(\mathrm{PPh}_{3}\right)_{4}\right]$, $\mathrm{Na}_{2} \mathrm{CO}_{3}, \mathrm{THF} / \mathrm{H}_{2} \mathrm{O}$ 1:1, reflux overnight, Ar then $\mathrm{NaH}$ (60\% in mineral oil), $\mathrm{CH}_{3} \mathrm{I}, \mathrm{DMF}$, room temperature, $2 \mathrm{~h}$; c) $\operatorname{Ir}(\mathrm{acac})_{3}, \mathrm{CF}_{3} \mathrm{CO}_{2} \mathrm{Ag}$, glycerin, reflux 5h, Ar.

Whilst the synthesis of $\mathbf{2}$ could be successfully achieved according to this pathway, a different strategy was needed in order to synthesize the hemicaged complex 1 (Scheme 6.2). The pyridine derivative 3 was reacted with 1,3,5-tris(2-bromoethyl)benzene in the presence of $\mathrm{NaH}(60 \%$ in mineral oil), giving the tripod 6 in quantitative yield. The $\mathrm{OH}$ group in derivative $\mathbf{3}$ is acidic, therefore it can be easily deprotonated upon treatment with a strong base like $\mathrm{NaH}$. Moreover, the reaction of the so obtained anion with 1,3,5tris(bromomethyl)benzene is highly selective due to the higher reactivity of the benzylic bromine. Subsequently, 6 was reacted with (4-methoxyphenyl) boronic acid under Suzuki coupling conditions, giving the tripodal ligand 7. The hemicaged complex 1 was obtained upon reaction of the tripodal ligand 7 with $\operatorname{Ir}(\mathrm{acac})_{3}$ in refluxing glycerin under argon atmosphere and it was purified by column chromatography (19\% yield). 


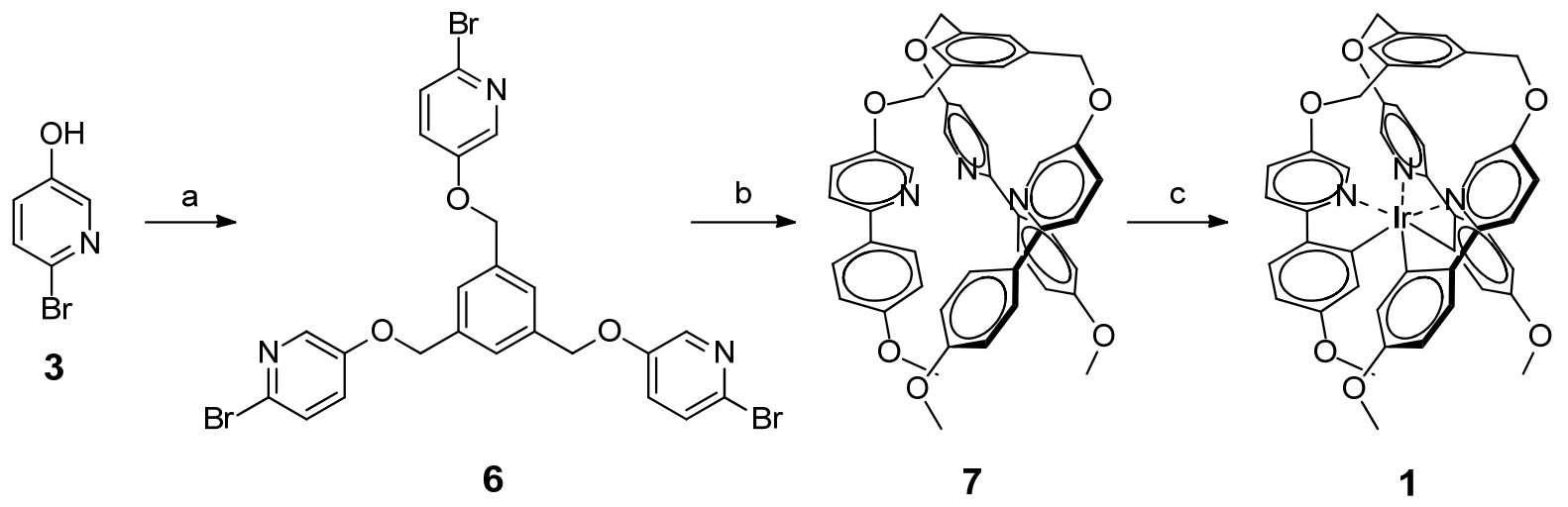

Scheme 6.2. Synthetic pathway of the hemicaged complex 1. Reaction conditions: a) 1,3,5tris(2-bromoethyl)benzene, $\mathrm{NaH}$ (60\% in mineral oil), DMF, $2 \mathrm{~h}$, room temperature; b) (4methoxyphenyl) boronic acid, $\left[\mathrm{Pd}\left(\mathrm{PPh}_{3}\right)_{4}\right], \mathrm{Na}_{2} \mathrm{CO}_{3}, \mathrm{THF} / \mathrm{H}_{2} \mathrm{O}$ 1:1, reflux overnight, Ar; c) $\operatorname{Ir}(\mathrm{acac})_{3}, \mathrm{CF}_{3} \mathrm{CO}_{2} \mathrm{Ag}$, glycerin, reflux 5h, Ar. (7 is not shown in the extended orientation for clarity reasons).

\subsection{Characterization}

All the intermediates and the target complexes were characterized by NMR spectroscopy and mass spectrometry. In this section only the NMR spectra of the $\operatorname{Ir}(\mathrm{III})$ complexes $\mathbf{1}$ and $\mathbf{2}$ are discussed, whilst the ${ }^{1} \mathrm{H}$ and ${ }^{13} \mathrm{C}$ chemical shifts of the intermediates are reported in the experimental section. The spectra of the hemicaged (1) and open (2) complexes are reported in Figure 6.3 together with the peak assignment. From the analysis of the ${ }^{1} \mathrm{H}-\mathrm{NMR}$ spectrum of the hemicaged complex 1 (Figure 6.3, A) it is possible to conclude that upon iridium(III) complexation, the $\mathrm{C}-\mathrm{O}$ bond of the methylene linkers loses its rotational freedom. Therefore, the two methylene protons become magnetically non-equivalent, resulting in two different peaks in the ${ }^{1} \mathrm{H}-\mathrm{NMR}$ spectrum. A similar behaviour was observed for all the hemicaged and caged Ir(III) complexes described in this thesis. Conversely, the ${ }^{1} \mathrm{H}-\mathrm{NMR}$ spectra of the open complex 2 (Figure 6.3, B) do not show any unequivalent aliphatic protons for the methyl protons of the methoxy group on both the pyridine and the phenyl ring, as expected for methoxy moieties with rotational freedom. Passing from the open to the hemicaged complex, both the internal protons in ortho- with respect to the electron-donating substituents show a characteristic shift: the proton $\mathbf{H a}$ (which is ortho- to the capping unit) shows an upfield shift of $1 \mathrm{ppm}$, whilst the proton $\mathbf{H f}$, (which is ortho- to the methoxy group) shows a downfield shift of $0.1 \mathrm{ppm}$. The shift of the Ha proton can be due to the shielding effect induced by the capping unit or by the pyridine rings on the other branches of the hemicage. However, on the basis of computational models (vide infra) it is possible to exclude a magnetic shielding 
exerted by the capping unit. The shift of the Hf proton is probably due to a deshielding effect induced by the phenyl ring on the other branches of the hemicage. Similar effects on the protons orho- to the $\mathrm{C} / \mathrm{N}$ atoms connected with the Ir have been observed also passing from the open to the hemicaged complexes described in Chapter 4. Moreover, since the capping unit of the hemicaged complex reported in Chapter 4 is aliphatic (and therefore cannot give any magnetic shielding effect) it can be concluded that the changes observed between the open and the hemicaged complexes are probably due to a geometric rearrangement induced by the presence of the capping unit. This conclusion is corroborated also by the computational modelling results: in the minimised structure of the hemicaged complex 1 (see Appendix 6.1 for computational details), the proton $\mathbf{H a}$ is out of the magnetic shielding cone of the aromatic capping unit and it is magnetically shielded by the pyridine ring on the other branch of the hemicage (the calculated distance between Ha and the pyridine's plane is 2.59 $\AA$ ). Analogously, the proton Hf faces the edge of a phenyl ring on the other branch of the hemicage and it is therefore deshielded (the calculated distance between $\mathbf{H f}$ and the phenyl's plane is $2.62 \AA$ ). Both complexes show only one set of NMR signals, which proves that the 3 fold symmetry expected for $f a c$-complexes is maintained. 
A
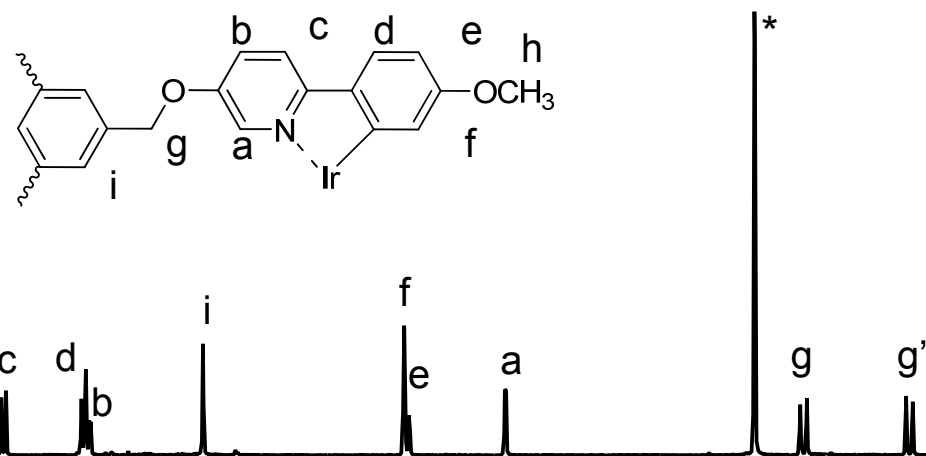

B
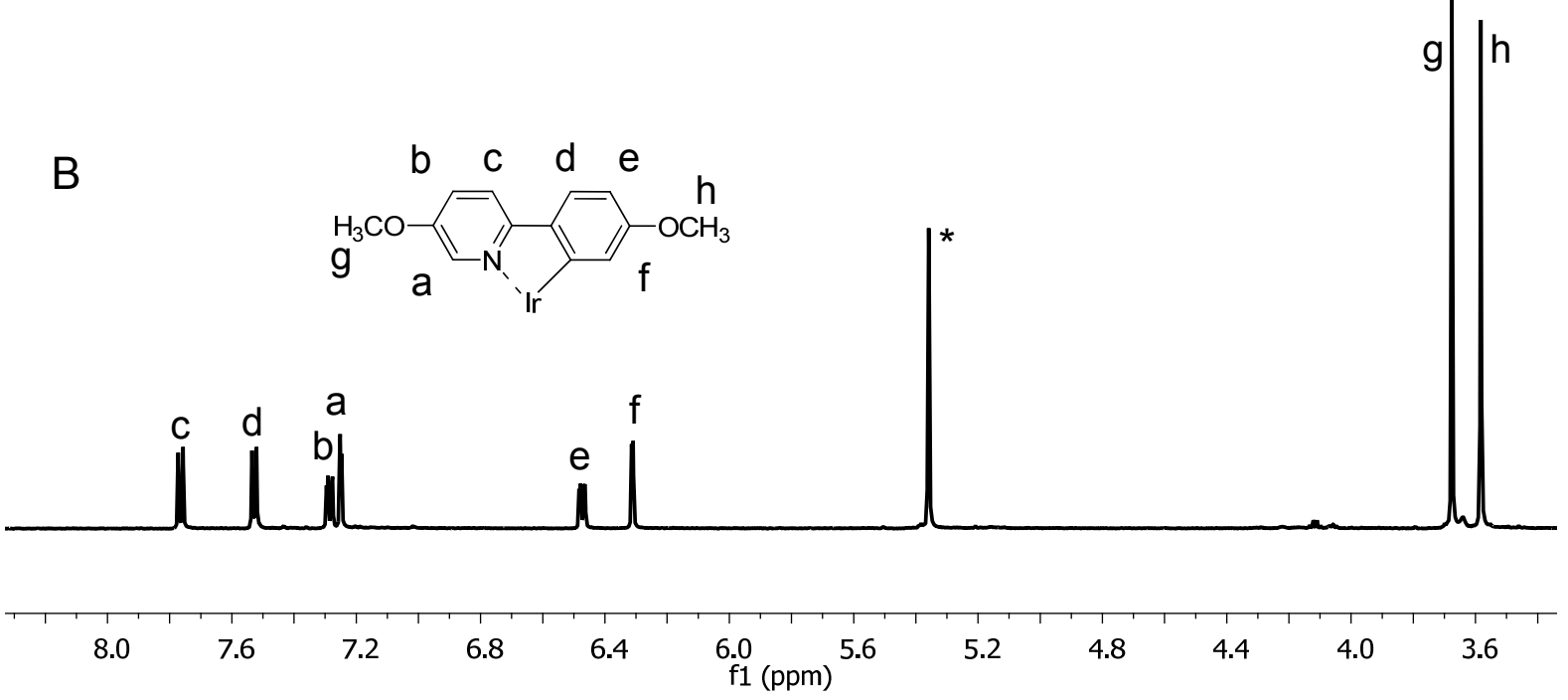

5.24

Figure 6.3. ${ }^{1} \mathrm{H}-\mathrm{NMR}$ spectra $\left(d_{2}-\mathrm{CH}_{2} \mathrm{Cl}_{2}\right)$ and peak assignment of the hemicaged complex $\mathbf{1}$ (A) and the open complex 2 (B).

In order to investigate the structural geometry of the complex, the hemicaged complex $\mathbf{1}$ was analysed using NOESY experiments in which the through-space couplings (Figure 6.4) clearly prove the hemicaged geometry. As a matter of fact, the coupling between protons $\mathbf{H a}$ and $\mathbf{H i}$ is observed only in $\mathbf{1}$ and not in the tripodal ligand itself, as expected for a hemicaged structure. Moreover, cross-peaks between protons $\mathbf{H d}$ and $\mathbf{H c}$, typical of $\operatorname{Ir}(\mathrm{ppy})_{3}$ derivatives, are also observed. 


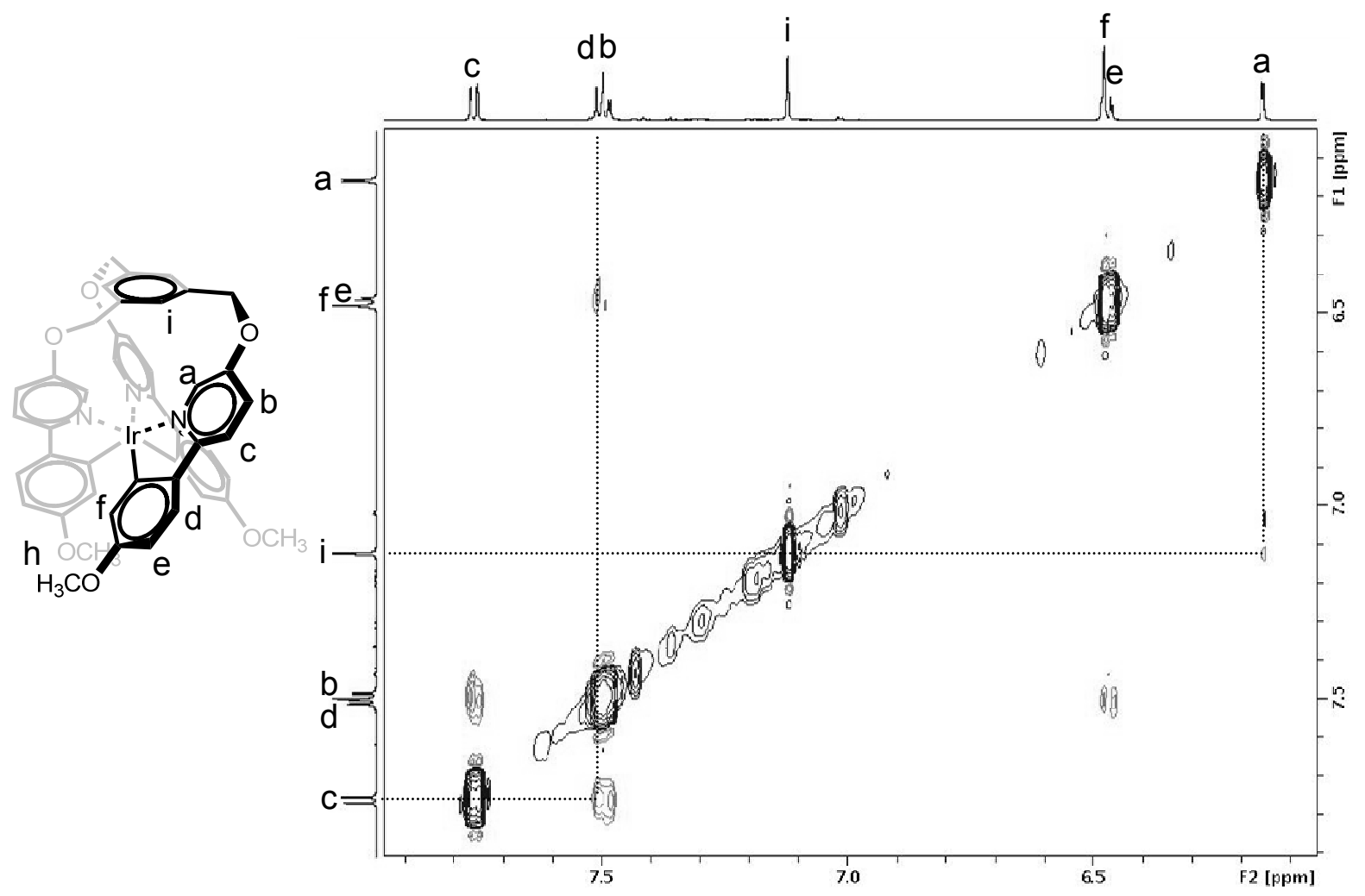

Figure 6.4. HH-NOESY spectrum of the hemicage complex $1\left(d_{2}-\mathrm{CH}_{2} \mathrm{Cl}_{2}\right)$. Section of the aromatic protons.

Furthermore, in the aliphatic-aromatic region of the NOESY spectrum (Figure 6.5), the different coupling of the diastereotopic $\mathbf{H g}$ and $\mathbf{H g}$ ' protons with proton $\mathbf{H b}$, and protons $\mathbf{H a}$ and $\mathbf{H i}$, respectively, give an indication of the different orientation of the two protons; towards the outside $(\mathbf{H g})$ and towards the inside $\left(\mathbf{H g}^{\prime}\right)$ of the molecule. It should be pointed out that proton $\mathbf{H g}^{\prime}$ could give a through-space coupling also with proton $\mathbf{H a}$ belonging to another branch of the tripod. Proton $\mathbf{H h}$, belonging to the methyl group, gives a throughspace coupling with both protons Hf and He on the apical position of the phenyl ring. The structure deduced on the basis of the NOESY spectrum is basically corroborated by computational results. The distances between protons which give cross-peaks in the NOESY spectrum, calculated for the minimized structure obtained from DFT calculations (see Appendix 6.1 for details), are reported in Table 6.1. 


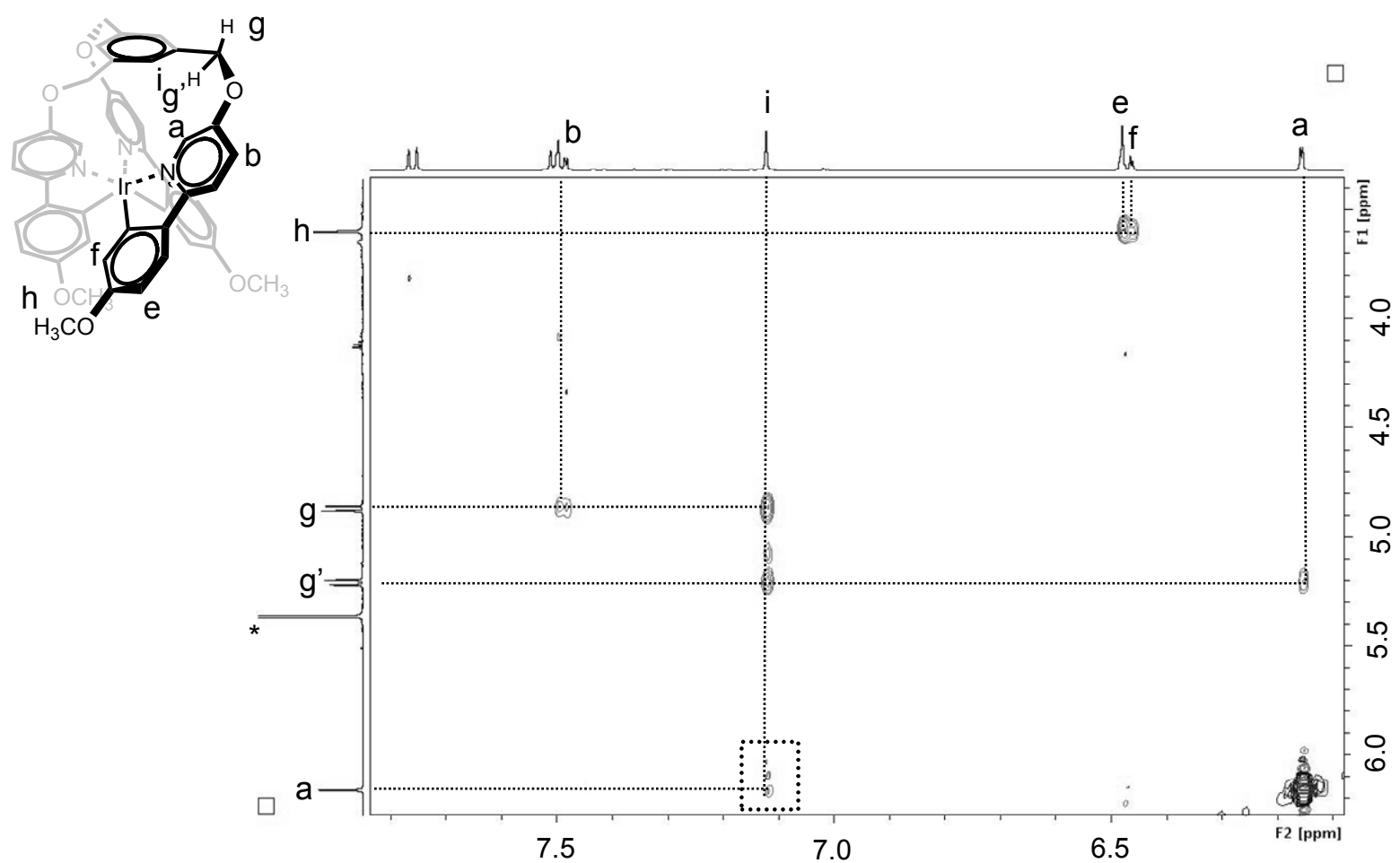

Figure 6.5. HH-NOESY spectrum of the hemicaged complex $1\left(d 2-\mathrm{CH}_{2} \mathrm{Cl}_{2}\right)$. Section of the aromatic-aliphatic interactions (labelling of protons not involved in the interactions is omitted for clarity). Box $=$ Ha-Hi interaction.

Table 6.1. Distances between protons involved in the NOESY interactions, calculated for a minimised structure obtained from DFT calculations.

\begin{tabular}{|c|c|c|c|}
\hline & $\begin{array}{c}\text { Distance } \\
\text { (A) }\end{array}$ & $\begin{array}{c}\text { Distance to another } \\
\text { branch }(\AA)\end{array}$ & $\begin{array}{c}\text { Intensity of the } \\
\text { NOESY cross-peaks }\end{array}$ \\
\hline Ha-Hg' & 4.2 & 4.3 & strong \\
\hline Ha-Hi & 4.4 & 4.4 & weak \\
\hline Hb-Hg & 2.8 & 7.7 & strong \\
\hline Hi-Hg' & 2.7 & 3.5 & very strong \\
\hline Hi-Hg & 3.8 & 2.6 & very strong \\
\hline $\begin{array}{l}\text { He-Hh } \\
\text { Hf-Hh }\end{array}$ & $3.3 *$ & $4.7 *$ & strong \\
\hline
\end{tabular}

* due to the rotational freedom of the methoxy group, an average of the possible distances is given. 


\subsection{Photophysical properties}

Absorption. The UV-Vis absorption spectra of complexes $\mathbf{1}$ and $\mathbf{2}$ are shown in Figure 6.6. The absorption maxima and shoulder of the complexes are reported in Table 6.2 together with their molar absorption coefficients. Both the hemicaged (1) and open (2) complex show a strong absorption band with absorption maxima at 287 and $357 \mathrm{~nm}$ (in the case of hemicage 1) and at 284 and $349 \mathrm{~nm}$ (in the case of open complex 2). The high energy absorption bands are usually assigned in $\operatorname{Ir}(\text { ppy })_{3}$ derivatives to ligand centered $\pi \rightarrow \pi^{*}$ transitions, while the weaker bands of lower energy are usually assigned to spin-allowed singlet-to-singlet metal to ligand charge transfer ( ${ }^{1}$ MLCT) transitions. ${ }^{9}{ }^{10}$ Moreover, the weak shoulder at lower energies (centered around $480 \mathrm{~nm}$ ) can be assigned to spin-forbidden singlet-to-triplet $\left({ }^{3}\right.$ MLCT) transitions, which are commonly observed in complexes containing heavy atoms (such as iridium), because of the considerable spin-orbit coupling that makes the singlet-totriplet transitions partially allowed. The hemicaged complex 1 shows slight bathochromic shifts of its absorption bands when compared to the open complex 2, which could be due to structural or electronic differences between the two ligands. ${ }^{3}$ A similar bathochromic shift in the open compared with the hemicaged complex has been observed also for $\mathrm{Ru}(\mathrm{II})$ hemicaged complexes bearing electron donating connecting units. ${ }^{2}$

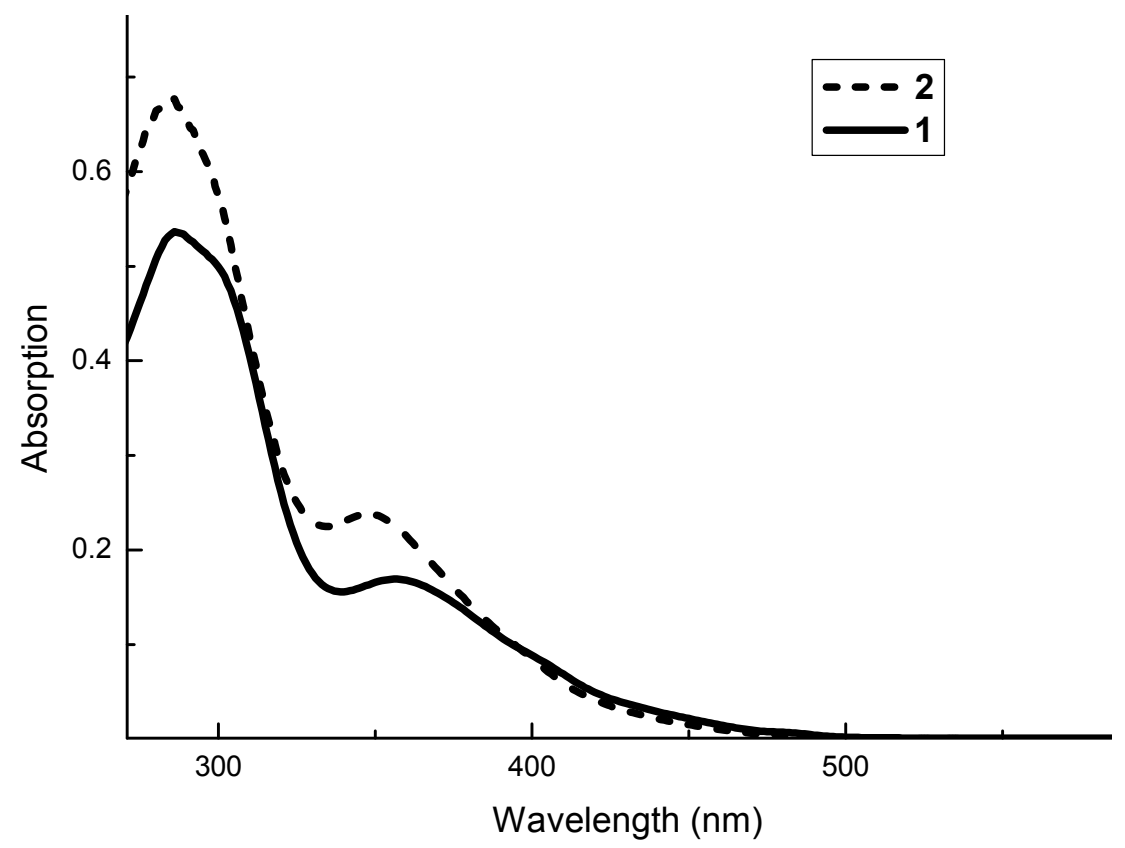

Figure 6.6. UV-Vis absorption spectrum of hemicaged (1) and open (2) complexes in DMF at room temperature. 
Table 6.2. UV-Vis absorption data of the complexes and their molar absorption coefficient in DMF at room temperature. sh. $=$ shoulder

\begin{tabular}{|c|c|}
\hline Compound & $\begin{array}{c}\text { Absorption } \\
\lambda(\mathbf{n m}),\left(\varepsilon\left(\mathbf{1 0}^{\mathbf{3}} \mathbf{M}^{-\mathbf{1}} \mathbf{c m}^{-\mathbf{1}}\right)\right)\end{array}$ \\
\hline $\mathbf{1}$ & $287(42), 304($ sh. 37) $357(13), 480($ sh. 0.5$)$ \\
\hline $\mathbf{2}$ & $284(42), 300($ sh. 35), 349 (15), 476 (sh. 0.3) \\
\hline
\end{tabular}

Luminescence. Both complexes show intense emission at room temperature (Figure 6.7). The presence of electron donating groups on the pyridine ring induces a slight blue shift in the emission when compared to the archetypical $\operatorname{Ir}(\text { ppy })_{3}$ as a consequence of the destabilization of the LUMO orbital. ${ }^{11}$ The hemicaged complex $\mathbf{1}$ exhibits, to a certain degree, a vibronic progression at room temperature, which is typical of substituted $\operatorname{Ir}(\mathrm{ppy})_{3}$ complexes with a partial LC character, while the open complex 2 shows a much less pronounced vibronic structure. This difference can be due to the higher rigidity in the $\pi$ conjugated ligand induced by the hemicage structure, whilst the open complex 2 results in a more flexible $\pi$-conjugated ligand. The photophysical properties of the two complexes are reported in Table 6.3. The emission of the hemicaged complex 1 is slightly blue shifted $\left(\lambda_{\max }\right.$ $=504 \mathrm{~nm})$ compared to the open complex $2\left(\lambda_{\max }=514 \mathrm{~nm}\right)$, which can be due either to the slight structural or electronic differences between the two complexes or to the locally lower polarity induced by the presence of the aromatic capping unit. ${ }^{10} \mathrm{~A}$ similar effect has been reported for a $\mathrm{Ru}(\mathrm{II})$ hemicaged complex with 1,3,5-tris(ethyl)benzene capping unit. ${ }^{2}$ 


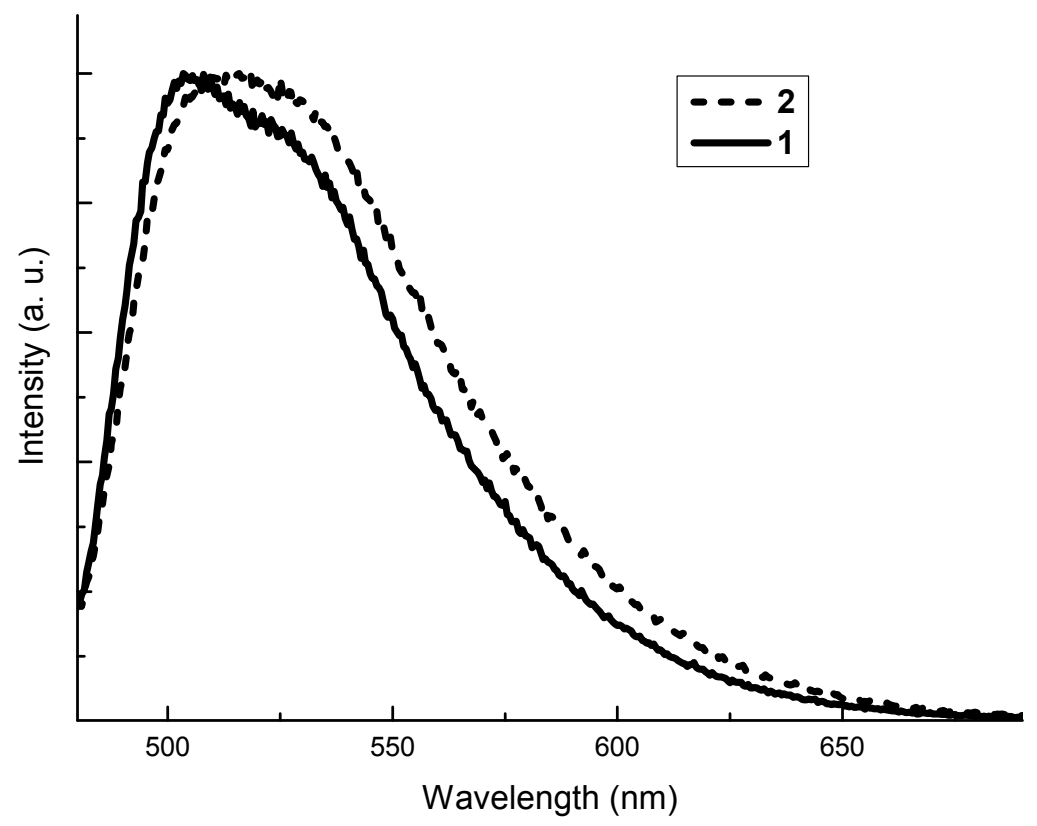

Figure 6.7. Normalized emission profiles of the hemicaged complex (1) and open complex (2) in DMF at $25^{\circ} \mathrm{C}$.

Both complexes show intense luminescence in absence of oxygen, with remarkably high quantum yields ( $\phi_{0}=0.71$ and 0.81 for $\mathbf{1}$ and $\mathbf{2}$, respectively). In absence of oxygen, a known triplet quencher, remarkably long lifetimes (in the order of microseconds) are observed, which corroborates the hypothesis of a ${ }^{3} \mathrm{MLCT}$ originated emission. Analogously to the quantum yields, the lifetime of the open complex $\mathbf{2}$ is much higher than the lifetime of the hemicaged complex 1.

Table 6.3. Luminescence properties of the hemicaged (1) and open (2) complexes in DMF at $25^{\circ} \mathrm{C}$

\begin{tabular}{|c|c|c|c|c|c|c|}
\hline Compound & $\begin{array}{c}\lambda_{\text {em }} \\
(\mathbf{n m})\end{array}$ & $\phi_{\mathbf{0}}$ & $\phi$ & $\begin{array}{c}\tau_{\mathbf{0}} \\
(\mathbf{n s})\end{array}$ & $\begin{array}{c}\tau \\
(\mathbf{n s})\end{array}$ & $\begin{array}{c}\mathbf{k}_{\mathbf{q}} \\
\left(\mathbf{M}^{-\mathbf{1}} \mathbf{s}^{-\mathbf{1}}\right)\end{array}$ \\
\hline $\mathbf{1}$ & 504 & 0.71 & 0.026 & 1692 & 65 & $2.3 \cdot 10^{10}$ \\
\hline $\mathbf{2}$ & 514 & 0.81 & 0.020 & 2474 & 61 & $2.5 \cdot 10^{10}$ \\
\hline
\end{tabular}

Oxygen quenching. For both complexes $\mathbf{1}$ and 2, a decrease in the quantum yield and lifetime is observed in presence of oxygen. In aerated solutions the hemicaged complex 1 
shows slightly higher quantum yields and lifetimes than the open complex 2 . The luminescence oxygen quenching of the complexes was quantitatively studied by determining the luminescence intensity of solutions with different concentrations of oxygen and by plotting the obtained results according to the Stern-Volmer equation (eq. 6.1):

$$
\frac{I_{0}}{I}=1+k_{q} \tau_{0}\left[O_{2}\right]
$$

$\mathrm{I}_{0}$ and $\mathrm{I}$ are the emission intensities in the absence or presence of quencher, respectively, $\mathrm{k}_{\mathrm{q}}$ is the quenching constant, $\tau_{0}$ is the lifetime in absence of quencher and $\left[\mathrm{O}_{2}\right]$ the concentration of oxygen in solution. ${ }^{12}$ The Stern-Volmer plots for the two complexes are shown in Figure 6.8. From the analysis of the quenching constants $\mathrm{k}_{\mathrm{q}}$ (Table 2) it is possible to determine the oxygen quenching efficiency. Similarly to other complexes described in this thesis that have the substituents on the pyridines' site of the complex, the hemicaged complex 1 shows a decrease of oxygen quenching compared to the open complex 2. Despite the higher shielding expected for a hemicage with a benzene-based capping unit (which is more bulky and less flexible than the triethylamine reported in Chapters 3,4 and 5), the oxygen quenching shown by the hemicaged complex $\mathbf{1}$ is only $10 \%$ lower than that of open complex $\mathbf{2}$. The lower shielding against oxygen quenching (compared to $40 \%$ quenching decrease shown by hemicaged complexes with amide groups) could be due to the different position of the LUMO orbital, which is probably localized on non-shielded carbon atoms. This hypothesis is corroborated by computational models (see Appendix 6.1). Analogous to what was done with the hemicaged complexes reported in Chapter 4 and 5, a hemicaged complex bearing a benzene-based capping unit connected through electron-donating groups with the phenyl ring could have been studied. However, it is clear from the results shown in Chapter 5 that the introduction of a capping unit in order to shield the atoms where the HOMO orbital is mostly localised, does not result in any change of luminescence oxygen quenching. Therefore, the investigation of a hemicaged structure functionalized on the phenyl ring with a benzenebased capping unit is not expected to add any further information to a general theory of the structural induced shielding against oxygen quenching. 


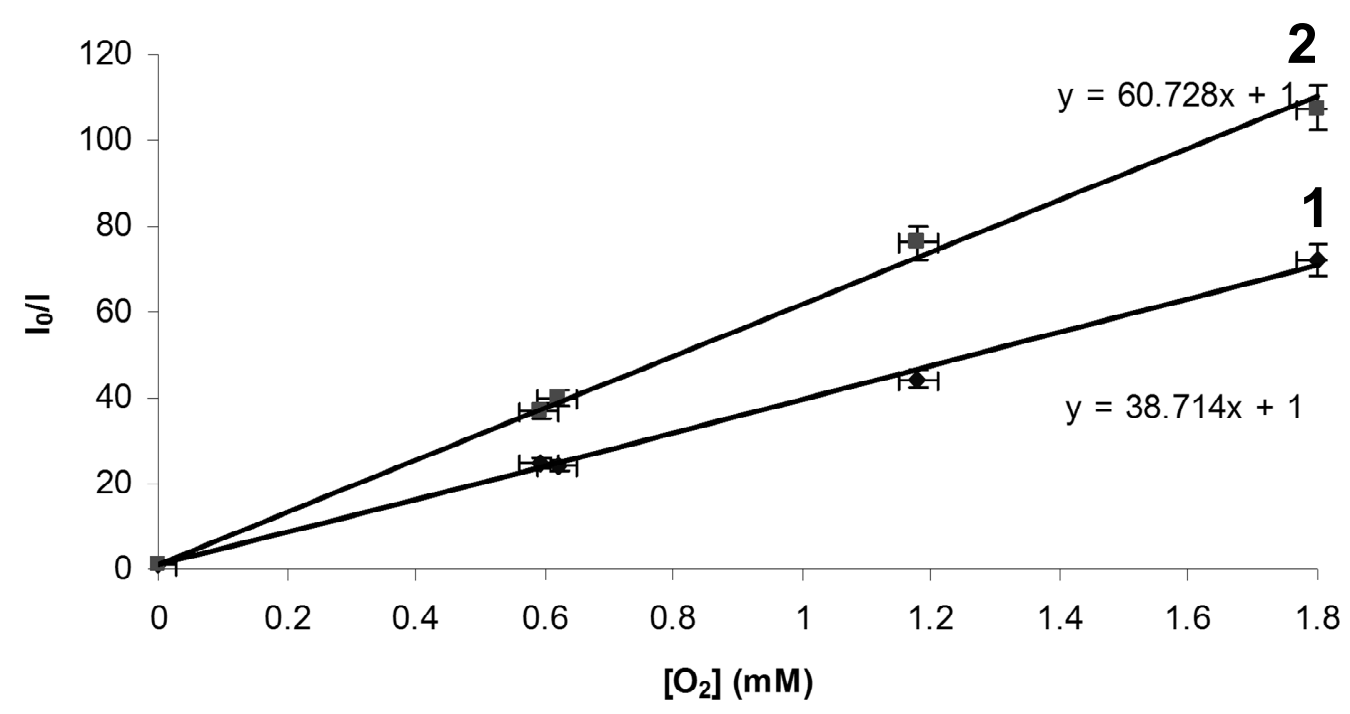

Figure 6.8. Stern-Volmer plot of the hemicaged (1) and open (2) complexes in DMF at $25^{\circ} \mathrm{C}$.

The synthesis of a caged complex (8, Figure 6.9) bearing a benzene-based capping unit both on the phenyl and on the pyridine ring was attempted without success. Because of the synthetic difficulties encountered and the discouraging results in terms of decrease of oxygen quenching observed for the hemicaged complex 1, the synthesis of the caged complex $\mathbf{8}$ was not further pursued. A description of the synthetic attempts for the synthesis of $\mathbf{8}$ is reported in the Appendix 6.2.

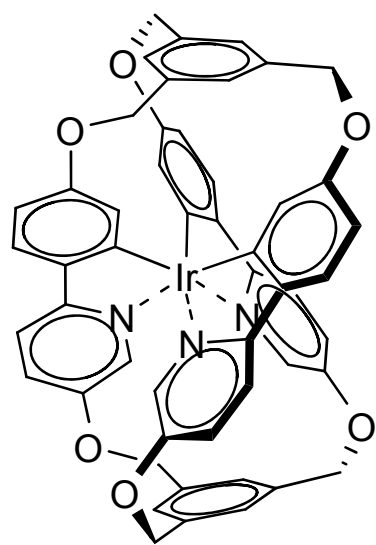

8

Figure 6.9 The structure of an ether-based Ir(III)-cage with benzene-based capping units. 


\subsection{Conclusions}

In this chapter the design, synthesis, characterization and luminescence properties of two related Ir(III) complexes with a hemicaged (1) and open (2) structure are reported. Both compounds show the typical absorption bands associated to $\operatorname{Ir}(\mathrm{ppy})_{3}$ derivatives and a strong luminescence and long lifetime in the absence of oxygen. As expected for complexes functionalized with electron-donating $\left(\sigma_{\mathrm{o}}=-0.39\right)$ groups, 1 and 2 show a slight blue shift of their emission maximum, with respect to the archetypical $\operatorname{Ir}(\mathrm{ppy})_{3}$. This is due to the different destabilization of the HOMO and LUMO orbitals induced by the presence of the oxymethyl moiety both on the phenyl and on the pyridine side of the ligands. Contrary to what was found for Ir(III)-hemicaged complexes functionalized with amide moieties (see Chapter 3, 4 and 5), where a $40 \%$ decrease of the oxygen quenching of the luminescence was observed, hemicage 1 shows only a 10\% decrease compared to the open complex 2 . This less pronounced shielding effect of $\mathbf{1}$ is probably due to the electron donating effect of the ether moiety, which localizes the LUMO orbital on all the carbons of the pyridine ring (see Appendix 6.1), which are not shielded by the aromatic capping unit due to the conformation induced by geometrical constraint of the hemicaged structure.

\subsection{Experimental section}

Oxygen- or water-sensitive reactions were conducted under a positive pressure of argon in oven-dried glassware, using Schlenk techniques. Unless otherwise stated, commercial grade reagents (Aldrich) were used without further purification. The purity of the final compounds was determined by NMR and MS spectrometry. Due to the low amount of final compound, it was not possible to perform elemental analysis. The NMR experiments were performed on a Bruker Avance II NMR spectrometer operating at $600.35 \mathrm{MHz}$ for ${ }^{1} \mathrm{H}$ and $150.09 \mathrm{MHz}$ for

${ }^{13} \mathrm{C}$ or on a Varian Unity 300 spectrometer operating at $300 \mathrm{MHz}$ for ${ }^{1} \mathrm{H}$. Chemicals shifts are given in ppm using the residual solvent signal as reference. Mass spectra were acquired on a Micromass LCT (ESI-MS) or Voyager-DE RP (MALDI-MS) spectrometer. UV-Vis spectra were measured on a Perkin Elmer Lambda $850 \mathrm{UV}$-Vis spectrophotometer. Steady-state luminescence spectra were measured using an Edinburgh FS900 fluorospectrometer. A 450 $\mathrm{W}$ xenon arc lamp was used as excitation source. Luminescence quantum yields at room temperature ( $\Phi$ and $\Phi_{\text {air }}$ ) were evaluated by comparing wavelength-integrated intensities $(I)$ of isoabsorptive optically diluted solutions $(A b s<0.1)$ with reference to fluorescein $\left(\Phi_{R}=0.92\right.$ in $\mathrm{NaOH} 0.1 \mathrm{M}$ ) standards and by using the equation 6.2 : 


$$
\Phi=\Phi_{R} \frac{n^{2} I}{n_{R}^{2} I_{R}}
$$

where $n$ and $n_{R}$ are the refractive index of the sample and reference solvent, respectively. ${ }^{13}$ Fluorescence lifetimes were determined using a FluoroMax4, Horiba Jobin Yvon spectrophotometer, equipped with a TCSPC extension and a pulsed $462 \mathrm{~nm}$ NanoLED for excitation (all Horiba Jobin Yvon). The recorded data were analyzed using the DAS6 software package of Horiba Jobin Yvon.

Degassed solutions were prepared by four freeze-pump-thaw cycles. Solutions with different oxygen concentration, suitable for the Stern-Volmer quenching studies, were prepared by using $\mathrm{N}_{2} / \mathrm{O}_{2}$ mixtures prepared with a Brooks 5850S Mass Flow control and by purging the fluorophore solutions for 40 minutes.

6-Bromopyridin-3-ol (3). $3.502 \mathrm{~g}$ (17.35 mmol) of (6-bromopyridin-3-yl)boronic acid were dissolved in $250 \mathrm{~mL}$ of dichloromethane. $5.4 \mathrm{~mL}$ of hydrogen peroxide (30\% in water, 1.11 $\mathrm{g} / \mathrm{mL}, 52.87 \mathrm{mmol}$ ) were added dropwise during 1 hour, and the mixture was reacted overnight. The solvent was evaporated and the solid dissolved in chloroform. The organic phase was washed 3 times with saturated $\mathrm{NaHCO}_{3}$, then dried over $\mathrm{Na}_{2} \mathrm{SO}_{4}$, the solvent removed and the resulting solid was dried under vacuum. Obtained $1.332 \mathrm{~g}$ (7.66 mmol, $44 \%$ ) of product. ${ }^{1} \mathrm{H}-\mathrm{NMR}\left(300 \mathrm{MHz}, \mathrm{CD}_{3} \mathrm{OD}\right): \delta 7.16\left(1 \mathrm{H}, \mathrm{d},{ }^{3} \mathrm{~J}_{\mathrm{HH}}=8.7 \mathrm{~Hz}\right) ; 7.40(1 \mathrm{H}, \mathrm{d}$, $\left.{ }^{3} \mathrm{~J}_{\mathrm{HH}}=8.7 \mathrm{~Hz}\right) ; 7.89(1 \mathrm{H}, \mathrm{s}) .{ }^{13} \mathrm{C}-\mathrm{NMR}\left(75 \mathrm{MHz}, \mathrm{CD}_{3} \mathrm{Cl}\right): \delta 158,141,133,132,130$.

1,3,5-Tris(((6-bromopyridin-3-yl)oxy)methyl)benzene (6). $1.000 \mathrm{~g}(5.75 \mathrm{mmol})$ of (3) was dissolved in DMF and $232 \mathrm{mg}$ of $\mathrm{NaH}(60 \%$ in oil, $5.80 \mathrm{mmol})$ were added to the solution. After few minutes, $510 \mathrm{mg}(1.43 \mathrm{mmol})$ of 1,3,5-tris(2-bromoethyl)benzene were added and the mixture was reacted for 2 hours. The product was precipitated upon addition of water, filtered and washed 2 times with diluted $\mathrm{CH}_{3} \mathrm{CO}_{2} \mathrm{H}$ and $\mathrm{NaOH}$. The solid was then dissolved in chloroform, washed with brine, dried over $\mathrm{Na}_{2} \mathrm{SO}_{4}$ and eventually the solvent was evaporated. Obtained $881 \mathrm{mg}(1.38 \mathrm{mmol}, 97 \%) .{ }^{1} \mathrm{H}-\mathrm{NMR}\left(300 \mathrm{MHz}, \mathrm{CDCl}_{3}\right): \delta 5.13(2 \mathrm{H}, \mathrm{s})$; $7.17\left(1 \mathrm{H}, \mathrm{d},{ }^{3} \mathrm{~J}_{\mathrm{HH}}=8.7 \mathrm{~Hz}\right) ; 7.40\left(1 \mathrm{H}, \mathrm{d},{ }^{3} \mathrm{~J}_{\mathrm{HH}}=8.7 \mathrm{~Hz}\right) ; 7.45(1 \mathrm{H}, \mathrm{s}) ; 8.14(1 \mathrm{H}, \mathrm{s}) .{ }^{13} \mathrm{C}-\mathrm{NMR}$ (75 MHz, $\left.\mathrm{CD}_{3} \mathrm{Cl}\right): \delta 154,138,137,133,129,126,125,70$. ESI-MS: calc. for $\mathrm{C}_{24} \mathrm{H}_{18} \mathrm{Br}_{3} \mathrm{~N}_{3} \mathrm{O}_{3}$ $[\mathrm{M}+\mathrm{H}]^{+} 636.1$ found 636.0. 
Tripodal ligand (7). $200 \mathrm{mg}(0.31 \mathrm{mmol})$ of the tripod 6, $150 \mathrm{mg}(0.99 \mathrm{mmol})$ of (4methoxyphenyl) boronic acid, $250 \mathrm{mg}(2.34 \mathrm{mmol})$ of $\mathrm{Na}_{2} \mathrm{CO}_{3}$ and $60 \mathrm{mg}(0.05 \mathrm{mmol})$ of $\mathrm{Pd}\left(\mathrm{PPh}_{3}\right)_{4}$ were dissolved in a mixture of THF/Water $1: 1$. The oxygen was removed by several cycles of Argon/Vacuum and the mixture refluxed overnight. The THF was removed and the water phase extracted with chloroform. The organic phase was dried over $\mathrm{Na}_{2} \mathrm{SO}_{4}$ and the solvent evaporated. The product was purified by column chromatography $\left(\mathrm{SiO}_{2}\right.$, Chloroform-Diethyl Ether 1:1) and recrystallized from Acetone. Obtained $140 \mathrm{mg}(0.20$ mmol, 62\%). ${ }^{1} \mathrm{H}-\mathrm{NMR}\left(300 \mathrm{MHz}, \mathrm{CD}_{3} \mathrm{Cl}\right): \delta 3.86(3 \mathrm{H}, \mathrm{s}) ; 5.20(2 \mathrm{H}, \mathrm{s}) ; 6.97\left(2 \mathrm{H}, \mathrm{d},{ }^{3} \mathrm{~J}_{\mathrm{HH}}=\right.$ $9.0 \mathrm{~Hz}) ; 7.31\left(1 \mathrm{H}, \mathrm{d},{ }^{3} \mathrm{~J}_{\mathrm{HH}}=8.4\right) ; 7.52(1 \mathrm{H}, \mathrm{s}) ; 7.59\left(1 \mathrm{H}, \mathrm{d},{ }^{3} \mathrm{~J}_{\mathrm{HH}}=8.4 \mathrm{~Hz}\right) ; 7.86\left(2 \mathrm{H}, \mathrm{d},{ }^{3} \mathrm{~J}_{\mathrm{HH}}\right.$ $=9.0 \mathrm{~Hz}) ; 8.42(1 \mathrm{H}, \mathrm{s}) .{ }^{13} \mathrm{C}-\mathrm{NMR}\left(75 \mathrm{MHz}, \mathrm{CD}_{3} \mathrm{Cl}\right): \delta 161,153,149,137,134,133,128$, 126, 121, 114, 70, 56. ESI-MS: calc. for $\mathrm{C}_{45} \mathrm{H}_{44} \mathrm{~N}_{3} \mathrm{O}_{6}[\mathrm{M}+\mathrm{H}]^{+} 718.8$ found 718.6.

Iridium Hemicaged Complex (1). $50 \mathrm{mg}(0.07 \mathrm{mmol})$ of the tripodal ligand 27, $34 \mathrm{mg}(0.07$ $\mathrm{mmol})$ of $\operatorname{Ir}(\mathrm{acac})_{3}$ and $46 \mathrm{mg}(0.21 \mathrm{mmol})$ of silver trifluoroacetate were dissolved in glycerine, and refluxed over 5 hours under inert atmosphere. After cooling down, the solution was diluted with water, extracted 3 times with dichloromethane, washed with brine and dried over $\mathrm{Na}_{2} \mathrm{SO}_{4}$. The solvent was removed and the product purified by preparative TLC (Hexane-Ethyl Acetate 6:4). Obtained $12 \mathrm{mg}$ (0.02 mmol, 19\%). ${ }^{1} \mathrm{H}-\mathrm{NMR}(600 \mathrm{MHz}$, $\left.\mathrm{CD}_{2} \mathrm{Cl}_{2}\right): \delta 3.55(3 \mathrm{H}, \mathrm{s}) ; 4.82\left(1 \mathrm{H}, \mathrm{d},{ }^{2} \mathrm{~J}_{\mathrm{HH}}=12.7 \mathrm{~Hz}\right) ; 5.16\left(1 \mathrm{H}, \mathrm{d},{ }^{2} \mathrm{~J}_{\mathrm{HH}}=12.7 \mathrm{~Hz}\right) ; 6.11(1 \mathrm{H}$, s); $6.42\left(1 \mathrm{H}, \mathrm{d},{ }^{3} \mathrm{~J}_{\mathrm{HH}}=2.6 \mathrm{~Hz}\right) ; 6.44(1 \mathrm{H}, \mathrm{s}) ; 7.08(1 \mathrm{H}, \mathrm{s}) ; 7.44\left(1 \mathrm{H}, \mathrm{d},{ }^{3} \mathrm{~J}_{\mathrm{HH}}=2.6 \mathrm{~Hz}\right) ; 7.46$ $\left(1 \mathrm{H}, \mathrm{d},{ }^{3} \mathrm{~J}_{\mathrm{HH}}=8.7 \mathrm{~Hz}\right) ; 7.72\left(1 \mathrm{H}, \mathrm{d},{ }^{3} \mathrm{~J}_{\mathrm{HH}}=8.7 \mathrm{~Hz}\right)$. MALDI-MS calculated for $\mathrm{C}_{45} \mathrm{H}_{36} \mathrm{IrN}_{3} \mathrm{O}_{6}$ $[\mathrm{M}+\mathrm{H}]^{+}$907.22, found 907.71. ${ }^{13} \mathrm{C}-\mathrm{NMR}\left(175 \mathrm{MHz}, d 2-\mathrm{CH}_{2} \mathrm{Cl}_{2}\right)$ : see Figure 6.10.

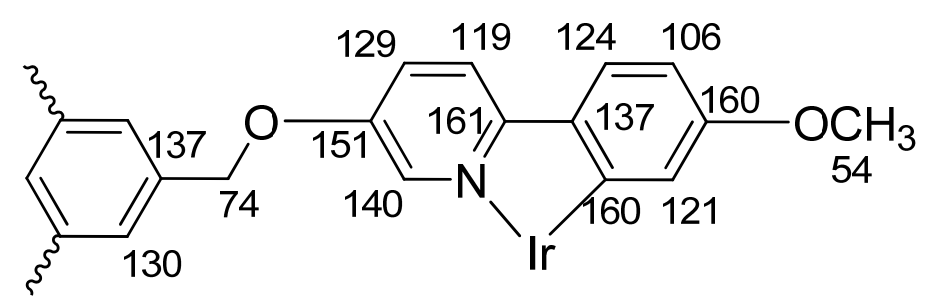

Figure 6.10. ${ }^{13} \mathrm{C}$ chemical shifts of hemicaged complex 1 derived from HMBC/HMQCNMR.

5-Methoxy-2-(4-methoxyphenyl)pyridine (4). $200 \mathrm{mg}$ (1.08 mmol) of 3, $165 \mathrm{mg}$ (1.09 mmol) of (4-methoxyphenyl) boronic acid, $250 \mathrm{mg}$ (2.34 mmol) of $\mathrm{Na}_{2} \mathrm{CO}_{3}$ and $60 \mathrm{mg}(0.05$ mmol) of $\mathrm{Pd}\left(\mathrm{PPh}_{3}\right)_{4}$ were dissolved in a mixture of THF/Water 1:1. The oxygen was removed by several cycles of Argon/Vacuum and the mixture refluxed overnight. After cooled down, 
the THF was removed and the water phase extracted with chloroform. The organic phase was dried over $\mathrm{Na}_{2} \mathrm{SO}_{4}$ and the solvent evaporated. The crude product was dissolved in dry DMF and $85 \mathrm{mg}$ (2.14 mmol) of $\mathrm{NaH}(60 \%$ dispersion in mineral oil $)$ and $135 \mu \mathrm{L}(2.14 \mathrm{mmol})$ of MeI were added and the resulting mixture was stirred for 2 hours. After the reaction mixture was poured on ice, the precipitate was then filtered and redissolved in chloroform. The organic phase was washed with brine, dried over $\mathrm{Na}_{2} \mathrm{SO}_{4}$ and the solvent was then evaporated. The crude product was purified by column choromatography $\left(\mathrm{SiO}_{2}\right.$, ChloroformDiethyl Ether 1:1). Obtained $71 \mathrm{mg}(0.33 \mathrm{mmol}, 31 \%)$. ${ }^{1} \mathrm{H}-\mathrm{NMR}\left(300 \mathrm{MHz}, \mathrm{CDCl}_{3}\right): \delta 3.86$ $(3 \mathrm{H}, \mathrm{s}) ; 3.89(3 \mathrm{H}, \mathrm{s}) ; 6.98\left(2 \mathrm{H}, \mathrm{d},{ }^{3} \mathrm{~J}_{\mathrm{HH}}=8.7\right) ; 7.26\left(1 \mathrm{H}, \mathrm{d},{ }^{3} \mathrm{~J}_{\mathrm{HH}}=8.7\right) ; 7.61\left(1 \mathrm{H}, \mathrm{d},{ }^{3} \mathrm{~J}_{\mathrm{HH}}=\right.$ 8.7); $7.88\left(2 \mathrm{H}, \mathrm{d},{ }^{3} \mathrm{~J}_{\mathrm{HH}}=8.7\right) ; 8.35(1 \mathrm{H}, \mathrm{s}) .{ }^{13} \mathrm{C}-\mathrm{NMR}\left(75 \mathrm{MHz}, \mathrm{CDCl}_{3}\right): 160,154,149,135$, $132,128,122,127,121,57,56$.

Iridium Open Complex (2). $60 \mathrm{mg}(0.28 \mathrm{mmol})$ of the phenylpyridine derivative 4, $45 \mathrm{mg}$ $(0.09 \mathrm{mmol})$ of $\operatorname{Ir}(\mathrm{acac})_{3}$ and $62 \mathrm{mg}(0.28 \mathrm{mmol})$ of silver trifluoroacetate were dissolved in $15 \mathrm{~mL}$ of glycerine. The oxygen was removed by several cycles Argon/Vacuum and the reaction mixture was refluxed overnight. The reaction crude was diluted with water and extracted 3 times with dichloromethane. Then, the organic phase was washed with water and brine, dried over $\mathrm{Na}_{2} \mathrm{SO}_{4}$ and the solvent evaporated. Purified by column chromatography $\left(\mathrm{SiO}_{2}\right.$, Hexane-Ethyl Acetate 6:4). Obtained $22 \mathrm{mg}(0.03 \mathrm{mmol}, 27 \%) .{ }^{1} \mathrm{H}-\mathrm{NMR}(600 \mathrm{MHz}$, $\left.\mathrm{CD}_{2} \mathrm{Cl}_{2}\right): \delta 3.54(3 \mathrm{H}, \mathrm{s}) ; 3.64(3 \mathrm{H}, \mathrm{s}) ; 6.27(1 \mathrm{H}, \mathrm{s}) ; 6.43\left(1 \mathrm{H}, \mathrm{d},{ }^{3} \mathrm{~J}_{\mathrm{HH}}=8.5\right) ; 7.21(1 \mathrm{H}, \mathrm{s}) ; 7.24$ $\left(1 \mathrm{H}, \mathrm{d},{ }^{3} \mathrm{~J}_{\mathrm{HH}}=8.9\right) ; 7.49(1 \mathrm{H}, \mathrm{d}, 8.5) ; 7.72\left(1 \mathrm{H}, \mathrm{d},{ }^{3} \mathrm{~J}_{\mathrm{HH}}=8.9\right)$. MALDI-MS calculated for $\mathrm{C}_{39} \mathrm{H}_{36} \mathrm{IrN}_{3} \mathrm{O}_{6}[\mathrm{M}+\mathrm{H}]^{+}$835.22, found 835.68. ${ }^{13} \mathrm{C}-\mathrm{NMR}$ : See Figure 6.11.

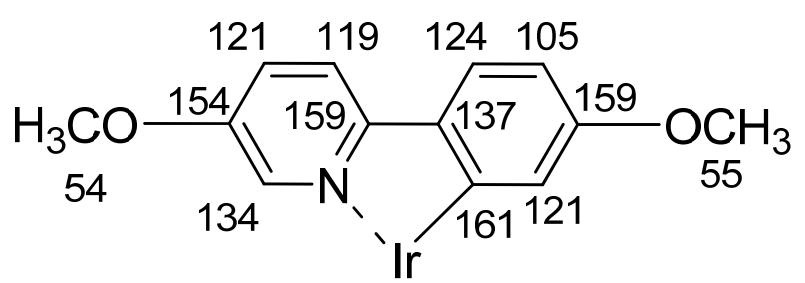

Figure 6.11. ${ }^{13} \mathrm{C}$ chemical shifts of open complex 2 derived from HMBC/HMQC-NMR.

\subsection{References}

1. Beeston, R. F.; Aldridge, W. S.; Treadway, J. A.; Fitzgerald, M. C.; DeGraff, B. A.; Stitzel, S. E., Inorg. Chem. 1998, 37, 4368-4379.

2. Beeston, R. F.; Larson, S. L.; Fitzgerald, M. C., Inorg. Chem. 1989, 28, 4187-4189. 
3. Barigelletti, F.; De Cola, L.; Balzani, V.; Belser, P.; Von Zelewsky, A.; Voegtle, F.; Ebmeyer, F.; Grammenudi, S., J. Am. Chem. Soc. 1989, 111, 4662-4668.

4. Oyler, K. D.; Coughlin, F. J.; Bernhard, S., J. Am. Chem. Soc. 2007, 129, 210-217.

5. Schaffner-Hamann, C.; von Zelewsky, A.; Barbieri, A.; Barigelletti, F.; Muller, G.; Riehl, J. P.; Neels, A., J. Am. Chem. Soc. 2004, 126, 9339-9348.

6. M. B. Smith; March, J., March's Advanced Organic Chemistry. Wiley-interscience: New York, 2001.

7. Miyaura, N.; Suzuki, A., Chem. Rev. 2002, 95, 2457-2483.

8. Voisin, A. S.; Bouillon, A.; Lancelot, J. C.; Rault, S., Tetrahedron 2005, 61, 1417-1421.

9. Tamayo, A. B.; Alleyne, B. D.; Djurovich, P. I.; Lamansky, S.; Tsyba, I.; Ho, N. N.; Bau, R.; Thompson, M. E., J. Am. Chem. Soc. 2003, 125, 7377-7387.

10. Holzer, W.; Penzkofer, A.; Tsuboi, T., Chem. Phys. 2005, 308, 93-102.

11. Flamigni, L.; Barbieri, A.; Sabatini, C.; Ventura, B.; Barigelletti, F., Photochemistry and photophysics of coordination compounds: Iridium. In Photochemistry and Photophysics of Coordination Compounds II, 2007; Vol. 281, pp 143-203.

12. Lakowicz, J. R., Principles of Fluorescence Spectroscopy. Springer: Singapore, 2006.

13. Montalti, M.; Credi, A.; Prodi, L.; Gandolfi, M. T., Handbook of Photochemistry. CRC Press: Boca Raton, 2006. 


\section{Appendix 6.1}

\section{Analysis of a computational model of the hemicaged complex 1 and its LUMO localization according to DFT calculations}

In this section the localization of the LUMO orbital according to DFT calculations and its effect on the oxygen quenching of the hemicaged complex $\mathbf{1}$ is discussed.

The geometry of the complex in vacuum was optimized by using a B3LYP functional with a 6-31G** basis set and the iridium atom was described by using a LANL2DZ basis set implemented in the software package Spartan '08. The same parameters were used for the calculation of the single point energy. Because of the excessive computational resources required, it was not possible to optimize the excited states of the molecule, therefore the LUMO of the ground state is used here as a first approximation of the excited state.

The optimized geometry is reported in Figure 6.12. The optimized geometry shows a C3 symmetry, as expected for a $f a c$ isomer of a homoleptic $\operatorname{Ir}(\mathrm{III})$ complex. Moreover, the calculated C-Ir and N-Ir bond length (2.03 and $2.18 \AA$ respectively) are in good agreement with the data (2.0246 and $2.1325 \AA$ respectively) obtained from single crystal X-ray diffractometry on $\operatorname{Ir}(\mathrm{ppy})_{3}$ complex. ${ }^{9}$ A further evidence of the consistency of the computational model can be found by comparison of the structural data obtained from NMR spectroscopy with the computational results. First of all, the calculated C3 symmetry of the hemicaged complex 1 was proved by the presence of only one set of signals in the ${ }^{1} \mathrm{H}-\mathrm{NMR}$ spectrum (Section 6.3). Secondarily, the comparison of the chemical shift of the proton Ha in the hemicaged (1) and open (2) complex shows a remarkable shift towards higher fields (1 ppm) induced by the shielding cone of the pyridine rings on other branches. Conversely, a shift towards lower fields $(0.1 \mathrm{ppm})$ is observed for the proton Hf, which is deshielded by the phenyl ring's edge on other branches of the hemicage. These effects are consistent with the structure obtained from DFT calculation (Figure 6.12).

The calculated LUMO orbital of the hemicaged complex 1 is reported in Figure 6.13 together with the LUMO orbital of $\operatorname{Ir}(\mathrm{ppy})_{3}$ for comparison purposes. The presence of an electrondonating group induces a different localization of the LUMO orbital in the hemicaged complex 1, compared to the $\operatorname{Ir}(\mathrm{ppy})_{3}$ complex. In 1, the LUMO orbital is completely localised only on the pyridine ring, whilst in $\operatorname{Ir}(\mathrm{ppy})_{3}$ is partly localised also on the phenyl ring. 
Moreover, in 1 the LUMO orbital is localised also on the carbon ortho- position with respect to the methoxy and the $\mathrm{N}$ atom, which does not give any contribution to the LUMO orbital of $\operatorname{Ir}(\text { ppy })_{3}$.According to computational results, the LUMO orbital is mostly localized on carbons which are poorly shielded by the capping unit, resulting in a low decrease of oxygen quenching compared to the open complex 2.
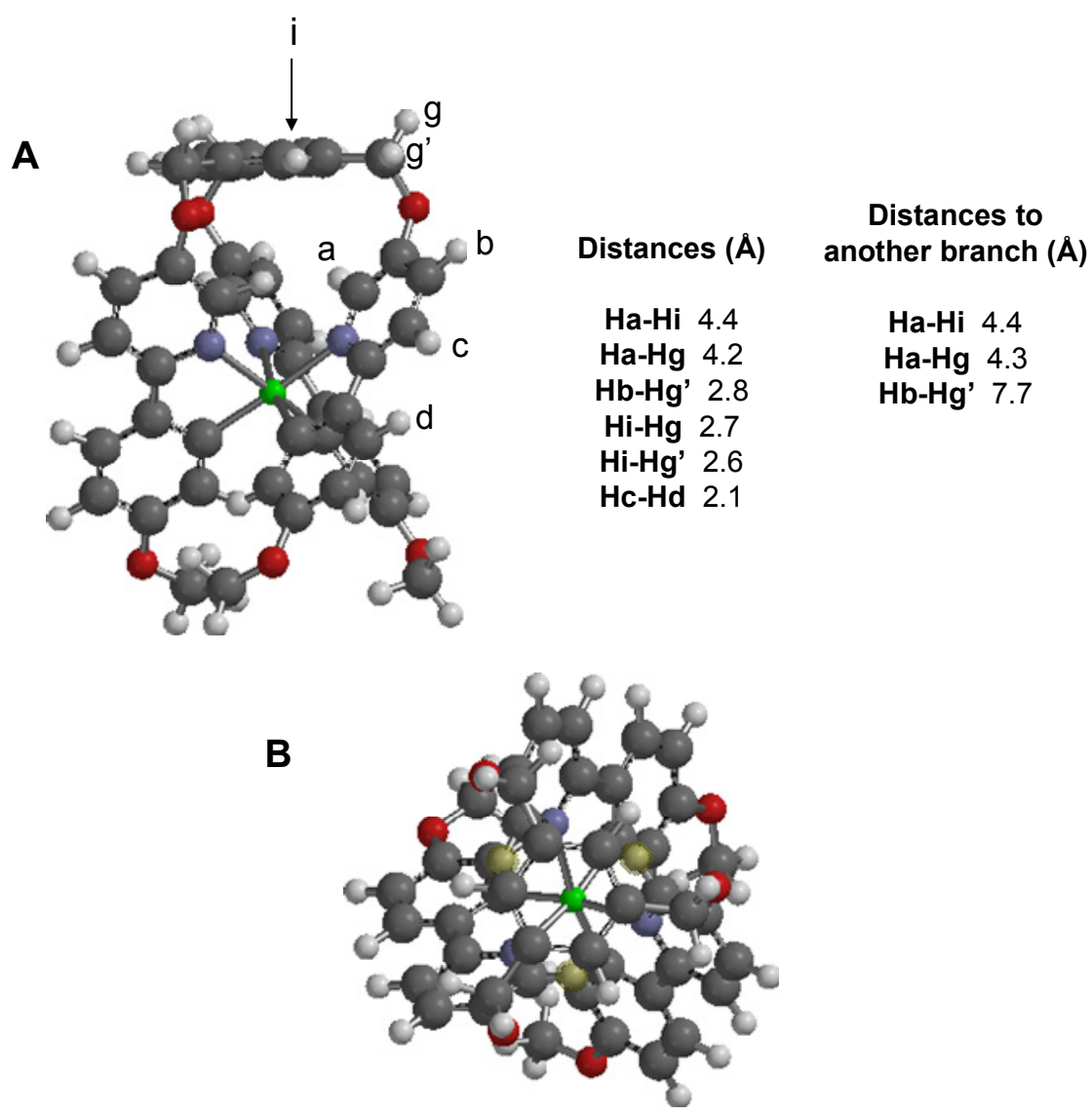

Figure 6.12. Structure of the hemicaged complex 1 from DFT calculations. A) Side view showing the distances of protons with through-space interactions in the NOESY spectrum. B) Top view showing the position of the Ha protons (yellow) with respect to the capping unit. 
A
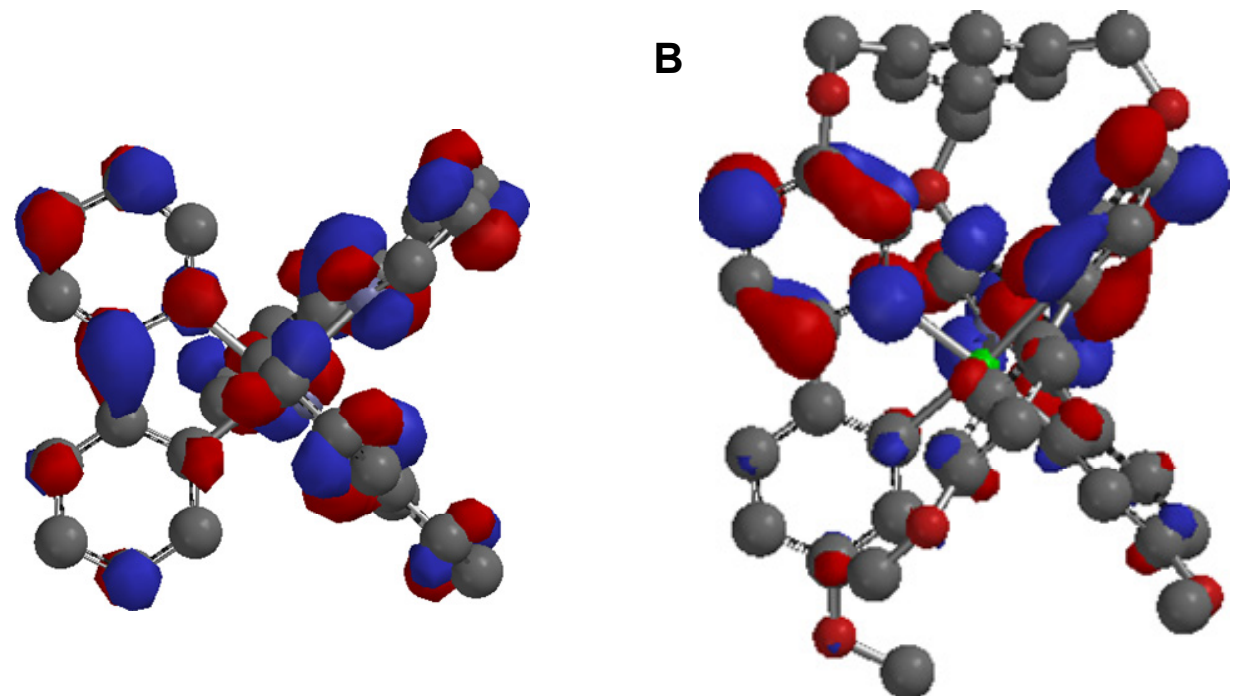

Figure 6.13. Calculated LUMO orbital of $\operatorname{Ir}(\mathrm{ppy})_{3}(\mathrm{~A})$ and of hemicaged complex 1 (B). Protons are omitted for clarity.

A more quantitative analysis of the LUMO orbital's localization can be done on the basis of the atomic contribution. A chart of the atomic contribution to the LUMO orbital of $\mathbf{1}$ is reported in Figure $6.14 \mathrm{~A}$, together with $\operatorname{Ir}(\mathrm{ppy})_{3}$.

A
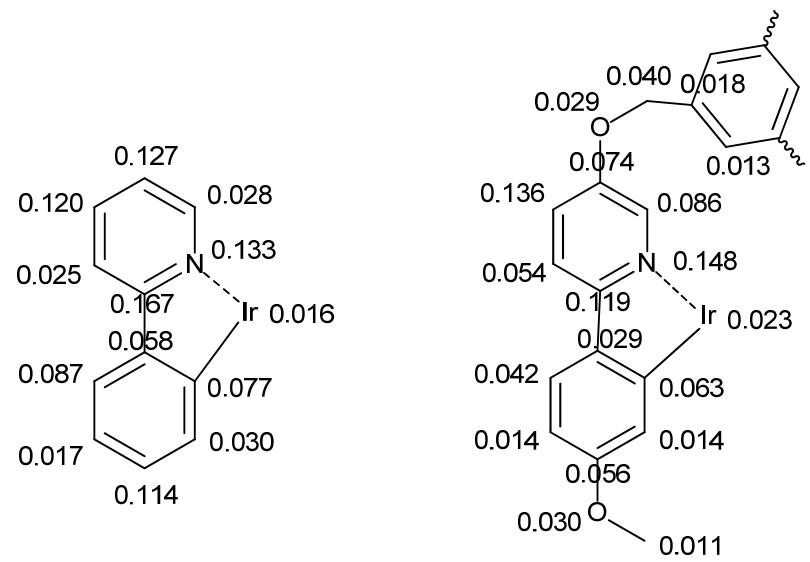

B

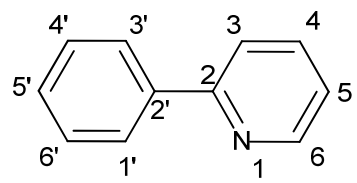

Figure 6.14. A)Atomic contribution to the LUMO orbital of $\operatorname{Ir}(\mathrm{ppy})_{3}$ (left) and hemicaged complex 1 (right). B) Numbering of carbon atoms of 2-phenylpyridine ligand.

The atomic contributions to the LUMO orbital are coherent with the picture of the LUMO given in Figure 6.13. The introduction of the capping unit on the pyridine ring and of the methoxy moiety on the phenyl ring (both in meta- position with respect to the $\mathrm{N}$ and $\mathrm{C}$ atoms 
connected with Ir) dramatically changes the distribution of the LUMO orbital with respect to $\operatorname{Ir}(\text { ppy })_{3}$. Generally speaking, in 1 the phenyl ring gives a lower contribution (22\%) to the LUMO orbital, whilst in $\operatorname{Ir}(\text { ppy })_{3}$ the contribution of the phenyl ring is higher $(35 \%)$. Therefore, the LUMO orbital of the hemicaged complex $\mathbf{1}$ is more localised on the pyridine ring than in $\operatorname{Ir}(\text { ppy })_{3}$. Moreover, both the capping unit on the pyridine ring and the methoxy group on the phenyl ring give only a modest contribution (14\%) to the LUMO orbital, which is therefore mostly localised on the $\operatorname{Ir}(\mathrm{III})$-tris(phenylpyridine) core. As expected from the resonance structures shown in Figure 6.1, the presence of an electron-donating group on position 5 of the pyridine ring increases the electronic density on the atoms which are in ortho- positions, i.e. the carbons C4 and C6 via a mesomeric effect. From the analysis of the atomic contribution to the LUMO orbital it is evident that the pyridine's atoms in ortho- to the oxymethyl group give a stronger contribution to the LUMO orbital than in $\operatorname{Ir}(\mathrm{ppy})_{3}$. For instance, the carbon C6 gives an almost 9\% contribution to the LUMO orbital of 1, whilst the same atom gives only a 3\% contribution to the LUMO orbital of $\operatorname{Ir}(\mathrm{ppy})_{3}$. Analogously, the carbon $\mathrm{C} 4$ gives an almost 14\% contribution to the LUMO orbital of 1 , whilst the contribution given by the same atom to the LUMO orbital of $\operatorname{Ir}(\mathrm{ppy})_{3}$ is $12 \%$. Surprisingly, the LUMO orbital is highly localised also on the atoms $\mathrm{C} 3$ and $\mathrm{N}$ belonging to the pyridine ring, although these atoms give only a modest contribution to the LUMO orbital of $\operatorname{Ir}(\mathrm{ppy})_{3}$. Conversely, the carbon $\mathrm{C} 2$ (which is in para- to the electron donating group and therefore is expected to give a high contribution to the LUMO orbital of 1) gives only a $12 \%$ contribution, whilst the same atom in $\operatorname{Ir}(\mathrm{ppy})_{3}$ gives an almost $17 \%$ contribution to the LUMO orbital. The reason of the different behaviours of the atoms $\mathrm{C} 3, \mathrm{~N}$ and $\mathrm{C} 2$ in $\mathbf{1}$ and in $\operatorname{Ir}(\text { ppy })_{3}$ is not clear yet. However, it is possible to hypothesize an effect of the methoxy group on the phenyl ring. In fact, contrary to $\mathrm{C} 2$, the atoms $\mathrm{C} 3$ and $\mathrm{N}$ are conjugated with the methoxy group through the bridge between the two rings. A further evidence of this conjugation is given by the previously discussed decreased localization of the LUMO orbital on the phenyl ring of $\mathbf{1}$.

The poor decrease of oxygen quenching shown by hemicaged complex 1 with respect to the open complex $\mathbf{2}$ can be explained on the basis of the localization of the LUMO orbital in $\mathbf{1}$. Several factors should be taken into account: 1) the presence of the electron-donating group on the position 5 of the pyridine ring induces a high localization of the LUMO orbital on the carbons $\mathrm{C} 4$ and $\mathrm{C} 6$; 2) the carbon C6 is located on the outside of the hemicaged molecule and therefore it is not shielded by the capping unit; 3) the carbon $\mathrm{C} 4$ is located on the inner side of the hemicaged molecule, but according to the computational model it is only poorly 
shielded by the capping unit and 4) an increased localization of the LUMO orbital on the external carbon $\mathrm{C} 3$ and on the internal nitrogen atom is observed. All these observations show that the low (10\%) quenching decrease observed for 1 with respect to 2 results from a balance between the LUMO components localised on unshielded atoms (C6 and C3) and the LUMO components localised on partly shielded atoms (C4 and N). 


\section{Appendix 6.2}

Preliminary results concerning the synthesis of an ether-based caged complex with a benzene-based capping unit

In this section the synthetic patways followed in order to synthesize an ether-based caged complex (8, Figure 6.15) functionalized with benzene-based capping unit are discussed. From a preliminary analysis it is evident that cage $\mathbf{8}$ cannot be synthesized starting from hemicaged complex $\mathbf{1}$, due to the stability of the methoxy group which cannot be selectively removed without affecting the capping unit. The methoxy group is relatively inert and can be removed only with strong demethylating agents like $\mathrm{BF}_{3}$, which would remove also the capping unit. As discussed in Chapter 3, in order to synthesize such a kind of caged complexes, a tripodal approach offers a higher level of control compared to a template-based approach, therefore also a synthesis starting from the open complex $\mathbf{2}$ is not promising and the definition of a suitable synthetic strategy is necessary.

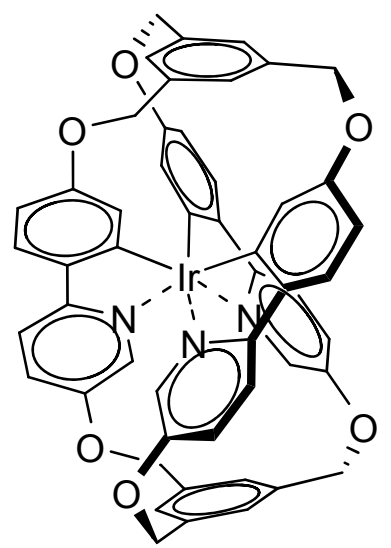

8

Figure 6.15. An ether-based Ir(III)-cage with benzene-based capping units.

The choice of an adequate protecting group for the phenyl moiety is of paramount importance for the synthesis of $\mathbf{8}$. The ideal protecting group should be stable under the harsh conditions necessary for the $\operatorname{Ir}(\mathrm{III})$ complexation, but it should be easily removable without affecting the capping unit. From this point of view, the common protecting groups (which are mostly based on aliphatic ethers) are not suitable, since their removal results also in cleavage of the ether-based capping unit. Silyl ethers are the most suitable candidates, since they show an 
acceptable thermal stability and can be easily cleaved with fluorides. The synthetic pathway followed for the synthesis of the unprotected hemicage $\mathbf{1 0}$ is reported in Scheme 6.3.

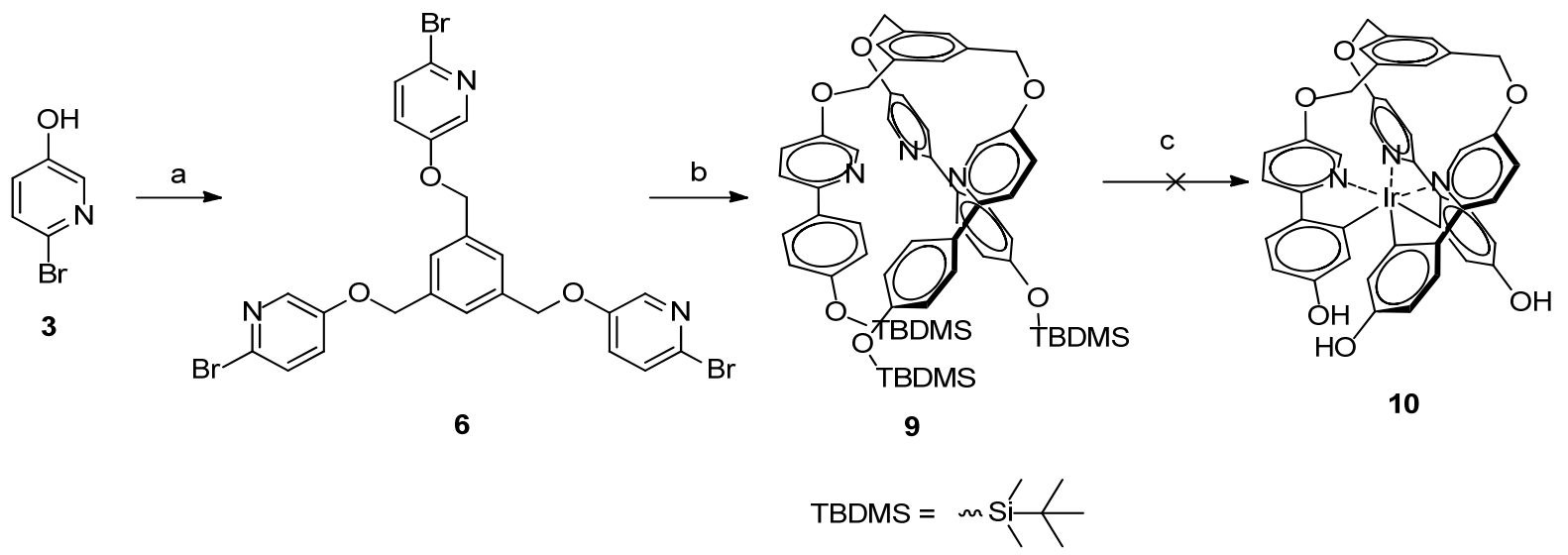

Scheme 6.3. Synthetic pathway for the synthesis of the unprotected hemicaged complex $\mathbf{1 0}$. Reaction conditions: a) 1,3,5-tris(2-bromoethyl)benzene, $\mathrm{NaH}$ (60\% in mineral oil), DMF, 2h, room temperature; b) 4-(tert-butyldimethylsilyloxy)phenylboronic acid, $\left[\mathrm{Pd}\left(\mathrm{PPh}_{3}\right)_{4}\right]$, $\mathrm{K}_{3} \mathrm{PO}_{4}$, dioxane $/ \mathrm{H}_{2} \mathrm{O}$ 1:1, reflux overnight, Ar; c) 1) $\operatorname{Ir}(\mathrm{acac})_{3}$, glycerin, reflux 5h, Ar; 2) TBAF, THF, 1h, room temperature.

Tripod 6 was conjugated with 4-(tert-butyldimethylsilyloxy)phenylboronic acid via Suzuki coupling. Due to the base-sensitivity of the TBDMS group, the use of a mild base $\left(\mathrm{K}_{3} \mathrm{PO}_{4}\right)$ was necessary in order to avoid the cleavage of the protecting group during the reaction. The tripodal ligand was obtained in $60 \%$ yield. However, the complexation of the tripod with Ir(III) was not successful, probably due to the high steric hindrance caused by the presence of the protecting group. On the other hand, the unreacted tripod was found in the reaction mixture, proving its stability under high temperature conditions.

Since the unprotected tripod did not give the expected complexation with Ir(III), a different protecting group was used. The TBDMS was removed with tetrabutylamonium fluoride (TBAF) and the resulting phenyl was then reacted with acetyl chloride giving the acetylated tripodal ligand 11. (Scheme 6.4) However, also in this case the complexation with Ir(III) was not successful and, therefore, the synthesis of caged complex 8 was abandoned. This decision was encouraged also by the poor results in terms of shielding against oxygen quenching given by hemicaged complex 1 . 


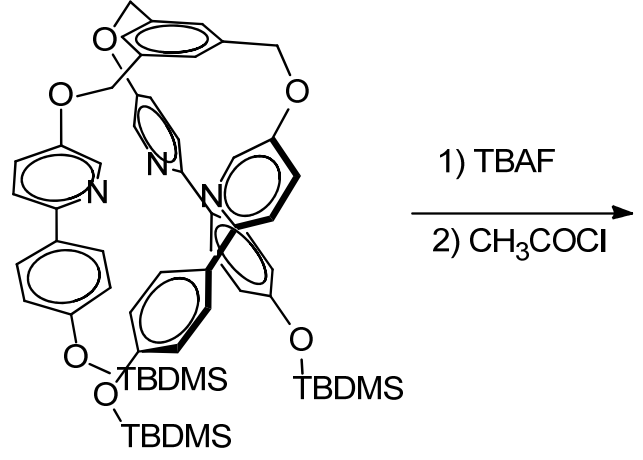

9

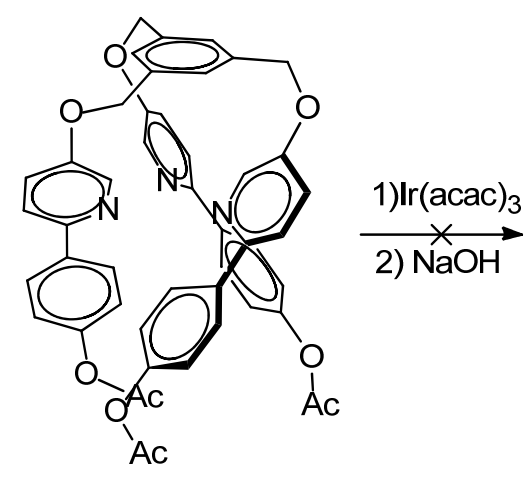

11

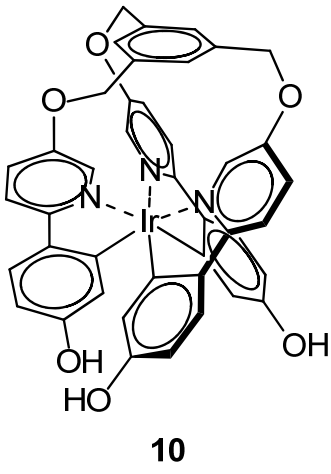

10

Scheme 6.4. Synthetic pathway for the synthesis of unprotected hemicage $\mathbf{1 0}$.

In conclusion, the synthesis of caged complex $\mathbf{8}$ was not feasible due to the lack of a suitable protecting group for the tripodal ligand, the stability of the protecting group itself and the low steric hindrance required for $\operatorname{Ir}(\mathrm{III})$ complexation. Moreover, the poor shielding shown by the hemicaged complex 1 towards oxygen quenching and the peculiar LUMO distribution observed from computational studies (see Appendix 6.1) did not justify a further investigation towards this direction. However, computational results suggest that a hemicaged or caged structure with a higher flexibility (i.e. with a longer linker between the capping unit and the $\operatorname{Ir}(\mathrm{III})$-tris(phenylpyridine) core) would probably result into a more effective shielding against oxygen quenching. On the other hand, the increased localization of the LUMO orbital on non-shielded atoms resulting from the presence of the electron-donating group on the pyridine ring suggests that the electron-donating moieties are probably not good candidates for the realization of hemicaged and caged $\operatorname{Ir}(\mathrm{III})$-complexes with a reduced degree of oxygen quenching. 


\title{
Chapter 7
}

There is excitement, adventure, and

challenge, and there can be great art in

organic synthesis.

R. B. Woodward

\section{Synthesis and oxygen quenching of the luminescence of an $\operatorname{Ir}($ III)- hemicaged complex with a 1,3,5-tris(ethyl)benzene capping unit}

\begin{abstract}
In this Chapter, the synthesis of an Ir(III)-tris(phenylpyridine) complex, functionalised on the phenyl rings with a 1,3,5-tris(ethyl)benzene capping unit, is reported and its structure in solution has been characterised by 1D and 2D NMR spectroscopy. The photophysical properties of the complex are discussed and compared with the archetypical $\operatorname{Ir}(\mathrm{ppy})_{3}$ and with the hemicaged complexes reported in Chapter 5 and in Chapter 6. The aromatic capping unit in the hemicaged complex has a limited effect on the oxygen quenching, which is comparable to that of $\operatorname{Ir}(\mathrm{ppy})_{3}$. This result corroborates the conclusions regarding the oxygen quenchingstructure related effect discussed in Chapters 4 and 5, namely that the introduction of a capping unit does not have any effect on oxygen quenching per se. The introduction of a capping unit is an efficient method to decrease the oxygen quenching of the luminescence only if the capping unit induces shielding on the atoms where the LUMO orbital is localised, i.e. on the pyridine ring.
\end{abstract}




\subsection{Introduction}

In Chapters 4 and 5 the synthesis of a series of $\operatorname{Ir}(\mathrm{III})$-tris(phenylpyridine) derivatives has been discussed. The derivatives are functionalized on the phenyl (Chapter 5) or the pyridine (Chapter 4) rings with a tris(2-amidoethyl)amine capping unit. The introduction of such substituent on the pyridine rings' side of the molecule induces a remarkable decrease $(40 \%)$ of oxygen quenching of the luminescence, deriving from the shielding of the atoms where the Lowest Unoccupied Molecular Orbital (LUMO) is localized. ${ }^{1}$ In fact, the introduction of the same capping unit on the phenyl ring (i.e. shielding the atoms where the Highest Occupied Molecular Orbital (HOMO) is localized) does not induce any decrease of oxygen quenching. Moreover, as reported in Chapter 6, an Ir(III)-tris(phenylpyridine) functionalized on the pyridine rings with a 1,3,5-tris(oxymethyl)benzene derivative shows only a limited $(10 \%)$ oxygen quenching decrease, as the LUMO is localized on unshielded atoms (due to the electron-donating properties of the ether linkage). The design of molecules that can be used to systematically study the structure-quenching relationship is rather challenging as there are dozens of molecules that can be designed on paper, but the synthetic possibilities and limitations have to be taken into consideration as well. In this Chapter, the synthesis of an "all-carbon backbone" iridium hemicaged complex with a 1,3,5-tris(ethyl)benzene capping unit is reported. The synthesis and the complete characterization of this compound by means of $1 \mathrm{D}$ and 2D-NMR spectroscopy is discussed and the luminescence properties of the complex are described and compared with those of the archetypical $\operatorname{Ir}(\mathrm{ppy})_{3}$. The oxygen quenching of luminescence was studied through Stern-Volmer analysis and compared to $\operatorname{Ir}(\text { ppy })_{3}$ and to the hemicaged complexes described in Chapter 5 (HC5) and 6 (HC6). The strategies to synthesize caged complexes with benzene-based capping units, connected through ethyl moieties, are discussed.

\subsection{Design and synthesis}

The effect of substituents on the ppy ligand on the luminescence of $\operatorname{Ir}(\mathrm{ppy})_{3}$ derivatives has been extensively studied ${ }^{1}$ and it has been demonstrated that electron-withdrawing substituents usually result into a red-shift of emission, compared to the archetypical $\operatorname{Ir}(\text { ppy })_{3}$, whilst electron-donor substituents usually result into a blue-shift of the emission. ${ }^{2}$ In the previous Chapters, the possibility of tuning the oxygen quenching of luminescence upon introduction of a suitable capping unit on the phenylpyridine ligand has been proven. ${ }^{3,4}$ However, the 
necessity of using a connecting group between the ligand and the capping unit inevitably results in a modification of the energy and localization of the HOMO and LUMO orbitals due to the substituent effect previously discussed. ${ }^{3,4}$ Therefore, in order to obtain a clear evidence of the effect of the capping unit on the luminescence and oxygen quenching sensitivity, it is necessary to use a connecting group which affects those parameters minimally. The ethyl moiety is an excellent candidate as connecting unit, because of its weak electron-donor character (Hammett constant $\sigma_{\mathrm{m}}=-0.07$ ). Following this principle, the hemicaged complex 1 was designed (Figure 7.1), synthesised, characterised and the luminescence properties studied. Moreover, in order to compare the shielding effect exerted by a caged ligand with weak electron donor groups with the caged complex reported in Chapter 3, the caged complex 2 (Figure 7.1) was designed and its synthesis attempted, starting from the hemicaged complex 1. Although isolation and purification of the caged complex 2 was unsuccessful, a preliminary report concerning the synthesis of the caged complex 2 is reported in Appendix 7.1.

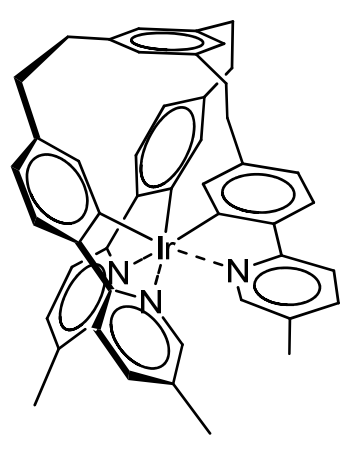

1

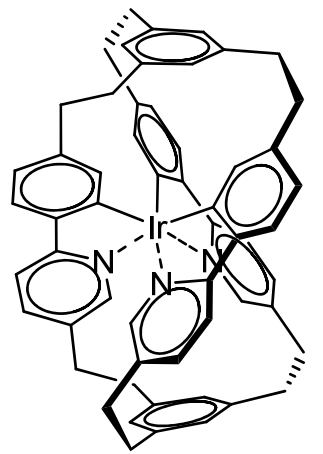

2

Figure 7.1. Hemicaged (1) and caged (2) iridium(III) complexes based on ethyl connecting groups.

The synthesis of the hemicage 1 (Scheme 7.1) was very challenging: the most promising synthetic strategy chosen was based on the synthesis of the trialkene intermediate 4 , which can be prepared starting from a substituted phenylpyridine $\mathbf{3}$. The trialkene $\mathbf{4}$ is subsequently reduced to 1,3,5-tris(4-(5-methylpyridin-2-yl)phenethyl)benzene (5) via catalytic hydrogenation. Eventually the hemicaged complex 1 can be obtained upon reaction of the tripodal ligand 5 with $\mathrm{IrCl}_{3}$ (Scheme 7.1). 


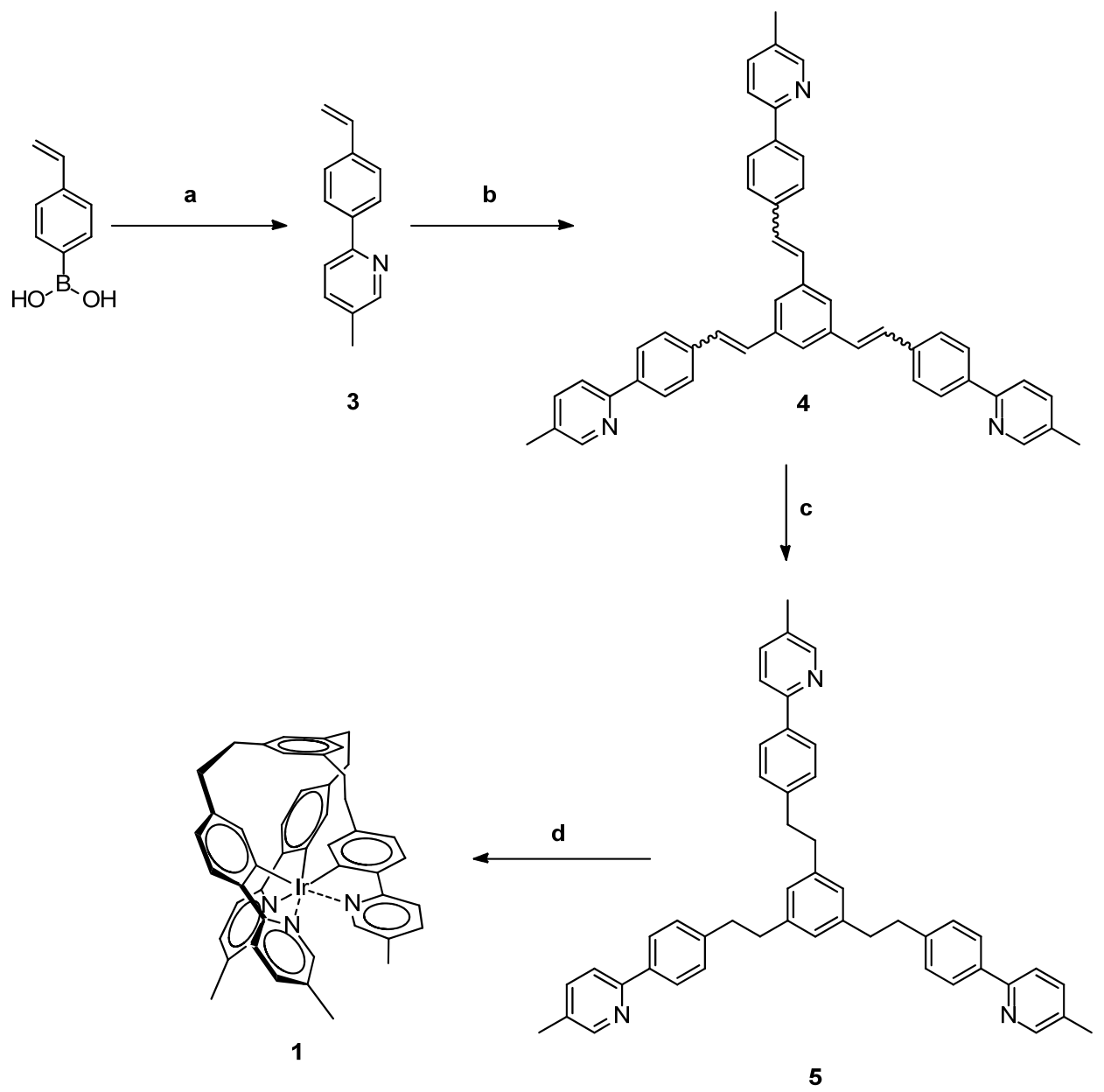

Scheme 7.1. Synthetic pathway to the hemicaged complex 1. Reaction conditions: a) 2bromo-5-methylpyridine, $\left[\mathrm{Pd}\left(\mathrm{PPh}_{3}\right)_{4}\right], \mathrm{CsF}, \mathrm{MeOH}$, reflux, overnight, Ar; b) 1,3,5triiodobenzene, $\mathrm{PdCl}_{2}$, Triethanolamine, $100^{\circ} \mathrm{C}, 24 \mathrm{~h}, \mathrm{Ar}$; c) Pd black, $\mathrm{H}_{2}$ (10 bar), $\mathrm{MeOH}, 2 \mathrm{~d}$; d) $\mathrm{IrCl}_{3}, \mathrm{CF}_{3} \mathrm{CO}_{2} \mathrm{Ag}$, glycerine, reflux, overnight, $\mathrm{Ar}$.

Different approaches for the synthesis of tripod 4 were attempted. At first, the synthesis of the trialkene derivative 4 was tried by using a Horner-Wadswort-Emmons (Scheme 7.2 A) or a Wittig reaction (Scheme 7.2 B), with unsuccessful results: in both cases only traces of the desired product were found. ${ }^{5,6}$ The synthesis of the trialkene 4 was eventually achieved (Scheme 7.1) by using a Pd-catalyzed coupling (Heck reaction) ${ }^{7}$ between the phenylpyridine derivative 3 (obtained via Suzuki coupling) ${ }^{8}$ and 1,3,5-triiodobenzene. Also in this case, in order to improve the reaction yields, different reaction conditions were investigated by using phosphine or carbene-based Pd catalysts, ${ }^{9}$ but only the method based on triethanolamine (which acts both as a ligand and solvent) was successful. The obtained tripod $\mathbf{4}$ is a mixture of several Z/E-isomers which were not separated by column chromatography, since all the 
isomers are expected to give the same product upon hydrogenation and therefore the alkene bonds in the crude compound were reduced without further purification.

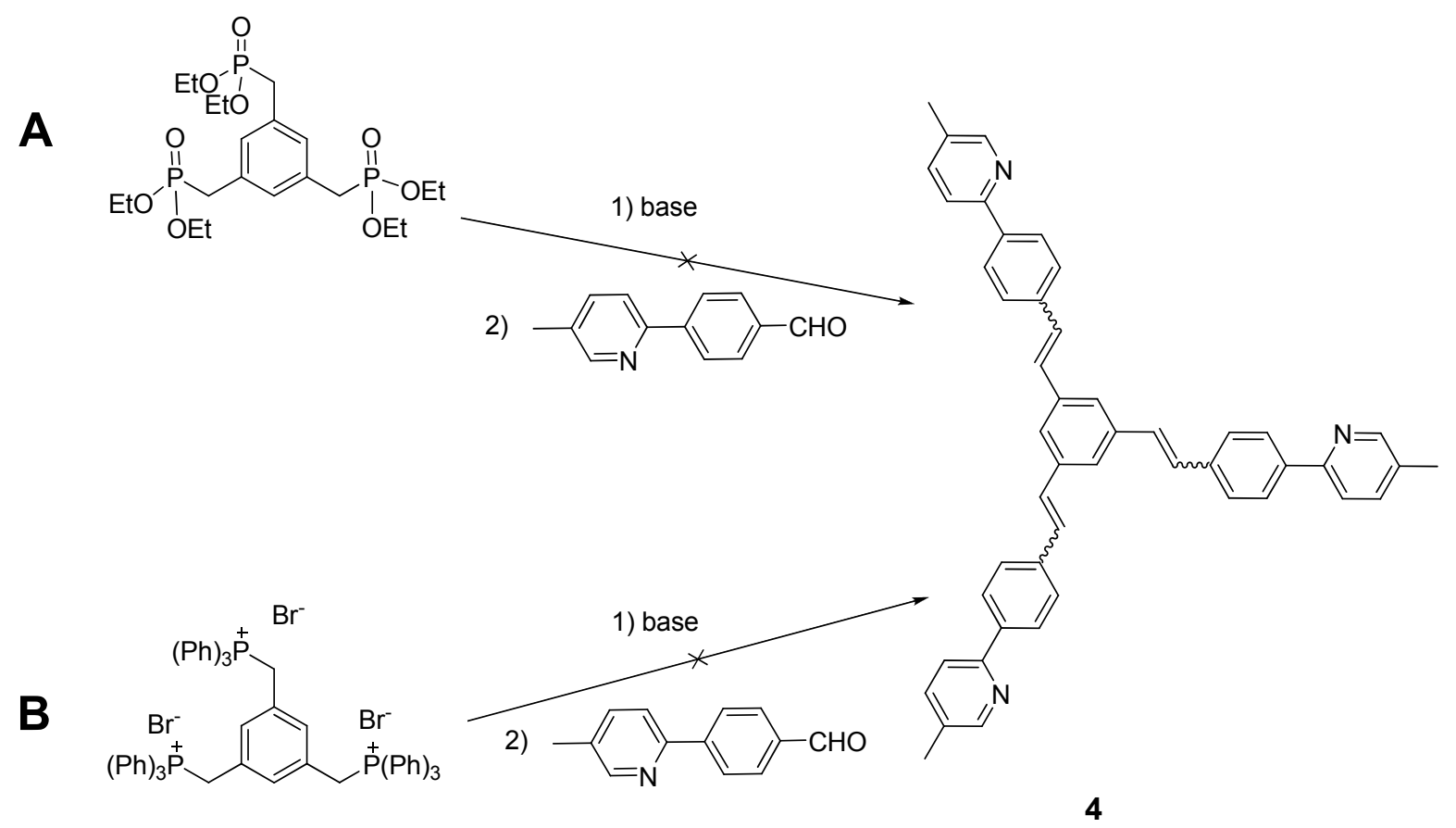

Scheme 7.2. Synthetic attempts for the synthesis of the trialkene 4: Horner-WadswortEmmons reaction (A) and Wittig reaction (B). General reaction conditions: THF, $0^{\circ} \mathrm{C}, 5 \mathrm{~h}$. Tried bases: $\mathrm{NaH}, t$-BuOK.

The hydrogenation of the tripodal ligand 4 was also very demanding, as the $\mathrm{Pd} / \mathrm{C}$ catalyst (which is the most used catalyst for hydrogenations) showed a high affinity for the reduction product $\mathbf{5}$, which was adsorbed on the catalyst surface without possibility of recovery. On the other hand, Adam's catalyst $\left(\mathrm{PtO}_{2}\right)$ and metallic sodium were both too reactive towards the pyridine ring: the former giving the complete hydrogenation of the pyridine ring to piperidine after a few hours and the latter generating a huge amount of side products (probably due to the Chichibabin reaction between the intermediate carbanion and the pyridine ring). ${ }^{10,11}$ Eventually, the reduction of the tripodal ligand $\mathbf{4}$ was achieved by using Pd black and hydrogen under pressure (10 bar) in methanol. It was observed that the polarity of the solvent plays a crucial role in this reaction: the hydrogenation attempted in less polar solvents (e.g. $\mathrm{CH}_{2} \mathrm{Cl}_{2}$ or EtOAc) did not give any result, even after prolonged hydrogenation times (up to one week). The obtained tripodal ligand, purified by column chromatography, was then reacted with $\mathrm{IrCl}_{3}$ in refluxing glycerine to give the hemicaged complex 1, purified by 
column chromatography on deactivated silica gel (Hexane: EtOAc 8:2) and eventually recrystallized from hot $n$-heptane.

\subsection{Characterization}

All the intermediates and the target complexes were characterized by NMR spectroscopy and mass spectrometry. The ${ }^{1} \mathrm{H}$ and ${ }^{13} \mathrm{C}$ chemical shifts of the intermediates are reported in the experimental section, while in this section only the 1D and 2D-NMR spectra of 1 are discussed. The ${ }^{1} \mathrm{H}-\mathrm{NMR}$ spectrum of hemicaged complex 1 (Figure 7.2) shows four different signals for the four protons of the two methylene units, indicating the restrained flexibility of the ethylene moiety of the capping unit, causing the geminal protons to be non-equivalent and diastereotopic in the chiral environment of the $\operatorname{Ir}(\mathrm{ppy})_{3}$ unit. This effect has been observed in all the hemicaged and caged complexes presented in this thesis. Together with the observation of one single set of phenylpyridine protons, this proves the structure of $\mathbf{1}$ to be highly symmetric, with the 3 -fold symmetry of the fac$\operatorname{Ir}(\text { ppy })_{3}$ unit being conserved. The geometrical constraint induced by the hemicaged structure causes a remarkable difference $(0.5 \mathrm{ppm})$ in the chemical shifts of the diastereotopic couples of protons $\mathbf{H h} / \mathbf{H h}^{\prime}$ and $\mathbf{H i} / \mathbf{H i}^{\prime}$. Moreover, the phenyl proton $\mathbf{H f}$ is shifted towards unusually high fields $(5.55 \mathrm{ppm})$ whilst the pyridine proton Ha has a chemical shift of $7.35 \mathrm{ppm}$.

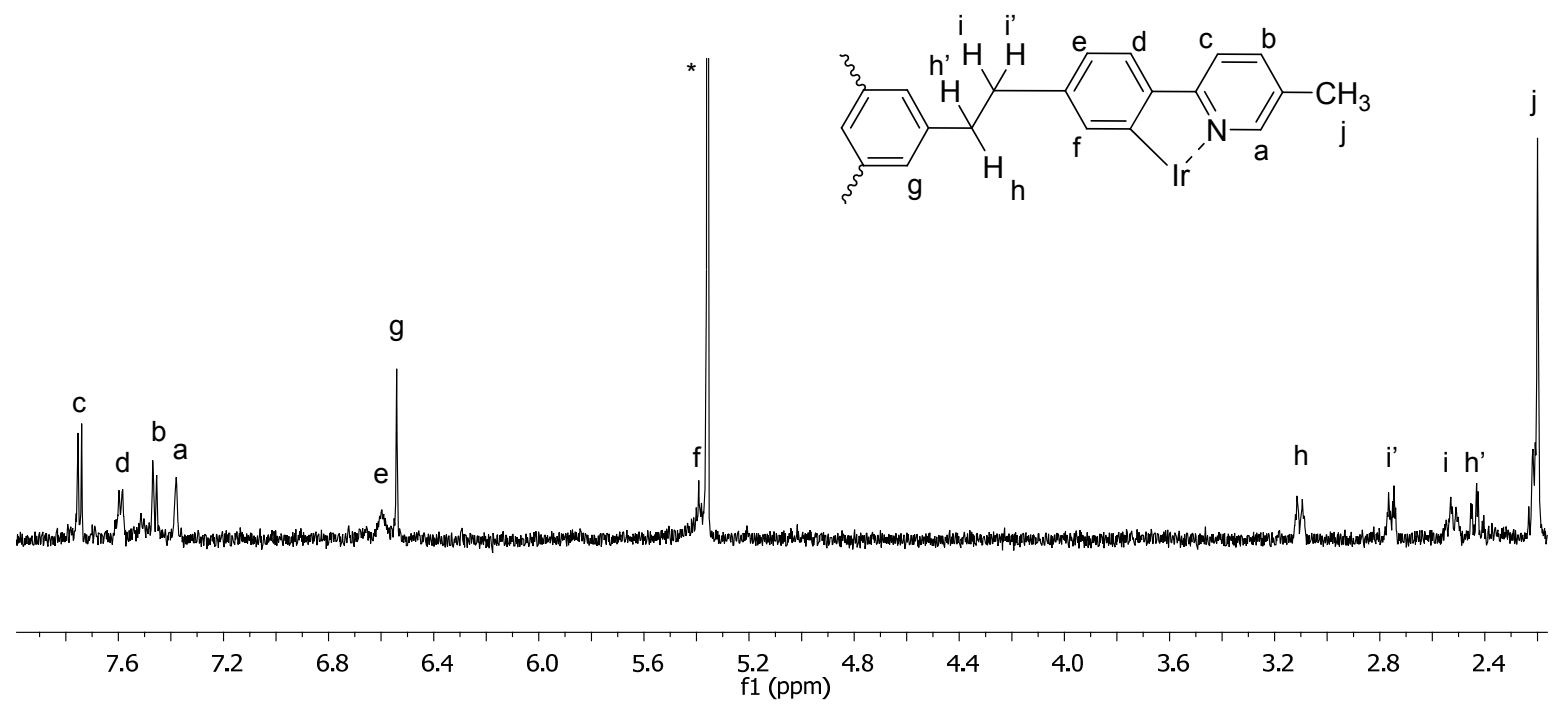

Figure 7.2. ${ }^{1} \mathrm{H}-\mathrm{NMR}$ of $\mathrm{Ir}(\mathrm{III})$-hemicaged complex 1. $d_{2}-\mathrm{CH}_{2} \mathrm{Cl}_{2}$. $*$ signals of the residual solvents. 
A comparison with the hemicaged complex reported in Chapter 6 (HC6), which is functionalised with the same benzene capping unit connected to the pyridine ring through ether groups, is shown in Figure 7.3. The chemical shifts of the "external" protons (i.e. the protons $\mathbf{H b} / \mathbf{H b}^{\prime}, \mathbf{H c} / \mathbf{H c}^{\prime}, \mathbf{H d} / \mathbf{H d}^{\prime}$ and $\mathbf{H e} / \mathbf{H e}^{\prime}$ which are on the phenylpyridine backbone) show only minor changes passing from 1 to HC6. This effect is probably due to the presence of oxygen atoms connected to the phenylpyridine of HC6. On the other hand, the "internal" protons $\mathbf{H a} / \mathbf{H a}^{\prime}$ and $\mathbf{H f} / \mathbf{H f}^{\prime}$ of the phenylpyridine and the $\mathbf{H g} / \mathbf{H g}^{\prime}$ proton belonging to the capping unit show more pronounced changes. In the hemicaged complex 1, the proton $\mathbf{H g}$ is more downfield shifted than the proton $\mathbf{H g}^{\prime}$ in HC6. This is probably due to a more pronounced magnetic shielding exerted by the phenyl ring located on the branches, consistent with the higher ring current of phenyl rings with respect to pyridine rings. ${ }^{12}$ The proton $\mathbf{H f}$ is more downfield shifted than the proton $\mathbf{H f}$. On the basis of computational models a magnetic shielding exerted by the aromatic capping unit should be excluded, since the proton $\mathbf{H f}$ is out of the shielding cone of the capping unit and, therefore, the downfield shift of the proton Hf is probably due to the magnetic shielding exerted by the phenyl ring located on another branch of the hemicage. A similar result is observed for the protons $\mathbf{H a}$ and $\mathbf{H a}^{\prime}$, as a magnetic shielding of $\mathbf{H a}^{\prime}$ exerted by the aromatic capping unit can be excluded on the basis of computational models (see Chapter 6 for details). Therefore, the downfield shift shown by $\mathbf{H a}^{\prime}$ with respect to $\mathbf{H a}$ is due to the magnetic shielding exerted by the pyridine of another branch of the hemicage.
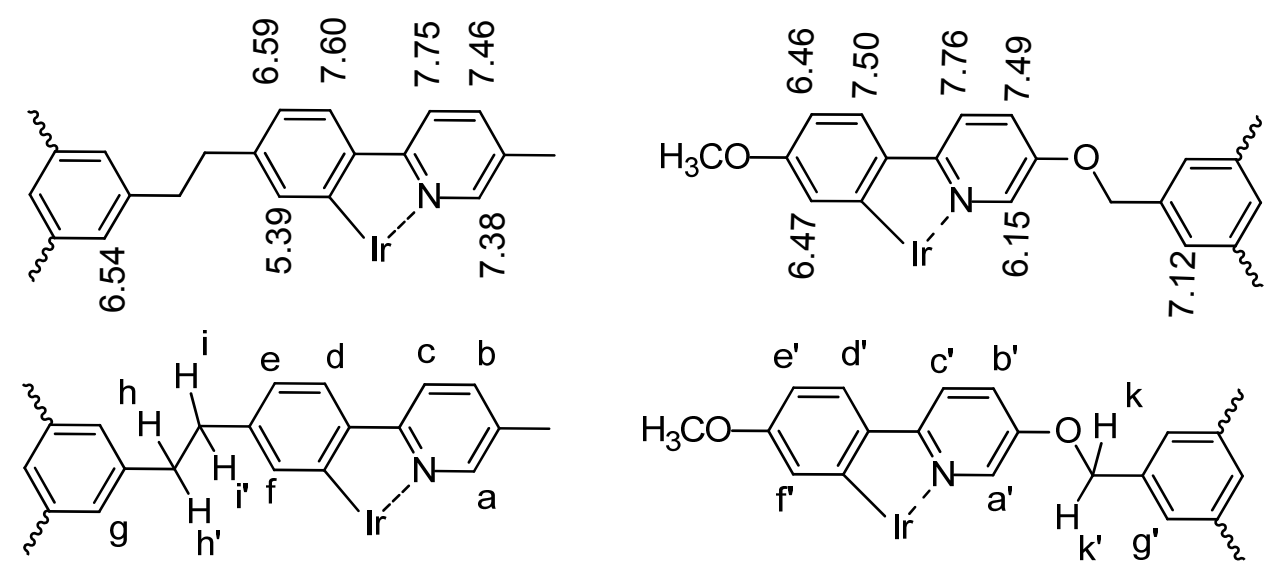

Figure 7.3. Comparison of the chemical shifts $\left(d_{2}-\mathrm{CH}_{2} \mathrm{Cl}_{2}\right)$ of the aromatic proton of 1 (left) and of the hemicaged complex described in Chapter 6 HC6 (right). The proton labelling used in the discussion is indicated in the bottom line. 
By 2D-NMR experiments (COSY, NOESY, HMQC, HMBC) all signals in the ${ }^{1} \mathrm{H}-\mathrm{NMR}$ spectra were assigned and the structure of the complex 1 was determined by characteristic NOE signals. The aromatic region of the NOESY spectrum (Figure 7.4) shows the throughspace coupling between the proton Hf (on the phenyl ring) and $\mathbf{H g}$ (on the capping unit), which is caused by the geometrical constraint induced by the hemicaged structure. The NOESY spectrum of the hemicaged complex HC6 (described in Chapter 6) shows similar through-space couplings between the protons $\mathbf{H a}^{\prime}$ (on the pyridine ring) and $\mathbf{H g}^{\prime}$ (on the capping unit).

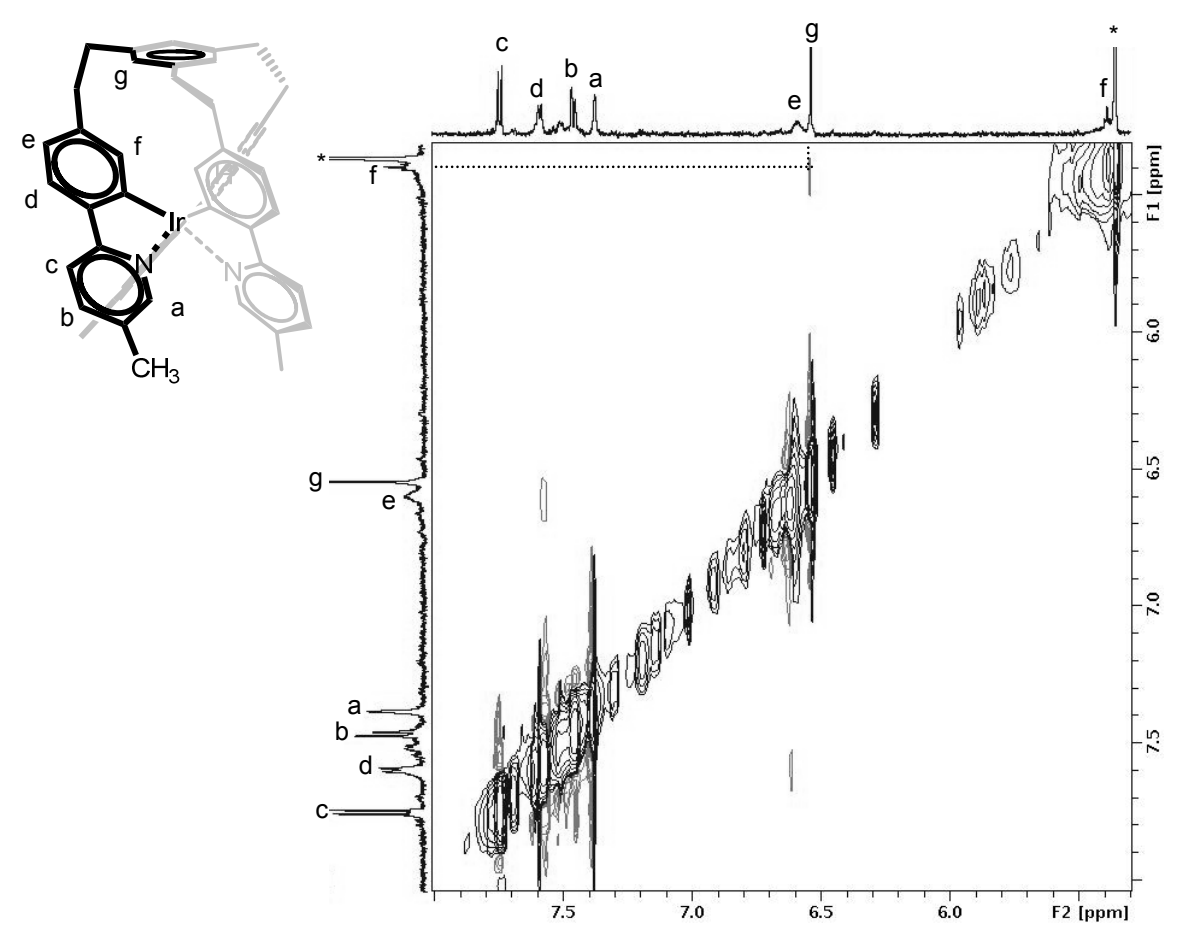

Figure 7.4. HH-NOESY spectrum of the $\operatorname{Ir}(\mathrm{III})$-hemicaged complex $1\left(d_{2}-\mathrm{CH}_{2} \mathrm{Cl}_{2}\right)$. Region of the aromatic protons.

Interestingly, the analysis of the through-space couplings between aliphatic and aromatic protons (Figure 7.5) reveals the peculiar orientation of the ethyl protons $\mathbf{H h}, \mathbf{H h}$, $\mathbf{H i}$ and $\mathbf{H i}$ '. As expected, the proton $\mathbf{H g}$, belonging to the capping unit, gives a through-space coupling with the protons $\mathbf{H h}$ and $\mathbf{H h}$ ', which are directly connected with the capping unit. Moreover, the proton $\mathbf{H g}$ gives a through-space coupling also with proton $\mathbf{H i}$, which is oriented towards the inside of the hemicage. Because of its orientation, the proton Hi gives also a throughspace coupling with the proton Hf, on the phenyl ring of the ppy. On the other hand, Hi' gives a through-space coupling with the proton $\mathbf{H e}$, and it is therefore oriented towards the outside of the molecule. The hemicaged complex HC6 described in Chapter 6 shows similar 
through-space couplings between the proton belonging to the capping unit and the protons Hk and Hk', directly connected to the capping unit. On the other hand, in HC6 the orientation of the Hk and H' $\mathbf{k}^{\prime}$ protons is slightly different, since a cross coupling between the protons $\mathbf{H a}$ '-Hk' and $\mathbf{H} \mathbf{b}^{\prime}$-Hk is observed, whilst no cross-coupling between the $\mathbf{H e} / \mathbf{H f}$ and $\mathbf{H h} / \mathbf{H h}^{\prime}$ is observed in 1. This difference in behavior of the two hemicages $\mathbf{1}$ and HC6 is probably due to the presence of O in HC6, which induces a higher geometrical constraint. A more detailed description of the NOESY spectrum of HC6 is given in Chapter 6 (see Fig. 7.3 for protons nomenclature). Protons $\mathbf{H a}$ and $\mathbf{H b}$, belonging to the pyridine ring, give a through-space coupling with the methyl protons $\mathbf{H j}$. Analogously, cross coupling between the protons belonging to the methoxy group and $\mathbf{H} \mathbf{f}^{\prime} / \mathbf{H e}^{\prime}$ protons on the phenyl ring are observed in the hemicage HC6.

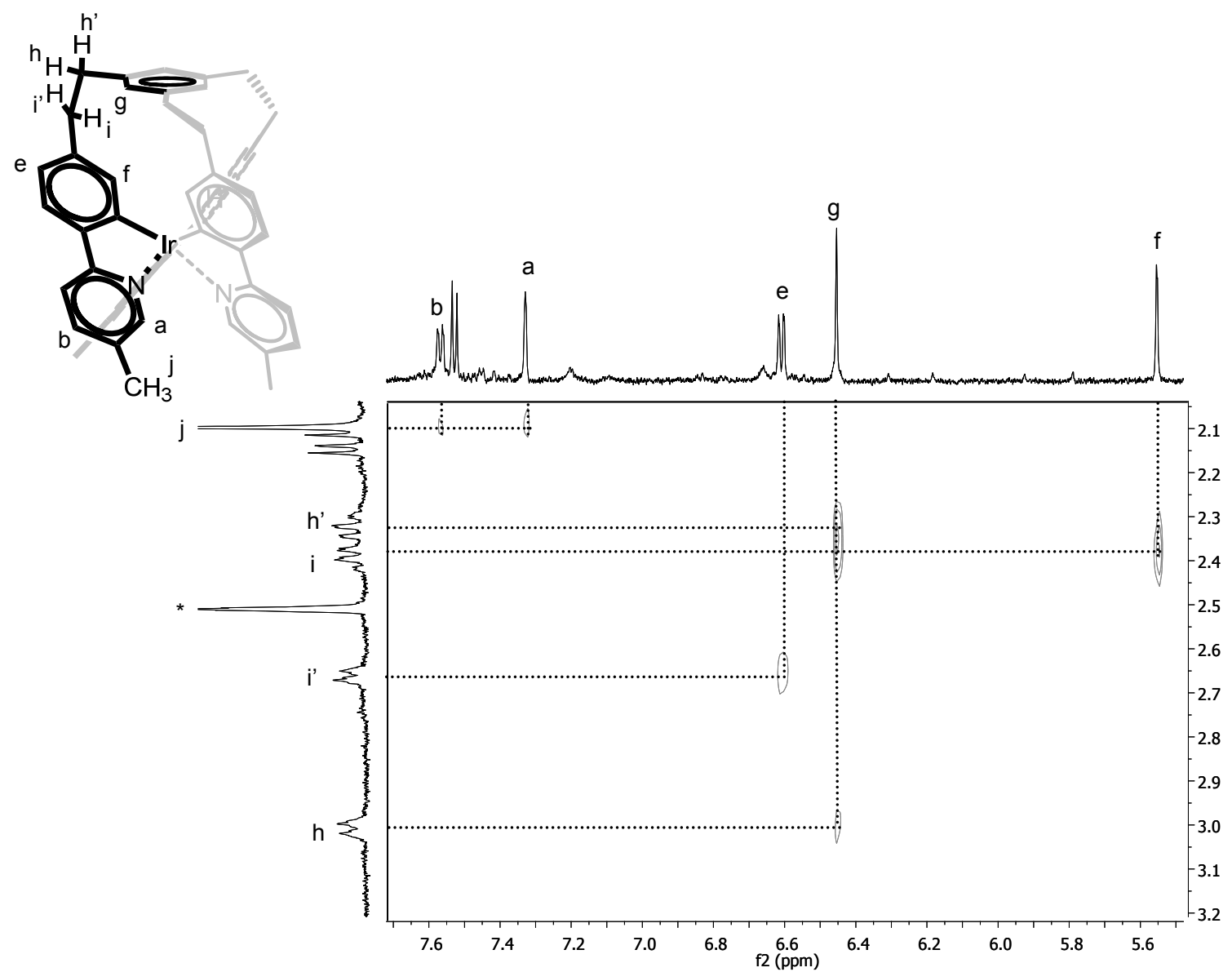

Figure 7.5. HH-NOESY spectrum of the $\operatorname{Ir}(\mathrm{III})$-hemicaged complex 1 ( $d_{6}$-DMSO). Interactions between aliphatic and aromatic protons. * = signal of the residual solvent. 


\subsection{Photophysical properties}

Absorption. The UV-Vis absorption spectrum of the hemicaged complex $\mathbf{1}$ is shown in Figure 7.6 and the typical absorption maxima and shoulder are reported in Table 7.1 together with their molar absorption coefficients. Typical absorption maxima (with their molar absorption coefficient) of $\operatorname{Ir}(\mathrm{ppy})_{3}$ is also reported in Table 7.1 for comparison purposes. Complex 1 shows a strong absorption band $\left(\varepsilon \geq 10^{4} \mathrm{M}^{-1} \mathrm{~cm}^{-1}\right)$ centred at $287 \mathrm{~nm}$ and weaker absorption bands $\left(\varepsilon \leq 10^{3} \mathrm{M}^{-1} \mathrm{~cm}^{-1}\right)$ between 350 and $450 \mathrm{~nm}$. By comparing with the absorption shown by $\operatorname{Ir}(\text { ppy })_{3},{ }^{13,14}$ the absorption bands centred at $287 \mathrm{~nm}$ can be assigned to ligand centred $\pi \rightarrow \pi^{*}$ transitions, while the weaker bands centred around $400 \mathrm{~nm}$ can be assigned to spin-allowed singlet-to-singlet metal to ligand charge transfer ( ${ }^{1}$ MLCT) transitions. Moreover, the weak shoulder at lower energies (centred around $480 \mathrm{~nm}$ ) can be assigned to a spin-forbidden singlet-to-triplet ${ }^{3}$ MLCT transition. Compared to $\operatorname{Ir}(\text { ppy })_{3}$, the hemicaged complex 1 shows a slight blue-shift of its MLCT absorption bands. Conversely, the ${ }^{1} \mathrm{LC}\left(\pi \rightarrow \pi^{*}\right)$ band of $\mathbf{1}$ is slightly blue shifted compared to that of $\operatorname{Ir}(\mathrm{ppy})_{3}$.

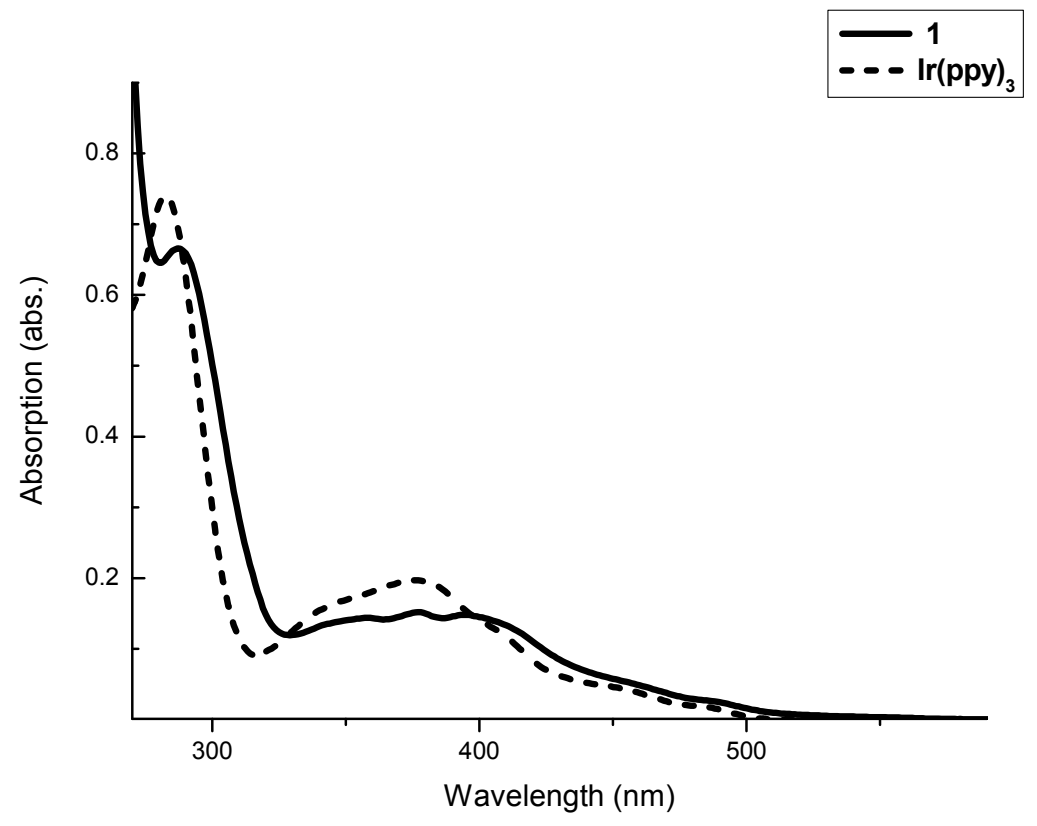

Figure 7.6. UV-Vis absorption spectrum of the hemicaged complex $\mathbf{1}$ (solid line) and $\operatorname{Ir}(\mathrm{ppy})_{3}$ (dashed line) in DMF at room temperature. 
Table 7.1. UV-Vis absorption data of the complex 1 and $\operatorname{Ir}(\text { ppy })_{3}$ and their molar absorption coefficient in DMF at room temperature. sh. = shoulder

\begin{tabular}{|c|c|}
\hline Compound & $\begin{array}{c}\text { Absorption } \\
\lambda(\mathbf{n m}),\left(\varepsilon\left(\mathbf{1 0}^{\mathbf{3}} \mathbf{M}^{-\mathbf{1}} \mathbf{c m}^{\mathbf{- 1}}\right)\right)\end{array}$ \\
\hline $\mathbf{1}$ & $287(43), 358(9.2), 377(9.7), 394(9.5), 486($ sh. 1.7) \\
\hline $\operatorname{Ir}(\mathbf{p p y})_{3}$ & $282(45), 340(9,5), 377(12), 407$ (sh. 7.6), 460 (sh. 2.3) \\
\hline
\end{tabular}

Luminescence. As shown in Figure 7.7, the hemicaged complex 1 shows intense luminescence at room temperature. The emission maximum remains unchanged with respect to $\operatorname{Ir}(\mathrm{ppy})_{3}$ as expected for $\operatorname{Ir}(\mathrm{III})$-tris(phenylpyridine) complexes bearing weak electron donors both on the phenyl and on the pyridine ring. ${ }^{1}$ The emission profile is structureless, which indicates a ${ }^{3}$ MLCT character of the emissive state. ${ }^{13}$

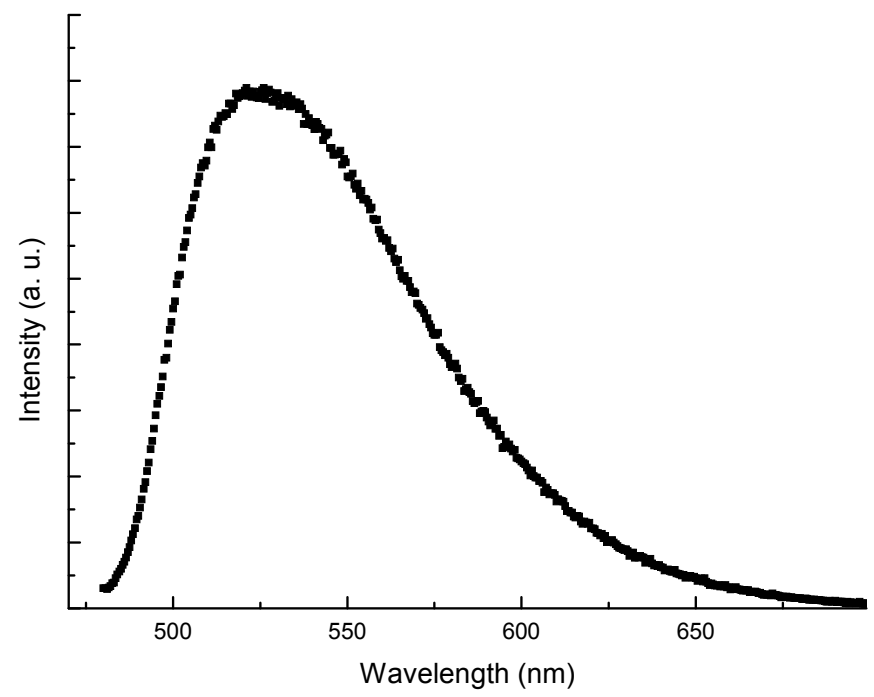

Figure 7.7. Emission profile of the hemicaged complex (1) in DMF at $25^{\circ} \mathrm{C}$.

The photophysical properties of the hemicaged complex are summarized in Table 7.2 together with those of $\operatorname{Ir}(\text { ppy })_{3}$ and of the hemicaged complexes HC6 and HC5 described in Chapter 6 and Chapter 5, respectively, for purposes of comparison. The hemicaged complex $\mathbf{1}$ is highly luminescent in oxygen-free solvent, with emission quantum yields in the order of $\phi_{0}=0.65$. Furthermore, a long emission lifetime $\left(\tau_{0}=1.5 \mu \mathrm{s}\right)$ is observed, corroborating the hypothesis of a triplet originated emission. In aerated solutions a general decrease of quantum 
yields and lifetimes is observed, as a consequence of the oxygen quenching. In presence of air the hemicaged complex 1 shows a quantum yield of $\phi=0.022$ and a lifetime of $\tau=52 \mathrm{~ns}$. The quantum yield and lifetime of the hemicaged complex $\mathbf{1}$ are lower than those of the archetypical $\operatorname{Ir}(\mathrm{ppy})_{3}$, both in deaerated and in aerated solutions (Table 7.2). A comparison with the hemicaged complex HC6 described in Chapter 6 shows that the stronger electrondonor character of the oxymethyl group in HC6 induces a stronger blue shift of the emission maximum of this compound with respect to 1. In deaerated solutions HC6 shows the same quantum yield as $\operatorname{Ir}(\mathrm{ppy})_{3}\left(\phi_{0}=0.71\right)$, but the lifetime has an intermediate value that lies between those of 1 and $\operatorname{Ir}(\text { ppy })_{3}\left(\tau_{0}=1692\right.$ ns). In aerated solutions, HC6 exhibits quantum yield and lifetime values which lie between those of 1 and $\operatorname{Ir}(\mathrm{ppy})_{3}(\phi=0.026$ and $\tau=65 \mathrm{~ns})$. The hemicaged complex HC5 described in Chapter 5 shows a slightly red-shifted emission with respect to $\mathbf{1}$, which is due to the presence of electron-withdrawing groups (amides) on the phenyl ring. The quantum yields of HC5 in aerated and degassed solutions are slightly higher than those observed for $1\left(\phi_{0}=0.67\right.$ and $\left.\phi=0.035\right)$ and the same behaviour is observed for the lifetime both in aerated and degassed solutions $\left(\tau_{0}=1775 \mathrm{~ns}\right.$ and $\left.\tau=78 \mathrm{~ns}\right)$. Despite the more rigid structure, which is expected to improve the luminescence properties of Ir(III) complexes, ${ }^{15}$ the introduction of a benzene-based capping unit connected with an ethyl chain to the phenylpyridine ligands was not the optimal approach in order to obtain a luminophore with enhanced luminescent properties with comparison to $\operatorname{Ir}(\mathrm{ppy})_{3}{ }^{16}$

Table 7.2. Photophysical properties of hemicaged complexes 1, HC6, HC5 and $\operatorname{Ir}(\text { ppy })_{3}$, measured in DMF at $25^{\circ} \mathrm{C}$.

\begin{tabular}{|c|c|c|c|c|c|c|}
\hline Compound & $\begin{array}{c}\lambda_{\text {em }} \\
(\mathbf{n m})\end{array}$ & $\phi_{\mathbf{0}}$ & $\phi$ & $\begin{array}{c}\tau_{\mathbf{0}} \\
(\mathbf{n s})\end{array}$ & $\begin{array}{c}\tau \\
(\mathbf{n s})\end{array}$ & $\begin{array}{c}\mathbf{k}_{\mathbf{q}} \\
\left(\mathbf{M}^{-\mathbf{1}} \mathbf{s}^{-\mathbf{1}}\right)\end{array}$ \\
\hline $\mathbf{1}$ & 522 & 0.65 & 0.022 & 1510 & 52 & $2.4 \cdot 10^{10}$ \\
\hline $\mathbf{I r}(\mathbf{p p y})_{\mathbf{3}}$ & 523 & 0.71 & 0.030 & 1873 & 82 & $2.4 \cdot 10^{10}$ \\
\hline HC6 & 504 & 0.71 & 0.026 & 1692 & 65 & $2.3 \cdot 10^{10}$ \\
\hline HC5 & 532 & 0.67 & 0.035 & 1775 & 78 & $1.5 \cdot 10^{10}$ \\
\hline
\end{tabular}

Oxygen quenching. In order to evaluate the shielding effect against oxygen quenching, the luminescence emission of samples containing different concentrations of oxygen was registered and plotted against the concentration of oxygen according to the Stern-Volmer equation (7.2): 


$$
\frac{I_{0}}{I}=1+k_{q} \tau_{0}\left[O_{2}\right]
$$

$\mathrm{I}_{0}$ and $\mathrm{I}$ are the intensity without and with the quencher, respectively, $\mathrm{k}_{\mathrm{q}}$ is the quenching constant, $\tau_{0}$ the excited state lifetime in absence of the quencher, and $\left[\mathrm{O}_{2}\right]$ the molar concentration of oxygen (the quencher). From the Stern-Volmer plots (see Figure 7.8) the quenching constants $k_{\mathrm{q}}$ (Table 7.2) were found to have the same value $\left(2.4 \cdot 10^{10} \mathrm{M}^{-1} \mathrm{~s}^{-1}\right)$ both for 1 and $\operatorname{Ir}(\mathrm{ppy})_{3}$. This implies the absence of any effect on the oxygen quenching deriving from the introduction of a benzene-based capping unit on the phenyl ring. This result can be explained considering the effect on the oxygen quenching on an $\operatorname{Ir}(\mathrm{III})$-hemicaged functionalized on the phenyl ring (HC5) already shown in Chapter 5. Since the LUMO is mostly localized on the pyridine ring, the introduction of a shielding group on the phenyl ring does not influence the oxygen quenching, as the degree of LUMO shielding is basically unchanged. Therefore, this result is a further proof of the necessity of shielding the atoms where the LUMO orbital is mostly localized, in order to obtain a decrease of oxygen quenching of luminescence.

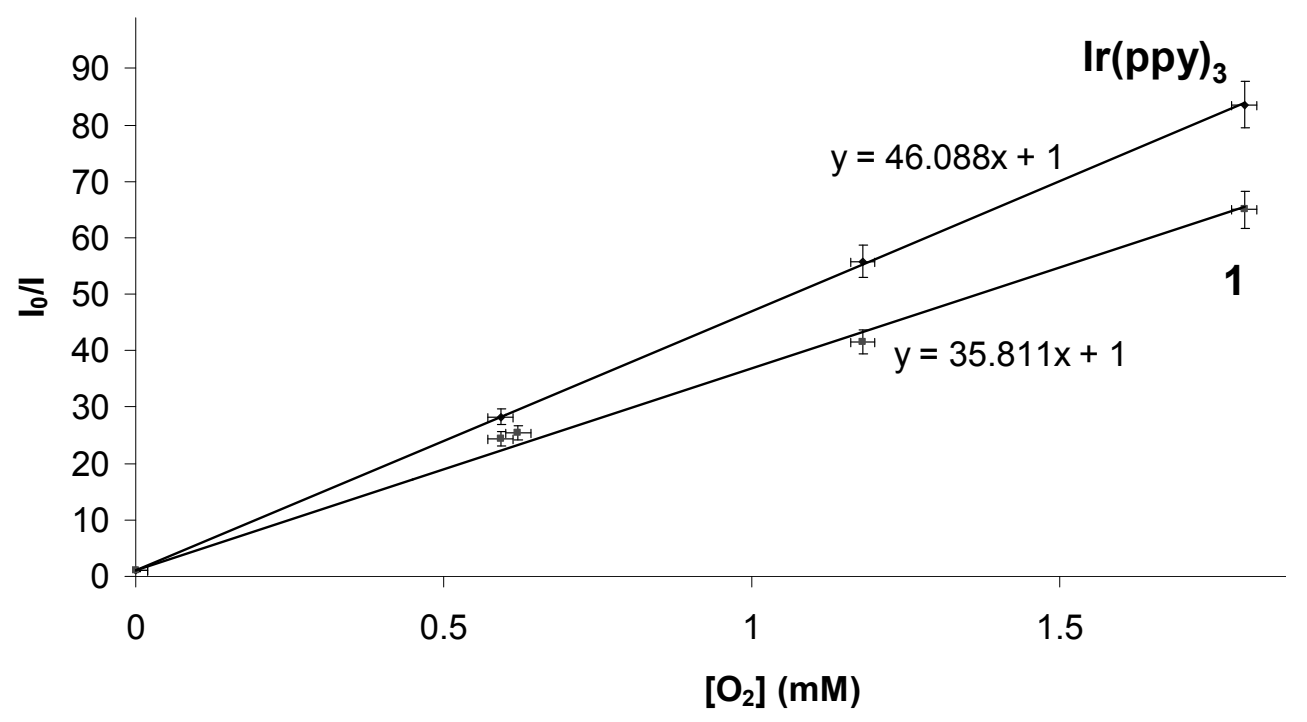

Figure 7.8. Stern Volmer plot of oxygen quenching of $\operatorname{Ir}(\mathrm{ppy})_{3}$ and hemicaged complex 1 in $\mathrm{DMF}$ at $25^{\circ} \mathrm{C}$. 
On the other hand, the hemicaged complex HC5 shows a lower oxygen quenching of luminescence than $\mathbf{1}\left(\mathrm{k}_{\mathrm{q}}=1.5 \cdot 10^{10}\right.$ and $\mathrm{k}_{\mathrm{q}}=2.4 \cdot 10^{10}$ respectively $)$ and this can be explained considering the thermodynamic parameters involved in the oxygen quenching process: the free energy of energy transfer $\left(\Delta \mathrm{G}_{\mathrm{el}}\right)$ which is defined according to equation 7.3 :

$$
\Delta G_{e t}=-\left(E_{00}-E_{O_{2} *}\right)
$$

$E_{00}$ is the energy of the 0-0 transition and $E_{02 *}$ the energy of the excited state of singlet

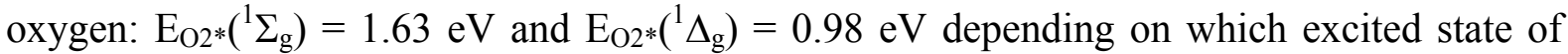
oxygen is initially produced during quenching. The free energy of electron transfer $\left(\Delta \mathrm{G}_{\mathrm{el}}\right)$ is given by eq. 7.4.

$$
\Delta G_{e l}=F\left(E_{F}^{o x}-E_{O_{2}}^{r e d}\right)-E_{00}+C
$$

$\mathrm{F}$ is the Faraday's constant, $\mathrm{E}_{\mathrm{F}}^{\mathrm{ox}}$ is the oxidation potential of the fluorophore, $\mathrm{E}_{\mathrm{O} 2}^{\mathrm{red}}$ is the reduction potential of oxygen $(-0.78 \mathrm{~V})$ and $\mathrm{C}$ is a Coulomb term (usually neglected in polar solvents). ${ }^{17-19}$ Although the low temperature emission profiles and potentiometric data are not available for $\mathbf{1}$, a preliminary comparison can be done by using published data concerning $\operatorname{Ir}(\text { ppy })_{3}$. The oxygen quenching constants and thermodynamic parameters of $1, \operatorname{Ir}(\mathrm{ppy})_{3}$ and HC5 are reported in Table 7.3.

Table 7.3 Oxygen quenching constant $\left(\mathrm{k}_{\mathrm{q}}\right)$ and thermodynamic parameters involved in the oxygen quenching mechanisms in DMF at room temperature.

\begin{tabular}{|c|c|c|c|c|}
\hline Compound & $\begin{array}{c}\lambda_{\text {em }} \\
(\mathbf{n m})\end{array}$ & $\begin{array}{c}\Delta \mathbf{G}_{\text {et }} \\
(\mathbf{k J} / \mathbf{m o l})^{*}\end{array}$ & $\begin{array}{c}\Delta \mathbf{G}_{\text {el }} \\
(\mathbf{k J} / \mathbf{m o l})\end{array}$ & $\begin{array}{c}\mathbf{k}_{\mathbf{q}} \\
\left(\mathbf{M}^{-\mathbf{1}} \mathbf{s}^{-\mathbf{1}}\right)\end{array}$ \\
\hline $\mathbf{1}$ & 522 & - & - & $2.4 \cdot 10^{10}$ \\
\hline $\mathbf{I r}(\mathbf{p p y})_{\mathbf{3}}$ & 523 & -154 & -106 & $2.4 \cdot 10^{10}$ \\
\hline $\mathbf{H C 5}$ & 532 & -144 & -60 & $1.5 \cdot 10^{10}$ \\
\hline
\end{tabular}

*) calculated by assuming $\left.\mathrm{E}_{\mathrm{O} 2 *}{ }^{1} \Delta_{\mathrm{g}}\right)=0.98 \mathrm{eV}$

The value of such a comparison is reinforced by the equal degree of oxygen quenching shown by $\operatorname{Ir}(\mathrm{ppy})_{3}$ and $\mathbf{1}$. The calculated thermodynamic parameters for $\operatorname{Ir}(\mathrm{ppy})_{3}\left(\Delta \mathrm{G}_{\mathrm{et}}=-154\right.$ $\mathrm{kJ} / \mathrm{mol}$ and $\Delta \mathrm{G}_{\mathrm{el}}=-106 \mathrm{~kJ} / \mathrm{mol}$ ) show that both energy and electron transfer for this complex 
are more favourable than for HC5 $\left(\Delta \mathrm{G}_{\mathrm{et}}=-144 \mathrm{~kJ} / \mathrm{mol}\right.$ and $\left.\Delta \mathrm{G}_{\mathrm{el}}=-60 \mathrm{~kJ} / \mathrm{mol}\right) .{ }^{20}$ In particular, the impressive decrease of the value of $\Delta \mathrm{G}_{\mathrm{el}}$ observed for HC5 reveals a greater contribution of electron transfer to the oxygen quenching of $\operatorname{Ir}(\mathrm{ppy})_{3}$. Therefore, the lower degree of oxygen quenching shown by HC5 with respect to 1 is probably due to a decreased thermodynamic feasibility of the quenching. This effect is mostly due to the presence of the amide group on the phenylpyridine ligands, which leads to a consequent increase of the oxidation potential of the complex. We can make this strong conclusion since there is no structural effect on the oxygen quenching of HC5 and 1.

A comparison with the hemicaged complex HC6 described in Chapter 6 (in which the same benzene-based capping unit is connected to the pyridine's side of the $\operatorname{Ir}(\mathrm{III})$ tris(phenylpyridine) core with ether groups) shows that HC6 presents a similar behaviour towards oxygen quenching as $\mathbf{1}$. The reason of the low oxygen quenching decrease shown by HC6 has been discussed in Chapter 6. The presence of the oxygen atom connected to the pyridine ring induces a localisation of the LUMO orbital mostly on the atoms which are in ortho- position with respect to the oxymethyl group, as a consequence of its electrondonating effect. On the other hand, from computational models it is evident that the atoms where the LUMO orbital is mostly localised are poorly shielded by the capping unit and therefore the shielding effect of the capping unit towards oxygen quenching is quite low (see Appendix 6.1).

\subsection{Conclusions}

In this chapter the design, synthesis and characterization of an $\operatorname{Ir}(\mathrm{III})$-tris(phenylpyridine) derivative with a hemicaged structure have been reported. The compound shows the same emission maximum as $\operatorname{Ir}(\text { ppy })_{3}$, as expected for a complex bearing weak electron-donor substituents on the phenylpyridine ligand. Moreover, compared to the archetypical $\operatorname{Ir}(\mathrm{ppy})_{3}$, the hemicaged complex 1 shows lower quantum yield and lifetime both in deaerated and aerated solvent, which is probably due to the extra vibrational (non radiative) path induced by the presence of the $\mathrm{C}-\mathrm{H}$ vibrators belonging to the 1,3,5-tris(ethyl)benzene capping unit. From the study of the luminescence oxygen quenching of $\mathbf{1}$ it was found that the quenching degree is the same as $\operatorname{Ir}(\text { ppy })_{3}$, thus corroborating the hypothesis that the introduction of a capping unit on the phenyl ring has a low effect on the oxygen quenching of the luminescence, independently of the steric hindrance of the capping unit. Therefore it is possible to conclude that the functionalization of the phenyl ring with a capping unit is not 
the right strategy in order to tune the oxygen quenching of $\operatorname{Ir}(\mathrm{III})$-tris(phenylpyridine) derivatives. The study of the oxygen quenching sensitivity of an $\operatorname{Ir}(\mathrm{III})$-hemicaged complex functionalised with a 1,3,5-tris(ethyl)benzene capping unit on the pyridines' side (where the LUMO is mostly localised) could be expected to show an oxygen quenching decrease based on the results described in Chapters 3, 4, and 5. However, the oxygen quenching is not only dependent on structural shielding, as relatively subtle changes in electron-density distribution on the ligand can have major consequences on the shielding properties of a capping unit. In fact, this shielding effect has not been observed for the hemicaged complex HC6 described in Chapter 6, in which the electron donating group on the ppy causes the LUMO orbital to be localised on atoms which are not shielded by the aromatic capping unit, thus resulting only in a minor decrease of oxygen quenching when compared to the open complex. Moreover, the synthesis of tripodal ligands in which a phenylpyridine is connected to a benzene based capping unit through ethyl linkers remains a synthetic challenge. In the case of a hemicaged complex functionalised on the pyridine side, a strategy based on the Heck coupling (following the same synthetic approach discussed for the synthesis of $\mathbf{1}$ ) is not straightforward due to the demanding synthesis of vinylpyridine derivatives. Another possible strategy based on the deprotonation of the methyl moiety in 5-methyl-2phenylpyridine and subsequent reaction with 1,3,5-tris(bromomethyl)benzene is not feasible due to the relative chemical inertness of the methyl moiety even towards very strong bases (as discussed in the Appendix 7.1).

In conclusion, although all-carbon based hemicage and cage iridium complexes are aesthetically appealing, considering the challenge represented by the synthesis of a suitable tripodal ligand, an $\operatorname{Ir}(\mathrm{III})$-hemicaged functionalised on the pyridine rings with a 1,3,5tris(ethyl)benzene capping unit is probably not a good candidate in order to further study the structural-induced effect on the oxygen quenching.

From the analysis of the oxygen quenching of hemicaged complexes reported in this thesis, it is evident that there are (mainly) two parameters that contribute to the structure-induced oxygen quenching decrease in hemicaged complexes. First, the presence of suitable groups on the pyridine rings' side which induce the localization of the LUMO orbital onto specific atoms and second, the presence of a capping unit that provides the shielding of the LUMO orbital. Both factors are crucial when the aim is to obtain a hemicaged complex with decreased oxygen quenching. Furthermore, it is also necessary to minimise the thermodynamic feasibility of oxygen quenching (i.e. $\Delta \mathrm{G}_{\mathrm{et}}$ and $\Delta \mathrm{G}_{\mathrm{el}}$ ). Finally, the oxygen quenching analysis of the caged complex reported in Chapter 3 shows that electron- 
withdrawing moieties (e.g. amides) are most likely the best candidates for the realization of Ir(III)-complexes with reduced oxygen quenching, since they fulfil all the structural, energetic and electronic requirements previously discussed.

\subsection{Experimental section}

Oxygen- or water-sensitive reactions were conducted under a positive pressure of argon in oven-dried glassware, using Schlenk techniques. Unless otherwise stated, commercial grade reagents (Aldrich) were used without further purification. The purity of the final compounds was determined by NMR spectroscopy and MS spectrometry. Due to the low amount of final compound, it was not possible to perform elemental analysis. The NMR experiments were performed on a Bruker Avance II NMR spectrometer operating at $600.35 \mathrm{MHz}$ for ${ }^{1} \mathrm{H}$ and $150.09 \mathrm{MHz}$ for ${ }^{13} \mathrm{C}$ or on a Varian Unity 300 spectrometer operating at $300 \mathrm{MHz}$ for ${ }^{1} \mathrm{H}$. Chemicals shifts are given in ppm using the residual solvent signal as reference. Mass spectra were acquired on a Micromass LCT (ESI-MS) or Voyager-DE RP (MALDI-MS) spectrometer. UV-Vis spectra were measured on a Perkin Elmer Lambda $850 \mathrm{UV}$-Vis spectrophotometer. Steady-state luminescence spectra were measured using an Edinburgh FS900 fluorospectrometer. A $450 \mathrm{~W}$ xenon arc lamp was used as excitation source. Luminescence quantum yields at room temperature ( $\Phi$ and $\Phi_{\text {air }}$ ) were evaluated by comparing wavelength-integrated intensities $\left(I\right.$ and $I_{R}$ ) of isoabsorptive optically diluted solutions $(\mathrm{Abs}<0.1)$ with reference to fluorescein $\left(\Phi_{\mathrm{R}}=0.92\right.$ in $\left.\mathrm{NaOH} 0.1 \mathrm{M}\right)$ standard and by using equation (7.5)

$$
\Phi=\Phi_{R} \frac{n^{2} I}{n_{R}^{2} I_{R}}
$$

where $n$ and $n_{R}$ are the refractive index of the sample and reference solvent, respectively. ${ }^{21}$ Fluorescence lifetimes were determined using a FluoroMax4, Horiba Jobin Yvon spectrophotometer, equipped with a TCSPC extension and a pulsed $462 \mathrm{~nm}$ NanoLED for excitation (all Horiba Jobin Yvon). The recorded data were analyzed using the DAS6 software package of Horiba Jobin Yvon.

Degassed solutions were prepared by four freeze-pump-thaw cycles. Solutions with different oxygen concentration, suitable for the Stern-Volmer quenching studies, were prepared by using $\mathrm{N}_{2} / \mathrm{O}_{2}$ mixtures prepared with a Brooks 5850S Mass Flow control and by purging the 
fluorophore solutions for 40 minutes. $\operatorname{Ir}(\mathrm{ppy})_{3}$ (sublimed grade) was purchased from Sigma Aldrich and its purity was checked by NMR prior to use.

5-Methyl-2-(4-vinylphenyl)pyridine (3). $1.515 \mathrm{~g}$ (0.01 mol) of 4-phenylvinylboronic acid and $1.615 \mathrm{~g}(0.0095 \mathrm{~mol})$ of 2-bromo-5-methylpyridine were mixed in $50 \mathrm{ml}$ of MeOH. $3 \mathrm{~g}$ of $\mathrm{CsF}$ and $610 \mathrm{mg}$ of $\mathrm{Pd}\left(\mathrm{PPh}_{3}\right)_{4}$ were added and the solution was refluxed overnight under inert atmosphere.

The hot mixture was filtered and the solvent evaporated. The solid was then extracted several times with $\mathrm{CHCl}_{3} / \mathrm{H}_{2} \mathrm{O}$. The organic phases were collected, washed with brine, dried over $\mathrm{Na}_{2} \mathrm{SO}_{4}$ purified by column chromatography $\left(\mathrm{SiO}_{2}\right.$, Hexanes:EtOAc 8:2). Obtained $1.38 \mathrm{~g}$ $(0.007 \mathrm{~mol} ; 70 \%)$ of pure product. White crystals.

The compound is light sensitive and should be kept in the dark and stored in the freezer. Spontaneous polymerization can happen when the compound is exposed to the light or warmed up.

${ }^{1} \mathrm{H}-\mathrm{NMR}\left(300 \mathrm{MHz}, \mathrm{CDCl}_{3}\right) \delta(\mathrm{ppm}): 8.51(\mathrm{~s}, 1 \mathrm{H}) ; 7.92(\mathrm{~d}, 2 \mathrm{H}, J=9 \mathrm{~Hz}) ; 7.62(\mathrm{~d}, 2 \mathrm{H}, J=9$ $\mathrm{Hz}) ; 7.63(\mathrm{~d}, 1 \mathrm{H}, J=9 \mathrm{~Hz}) ; 7.55(\mathrm{~d}, 1 \mathrm{H}, J=9 \mathrm{~Hz}) ; 7.50$ (d, 2H, $J=9 \mathrm{~Hz}) ; 6.77$ (dd, 1H); 5.84

$(\mathrm{d}, 1 \mathrm{H}) ; 5.31(\mathrm{~d}, 1 \mathrm{H}) ; 2.37(\mathrm{~s}, 3 \mathrm{H}) .{ }^{13} \mathrm{C}-\mathrm{NMR}\left(\mathrm{CDCl}_{3}\right) \delta(\mathrm{ppm}): 154,150,139,138,137,132$, 127, 126, 120, 114, 18. MS-ESI+ (m/z): $196.1[\mathrm{M}+\mathrm{H}]^{+}$(calc. 196.1)

1,3,5-Tris(4-(5-methylpyridin-2-yl)phenethyl)benzene (5). $1.015 \mathrm{~g} \mathrm{(5} \mathrm{mmol)} \mathrm{of} \mathrm{5-methyl-}$ 2-(4-vinylphenyl)pyridine, $666 \mathrm{mg}(1.46 \mathrm{mmol})$ of 1,3,5-triiodobenzene and $160 \mathrm{mg}$ of $\mathrm{Pd}(\mathrm{OAc})_{2}$ were mixed in $25 \mathrm{ml}$ of triethanolamine. The mixture was heated overnight under inert atmosphere. After cooling down, water was added to the reaction mixture and extracted several times with $\mathrm{CHCl}_{3}$. The organic phases were collected and washed 3 times with $\mathrm{NH}_{4} \mathrm{Cl}, \mathrm{H}_{2} \mathrm{O}$ and brine and eventually dried over $\mathrm{Na}_{2} \mathrm{SO}_{4}$. The reaction crude was dissolved in $\mathrm{MeOH}$ (due to the low solubility, the addition of $1-5 \mathrm{ml}$ of EtOAc is necessary), a catalytic amount of Pd black was added and the mixture was hydrogenated overnight at $10 \mathrm{bar}$. The reaction mixture was then filtrated over celite and purified by column chromatography $\left(\mathrm{SiO}_{2}\right.$, Hexane: EtOAc 6:4). Obtained $130 \mathrm{mg}$ (0.2 mmol; 14\%). White viscous oil.

${ }^{1} \mathrm{H}-\mathrm{NMR}\left(300 \mathrm{MHz}, \mathrm{CDCl}_{3}\right) \delta(\mathrm{ppm}): 8.51(\mathrm{~s}, 3 \mathrm{H}) ; 7.89$ (d, 6H; $\left.J=9 \mathrm{~Hz}\right) ; 7.59$ (dd, 6H, $J=9$ $\mathrm{Hz}) ; 7.23$ (d, 6H, $J=9 \mathrm{~Hz}) ; 6.87$ (s, 3H); 2.90 (s, 9H); 2.37 (s, 12H). ${ }^{13} \mathrm{C}-\mathrm{NMR}(150 \mathrm{MHz}$, $\left.\mathrm{CDCl}_{3}\right)$ : See Figure 7.9. MS-ESI+ (m/z): $664.7[\mathrm{M}+\mathrm{H}]^{+}$(calc. 664.3) 


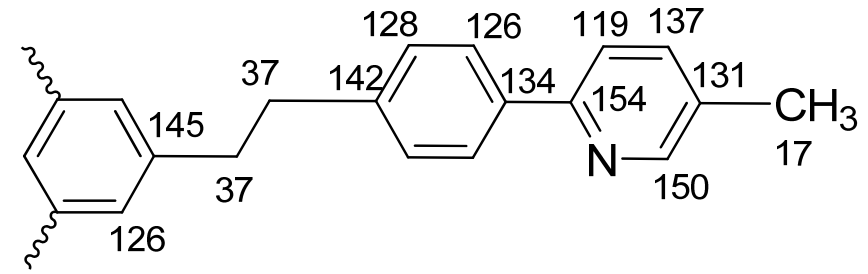

Figure 7.9. ${ }^{13} \mathrm{C}$ chemical shifts of hemicaged complex 1 derived from HMBC/HMQC-NMR.

Ir-Hemicaged Complex (1). $100 \quad \mathrm{mg}$ of 1,3,5-tris(4-(5-methylpyridin-2yl)phenethyl)benzene, $43 \mathrm{mg}$ of $\mathrm{IrCl}_{3}$ and $100 \mathrm{mg}$ of $\mathrm{CF}_{3} \mathrm{CO}_{2} \mathrm{Ag}$ were mixed in $25 \mathrm{ml}$ of glycerine ( 5 drops of $\mathrm{H}_{2} \mathrm{O}$ and $1 \mathrm{ml}$ of $\mathrm{CH}_{2} \mathrm{Cl}_{2}$ were added in order to improve the solubility $\mathrm{IrCl}_{3}$ and the ligand, respectively) and the oxygen was removed by Argon/vacuum cycles. The mixture was then refluxed overnight under Ar atmosphere. After cooling down, the mixture was extracted several times with dichloromethane. The organic phases were collected, washed with water and brine and dried over $\mathrm{Na}_{2} \mathrm{SO}_{4}$. The crude mixture was then purified by chromatography (deactivated (5\% TEA) $\mathrm{SiO}_{2}$, Hexane:EtOAc 8:2) and crystallized from hot n-heptane. Obtained $23 \mathrm{mg}(0.027 \mathrm{mmol}, 20 \%)$ of a yellow solid.

${ }^{1} \mathrm{H}-\mathrm{NMR}(600 \mathrm{MHz}, d 6-\mathrm{DMSO}): \delta(\mathrm{ppm}): 7.89(1 \mathrm{H}, \mathrm{s}) ; 7.57(1 \mathrm{H}, \mathrm{d}, J=3 \mathrm{~Hz}) ; 7.52(1 \mathrm{H}, \mathrm{d}, J$ $=3 \mathrm{~Hz}) ; 7.33(1 \mathrm{H}, \mathrm{s}) ; 6.61(1 \mathrm{H}, \mathrm{d}, J=6 \mathrm{~Hz}) ; 6.45(1 \mathrm{H}, \mathrm{s}) ; 5.55(1 \mathrm{H}, \mathrm{s}) ; 3.01(1 \mathrm{H}, \mathrm{d}, J=$ $6 \mathrm{~Hz}) ; 2.66(1 \mathrm{H}, \mathrm{d}, J=6 \mathrm{~Hz}) ; 2.39(1 \mathrm{H}, \mathrm{m}) ; 2.32(1 \mathrm{H}, \mathrm{m}) ; 2.1(3 \mathrm{H}, \mathrm{s}) .{ }^{13} \mathrm{C}-\mathrm{NMR}(150 \mathrm{MHz}$, d6-DMSO): See Figure 7.9. MS-ESI+ (m/z): $853.1\left(\mathrm{M}^{+}\right)$.

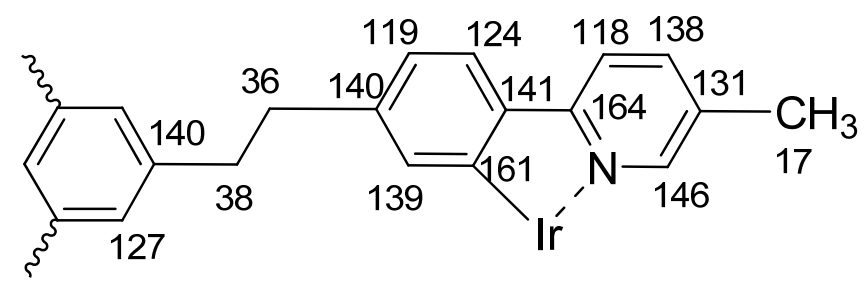

Figure 7.10. ${ }^{13} \mathrm{C}$ chemical shifts of hemicaged complex 1 derived from HMBC/HMQCNMR. 


\subsection{References}

1. Flamigni, L.; Barbieri, A.; Sabatini, C.; Ventura, B.; Barigelletti, F., Photochemistry and photophysics of coordination compounds: Iridium. In Photochemistry and Photophysics of Coordination Compounds II, 2007; Vol. 281, pp 143-203.

2. Lowry, M. S.; Bernhard, S., Chem. Eur. J. 2006, 12, 7970-7977.

3. Schaffner-Hamann, C.; von Zelewsky, A.; Barbieri, A.; Barigelletti, F.; Muller, G.; Riehl, J. P.; Neels, A., J. Am. Chem. Soc. 2004, 126, 9339-9348.

4. Vlcek, A.; Zalis, S., Coord. Chem. Rev. 2007, 251, 258-287.

5. Stuhr-Hansen, N.; Christensen, J. B.; Harrit, N.; Bjornholm, T., J. Org. Chem 2003, 68, 1275-1282.

6. Gerold, J.; Holzenkamp, U.; Meier, H., Eur. J. Org. Chem 2001, 2757-2763.

7. Beletskaya, I. P.; Cheprakov, A. V., Chem. Rev. 2000, 100, 3009-3066.

8. Miyaura, N.; Suzuki, A., Chem. Rev. 2002, 95, 2457-2483.

9. Wang, A. E.; Xie, H. H.; Wang, L. X.; Zhou, Q. L., Tetrahedron 2005, 61, 259-266.

10. Azzena, U.; Dettori, G.; Lubinu, C.; Mannu, A.; Pisano, L., Tetrahedron 2005, 61, 8663 8668.

11. Mach, U. R.; Hackling, A. E.; Perachon, S.; Ferry, S.; Wermuth, C. G.; Schwartz, J. C.; Sokoloff, P.; Stark, H., ChemBioChem 2004, 5, 508-518.

12. Abraham, R. J.; Reid, M., J. Chem. Soc.-Perkin Trans. 2 2002, 1081-1091.

13. Lamansky, S.; Djurovich, P.; Murphy, D.; Abdel-Razzaq, F.; Lee, H. E.; Adachi, C.; Burrows, P. E.; Forrest, S. R.; Thompson, M. E., J. Am. Chem. Soc. 2001, 123, 43044312.

14. Holzer, W.; Penzkofer, A.; Tsuboi, T., Chem. Phys. 2005, 308, 93-102.

15. You, Y.; Park, S. Y., Dalton Trans. 2009, 1267-1282.

16. This conclusion is corroborated by the analysis of the non-radiative constant $\mathrm{k}_{\mathrm{nr}}$.

17.Abdel-Shafi, A. A.; Beer, P. D.; Mortimer, R. J.; F., W., Helv. Chim. Acta 2001, 84, 2784-2795.

18. Bodesheim, M.; Schutz, M.; Schmidt, R., Chem. Phys. Lett. 1994, 221, 7-14.

19. Mulazzani, Q. G.; Sun, H.; Hoffman, M. Z.; Ford, W. E.; Rodgers, M. A. J., J. Phys. Chem. 1994, 98, 1145-1150.

20. Tamayo, A. B.; Alleyne, B. D.; Djurovich, P. I.; Lamansky, S.; Tsyba, I.; Ho, N. N.; Bau, R.; Thompson, M. E., J. Am. Chem. Soc. 2003, 125, 7377-7387.

21. Montalti, M.; Credi, A.; Prodi, L.; Gandolfi, M. T., Handbook of Photochemistry. CRC Press: Boca Raton, 2006.

22. Oyler, K. D.; Coughlin, F. J.; Bernhard, S., J. Am. Chem. Soc. 2007, 129, 210-217.

23. M. B. Smith; March, J., March's Advanced Organic Chemistry. Wiley-interscience: New York, 2001. 


\section{Appendix 7.1.}

\section{Synthetic attempts for the synthesis of caged complex 2.}

The hemicaged complex 1 was originally designed as an intermediate for the synthesis of caged complex 2. In this appendix an account of the reaction conditions tried in order to synthesize the caged complex $\mathbf{2}$ is reported.

The most promising strategy for the synthesis of $\mathbf{2}$ consists of deprotonation of the methyl moieties of the hemicage 1 with a suitable base, followed by a nucleophilic substitution of the obtained carbanion with 1,3,5-tris(tribromomethyl)benzene (Figure 7.11). ${ }^{22}$ The main challenge of this reaction is finding a suitable base. Meta-methylpyridine is a weak acid (pKa $=36 / 37$ ) and therefore the use of a strong base (i.e. an organolithium base) is mandatory. On the other hand, also the protons on the pyridine ring are slightly acidic: pyridine derivatives react with $n$-BuLi resulting in the functionalization of the pyridine moiety with a butyl group (Chichibabin reaction). Therefore, an ideal base for this reaction must have an adequate strength (in order to deprotonate the methyl unit) but should be weak enough to prevent the Chichibabin reaction.

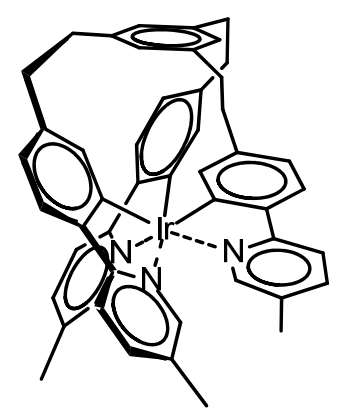

1

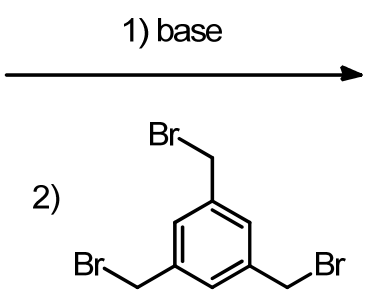

侐

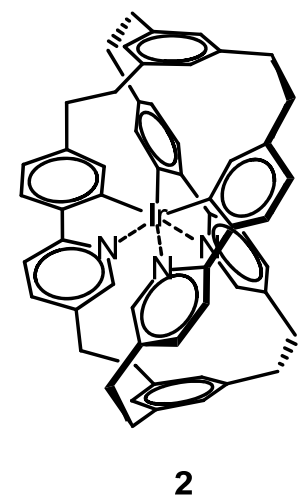

2

Figure 7.11. Possible strategy for the synthesis of 2.

In order to find a suitable base that meets the requirements described in the previous paragraph, three different organolithium bases with different strengths were tested, namely lithium derivatives of diisopropylame (A), 2,2,6,6-tetramethylppiperidine (B) and pyrrolidine (C). The structures and the $\mathrm{pKa}$ of the conjugated acids are shown in Figure 7.12. ${ }^{23}$ 
<smiles>CC(C)NC(C)C</smiles>

A

$\mathrm{pKa}=36$<smiles>CC1(C)CCCC(C)(C)N1</smiles>

B

pKa $=37$

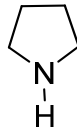

C

$\mathrm{pKa}=44$

Figure 7.12 Structure and $\mathrm{pKa}$ values of the conjugated acids used for the deprotonation of $\mathbf{1}$.

In a preliminary screening, all the three bases were found to be strong enough to deprotonate the model compound 3-methylpyridine. In a typical experiment, 3-methylpyperidine was dissolved in anhydrous THF and treated with the lithium derivatives of A, B or C (freshly prepared by reaction of $n-\mathrm{BuLi}$ with $\mathrm{A}, \mathrm{B}$ or $\mathrm{C}$ in THF at $-78^{\circ} \mathrm{C}$ ). The reaction mixture was kept at $-78^{\circ} \mathrm{C}$ for $1 \mathrm{~h}$, then warmed up at $0^{\circ} \mathrm{C}$ for an hour and, subsequently, the reaction was quenched upon addition of $\mathrm{CD}_{3} \mathrm{OD}$, in order to obtain the deuterated derivative $\mathrm{D}$ (Figure 7.13). The reaction was checked by ${ }^{1} \mathrm{H}-\mathrm{NMR}$ and a decrease of the $\mathrm{CH}_{3}$ signal was observed: the integral of the $\mathrm{CH}_{3}$ signal went from 3 to 2 , as expected for a monodeuteration of the methyl moiety.

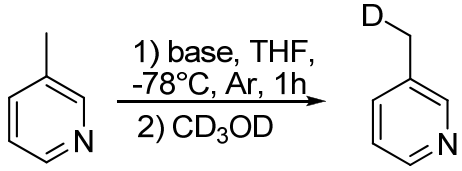

Figure 7.13. Deuteration of 3-methylpyridine.

Unfortunately, the use of LDA (according to the reaction shown in Figure 7.11) resulted in a very poor yield of the caged complex, together with the starting material and partially substituted complexes, as evident from the mass spectrum shown in Figure 7.14. All the peaks observed in the MS spectrum show the expected isotopic patterns. Isotopic patterns are due to the fact that many atoms are found in nature as a mixture of several isotopes with a constant abundance. Iridium atoms are found in nature as an admixture of two isotopes: ${ }^{191} \mathrm{Ir}$ and ${ }^{193} \mathrm{Ir}$ in a $1.7: 1$ proportion, whilst nitrogen atoms have two isotopes $\left({ }^{14} \mathrm{~N}\right.$ and $\left.{ }^{15} \mathrm{~N}\right)$ in a 250:1 proportion. Therefore, $\operatorname{Ir}(\mathrm{III})$-complexes containing $\mathrm{C}$ and $\mathrm{N}$ atoms will show a typical pattern which reflects the possible isotopic combinations with a relative intensity based on the probability of each combination of isotopes. For instance, the theoretical isotopic pattern calculated for the hemicaged complex $\mathbf{1}$ is reported in Figure 7.15 A. The same pattern is 
experimentally observed for the peak of $\mathbf{1}$ in the mass spectrum of the reaction mixture (Figure 7.14). The isotopic pattern is a sort of fingerprint of the ion and therefore corroborates the assignment of the signal observed in the mass spectrum to the hypothesised structure. Upon introduction of bromine atoms, the isotopic pattern changes due to the isotopic composition or $\mathrm{Br}$, which is found in nature as an admixture of two isotopes $\left({ }^{79} \mathrm{Br}\right.$ and ${ }^{81} \mathrm{Br}$ ) with an almost 1:1 ratio. The calculated isotopic pattern of the partially closed cage complex bearing one bromine atom is shown in Figure 7.15 B. The mass peak observed at $863.6 \mathrm{~m} / \mathrm{z}$ (with the same isotopic pattern of $\mathbf{1}$ ) is probably due to a fragmentation of the hemicaged complex 1 with loss of a $\mathrm{CH}_{3}$ moiety.

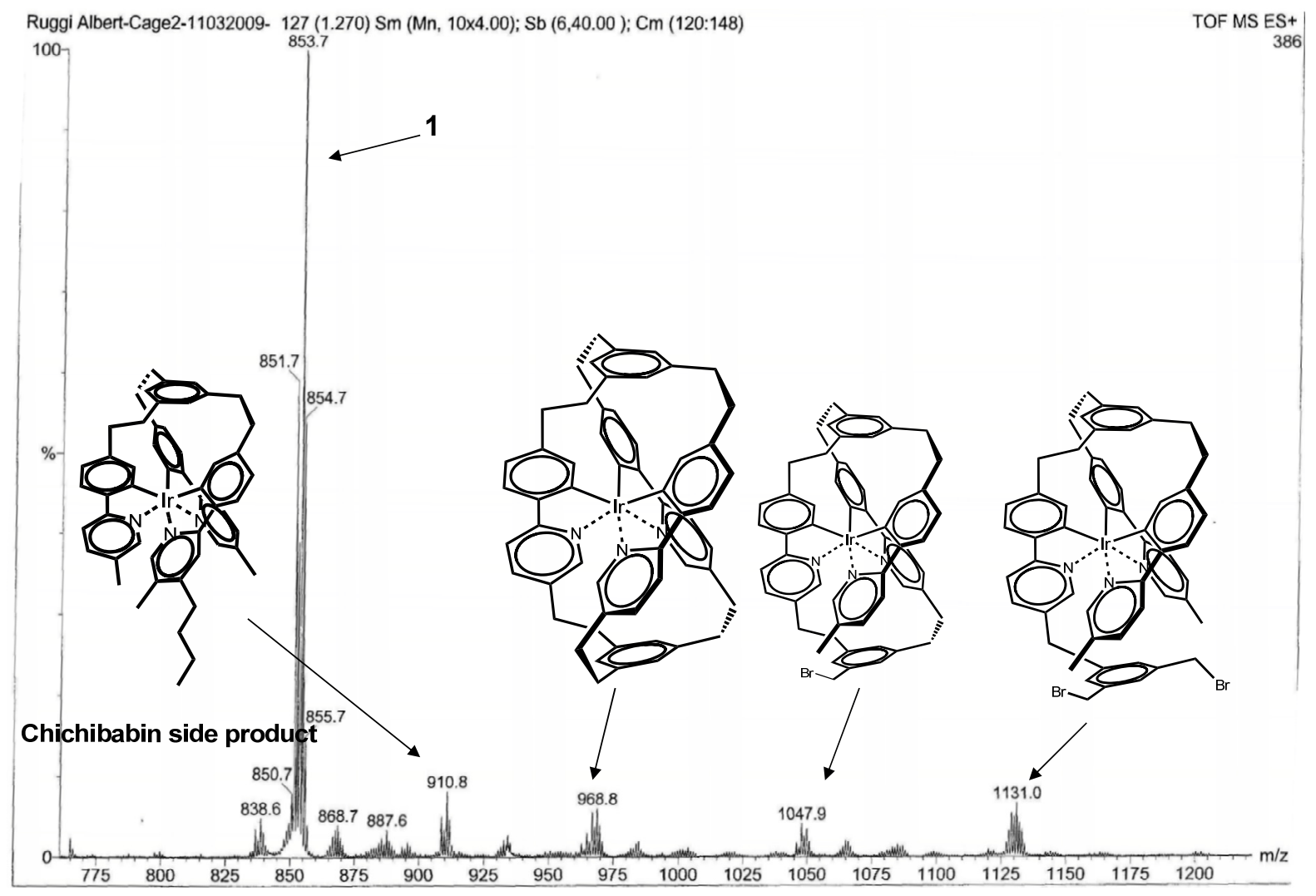

Figure 7.14. Synthesis of the caged complex 2. ESI-MS spectrum of the reaction mixture. 

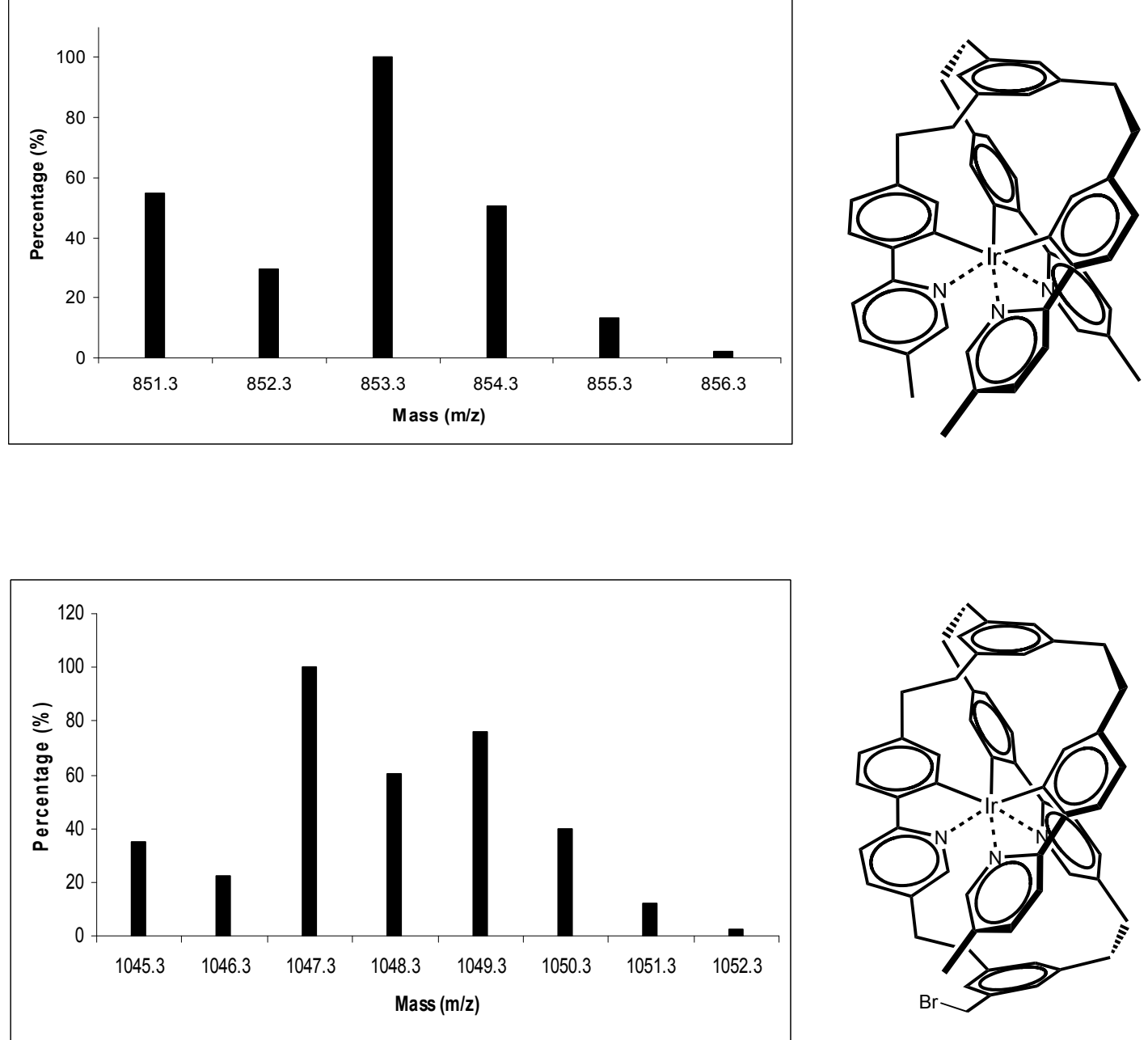

Figure 7.15. Theoretical isotopic pattern for 1 (A) and for the partly closed caged complex bearing one bromine atom (B). Isotopic patterns calculated with the Isotope Distribution Calculator from Scientific Instrument Services available online from www.sisweb.com.

The presence of the Chichibabin side product is due to the use of an excess of $n$-BuLi during the preparation of the LDA base. Despite the great steric hindrance of the hemicaged complex, the formation of oligomers (i.e. derivatives obtained upon nucleophilic attachment of several moieties of $\mathbf{1}$ to 1,3,5-tris(bromomethyl)benzene) are not observed.

Results showed that the conversion did not improve by using stronger bases, but the presence of unidentified side products with 1,3,5-tris(bromomethyl)benzene was observed. On the other hand, the isolation of a pure sample of $\mathbf{2}$ from the reaction mixture was not possible. Eventually, considering the synthetic difficulties encountered, the predictions obtained from computational models and the poor shielding of the LUMO orbital expected for this compound on the basis of the results previously discussed in this Chapter, the synthesis of 2 was not further pursued. 


\title{
Chapter 8
}

To run o'er better waters hoists its sail

The little vessel of my genius now,

That leaves behind itself a sea so cruel

Dante, Purg., I

\section{Dendritic ruthenium(II)-based dyes tunable for diagnostic or therapeutic applications*}

\begin{abstract}
In this chapter the synthesis, characterization, and photophysical behaviour of two new luminescent dendrimers based on ruthenium(II)-dyes, carrying 32 positive (1) or 32 negative (2) charges, are described. The combination of stoichiometric control and absence of selfquenching of the ruthenium dyes yields a maximum increase of the fluorescence (16x) of the dendrimer (corresponding to the number of substituents) and offers a straightforward and promising approach to the realization of very bright labels. The uptake of $\mathbf{1}$ and $\mathbf{2}$ in tumour cell lines has been studied and shows excellent diagnostic imaging properties and remarkable different phototoxicity for the two dendrimers.
\end{abstract}

\footnotetext{
* Part of this chapter has been pubished in Ruggi, A.; Beekman, C.; Wasserberg D.; Subramaniam, V.; Reinhoudt, D. N.; van Leeuwen, F. W. B.; Velders, A. H., Chem.-Eur. J. 2011, 17, 464-467.
} 


\subsection{Introduction}

The development of novel highly fluorescent agents is of paramount importance for biological and medical diagnostic applications. ${ }^{1-3}$ In the last decade, a number of nanosized materials e.g. semiconductor Quantum Dots ${ }^{4}$ and silica nanoparticles ${ }^{5}$ have been developed, but the lack of control over the functionalization stoichiometry, ${ }^{6}$ together with potential toxicity effects of such nanoparticles, ${ }^{7}$ are restraining their further implementation. Dendrimers are a class of polymers with well defined hyperbranched structures, which, depending on the type and generation, have a size of 1-10 $\mathrm{nm}^{8}$ Control over the functionalization stoichiometry and stepwise introduction of multiple label, ${ }^{9}$ targeting, ${ }^{10}$ or therapeutic functionalities, ${ }^{11}$ make dendrimers an ideal platform for in vitro and in vivo biomedical applications. ${ }^{11}$ Ruthenium(II) luminophores have been used both for nonbiological, e.g. solar cells, ${ }^{12}$ and biological applications, e.g. electro-chemiluminescence, ${ }^{13}$ protein labelling, ${ }^{14}$ in vivo imaging ${ }^{15,} 16$ and photodynamic therapy. ${ }^{17} \mathrm{~A}$ few examples of ruthenium(II)-based luminescent dendrimers have been reported ${ }^{18-20}$ but their potential as bright labels for biomedicinal applications has not yet been explored.

In this chapter we describe the design, synthesis, characterization and photophysical properties of two G2 PAMAM dendrimers with a cystamine core decorated with $16 \mathrm{Ru}(\mathrm{II})$ based luminophores carrying 32 positive or negative charges. Moreover, we report about the interaction of these dendritic dyes with cancer cells and their remarkably different phototoxicity.

\subsection{Design and synthesis}

Despite the fact that the idea of using a structure with multiple luminescent labels is a quite trivial way to achieve high brightness, ironically, increasing the number of fluorescent moieties on a dendrimer does not necessarily result in an increase of their fluorescence intensity, due to propensity for $\pi$-stacking and self quenching typical of most organic dyes. ${ }^{21}$, ${ }^{22}$ It is known from the literature that most organic dyes (including Alexa ${ }^{\circledR}$ dyes, which are among the best organic fluorophores available) give only a poor brightness enhancement upon multiple labelling (for instance on proteins) and that the introduction of a number of fluorophores beyond a critical value (never higher than 4-5 in the best cases) results in the opposite effect: an evident decrease of brightness. ${ }^{21}$ Octahedral six-coordinated transition metal-based $\pi$-luminophores generally show a large Stokes shift and give negligible stacking, 
with a reduced self-quenching, making them ideal candidates for multiple labelling. ${ }^{23}$ Ruthenium(II)-based fluorophores, in particular, are attractive for the realization of a proof of principle of brightness enhancement upon multiple labelling, since they combine good luminescence properties with a straightforward synthesis.

With these ideas in mind, we decided to decorate a generation 2 (G2) PAMAM dendrimer with 16 luminescent moieties based on $\left[\mathrm{Ru}(\mathrm{bpy})_{3}\right]^{2+}$ derivatives carrying 32 positive (1) and negative (2) charges, respectively (Figure 8.1).

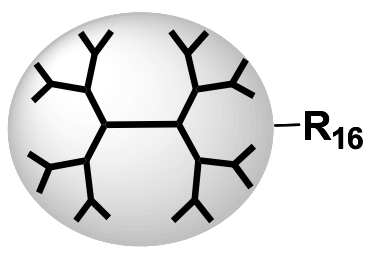

R:

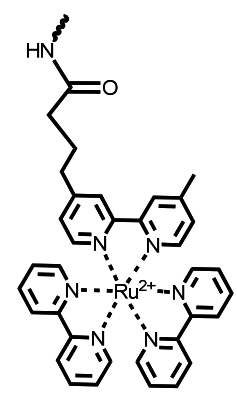

1

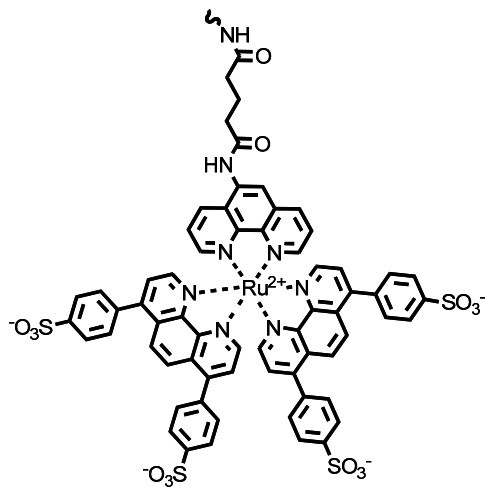

2

Figure 8.1. G2 PAMAM dendrimer decorated with $16 \mathrm{Ru}(\mathrm{II})$-based luminophores carrying 32 positive (1) or negative (2) charges.

Both dendrimers were synthesized according to the pathway shown in Scheme 8.1. A G2PAMAM (polyamidoamine) dendrimer, with a cystamine core and sixteen surface amino groups was decorated with a bipyridine or phenanthroline derivative via $\mathrm{DCC} / \mathrm{HOBt}$ coupling $\left(\right.$ DCC $=N, N^{\prime}$-dicyclohexylcarbodiimide, $\mathrm{HOBt}=$ hydroxylbenzotriazole $),{ }^{18}$ and further functionalized with $\left[\mathrm{Ru}(\mathrm{bpy})_{2} \mathrm{Cl}_{2}\right]$ or $\left[\mathrm{Ru}(\mathrm{pheS})_{2} \mathrm{Cl}_{2}\right]$ (bpy = 2,2 '-bipyridine and pheS $=4,4$ '(1,10-phenanthroline-4,7-diyl)dibenzene sulfonate) in order to obtain a positively or negatively charged dendrimer, respectively. The final compounds were purified by size exclusion chromatography. The choice of decorating the dendrimer in two steps, first introduction of a bipyridine (bpy) 1/phenanthroline (pheS) 2 ligand (L) and subsequent complexation with the $\left[\mathrm{RuL}_{2}\right] \mathrm{Cl}_{2}$ derivatives, was mainly due to the necessity of avoiding a high steric hindrance upon dendrimer functionalization. Furthermore, this approach offers the possibility of checking the degree of functionalization with TLC tests for primary amines (e. g. ninhydrin test), which cannot be used on the final compounds because of the interference of the colour of complexes $\mathbf{1}$ and $\mathbf{2}$. 

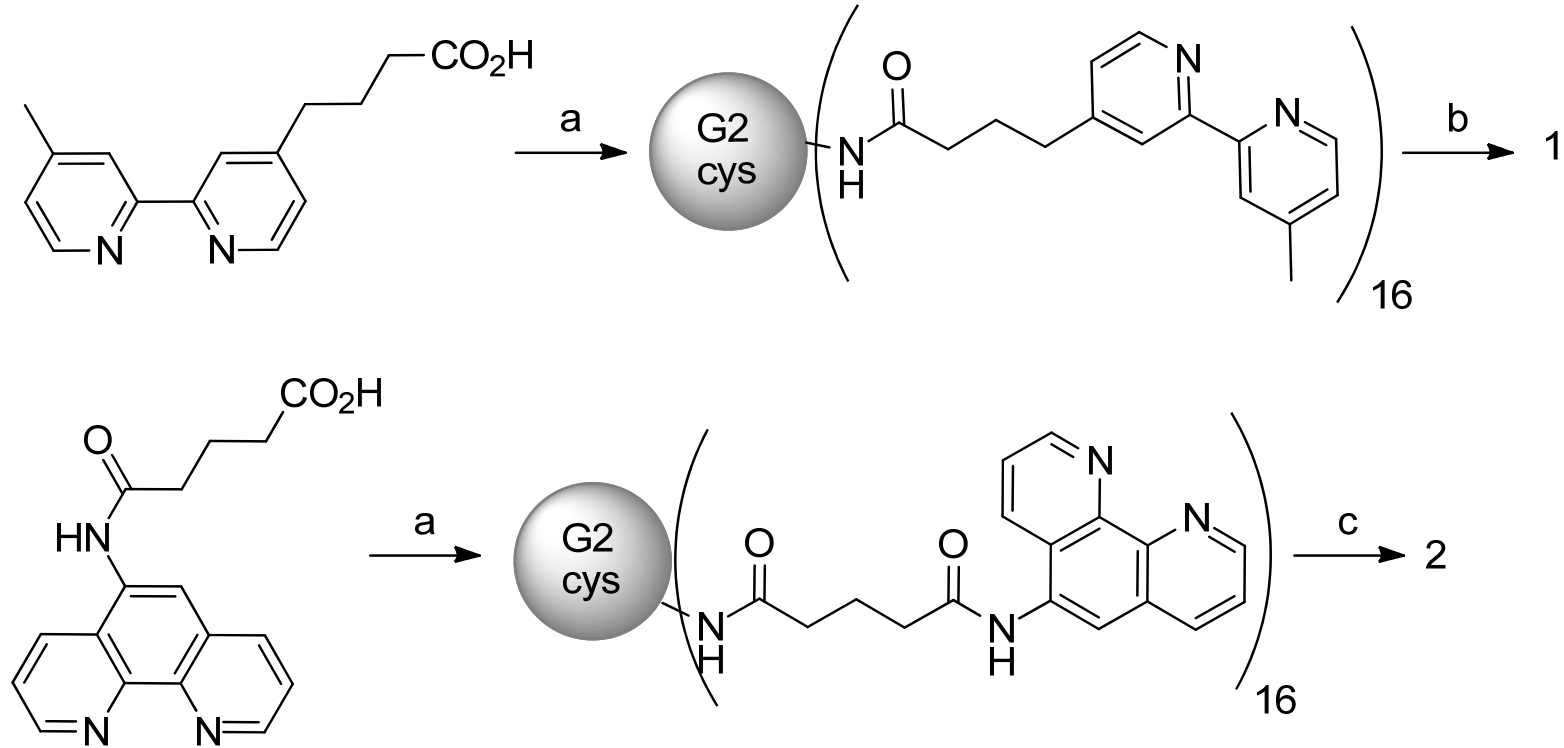

Scheme 8.1. Synthetic pathway for the synthesis of the Ru(II)-decorated dendrimers 1 and 2. Reaction conditions: a) PAMAM (G2)-cystamine, DCC, HOBt, DMAc, 2d, 60 ${ }^{\circ}$, Ar; b) $\left[\mathrm{Ru}(\mathrm{bpy})_{2}\right] \mathrm{Cl}_{2}, \mathrm{EtOH}$, reflux, 10h; c) $\left[\mathrm{Ru}\left(\mathrm{pheSNa}_{2}\right)_{2}\right] \mathrm{Cl}_{2}, \mathrm{EtOH}$, reflux, $10 \mathrm{~h}$.

\subsection{Characterization and photophysical properties}

All the intermediates and target compounds were characterized by NMR spectroscopy and mass spectrometry. The ${ }^{1} \mathrm{H}$ chemical shifts of the intermediates are reported in the experimental section, while in this section only the NMR spectra of the functionalized dendrimers are discussed. The bpy- and phenantroline functionalized dendrimers were characterized by NMR spectroscopy and mass spectrometry, proving the complete functionalization of all 16 end groups of the second generation PAMAM dendrimer. The intermediate G2-bpy 16 shows high resolution ${ }^{1} \mathrm{H}-\mathrm{NMR}$, with a slight broadening of signals which is due to the size of the molecule and the fact that all subunits can be restricted in their orientation in the dendrimer due to sterical hindrance and/or partly backfolding of branches (Figure 8.2). Also the Ru(II)-decorated dendrimers were successfully characterized by NMR spectroscopy even though for dendrimers this is notoriously difficult, and particularly $\mathbf{1}$ shows surprisingly high resolution data, allowing full assignment of peaks through 1D and 2D homo- and heteronuclear experiments (Figure 8.3). Comparison of the integration values of the dendrimer core peak signals with the aromatic and bpy-ethyl peak signals indicate derivatization of all 16 end groups with $\left[\mathrm{Ru}(\mathrm{bpy})_{3}\right]^{2+}$ units. 


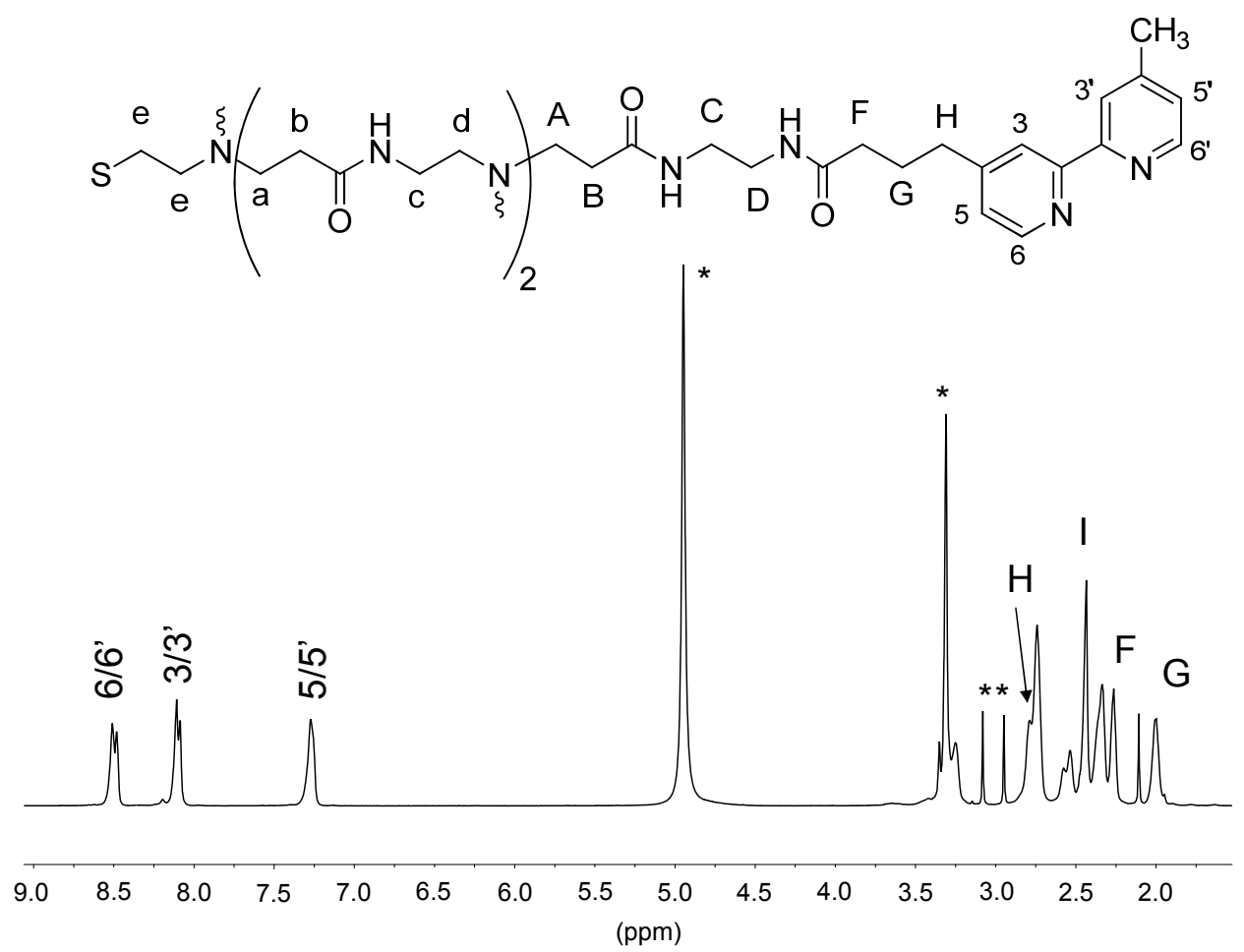

Figure 8.2 Peak assignment of ${ }^{1} \mathrm{H}-\mathrm{NMR}\left(d_{4}-\mathrm{MeOH}\right)$ of G2-bpy ${ }_{16} \cdot *=$ residual solvents.

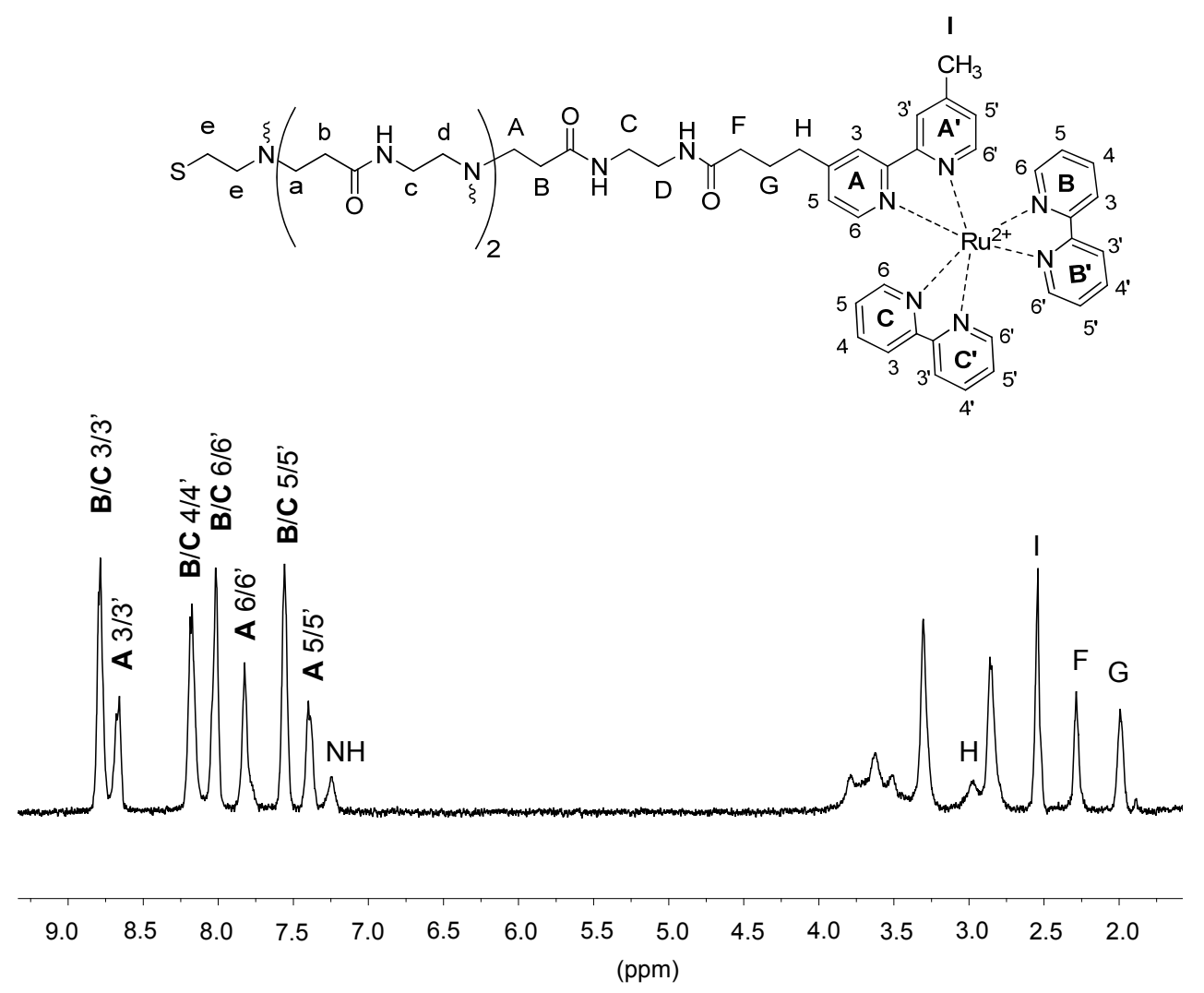

Figure 8.3. Peak assignment of ${ }^{1} \mathrm{H}-\mathrm{NMR}\left(d_{6}\right.$-acetone) of $\mathbf{1}\left(\mathrm{PF}_{6}^{-}\right.$salt). All pyridine rings are unequivalent; however the corresponding protons of the pyridine rings $\mathbf{B} / \mathbf{B}^{\prime}$ and $\mathbf{C} / \mathbf{C}$ 'resonate at practically the same frequencies. 
In particular pulse-field gradient spin echo (PFGSE) DOSY experiments proved to be a powerful tool in the characterization of these macromolecules, which have a molecular weight of about $20 \mathrm{kDa}$. Firstly, NMR diffusion measurements excluded the presence of unreacted bifunctional $\left[\mathrm{Ru}(\mathrm{bpy})_{2} \mathrm{Cl}_{2}\right]$ or unreacted dendrimer in the final product $\mathbf{1}$ and, secondly, allowed the determination of the hydrodynamic radius $(\mathrm{R})$ of the dendrimer through the Stokes-Einstein equation (eq. 8.1). ${ }^{24,25}$

$$
D=\frac{k T}{6 \pi \eta R}
$$

Where $\mathrm{D}$ is the diffusion constant, $k$ is the Boltzmann constant, $\mathrm{T}$ is the temperature and $\eta$ is the viscosity of the solvent. The hydrodynamic radius $\mathrm{R}$ can be determined via the ratio of the diffusion constants $\mathrm{D}$ of the proton signals of a reference molecule, i.e. the single dye, and those of the dendrimer, measured on a mixture of the two compounds. Using $\left[\mathrm{Ru}(\mathrm{bpy})_{3}\right]^{2+}$ as internal standard $(\mathrm{R}=0.9 \mathrm{~nm})^{26}$ the calculated $\mathrm{R}$ value for 1 was $5 \mathrm{~nm}$ (Figure 8.4), which is consistent with the size of a non-functionalized fourth generation PAMAM dendrimer. ${ }^{[21]}$ This size is in fact expected for a G2 dendrimer with sixteen $1 \mathrm{~nm}$ sized end groups. Although the NMR signals of $\mathbf{2}$ are very broad, the (PFGSE) DOSY data show the absence of starting material and, from the diffusion constant, $\mathbf{2}$ has been determined to have the same size as 1 .

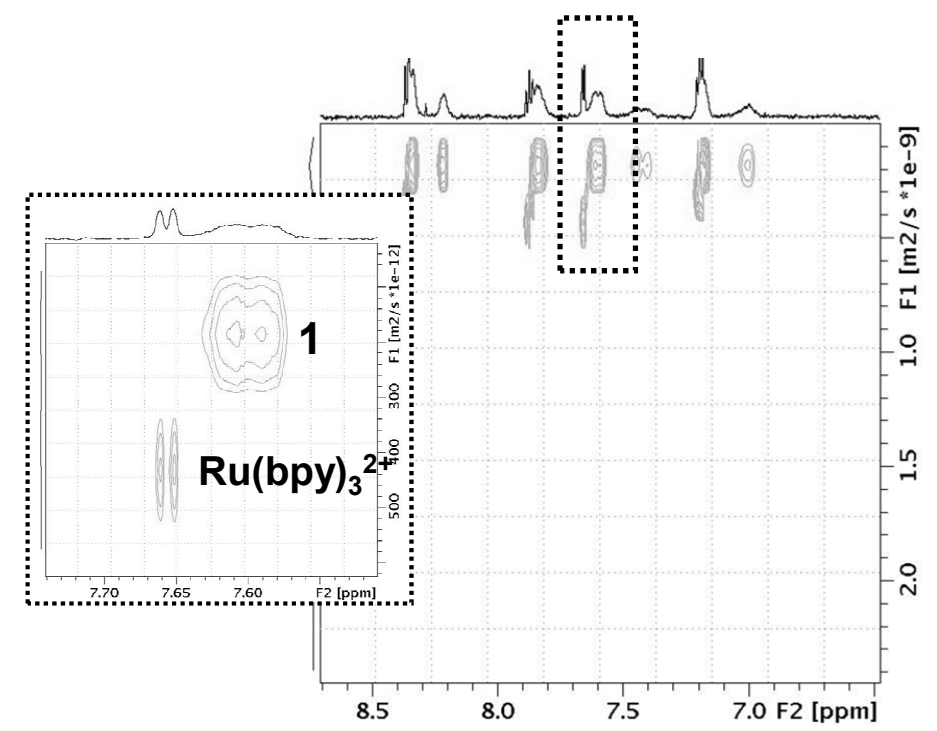

Figure 8.4. Pseudo-2D DOSY plot of a mixture of 1 and $\left[\mathrm{Ru}(b p y)_{3}\right]^{2+}$ in $\mathrm{D}_{2} \mathrm{O}$. (aromatic protons region). Inset shows the enlarged region of the H6 protons, evidencing the difference in diffusion constant between $\mathbf{1}$ (broad peak) and free dye (sharp doublet). 
For correct determination of the absorption coefficient of dendrimers the precise concentration of a solution is a prerequisite. A stock solution of $\mathbf{1}$ was prepared using the $\mathrm{PF}_{6}$-salt of 1 , which had been purified by repetitive recrystallization from acetone/ether and acetone/water, and the purity of which was determined by titration with 2,2,2-trifluoroethanol followed with ${ }^{19} \mathrm{~F}$ NMR spectroscopy. The purity of the $1-\mathrm{PF}_{6}$ dendrimer was $>95 \%$ with the impurities probably being residual, co-precipitated, solvent molecules. The absorption coefficient $\varepsilon$ of $1-\mathrm{PF}_{6}$ was determined to be $2.8 \cdot 10^{5} \mathrm{~cm}^{-1} \mathrm{M}^{-1}$ at $462 \mathrm{~nm}$ which is close to the theoretical 16-fold amplification with respect to the single dye. For the negatively charged dendrimer 2, NMR titration with ${ }^{19} \mathrm{~F}$ NMR is not an option due to the absence of fluorine atoms, but based on the DOSY data showing a single set of slowly diffusing peaks like $\mathbf{1}$, the purity of $\mathbf{2}$ is estimated to be $>95 \%$ (as for $\mathbf{1}$ ), and the absorption coefficient of $\mathbf{2}$ is determined to be $3.310^{5} \mathrm{~cm}^{-1} \mathrm{M}^{-1}$ at $452 \mathrm{~nm}$. Both dendrimers 1 and 2 show a linear 16-fold increase of the absorption coefficient with respect to the single dyes, and a concomitant improvement of the emission intensity with the quantum yield remaining unchanged. It should be stressed out that this constitutes a remarkable increase in brightness $(\varepsilon \times \phi)$ : both 1 and 2 giving an almost 16-fold improvement of the emission compared to the equimolar single dyes (Figure 8.5). This is the first example of a luminescence amplification obtained with multiple dyes that is in line with the maximum theoretical amplification value, and demonstrates the potential of luminescent metal complexes in the realization of very bright labels. The amplification of the brightness of the ruthenium dendrimers proves lack of selfquenching, in contrast to dendrimers decorated with organic dyes, that suffer from self quenching. $^{21,22}$ Dendrimers 1 and $\mathbf{2}$ show a luminescence brightness similar to rhodamine, which is among the brightest dyes available, ${ }^{27}$ and higher generation $\mathrm{Ru}(\mathrm{II})$-dendrimers are therefore expected to beat the brightness records for single (macro)molecular dyes. 

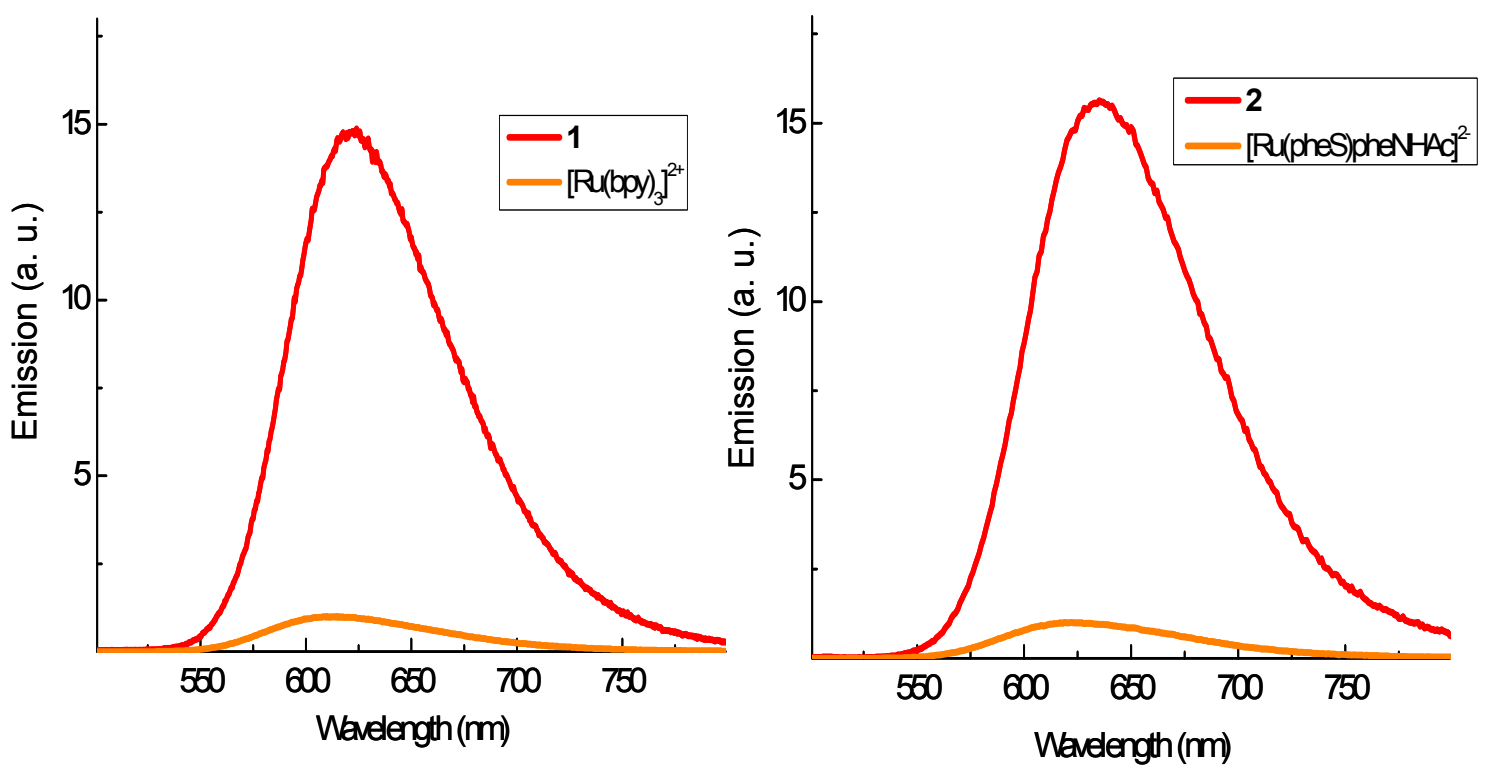

Figure 8.5. Normalized emission of equimolar aqueous solutions $(2 \mu \mathrm{M})$ of 1 (left), 2 (right) and relative reference single dye compounds. $\lambda_{\mathrm{exc}}=450 \mathrm{~nm}$.

The luminescence properties of the two dendrimers and of the single dyes are reported in Table 8.1. Beside the already discussed increase of the molar absorption coefficient $\varepsilon$, the quantum yield $\phi$ of the luminophores is almost the same, as expected in absence of selfquenching. Moreover, also the lifetimes of dendrimer $\mathbf{1}$ and of the single dye $\left[\mathrm{Ru}(\mathrm{bpy})_{3}\right] \mathrm{Cl}_{2}$ are not very different. Conversely, the emission lifetime of 2 increases compared to that of the single dye by a factor of 2.5. The lifetime of $\mathbf{2}$ is not monoexponential and indicates a distribution of varying environments felt by the dyes. This effect, together with the fact that, contrary to $\mathbf{1}$, the ${ }^{1} \mathrm{H}-\mathrm{NMR}$ of $\mathbf{2}$ shows broad bands, indicative of different chemical environments for different $\mathrm{Ru}(\mathrm{II})$ end group moieties, can be explained in terms of a partial refolding of the dendrimer end groups. 
Table 8.1. Absorption and emission properties of fluorophores in water $(\mathrm{pH}=7)$.

\begin{tabular}{|c|c|c|c|c|}
\hline & $\lambda_{\text {exc }}(\mathbf{n m}) ; \boldsymbol{\varepsilon}\left(\mathbf{M}^{-1} \mathbf{c m}^{-\mathbf{1}}\right)$ & $\begin{array}{c}\lambda_{\text {em }} \\
\mathbf{( n m})\end{array}$ & $\phi_{\text {air }}\left(\mathbf{H}_{\mathbf{2}} \mathbf{O}\right)$ & $\begin{array}{c}\tau_{\text {air }} \\
(\mathbf{n s})\end{array}$ \\
\hline$\left[\mathbf{R u}(\mathbf{b p y})_{\mathbf{3}}\right] \mathbf{C l}_{\mathbf{2}}$ & $\begin{array}{c}285 ; 1.0 \cdot 10^{5} \\
456 ; 1.7 \cdot 10^{4}\end{array}$ & 620 & 0.028 & 364 \\
\hline $\mathbf{1}$ & $\begin{array}{c}285 ; 2.0 \cdot 10^{6} \\
456 ; 2.8 \cdot 10^{5}\end{array}$ & 620 & 0.026 & 343 \\
\hline$\left[\mathbf{R u}(\mathbf{p h e S N a})_{2} \mathbf{p h e N H A c ]}\right.$ & $\begin{array}{c}277 ; 1.3 \cdot 10^{5} \\
458 ; 2.0 \cdot 10^{4}\end{array}$ & 625 & 0.048 & 840 \\
\hline $\mathbf{2}$ & $277 ; 1,7 \cdot 10^{6}$ & 625 & 0.051 & $\begin{array}{c}\tau_{1}=2240 \\
\left(\mathrm{f}_{1}=0.93\right) \\
\tau_{2}=251 \\
\left(\mathrm{f}_{2}=0.07\right)\end{array}$ \\
\hline
\end{tabular}

\subsection{Biological applications}

Because of their diagnostic potential, there is an increasing interest in the interaction of $\mathrm{Ru}(\mathrm{II})$-based dyes with viable cells, ${ }^{15-17,28,29}$ and the cellular uptake of $\mathbf{1}$ and $\mathbf{2}$ was studied by confocal fluorescence microscopy. CT26 colon carcinoma cells were incubated with a 10 $\mu \mathrm{M}$ solution of the dendrimers in physiological solution for 30 minutes at $37^{\circ} \mathrm{C}$. Fluorescence microscopy images $\left(\lambda_{\mathrm{exc}}=405 \mathrm{~nm}, \lambda_{\mathrm{em}}=620 \mathrm{~nm}\right)$ indicate that both dendrimers accumulate in cells in a similar manner, namely via retention in the lipid membranes (see Figure 8.6). Costaining with Lysotracker ${ }^{\mathrm{TM}}$ (Invitrogen) suggests that after accumulation in the outer membrane these nano-sized dyes are internalized via passive endocytosis and accumulated in the lysosomes. 


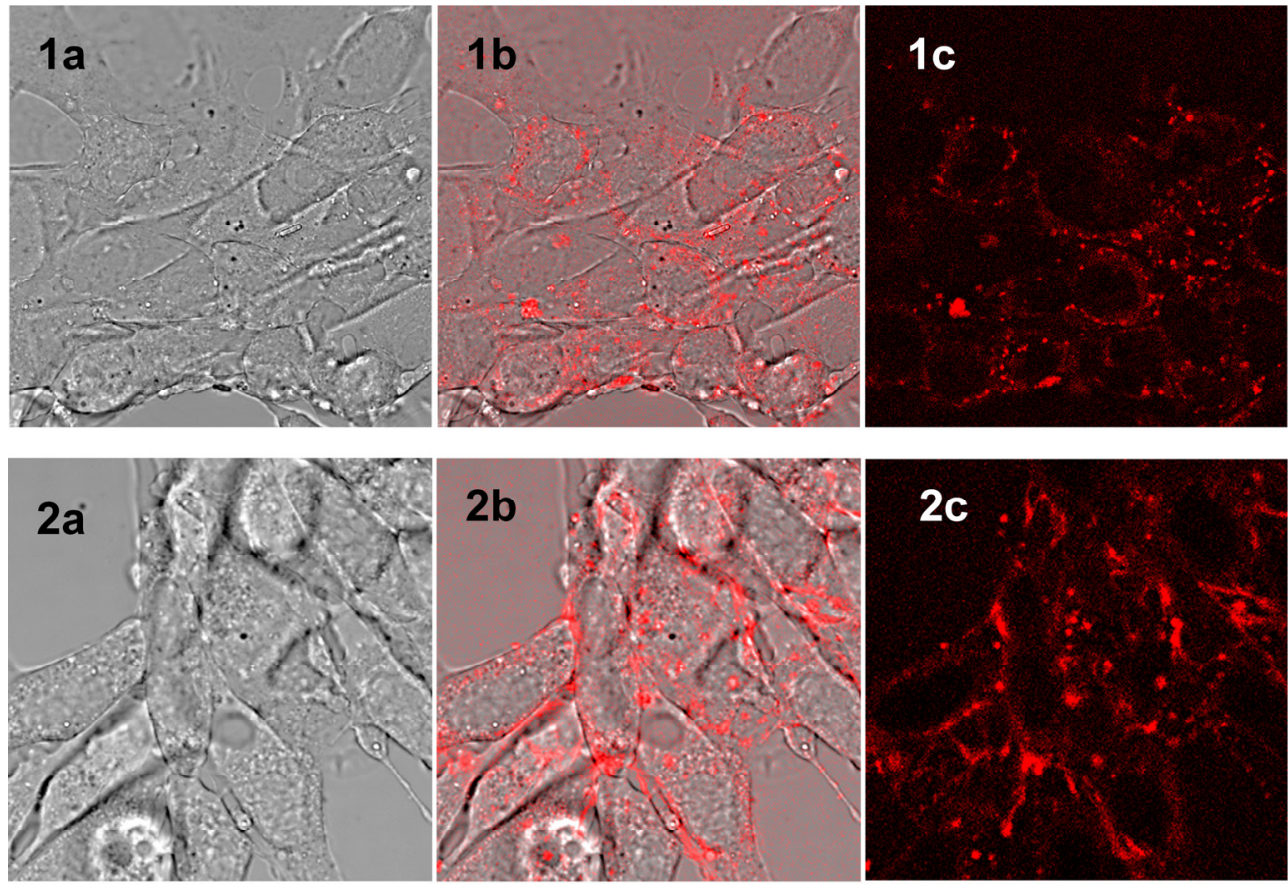

Figure 8.6. Viable CT26 cells incubated with 1 and 2. From left to right: transmission image (a), merge (b) and luminescence image (c).

Ruthenium(II) complexes are known to be phototoxic due to the generation of singlet oxygen $\left({ }^{1} \mathrm{O}_{2}\right)$ upon irradiation with UV and visible light. ${ }^{17,30,31}$ The phototoxicity of our dendrimers was evaluated for potential photodynamic therapeutic applications by incubating CT26 cells with 1 and 2 for $15 \mathrm{~min}$ at $37^{\circ} \mathrm{C}$ in physiological solution followed by illumination with 405 $\mathrm{nm}$ light for $30 \mathrm{~min}$. The illuminated area in the sample incubated with the positively charged dendrimer 1 shows massive nonspecific internalization of the dye in the cells. Accumulation occurs in the cytosol and the RNA containing nucleoli (see Figure 8.7 A top), while for nonirradiated cells the distribution did not change (see Figure 8.7 A bottom). Intracellular fluorescence spectroscopy confirms that the detected luminescence indeed comes from the Ru-dyes and differs from the spectrum of the autofluorescence (see Figure 8.7 B and Figure 8.5). A reduction of the cell (membrane) integrity is commonly accompanied by increased and nonspecific uptake. Therefore, the increased dendrimer accumulation in the illuminated area suggests 1 to be phototoxic. Remarkably, under the same conditions, the negatively charged dendrimer $\mathbf{2}$ does not show any appreciable phototoxicity as can be seen from figure $8.7 \mathrm{C}$. 

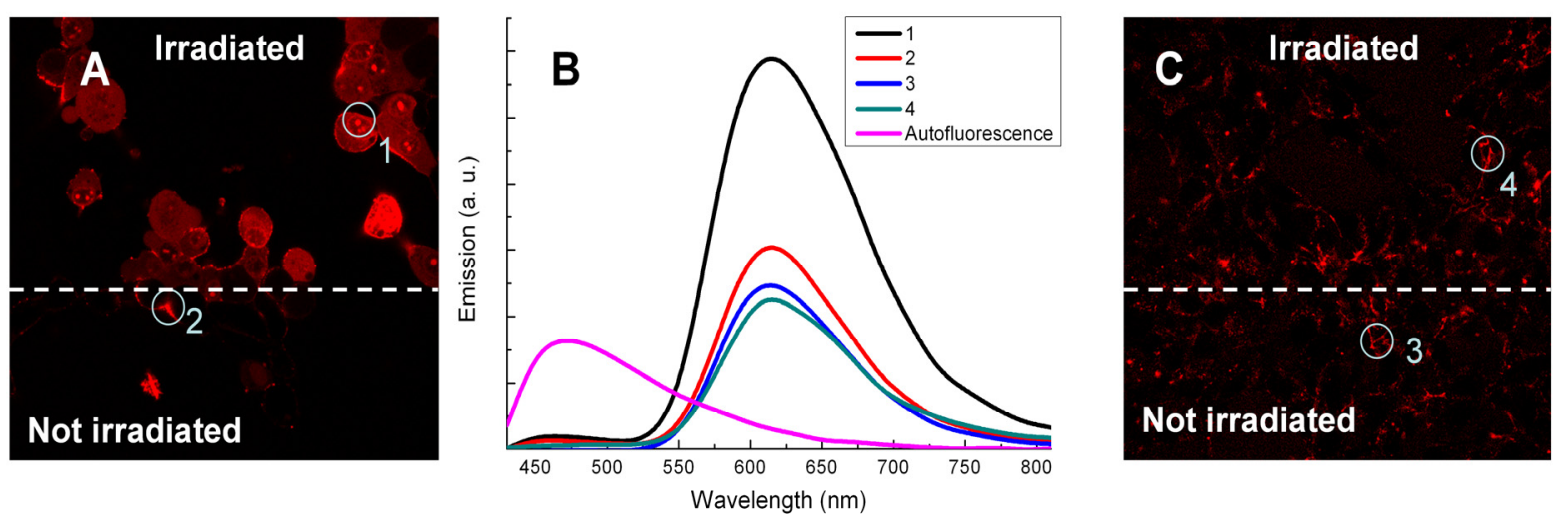

Figure 8.7. UV illumination of CT26 cells after incubation with $\mathbf{1}$ (A) and $\mathbf{2}$ (C); the section above the dotted line was illuminated ( $405 \mathrm{~nm}, 30$ minutes), while the section below the dotted line did not receive any illumination. B) Photoluminescence spectra of different regions of interest corresponds to $\mathbf{1}$ and $\mathbf{2}$ and does not overlap with autofluorescence under the same conditions.

Both $\mathrm{Ru}(\mathrm{II})$-based luminophores produce comparable amounts of singlet oxygen upon irradiation in the presence of Singlet Oxygen Sensor Green (Invitrogen), so the different phototoxicities of the two dendrimers could be due to structural differences. ${ }^{32}$ A possible explanation is a partial refolding of the $\mathrm{Ru}(\mathrm{II})$ moieties, which could actually happen in the case of the negatively charged $\mathrm{Ru}$ (II) moieties of $\mathbf{2}$, as the core of the dendrimer is partially positively charged, whereas for $\mathbf{1}$ the opposite is true. This hypothesis is in line with the previously discussed results obtained from NMR and time-resolved fluorescence. Another possible cause of the remarkable difference in phototoxicity of the two ruthenium-decorated dendrimers resides in the different charge of the macromolecules, which could induce a different internalization and/or localization at cellular level due to a different interaction with cell membranes and organelles.

\subsection{Conclusions}

In this chapter we have reported the synthesis and the characterization of two luminophores based on PAMAM dendrimers functionalized with two $\mathrm{Ru}(\mathrm{II})$-based dyes carrying 32 positive (1) or 32 negative (2) charges. From the study of the absorption and emission properties, it was found that by using ruthenium(II) dyes it is possible to avoid selfquenching and therefore dramatically enhance the luminescence signal intensity of 
dendrimers. The absence of self-quenching in combination with the stoichiometric control offers a straightforward strategy for the realization of highly bright labels with potential applications not only in biodiagnostic fields but also in other fields (e.g. solar cells, OLED technology) where high brightness is a crucial requirement. Moreover, the negative dendrimer 2 does not appear to be phototoxic and can be used in diagnostic fluorescence assays, e.g. fluorescence immunohistochemistry, whilst the positively charged dendrimer $\mathbf{1}$ holds promise as photodynamically active compound.

\subsection{Experimental section}

BpyCO $_{2} \mathrm{H}^{33}{ }^{33} \mathrm{PhenCO}_{2} \mathrm{H},{ }^{34}\left[\mathrm{Ru}(\mathrm{bpy})_{2}\right] \mathrm{Cl}_{2},{ }^{35} \quad\left[\mathrm{Ru}\left(\text { pheSNa}_{2}\right)_{2}\right] \mathrm{Cl}_{2},{ }^{36}$ PheNHAc $^{36}$ and $\left[\mathrm{Ru}\left(\text { pheSNa }_{2}\right)_{2}(\mathrm{PheNHAc})\right]^{36}$ were prepared according to literature procedures. All the commercially available chemicals (Aldrich) were used without further purification. The NMR experiments were performed on a Bruker Avance II NMR spectrometer operating at 600.35 MHz for ${ }^{1} \mathrm{H}$ and $150.09 \mathrm{MHz}$ for ${ }^{13} \mathrm{C}$. Chemicals shifts are given in ppm using the residual solvent signal as reference. Mass spectra were acquired on a Voyager-DE RP (MALDI-MS) spectrometer. UV-Vis spectra were measured on a Perkin Elmer Lambda 850 UV-Vis spectrophotometer. Steady-state luminescence spectra were measured using an Edinburgh FS900 fluorospectrometer. A $450 \mathrm{~W}$ xenon arc lamp was used as excitation source. Luminescence quantum yields at room temperature $\left(\Phi_{\text {air }}\right)$ were evaluated by comparing wavelength-integrated intensities ( $I$ and $I_{\mathrm{R}}$ ) of isoabsorptive optically diluted solutions $(\mathrm{Abs}<0.1)$ with reference to $\left[\mathrm{Ru}(\mathrm{bpy})_{3}\right] \mathrm{Cl}_{2}\left(\Phi_{\mathrm{R}}=0.028\right.$ in air-equilibrated water $)$ standard and by using the eq. 8.2:

$$
\Phi=\Phi_{R} \frac{n^{2} I}{n_{R}^{2} I_{R}}
$$

where $n$ and $n_{R}$ are the refractive index of the sample and reference solvent, respectively. ${ }^{37}$

Luminescence lifetimes of the compounds were determined by recording the decay curves of the luminescence intensity at $613 \mathrm{~nm}$ using the TCSPC option on a Horiba Jobin-Yvon Fluoromax 4 instrument and a pulsed solid state LED as excitation source at $462 \mathrm{~nm}$ wavelength. Solutions were prepared in doubly distilled water at concentrations between 1 micromolar and 100 nanomolar. In order to obtain the lifetimes the decay curves were fitted with monoexponential decay functions except for the negatively charged dendrimer 2 , which 
required a fit by using a biexponential decay function. The fractional contributions $\mathrm{f}_{\mathrm{i}}$ were calculated according to the eq. 8.3:

$$
f_{i}=\frac{\alpha_{i} \tau_{i}}{\sum_{n} \alpha_{n} \tau_{n}}
$$

Where $\alpha$ is the pre-exponential factor and $\tau$ the lifetime. ${ }^{21}$

General synthesis of the G2-lig ${ }_{16}$ dendrimers. ${ }^{18}$ To a solution of 20 eq. of $\mathrm{BpyCO}_{2} \mathrm{H}$ or $\mathrm{PheCO}_{2} \mathrm{H}$ dissolved in dry $N, \mathrm{~N}^{\prime}$-dimethylacetamide, 20 eq. of $N, N^{\prime}-$ dicyclohexylcarbodiimilde (DCC) and 20 eq. of hydroxybenzotriazole (HOBt) were added. 1 eq. of G2-PAMAM Cystamine core dendrimer $(20 \%$ sol. $\mathrm{MeOH})$ was added and the mixture was then heated overnight at $60^{\circ} \mathrm{C}$ under $\mathrm{Ar}$ atmosphere. The reaction mixture was then cooled at room temperature and filtered. The solution was precipitated with diethylether and the solid dissolved in methanol. The solvent was subsequently removed under reduced pressure. The obtained compound gave negative reaction with ninhydrin and was pure enough to be used for the next reaction without further purification.

Analytical data for G2-bpy ${ }_{16}{ }^{1} \mathrm{H}-\mathrm{NMR}\left(600 \mathrm{MHz}, d_{4}-\mathrm{MeOH}\right): \delta(\mathrm{ppm}) 8.50(2 \mathrm{H}) ; 8.10$ $(2 \mathrm{H}) ; 7.27(2 \mathrm{H}) ; 3,35(1 \mathrm{H}) ; 3.25(1 \mathrm{H}) ; 2.79-2.74(6 \mathrm{H}) ; 2.57-2.54(2 \mathrm{H}) ; 2.44(3 \mathrm{H}) ; 2.33(3 \mathrm{H})$; $2.26(2 \mathrm{H}) ; 2.01(2 \mathrm{H})$. MALDI-TOF: (m/z): $7195.8[\mathrm{M}+\mathrm{K}]^{+}$

Analytical data for G2-phen ${ }_{16}$. This compound precipitated spontaneously from the reaction mixture and was washed with acetone and dichloromethane to remove impurities. Due to the low solubility, even in DMSO, the ${ }^{13} \mathrm{C}$-NMR was not measured.

${ }^{1} \mathrm{H}-\mathrm{NMR}\left(600 \mathrm{MHz}, d_{4}-\mathrm{MeOH}\right): \delta(\mathrm{ppm}) 10.14(1 \mathrm{H}) ; 9.08(1 \mathrm{H}) ; 8.98(1 \mathrm{H}) ; 8.50(1 \mathrm{H}) ; 8.39$ $(1 \mathrm{H}) ; 8.15(1 \mathrm{H}) ; 7.96 \quad(2 \mathrm{H}) ; 7.77 \quad(1 \mathrm{H}) ; 7.59 \quad(1 \mathrm{H}) . \quad$ MALDI-TOF: $(\mathrm{m} / \mathrm{z}): 8021.4$ $\left[\mathrm{M}+\mathrm{CH}_{3} \mathrm{OH}+\mathrm{H}\right]^{+}$

General synthesis of the $\mathbf{G} 2-\mathbf{R u}_{\mathbf{1 6}}$ dendrimers. 1 eq. of $\mathrm{G} 2-\mathrm{lig}_{16}$ and 20 eq. of $\left[\mathrm{Ru}(\mathrm{bpy})_{2}\right] \mathrm{Cl}_{2}$ or $\left[\mathrm{Ru}\left(\mathrm{pheSNa}_{2}\right)_{2}\right] \mathrm{Cl}_{2}$ were dissolved in ethanol and few drops of water were added. The mixture was then refluxed overnight under Ar. The solvents were evaporated under reduced pressure and the resulting solid dissolved in water. The compound was then purified by repeated size exclusion chromatography (Sephadex G-25) and lyophilized. 
Analytical data for 1. ${ }^{1} \mathrm{H}-\mathrm{NMR}\left(600 \mathrm{MHz}, d_{2}-\mathrm{H}_{2} \mathrm{O}\right): \delta(\mathrm{ppm}) 8.80(2 \mathrm{H}) ; 8,66(1 \mathrm{H}) ; 8.19$

$(2 \mathrm{H}) ; 8.02(2 \mathrm{H}) ; 7.82(1 \mathrm{H}) ; 7.56(2 \mathrm{H}) ; 7.40(1 \mathrm{H}) 7.24(0.5 \mathrm{H}) ; 3,79-3.51$ (br, 2.5H); 3.30

$(2 \mathrm{H}) ; 2.97(0.5 \mathrm{H}) ; 2.06(2 \mathrm{H}) ; 2.54(1.5 \mathrm{H}) ; 2.28(1 \mathrm{H}) ; 1.99(1 \mathrm{H})$. MALDI-TOF: (m/z):

$14917.1[\mathrm{M}]^{+}$

Analytical data for 2. Because of the broadening of NNR signals shown by this compound, the peak assignment was not possible. Aromatic/aliphatic ratio: calc. 1.70 found: 1.68 MALDI-TOF: (m/z): $26780.4[\mathrm{M}-\mathrm{Na}+\mathrm{H}]^{+}$

\subsection{References}

1. Weissleder, R.; Ntziachristos, V., Nat. Med. 2003, 9, 123-128.

2. Mayer, A.; Neuenhofer, S., Angew. Chem. Int. Ed. 1994, 33, 1044-1072.

3. Rao, J. H.; Dragulescu-Andrasi, A.; Yao, H. Q.; Yao, H. Q., Curr. Opin. Biotech. 2007, $18,17-25$.

4. Medintz, I. L.; Uyeda, H. T.; Goldman, E. R.; Mattoussi, H., Nat. Mater. 2005, 4, 435446.

5. Meiser, F.; Cortez, C.; Caruso, F., Angew. Chem. Int. Ed. 2004, 43, 5954-5957.

6. Debbage, P.; Jaschke, W., Histochem. Cell Biol. 2008, 130, 845-875.

7. Derfus, A. M.; Chan, W. C. W.; Bhatia, S. N., Nano Letters 2004, 4, 11-18.

8. Tomalia, D. A.; Naylor, A. M.; Goddard, W. A., Angew. Chem. Int. Ed. 1990, 29, 138175.

9. Kobayashi, H.; Koyama, Y.; Barrett, T.; Hama, Y.; Regino, C. A. S.; Shin, I. S.; Jang, B. S.; Le, N.; Paik, C. H.; Choyke, P. L.; Urano, Y., ACS Nano 2007, 1, 258-264.

10. Quintana, A.; Raczka, E.; Piehler, L.; Lee, I.; Myc, A.; Majoros, I.; Patri, A. K.; Thomas, T.; Mule, J.; Baker, J. R., Pharm. Res. 2002, 19, 1310-1316.

11. Tekade, R. K.; Kumar, P. V.; Jain, N. K., Chem. Rev. 2009, 109, 49-87.

12. Oregan, B.; Gratzel, M., Nature 1991, 353, 737-740.

13. Miao, W. J., Chem. Rev. 2008, 108, 2506-2553.

14. Ryan, E. M.; Okennedy, R.; Feeney, M. M.; Kelly, J. M.; Vos, J. G., Bioconj. Chem. 1992, 3, 285-290.

15. Paxian, M.; Keller, S. A.; Cross, B.; Huynh, T. T.; Clemens, M. G., Am. J. Physiol.Gastr. L. 2004, 286, G37-G44.

16. Lo, K. K. W.; Tsang, K. H. K.; Sze, K. S.; Chung, C. K.; Lee, T. K. M.; Zhang, K. Y.; Hui, W. K.; Li, C. K.; Lau, J. S. Y.; Ng, D. C. M.; Zhu, N., Coord. Chem. Rev. 2007, 251, 2292-2310.

17. Boca, S. C.; Four, M.; Bonne, A.; Sanden, B. v. d.; Astilean, S.; Baldeck, P. L.; Lemercier, G., Chem. Commun. 2009, 4590-4592.

18. Storrier, G. D.; Takada, K.; Abruna, H. D., Langmuir 1999, 15, 872-884.

19. Younes, A. H.; Ghaddar, T. H., Inorg. Chem. 2008, 47, 3408-3414.

20. Lee, D. N.; Kim, J. K.; Park, H. S.; Jun, Y. M.; Hwang, R. Y.; Lee, W.-Y.; Kim, B. H., Synthet. Met. 2005, 150, 93-100.

21. Lakowicz, J. R., Principles of Fluorescence Spectroscopy. Springer: Singapore, 2006.

22. Wängler, C.; Moldenhauer, G.; Saffrich, R.; Knapp, E. M.; Beijer, B.; Schnölzer, M.; Wängler, B.; Eisenhut, M.; Haberkorn, U.; Mier, W., Chem. Eur. J. 2008, 14, 8116-8130.

23. Fernandez-Moreira, V.; Thorp-Greenwood, F. L.; Coogan, M. P., Chem. Comm. 2010, 46, 186-202. 
24. Cohen, Y.; Avram, L.; Frish, L., Angew. Chem. Int. Ed. 2005, 44, 520-554.

25. Gomez, M. V.; Guerra, J.; Myers, V. S.; Crooks, R. M.; Velders, A. H., J. Am. Chem. Soc. 2009, 131, 14634-5.

26. Biner, M.; Burgi, H. B.; Ludi, A.; Rohr, C., J. Am. Chem. Soc. 1992, 114, 5197-5203.

27. Lavis, L. D.; Raines, R. T., ACS Chem. Biol. 2008, 3, 142-155.

28. Puckett, C. A.; Barton, J. K., Biochemistry 2008, 47, 11711-11716.

29. Gill, M. R.; Garcia-Lara, J.; Foster, S. J.; Smythe, C.; Battaglia, G.; Thomas, J. A., Nat. Chem. 2009, 1, 662-667.

30. Schmitt, F.; Govindaswamy, P.; Suss-Fink, G.; Ang, W. H.; Dyson, P. J.; JuilleratJeanneret, L.; Therrien, B., J. Med. Chem. 2008, 51, 1811-1816.

31. Demas, J. N.; Diemente, D.; Harris, E. W., J. Am. Chem. Soc. 1973, 95, 6864-6865.

32. Garcia-Fresnadillo, D.; Georgiadou, Y.; Orellana, G.; Braun, A. M.; Oliveros, E., Helv. Chim. Acta 1996, 79, 1222-1238.

33. Della Ciana, L.; Hamachi, I.; Meyer, T. J., J. Org. Chem. 1989, 54, 1731-1735.

34. Ramiro, P.; García-Fresnadillo, D.; Orellana, G., Tetrahedron 2005, 61, 9478-9483.

35. Villegas, J. M.; Stoyanov, S. R.; Huang, W.; Lockyear, L. L.; Reibenspies, J. H.; Rillema, D. P., Inorg. Chem. 2004, 43, 6383-6396.

36. Garcia-Fresnadillo, D.; Orellana, G., Helv. Chim. Acta 2001, 84, 2708-2730.

37. Montalti, M.; Credi, A.; Prodi, L.; Gandolfi, M. T., Handbook of Photochemistry. CRC Press: Boca Raton, 2006. 


\section{Summary}

The design of luminophores with high brightness is of crucial importance for many applications like the realization of Organic Light Emitting Diodes (OLEDs), and for biomedical imaging. However, despite the great number of works dedicated to the definition of the possible strategies for the realization of bright compounds, we are still far from a "perfect" luminophore for biological applications. The design of highly bright luminophores for biological imaging still constitutes a major challenge: the necessity of conjugating a high brightness (the product of the quantum yield and the molar extinction coefficient) with a low degree of oxygen quenching (which is necessary in order to keep a high luminescence in the oxygen-rich bio-environment) is still an open problem. Semiconductor Quantum Dots (QDs) are so far, the best candidates for biological applications since they show quantum yields closed to the unity and low oxygen sensitivity. However, despite the brilliant performances shown by QDs, their in vivo toxicity is still a major concern, especially from the perspective of a human application.

Transition metal complexes are ideal candidates for the realization of bright luminophores, considering their high stability in biological environment and the possibility of tuning their optical properties by conveniently changing the structure of the ligands. Ruthenium(II) and iridium(III) complexes, in particular, are among the most studied transition metal complexes and the large amount of literature available makes them ideal candidates for further improvement. Two possible strategies can be followed in order to improve the optical properties of a luminophore: the decrease of its oxygen quenching degree and the amplification of its brightness. The first strategy is quite promising especially in order to improve the optical properties of $\operatorname{Ir}(\mathrm{III})$-complexes, which show a pronounced oxygen sensitivity. Conversely, the brightness amplification via multiple labelling is particularly attractive for $\mathrm{Ru}(\mathrm{II})$-complexes, which are barely sensitive to oxygen quenching but show also a low emission quantum yield. In this thesis both strategies have been applied in order to realise highly bright luminescent compounds based on $\mathrm{Ru}(\mathrm{II})$ or $\mathrm{Ir}(\mathrm{III})$ complexes. Moreover, since there is only a limited amount of literature concerning the tunability of the oxygen quenching of Ir(III)-complexes, a systematic study has been conducted in order to clarify the structure-quenching relationship. 
A cage-type ligand can prevent the luminescence quenching by solvent molecules, as shown for lanthanide(III) complexes, or prevent photo-decomposition as shown for a ruthenium(II) complex. In Chapter 3 the synthesis and the design strategy of the first Ir(III)-complex with a caged structure (1) is reported. The geometrical structure of the complex in solution is elucidated using mono- and bi-dimensional NMR experiments. The caged complex shows an $80 \%$ lower quenching with respect to the archetypical $f a c-\operatorname{Ir}(\mathrm{ppy})_{3}$ (ppy $=2$-phenylpyridine). This result shows that the cage-based approach constitutes an efficient strategy for decreasing the oxygen quenching degree of iridium complexes. However, in order to understand the origin of such an impressive quenching decrease, more extensive experiments are required.

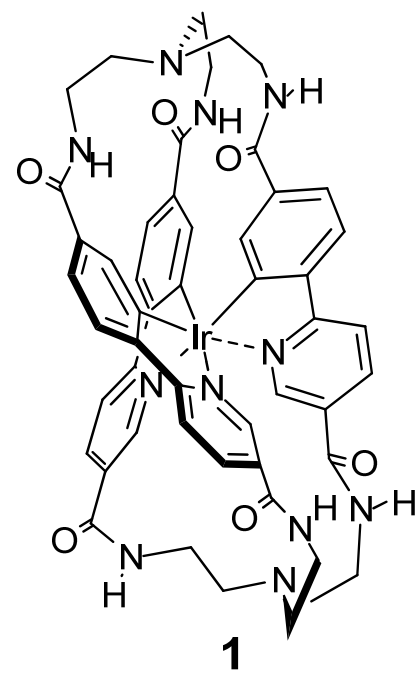

In Chapter 4 and Chapter 5 the results of a systematic investigation concerning the structurerelated effect on oxygen quenching are reported. The syntheses of a series of $\operatorname{Ir}(\mathrm{III})-$ tris(phenylpyridine) derivatives connected through amide groups with either a capping unit $(2,4)$ or an uncapped moiety $(3,5)$ localised on the pyridine or on the phenyl ring are described. The structural characterisation of the four compounds by means of mono- and bidimensional NMR spectroscopy is discussed and compared with the structural properties of the complexes described in Chapter 3. A detailed analysis of the oxygen quenching degree of the two pairs of complexes is reported. The quenching study show that the hemicaged complex 2 shows a 40\% decrease of the oxygen quenching with respect to the non-caged complex 3 , whilst only a minor difference $(6 \%)$ of oxygen quenching was observed between 4 and 5. These results show that in order to achieve a decrease of the quenching it is necessary to introduce the capping unit on the pyridine ring, where the LUMO orbital is mostly localised. The minor changes in terms of thermodynamic feasibility of the quenching between the members of each pair of complexes $(2,3$ and 4,5$)$ constitute a further proof of the structural origin of the oxygen quenching decrease. 


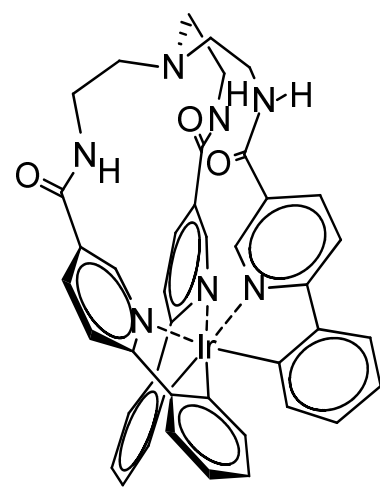

2

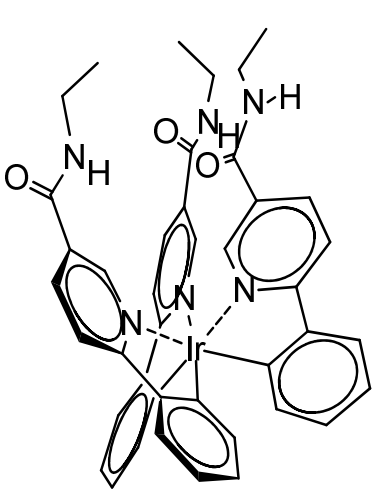

3

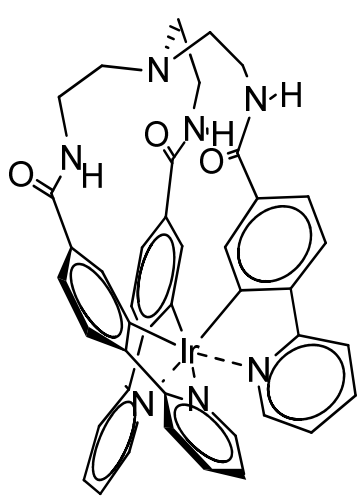

4

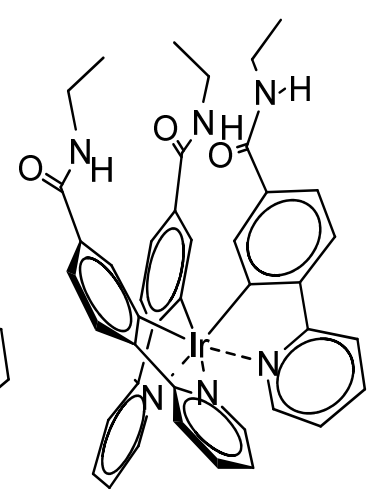

5

In order to extend the study of the structural-related oxygen quenching to systems with electron donating groups, a hemicaged Ir(III)-complex functionalised with a 1,3,5tris(oxymethyl)benzene capping unit (6) is reported in Chapter 6. The optical properties of this complex has been studied and compared with the parent open complex bearing methoxy groups on both the phenyl and the pyridine ring (7). In spite of the more hindering capping unit (with respect to the tris(2-ethylamide) studied in the complexes of Chapters 3, 4 and 5), the hemicaged complex 6 shows only a 10\% decrease of oxygen quenching when compared to the open complex. The reason of such a modest decrease is not completely clear. However, by using the structural data obtained from the mono- and bi-dimensional NMR experiments and the structural and electron density data obtained from DFT calculations, it is possible to hypothesize that the presence of an electron- donating group induces a major change in the localization of the LUMO orbital, compared to the localization of the LUMO in the archetypical $\operatorname{Ir}(\mathrm{ppy})_{3}$. This change is reflected in a higher atomic contribution to the LUMO orbital given by the carbon atoms which are in ortho- to the electron-donating group on the pyridine ring. These atoms are only partially shielded by the capping unit, thus resulting in a poor efficiency of shielding against oxygen quenching.

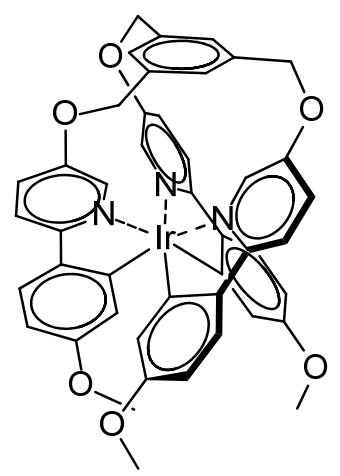

6

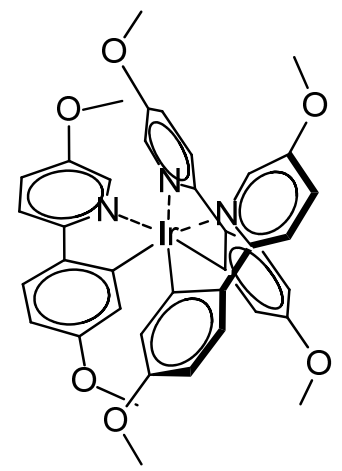

7 
In Chapter 7 an $\operatorname{Ir}(\mathrm{III})$-hemicaged complex functionalised with a 1,3,5-tris(ethyl)benzene capping unit on the phenyl ring (8) is described and compared with the archetypical $\operatorname{Ir}(\mathrm{ppy})_{3}$. The absence of any difference in terms of oxygen quenching between 8 and $\operatorname{Ir}(\mathrm{ppy})_{3}$ constitutes a further proof of the necessity of shielding the atoms which give a higher contribution to the LUMO orbital, in order to achieve a decrease of oxygen quenching.

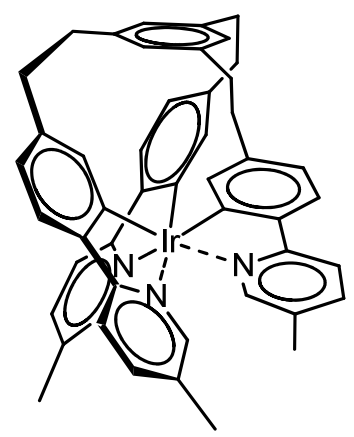

8

In Chapter 8 two dendrimers functionalised with positively (9) or negatively (10) charged $\mathrm{Ru}(\mathrm{II})$-polypyridine complexes are described. The use of transition metal luminophores allows to linearly increase the brightness upon molar absorption coefficient increase. The uptake of $\mathbf{9}$ and $\mathbf{1 0}$ in tumour cell lines has been studied and shows excellent diagnostic imaging properties and remarkable different phototoxicity for the two dendrimers. More in detail, the positively charged dendrimer (9) shows a strong phototoxicity, which is likely due to the efficient production of singlet oxygen $\left({ }^{1} \mathrm{O}_{2}\right)$ upon photosensitizazion. On the other hand, despite the production of ${ }^{1} \mathrm{O}_{2}$ has been also observed in the case of the negatively charged dendrimer (10), this compound does not show any appreciable phototoxicity. On the basis of the NMR experiments and of the photophysical properties, it has been hypothesized that this difference is due to the fact that in the dendritic dye 10, the negatively charged $\mathrm{Ru}(\mathrm{II})$-complexes are folded towards the inner core of the dendrimer, thus resulting in a non efficient interaction of the generated singlet oxygen with the cells.

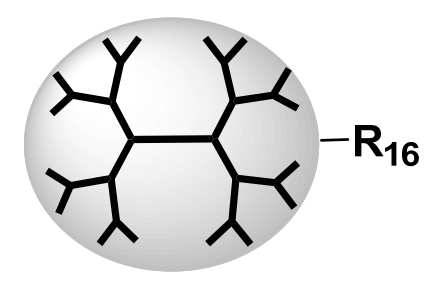

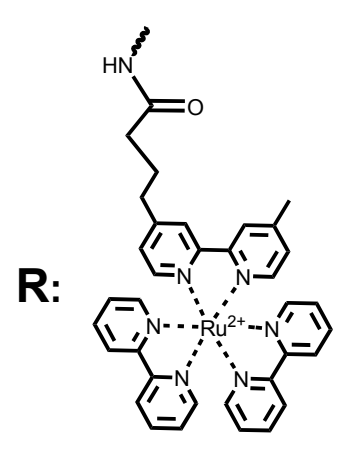

9

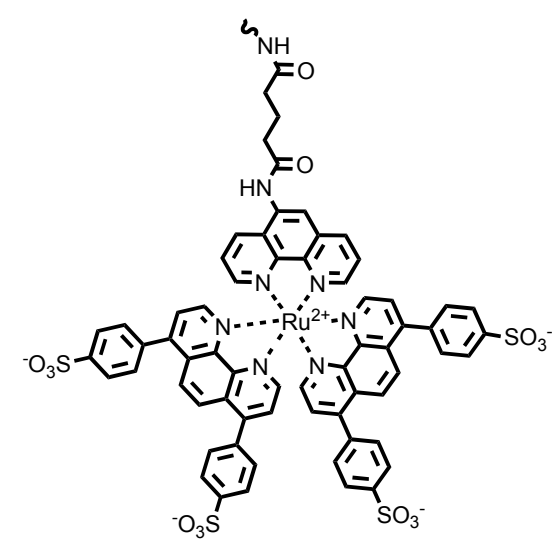

10 


\section{Samenvatting}

Het ontwerp van luminoforen met een hoge helderheid ('brightness') is van groot belang voor vele toepassingen, zoals Organische Licht-Emitterende Diodes (OLEDs), en voor biomedische diagnostiek. Echter, ondanks de grote hoeveelheid onderzoek aan mogelijke strategieën voor heldere verbindingen, zijn we nog ver af van de 'perfecte' luminofoor voor bio/medische toepassingen. Het bedenken van uiterst heldere luminoforen voor dit soort toepassingen is vooralsnog geen sinecure en behelst serieuze uitdagingen: het combineren van helderheid (gedefinieerd als het product van de kwantumopbrengst en de molaire extinctie coëfficiënt) met een laag uitdoven van de luminescentie door zuurstof (noodzakelijk om hoge luminescentie te houden in zuurstof ruik bio-milieu) is nog steeds een probleem. Halfgeleider kwantumdots (Quantum Dots, QDs) zijn op het moment de beste kandidaten voor bio-toepassingen aangezien ze kwantumopbrengsten van nagenoeg $100 \%$ hebben en vrijwel ongevoelig voor zuurstof zijn. Echter, ondanks de briljante prestaties van kwantumdots, is hun in vivo toxiciteit een serieus probleem, met name voor toekomstige humane toepassingen.

Overgangsmetaalverbindingen zijn ideale kandidaten om heldere luminoforen te realiseren, gezien hun hoge stabiliteit in biologisch milieu en de mogelijkheid om de optische eigenschappen subtiel af te stellen door de ligandstructuur te veranderen. Ruthenium(II) en iridium(III) verbindingen zijn twee van de meest bestudeerde luminescente overgangsmetaalverbindingen en de grote hoeveelheid beschikbare literatuur daarover maakt ze ideale kandidaten om verder te optimaliseren. Er zijn grofweg twee manieren om de optische eigenschappen van een luminofoor te verbeteren: het verlagen van zijn gevoeligheid voor zuurstof, en het verbeteren van de helderheid door de extinctie coëfficiënt te verhogen. De eerste strategie is in het bijzonder veelbelovend om de optische eigenschappen van iridium(III)verbindingen te verbeteren, die namelijk zeer gevoelig voor zuurstof zijn. Daarentegen is het verhogen van de helderheid van luminoforen door meerdere verbindingen in een molecuul te plaatsen juist voor ruthenium(II) verbindingen interessant, omdat ze nauwelijks gevoelig zijn voor zuurstof maar ook relatief lage kwantumopbrengsten hebben. In dit proefschrift zijn beide strategieën gevolgd om zeer heldere luminoforen van iridium(III) en ruthenium(II) verbindingen te maken. Bovendien blijkt er slechts een beperkte hoeveelheid literatuur te bestaan over de zuurstof gevoeligheid van luminescente iridium(III) 
verbindingen, en daarom is een systematische studie uitgevoerd om de structuur-uitdoof eigenschappen van deze luminoforen te bepalen.

Zogenaamde 'kooi-liganden' kunnen het uitdoven van luminescentie voorkomen als dat door oplosmiddelen komt, zoals is bewezen voor lanthanide(III) verbindingen, of kunnen de fotodecompositie voorkomen, zoals voor een ruthenium(II) verbinding is bewezen. In Hoofdstuk 3 zijn het ontwerp en synthese van de eerste iridium(III) verbinding met een kooi-ligand beschreven (1). De geometrische structuur van de verbinding in oplossing is bepaald met behulp van één- en tweedimensionale kernspinresonantie (NMR) experimenten. De 'kooiverbinding' heeft een $80 \%$ lagere uitdoving van de luminescentie door zuurstof dan de archetypische verbinding $f a c-\operatorname{Ir}(\mathrm{ppy})_{3}$ (ppy $=2$-phenylpyridine). Dit bewijst dat de kooistrategie een efficiënte methode blijkt om de gevoeligheid van iridium(III) verbindingen voor zuurstof te verminderen. Echter, om de oorsprong van deze verminderde gevoeligheid voor zuurstof te doorgronden zijn meer experimenten vereist.

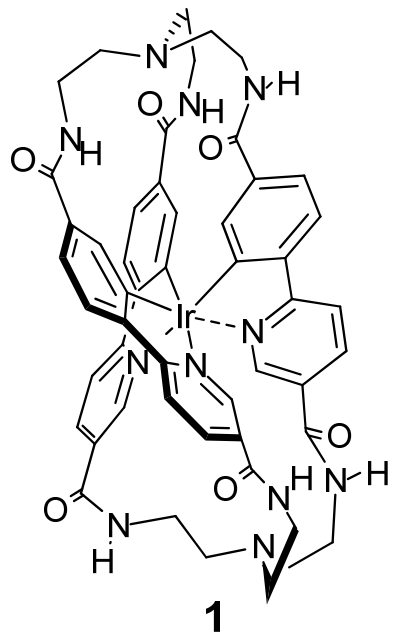

In Hoofdstuk 4 en Hoofdstuk 5 zijn de resultaten beschreven van een systematische studie naar de structuur-gerelateerde eigenschappen die het uitdoven van luminescentie beïnvloeden. De syntheses zijn beschreven van een serie $\operatorname{Ir}(\mathrm{III})$-tris(phenylpyridine) verbindingen met amide groepen die of een sluitstuk-groep hebben $(\mathbf{2}, \mathbf{4})$ of juist niet $(\mathbf{3}, \mathbf{5})$, welke op de pyridine of op de phenyl ring zitten. De structuren van de verbindingen zijn bepaald met behulp van één- en tweedimensionale kernspinresonantie (NMR) experimenten en zijn bediscussieerd in de context van de verbindingen uit Hoofdstuk 3. Een gedetailleerde analyse van de mate van uitdoving van de luminescentie door zuurstof is beschreven voor beide paren verbindingen. Deze uitdovings-studie laat zien dat de 'half-kooi-verbinding' 2 een $40 \%$ lagere gevoeligheid voor zuurstof heeft dan de gerelateerde 'niet-kooi-verbinding' 3, terwijl er maar een zeer beperkt verschil (6\%) is gevonden voor de verbindingen 4 en $\mathbf{5}$. Deze resultaten tonen aan dat, voor het verkrijgen van een lagere gevoeligheid van het uitdoven 
van de luminescentie, het noodzakelijk is om een sluitstuk in de ligand structuur te hebben, en wel aan de kant van de pyridines, daar waar de LUMO ('Lowest Unoccupied Molecular Orbital") is gelokaliseerd. Het minieme verschil voor beide sets verbindingen $(\mathbf{2}, \mathbf{3}$ en $\mathbf{4}, \mathbf{5})$ in thermodynamische parameters die de zuurstofgevoeligheid bepalen, is een extra bewijs dat de oorsprong voor de verminderde zuurstofgevoeligheid gerelateerd is aan de structuur.

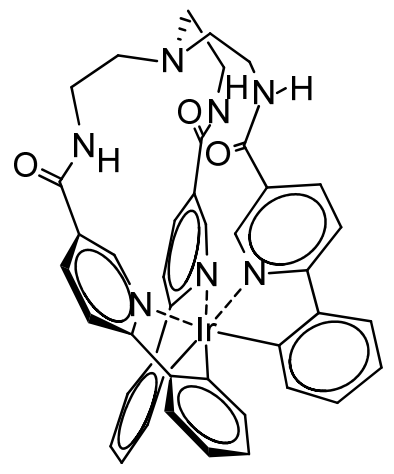

2

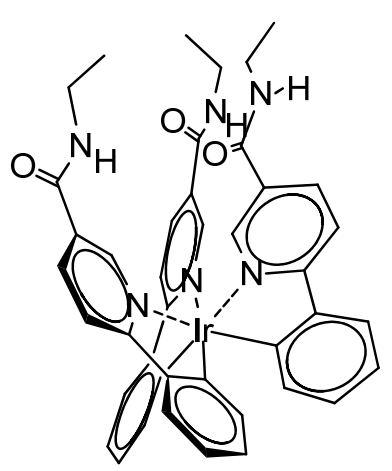

3

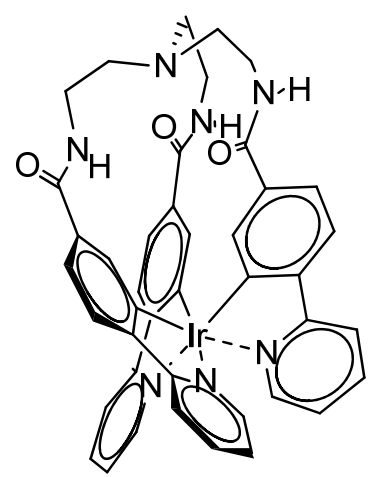

4

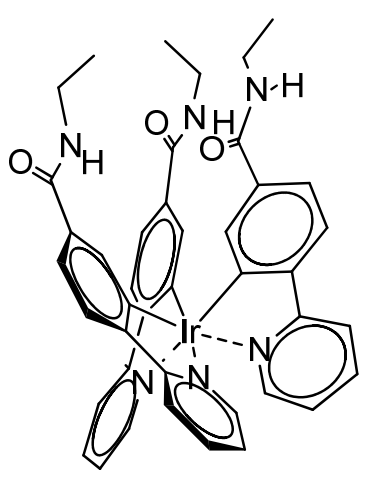

5

Om het onderzoek aan structuur-gerelateerde doven van luminescentie door zuurstof verder uit te breiden met elektrondonerende functionele groepen, is een 'half-kooi' Ir(III) verbinding met een 1,3,5-tris(oxymethyl)benzeen sluitstuk ligand (6) beschreven in Hoofdstuk 6. De optische eigenschappen van deze verbinding zijn beschreven en vergeleken met de gerelateerde open verbinding die methoxy groepen heeft op zowel de phenyl als the pyridine ring (7). Ondanks de grotere afsluitende functionele groep (in vergelijk met de tris(ethylamide) bestudeerd in Hoofdstukken 3, 4, en 5), laat de luminescente 'half-kooi' verbinding 6 slechts een 10\% lagere gevoeligheid voor zuurstof zien ten opzichte van de open verbinding. De reden voor deze slechts beperkte afname is niet helemaal duidelijk. Gebruik makend van structurele informatie verkregen van één- en tweedimensionale NMR experimenten, en de structurele en elektronendichtheid data verkregen uit 'DFT' berekeningen, is het mogelijk te stellen dat elektrondonerende groepen een groter effect te weeg brengen in de verspreiding van het LUMO orbitaal, in vergelijk met het LUMO orbitaal in de archetypische verbinding $\operatorname{Ir}(\mathrm{ppy})_{3}$. Dit verschil is met name evident in de hogere atomaire bijdrage aan het LUMO orbitaal door de koolstofatomen die in ortho zijn geplaatst ten opzichte van de elektrondonerende groep. Deze atomen worden slechts gedeeltelijk afgeschermd door het afsluitstuk ligand, met als gevolg dat er een relatief lage afscherming is tegen het uitdoven van luminescentie door zuurstof. 


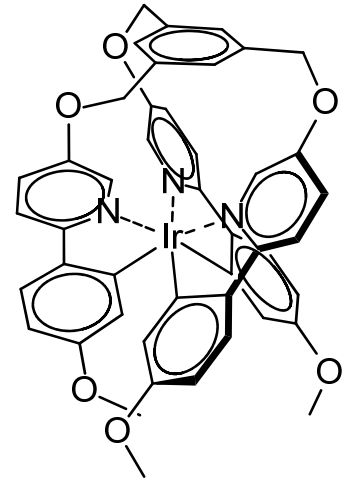

6

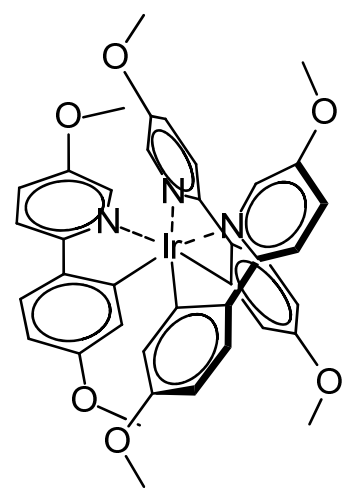

7

In Hoofdstuk 7 wordt een 'half-kooi' Ir(III) verbinding met een 1,3,5-tris(ethyl)benzeen sluitstuk ligand op de phenyl ringen (8) beschreven en vergeleken met de archetypische verbinding $\operatorname{Ir}(\text { ppy })_{3}$. De afwezigheid in dit geval van een enkel verschil in gevoeligheid voor zuurstof voor 8 en $\operatorname{Ir}(\mathrm{ppy})_{3}$ is een aanvullend bewijs voor de noodzaak om specifieke atomen af te schermen die een hogere bijdrage leveren aan het LUMO orbitaal, indien een lagere gevoeligheid voor zuurstof wordt nagestreefd.

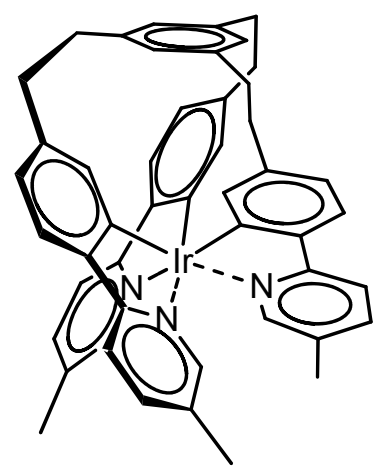

8

In Hoofdstuk 8 worden twee dendrimeren, gefunctionaliseerd met positief (9) of negatief (10) geladen ruthenium(II) polypyridine verbindingen beschreven. Het gebruik van overgangsmetaalverbindingen leidt tot een lineaire toename van de helderheid met de toename van de molaire extinctie coëfficiënt. De opname van 9 en $\mathbf{1 0}$ in tumorcellijnen is bestudeerd en laat uitstekende eigenschappen zien, wat betreft diagnostische beeldvorming, en een opmerkelijk verschil in fototoxiciteit voor de twee verbindingen. De positief-geladen dendrimeer 9 laat een hoge fototoxiciteit zien, welke waarschijnlijk komt van de efficiënte vorming van singlet zuurstof $\left({ }^{1} \mathrm{O}_{2}\right)$. Ondanks dat de negatief-geladen dendrimeer 10 ook ${ }^{1} \mathrm{O}_{2}$ genereert, laat die geen significante fototoxiciteit zien. Op basis van NMR experimenten en de fotofysische eigenschappen lijkt het dat de negatief geladen ruthenium(II) verbindingen in 
$\mathbf{1 0}$ teruggevouwen kunnen zijn in de dendrimeer, wat een minder efficiënte vorming van ${ }^{1} \mathrm{O}_{2}$ kan geven en de verminderde fototoxiciteit verklaart.

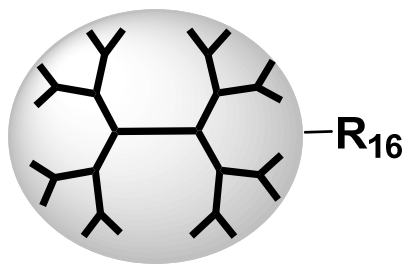

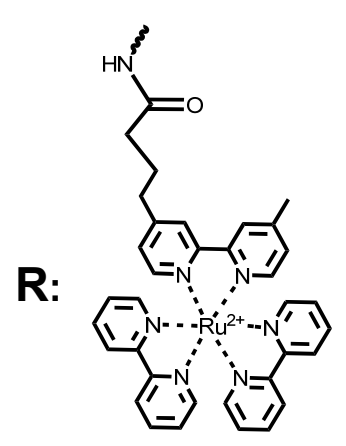

9

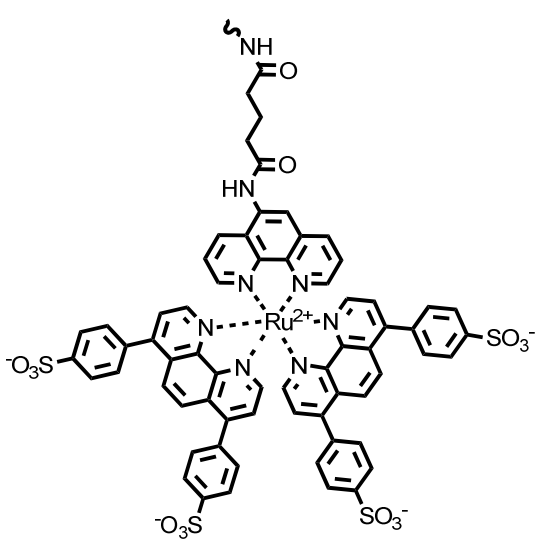

10 


\section{Acknowledgements}

Well, eventually it is also time to write the acknowledgement section. In these four years (and a half) I've been thinking a lot about the content of this section, the people to include and what to write. But now I'm really writing it all my fantastic structures and ideas are gone. I know that this section will probably be the most read of the whole thesis, therefore writing something interesting is a hard responsibility!

While I was sitting on the balcony of my new apartment in Lausanne, thinking about which kind of structure I had to follow in this section, suddenly I had an enlightenment: follow the masters! Ok, is not such a great revelation, I agree, but it is better than nothing, indeed. One of my favourite activities after lunch in Twente was looking for weird literature. One day I found a paper with this great beginning:

"Born in the now occupied part of Cyprus, I was not exactly poised for an academic career in chemistry, certainly not one that would bring my pen to these pages. Rather, the privilege of writing this essay is due overwhelmingly to my good fortune of encountering so many resplendent people.

These individuals opened paths and helped me travel a personal odyssey which led me westwards where I found a new home in California, not so different in landscape and beauty from the one I lost in Cyprus."

(Tetrahedron, 59 (2003), 6683-6738)

Do not worry! I am not going to write here the history of my life (like the author did -for almost five pages- in the cited paper). But I see a few connection points with him: 1) my family comes from a small island close to Naples; 2) when I started "playing" with chemistry (I was eight) I would never had expected that one day somebody could pay me to 
play this funny "game"; 3) I left my country as well and, above all, 4) my Ph.D. has really been a "personal odyssey"!!!

Obviously there are also many differences between me and the author: the most important is that I'm not K. C. Nicolaou! But I still have some time to improve :)

After this introduction, it is time to acknowledge the people who did something for me during my Ph.D. period. Traditionally, one has to thank first the promotor, then the daily supervisor, then the paraninfen...I do not like too organized schemes (it was clear from my fume hood!) but I will try to follow such a path.

First of all I have to thank my promotor, Prof. David Reinhoudt. David, thank you for your support. I was quite unlucky to start my Ph.D. just a few months before your retirement. However, you have been always available whenever I asked for a meeting with you. Thank you also for having accepted to correct the thesis by email. Hopefully I have been a good $\mathrm{Ph} . \mathrm{D}$. student for you, albeit I did not reach the great number of publications of most of your students, but I did my best.

Dr. Aldrik Velders, my daily supervisor. Aldrik, we had a quite complex relationship, I would say of "fight and love" (I hope Raissa is not jealous!). Many times we had heavy discussions since our working style is quite different: you have learnt soon that I do not like your "systematic" approach and that I prefer to follow more creative ways. However, we always had a reciprocal respect and I have found in you a very human person, which is not so common. I have to thank you for your moral and practical support during the illness of my mother-in-law and for having accepted to correct my thesis through internet (emails and Skype...we just missed carrier pigeons) while I was in Italy after her death. You gave me something very important: the research freedom (and the protection against the lab checks!). Probably sometimes you had the feeling that I did not follow your suggestions because I felt "superior", but I've never felt like that. In the last period of the Ph.D. we both became (a bit) more flexible and the result has been a nice piece of work. We did not save the world, it is true, but we got something interesting. I will remember forever our beer and cigar sessions, when in the faculty club it was still allowed to smoke. Mi rendo conto che farmi da supervisor non deve essere stato facile nemmeno per te: so bene che il mio carattere a volte non è facile da prendere, ma ora, alla fine di tutto, posso dire che è stato un piacere lavorare con te e che se in questo nuovo posto mi trovo bene lo devo anche a te e alle nostre litigate.

* Indeed, in Italy they still don't do it! 
Sei stato come un fratello maggiore per me e mi ricorderò sempre la cena da Cioppino's a San Francisco dopo il mio talk. Grazie mille e dai un bacio a Emilie e Fabian da parte mia!

Before passing to the paraninfen and friends I have to thank some other academic people: my Master supervisor, Prof. L. Mandolini, and his group from the University of Rome "La Sapienza, and Prof. Luisa De Cola. Since they are in my defence committee, I hope it will not sound like an act of flattery.

Prof. Mandolini, Roberta e Stefano, vi devo ringraziare per avermi insegnato tante cose durante l'internato per la laurea e per essermi stati continuamente vicini anche durante il dottorato. Roberta in particolare è sempre stata gentilissima ad accogliere i miei sfoghi quando le cose andavano male e ad incitarmi a non disperare. Devo a voi se fin dall'inizio del dottorato sono stato indipendente.

Prof. De Cola, grazie per essere stata (a volte inconsciamente) la mia ispiratrice. Dalle sue pubblicazioni ho imparato quasi tutto quello che so sull'iridio e il rutenio, sia per la parte pratica che per quella teorica (e spero che quello che ho imparato basti per la difesa!). La ringrazio per avermi accolto nei suoi laboratori per fare delle misure sui miei complessi: in quei pochi giorni ho imparato tantissimo! Se avessi avuto l'opportunità di collaborare di più con lei il mio lavoro ne avrebbe sicuramente giovato. La ringrazio anche per avermi dedicato un po' del suo tempo per darmi dei consigli personali sulla mia carriera e per essersi gentilmente offerta di fare da referente per il mio post-doc.

I have to thank also all the technicians of the lab: Richard (I will miss your sermons about "how life goes in this country" and the discussions during lunch. From you I've learnt a lot about Netherlands! Thank you also for the practical help and for the "always do a backup of your data" suggestion...it saved my thesis in the last week!), Tieme (I own you a special THANK YOU for your patience with the MS. Sometimes the instrument was out of order immediately after my use, but IT WAS NOT MY FAULT, I swear!) Marcel ("have my chemicals arrived? Not yet? But I've placed the order 3 weeks ago!!!) and Bianca ("can I do a quick NMR with the 600? Just 5 minutes..." -3 hours later- "10 minutes more, please!"). Thank you for your patience and for having stood my "italian passion" with your "dutch tolerance". I want to thank also the secretaries (Izabel, Nicole and all the others who sat in the office) for the support with paperworks. 
Ok, now the academic section is over and it is time to thank the "crew", the "cannon fodder": the people from the labs!

First of all I have to thank my paraninfen: Jealemy and Carlo.

Jealemy, my Venezuelan-dutch sister...the description of what you have done for me could fill the entire thesis. I'm very sorry for having bothered you sooo much with my dutchrelated questions (could you translate this? Could you call those guys? Could you come here to translate what this woman is saying?). After this experience I decided to move to a place where I could understand and speak the local language, so you were the last victim of my linguistic ignorance. Are you happy?! (-) Always speaking about language, I have to thank you for having improved my English. OK, I am not Shakespeare now, but when I came to Twente my English was really terrible. You know, I studied English at the "University of Life" and you helped me a lot with our conversations and MSN-chats. Thank you also for the great corrections of the concept thesis. I really wish you all the best, since you definitely deserve it. We were companions in misfortune in the Ph.D. odyssey and also in the SMCT sinking. I will miss somebody like you. ¡Hasta siempre, comandante!

Carlo, it is a pity that you came so late! You have been a very good friend. I will remember our trips to Cologne looking for schweinshaxe and beer, especially the last one, when my car suddenly turned into a Ferrari due to the broken silencer. I have to thank you for the calculations with Spartan: we started together a computational adventure. Thank you also for the chemical discussions and for the practical recipes like "how to remove pyridine from the crude and still being able to have babies" and for the EDC coupling procedure. And how can I forget your invaluable help during the "carpet removal" section? Thank you, thank you, thank you!

Ummm...ok, now it is time to start the lab tour. I hope I will not skip anybody. Just in case, keep in mind that all of you will be forever in my heart, ok?

Of course I must start with my students: Joanna, Mik, Arno and Miguelito-san. It has been really a pleasure to work with all of you. I hope that I've managed to teach you something else than how to make a mess on your bench! Miguel, you deserve a special acknowledgement. You are a great chemist, go on like that! Your help was invaluable for Chapter 3 and 6. I have to thank also students from the AMS lab, especially those two (I 
don't remember your name, I'm sorry) who wasted a $1000 €$ flask of dendrimer in a reaction (why should you read the reaction protocol when there are so many interesting things on Facebook?). Ok, now let's go with the old and new people in the lab!

Martine, merci pour tes conseilles à propos du post doc en France. Je suis allé à Lausanne...c'est la même chose plus ou moins! Chien-Chin, you have always been so kind whenever I've asked about monolayers...thank's God I've never worked with those (nanob!£\#@). Shu Han, I have so many things to say about you...I will remember forever your noisy voice (aaaaaaaa...like a fire alarm!) and our fantastic travel to Zermatt, including the $12 \mathrm{~h}$ driving odyssey in the snow. Mirko, che te devo di, hai avuto ragione, pare che ce l'ho fatta pure io a finire! Grazie per il tuo buon senso e per essere venuto dalla Spagna per la promotion. Henkino (quest'amoreeee)...soo many discussions about the "dutch way" including crucial parking tips ("stop complaining for once in your life...and also the synthetic skills of the guy"...I still haven't got the connection between the two things). Moira, ma er cibbo 'ndo sta?! Mi hai chiesto talmente tante volte la data della promotion che alla fine l'ho dovuta fare! Elisabetta, alias Lenin ("Bakunin ventiquattrore"...grazie per avermi fatto scoprire Enzo del Re!). Reina Victoria de Ciudad Real, thank you for your nice messages on Facebook! Laura (aka "el generalissimo"), you were 200\% right about the situation here...how could I be so blind? Are you a prophet? Nachete (aka "il friggitore"), I will remember forever the stench of fried stuffs in our kitchen (I'm joking but not so much!) and your smart suggestions! Xin-Li, it was funny to meet you in San Francisco, even if after having spent one year in Berkeley you still didn't know any decent place to eat in the downtown...you should really work a lot, there! Oya, the craziest girl I've ever met, bonne chance à Paris! Alessio P., mo er piecceddi ce l'ho pure io, tié $(;)$ Srinidhi, thank you for all the tips about Ir and Ru and for the copy of the thesis of Enrico. Riccardone, che peccato che non sei potuto venire, tanti auguri per l'Ammerica! Emanuele...facile fa l'erasmus col compaesano tuo eh? In bocca al lupo caro! Francesca C. Beh a te non posso dire proprio niente...ci vediamo al matrimonio!!! Grazie per essere venuta! Riccardo, compagno d'arrampicate (te la ricordi Ibbenbüren?) speriamo di poter tornare presto ad arrampicare in Italia, intanto tieni le mani a posto con le gallinelle del lab. di Roma, sennò Francesca te mena! Maryana, you have been always so kind! Thank you for coming. Arancha...what can I say, you are a kind of chameleon and politics is definitely the right place for you. In a couple of years probably you will be the next Zapatero... Dae Jun (DJ), "how many papers have you published?" this is exactly the best question to ask during a 10-minutes coffee break! I really hope that now your life is much better now than in Enschede! 
Now let's come to more recent people, those who are still sitting in the lab: Nicolai, do you remember what I told you on the boat to Edinburgh? I'm sure that now you agree with me! Don't give up, it's almost done...you just need a bit of BLABLEDO and some TOOMO AND TOOMO... and btw, STOP THINKING, DO SOME CHEMISTRY! Mudassir, you are a real gentlemen and I would like to get the secret of your smile and of your patience. POOGH up your life! Vijay, you are really imperturbable: your house burns, SMCT collapses and you still smile... what's your secret man? Oh, Kim, the playboy of the lab, you were a kind of continuous English test for me. Good luck with your ph.d. and don't worry... in case just speak aussie and they will not understand anything (:) Denis, tovarish, you were so funny... a bird told me that for some reasons now you will come quite often to Switzerland, so why don't you come to visit me once? Janet, thank you for all your tips about thesis, Switzerland, Turkey and all. Peter, thank you also for all your tips about living in Lausanne. At the beginning I was a bit too rude with you, I'm sorry, you are a good guy! Raluchina, could you tell me what are you doing in a low temperatures lab?! Freezing the chicken livers from Vijay? It was nice to play squash with you... as long as the police didn't stop me! Jordi, hai trovato un'altra strada per vivere in Olanda e hai fatto bene! Tanti auguri per il futuro! Francesco, grazie per le cenette e per gli scambi di consigli culinari...non ho scordato la lista di "dove trovare cosa", tranquillo! Roberto Ricciardi (per non far confusion con l'altro), beh noi ci siamo visti di corsa. Tanti auguri per il ph.d., spero che non ce ne sarà bisogno! Franscesca S., grazie per venire da Padova...come ti trovi fra i polentoni? Sven, you are so funny when you mock Italian accent (I'm joking). I will remember forever your interview about Barcelona and thieves. Thank's God you didn't go to Italy (;) Alberto and Melanie, you're both sooo silent...smile a bit more, life is not that bad...abroad! Carmen, meine liebe Deutch (I hope it's correct!), thank you so much for the pretzeln, I've found a good shop also here in the center of Lausanne, so I shouldn't go to Gronau anymore. You're another great chemist...just throw away that stupid peptide synthesizer! Anna, all my best wishes for your job and life! Don't be down, ok? Deniz, another great (and silent) chemist...good luck for your future! Roberto, how many papers have you published in the last week? 20? You are creating a new field: from click chemistry to photo(shop)chemistry! Ops, I'm sorry...nanonanophoto... (;) Alessandro C., grazie anche a te per i consigli sul trovar casa a Losanna, speriamo di incontrarci una buona volta! Severine, merci pour tes livres et pour notre conversation en français. Tu m'as aidé beaucoup! Dodo, it's a pity that you are not here, we had a good collaboration and I have to thank you for all the answers to my "stupid questions" about photochemistry and all. Last but not least, I want to...well, 
"thank" it's not the best word, let's say "remember" the "unknown phone caller"...you know who you are. Well, I wish you exactly what you did for me. And btw...I'm still alive! Ok, now a more serious section: prrrrrrrofessors (and so on): Jurrian, Jeroen and Pascal, thank you for your questions during the colloquia (indeed, fluorescein is a good standard for QY (:) ). Wim, when I had the interview with you it has been a kind of nightmare...btw, I can survive without eating pasta, although I'm from the Zouth! Mercedes, did we do great chemistry together? "Great chemistry", perhaps, "together", probably not, but I did my best to survive here. Thank you for having hired me (and left to Aldrik). Rolf...how easy is to write a research project? Perhaps it depends on who has to do the practical work! Fijs, the week that I've spent with you in Amsterdam was an appalling experience, but there was a positive point: at the end of the week I was able to understand Dutch, since that was the official language during lunch $: ;$

Matteo Mauro e Federico Polo from De Cola's group in Munster, grazie mille per il grande lavoro fatto, specialmente Matteo, a cui ho rotto le scatole fino alla fine cone le mie domande di fotochimica, di computazionale...un po' di tutto insomma!

I want to thank the fish sellers in Enschede ("Met Albert, UT, maag ik bestellen?") for their great jokes in Dutch (which of course I could not understand!), the Italian supermarket and the tobacconist in Kohln (when I found them, I felt like at home!) and the half italian mechanic in Enschede who fixed my car when the guys from Kwik Fit gave up.

In these four years I've been travelling around a lot, but I have to thank the Netherlands because it has been a very generous country. Ok, the weather is not the best and is too flat, but I've got a lot of possibilities here and I've met great people. I know that I'm not going to be very popular for this, but I have to thank also Germany: in these years it was like a second house for me. I really love it!

I want to thank my new boss Prof. Severin and its group at EPFL (Mirela, Julie, Bo, Matt, Justus, Burçak, Vera, Gregor, Clement, Erin, Alex, Euro, Benan, Christina and the head of the magasin Giovanni). I really feel at home there and everybody is very friendly. In the last weeks the Prof. has been very patient whilst I was working a lot at the thesis during working time (since my laptop collapsed 2 weeks ago).

And now the last and most important part of the acknowledgement. 
I have to thank my family for the support that they have been giving to me during all the $\mathrm{Ph} . \mathrm{D}$. period. They suffered with me and shared the moments of happiness. Grazie infinite per tutto quello che avete fatto per me, per i consigli e per avermi sempre spinto a non mollare ed andare avanti. Quando ho deciso di andar via non è stato facile, ma ora che vi siete sbarazzati di me non mi volete più a casa coi miei 10mila libri eh? Anche questa è fatta!

A big thank to my beloved girlfriend Chiara. Fra alti e bassi abbiamo superato anche questo periodo che è stato così doloroso e difficile per entrambi. Non è facile vivere con uno come me, così ossessionato da questa roba, ma vedrai che riusciremo finalmente a stare insieme ed a fare una nostra famiglia. Grazie per sopportarmi sempre. Ti amo tanto!

Eventually I want to remember my mother-in-law who passed away the last October. I want to dedicate the work described in this thesis to her memory.

Thank you all from the depths of my heart!

Lausanne, $16^{\text {th }}$ May 2011

a. 


\section{About the author}

Albert Ruggi was born in Naples (Italy) on February $20^{\text {th }} 1980$. He studied chemistry at the University of Roma "La Sapienza", where he received his degree (cum laude) in Organic Chemistry on May 2006. During his undergraduate training period he worked under the supervision of Prof. L. Mandolini and Dr. R. Cacciapaglia on Dynamic Covalent Chemistry of acetal-based cyclophanes. From July 2006, he was Ph.D. candidate in the group of Prof. Reinhoudt at Twente University under the supervision of Dr. Aldrik H. Velders. The results of his research during the Ph.D. period are described in this thesis.

He is currently postdoctoral fellow in the group of Prof. Kay Severin, at the Ècole Polytechnique Fédérale de Lausanne (EPFL), working on metal-mediated self assembly in water. 